\title{
ÍNDICE DE DESENVOLVIMENTO MUNICIPAL - IDM: \\ UMA ALTERNATIVA PARA MENSURAÇÃO DO DESENVOLVIMENTO HUMANO NOS MUNICÍPIOS DO ESTADO DE SÃO PAULO.
}

FERNANDO FREI

Tese apresentada na área de concentração de Epidemiologia da Faculdade de Saúde Pública da Universidade de São Paulo para Obtenção do Grau de Doutor.

Área de concentração: Epidemiologia

ORIENTADORA: PROFª ${ }^{\mathrm{a}}$ DR'. NILZA NUNES DA SILVA 
À Diva Rodrigues Frei

(In Memoriam) 


\section{AGRADECIMENTOS}

Os meus agradecimentos à Profa ${ }^{\text {. }} \mathrm{Dr}^{\mathrm{a}}$. Nilza Nunes da Silva pela orientação, incentivo e desprendimento.

Ao Prof. Dr. Jorge Oishi pelas discussões e sugestões valiosas.

Aos professores da FCLAssis - UNESP, Pedro Henrique Godinho, José Luiz Guimarães, Bárbara Brandão de Almeida Prado e Eduardo Galhardo pelo estímulo.

Ao amigo Eduardo Luiz Peric Torrano pelos préstimos incalculáveis na área de informática.

À Juliana Albuquerque de Camargo Frei por seu carinho e companheirismo. 


\section{RESUMO}

Apresenta-se o estudo conceitual da criação de um indice de desenvolvimento humano para municipios, denominado Índice de Desenvolvimento Municipal IDM. Utiliza para tanto, indicadores representados por coeficientes da área de saúde, de segurança, de saneamento e da área de educação, totalizando dez coeficientes. A periodicidade de atualização de tais indicadores é anual, motivo pelo qual foram escolhidos.

O cálculo do índice é baseado na distância Euclidiana dos coeficientes observados para um valor ótimo almejado em cada área. O resultado final é obtido mediante a padronização da distância Euclidiana e aplicação da funçăo antilog nos resultados e multiplicação pela constante 100 , o que resulta em uma escala que varia de zero a mil, sendo zero o pior resultado de desenvolvimento e 1000 o melhor resultado.

Os resultados da aplicação do IDM para todos os municipios do Estado de São Paulo, em dois anos distintos, 1991 e 1996, podem atestar a evolução do desenvolvimento. A área de Educação se destaca, comprovando a tendência de melhoria no atendimento escolar e diminuição da evasão. No que tange a segurança, o IDM desta área apresenta uma queda de 1991 para 1996, principalmente nos municípios da Grande São Paulo, mas este fenômeno também é observado em outras áreas do Estado.

Devido a simplicidade de cálculo e interpretação do índice proposto, foi desenvolvido um aplicativo informatizado que permite a análise dos resultados do IDM para os anos de 1991 e 1996, bem como o cálculo para qualquer município em qualquer período de tempo.

Descritores: Índices, Indicadores, Desenvolvimento Humano, Exclusão Social. 


\section{SUMARY}

This is a conceptual study of the creation of a index of human growth for the towns, wich is called "Indice de Desenvovimento Municipal - IDM" (Municipal Growth Index). It uses indicators represented by coefficients of areas such as health, security, sanitation and education, totalizing, ten coefficients. The updating of these coeficients is annual; that is why they were chosen.

The index calculation is based on the Euclidean distance of the coefficients take into consideration for a first rate value desired in each area. The final result is obtained through of the standardized Euclidean distance and application of the antilog function in the results and the multiplication by the 100 constant, which the result of a scale which varies from zero to a thousand, being zero the worst result of growth and 1,000 the best one.

The results of the application of the IDM in all the towns of São Paulo State in two select years, 1991 and 1996 can show the progress of the growth. The education area stands out showing the trend for improvement in school care and less dropping out. As far as security is concerned the IDM of this sector shows a decrease from 1991 to 1996, particularly in the counties around the São Paulo but this fact is also seen in other areas of the state.

As the calculation and interpretation of the index is very simple a system of informatization was developed which gives way to the analysis of IDM results for the years 1991 and 1996 as well as the calculation for any town in any time.

Key words: Indexes, indicators, human growth, social exclusion. 


\section{ÍNDICE}

1 INTRODUÇÃO

1.1 Medidas de Desenvolvimento Humano

1.1.1 Produto Interno Bruto

1.1.2 Curva de Lorentz e Gini

1.1.3 Physical Quality of Life Index

1.1.4 Índice de Desenvolvimento Humano - IDH

1.1.5 Índice de Desenvolvimento Humano Modificado - IDH-M

1.1.6 Indice Paulista de Responsabilidade Social - IPRS

2 OBJETIVOS

3 METODOLOGIA

3.1 Unidade de análise e dados utilizados

3.2 Áreas temáticas e seleção dos indicadores

3.3 Composição do Índice de Desenvolvimento Municipal (IDM)

3.4 Sistema IDM Informatizado

3.5 Características metodológicas do Índice de Exclusão Social - lex e Índice de Exclusão Social Modificado - IEXSOC

4 RESULTADOS

4.1 Desenvolvimento dos Municipios Paulistas segundo IDM

4.2 Análise de Correlação

4.3 Comparação entre resultados do Índice de Desenvolvimento

Municipal - IDM, Índice de Exclusão Social - lex e Índice de Exclusão

Social Modificado - IEXSOC

5 DISCUSSÃO

6 CONCLUSÕES

7 REFERÊNCIAS BIBLIOGRÁFICAS

ANEXOS 


\section{INTRODUÇÃO}

A construção de índices que possam aferir o desenvolvimento humano das populações vem ganhando importância desde meados da década de 1970.

O propósito do desenvolvimento é oferecer às pessoas maiores opções, aquisição do conhecimento, saúde, liberdade política, participação em suas comunidades, segurança pessoal entre outras (PNUD, 1990).

Nos últimos cinqüenta anos a pobreza tem diminuido mais que nos últimos quinhentos, sendo reduzida em algumas áreas em quase todos os países. Os indicadores de desenvolvimento humano vêm avançando nas últimas décadas. Desde 1960 a mortalidade infantil decresceu mais da metade nos paises em desenvolvimento, a proporção de crianças fora da escola primária caiu de $50 \%$ para menos de $25 \%$ (figura 1), e as taxas de desnutrição caíram quase que um terço, (PNUD, 1997).
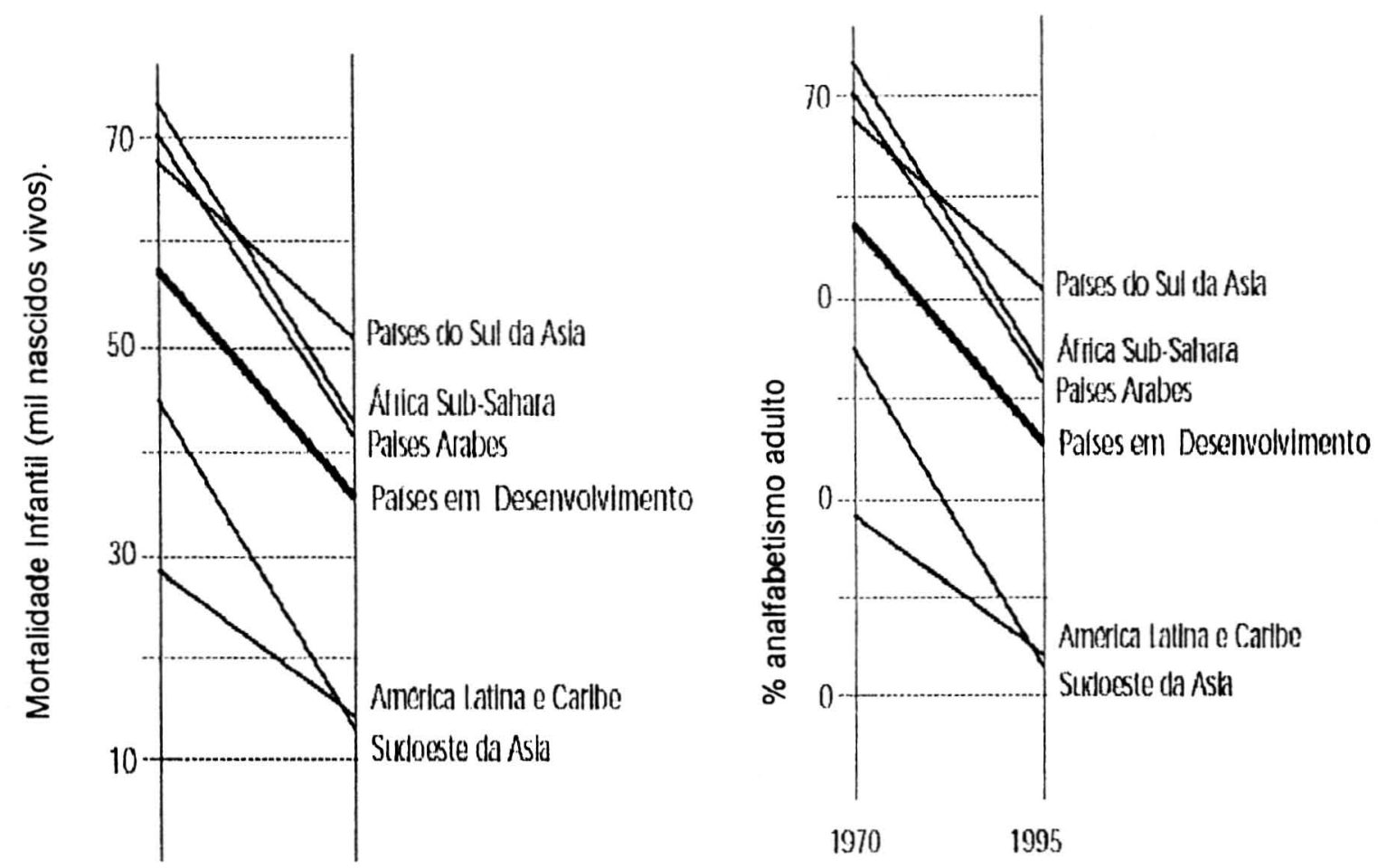

Figura1. Mortalidade Infantil e analfabetismo adulto. Regiões mundiais. 1970 e 1995 Fonte: PNUD, 1997. 
Outros paises que somam mais de 1,6 bilhões de habitantes reduziram a proporçăo de pessoas que viviam abaixo da linha de pobreza em menos de 20 anos. Além dos avanços em renda per capita, houve um grande progresso nesses paises na expectativa de vida e acesso a serviços sociais básicos (PNUD, 1997).

Nos países em desenvolvimento, durante as últimas três décadas, a esperança de vida aumentou cerca de 10 anos - de 55 anos em 1970 para 65 anos em 1998. A taxa de alfabetização de adultos aumentou de $48 \% \mathrm{em}$ 1970 para $72 \%$ em 1998. E a taxa de mortalidade infantil foi reduzida de 111 por mil nascidos vivos, em 1970, para 64 em 1998. A taxa líquida de escolaridade combinada, dos ensinos primário e secundário, aumentou de 50\% em 1970 para $72 \%$ em 1998 (PNUD, 2000).

Os países em desenvolvimento, a partir da década de 1950, tiveram um aumento na aceleração econômica que os conduziu à melhoria das condições de vida de suas populações, fazendo com que os niveis de pobreza recuassem. Estimativas apontam que no final do século $X X$ e início do XXI, aproximadamente de 3 a 4 bilhões de pessoas no mundo terão experimentado melhorias significativas no padrão de suas vidas e aproximadamente entre 4 e 5 bilhões de pessoas terão acesso à educação básica e à saúde (PNUD, 1997).

No entanto, as desigualdades ainda persistem em altos patamares, mesmo em paises como Estados Unidos, Suécia e Inglaterra. A desigualdade entre os países também cresceu. A concentração de renda tem aumentado nas últimas décadas. Dados do Programa das Nações Unidas para o Desenvolvimento de 1999 mostram que os $20 \%$ da população mais rica, que vive em países desenvolvidos, detêm $84 \%$ do Produto Interno Bruto, enquanto os $20 \%$ mais pobres desses mesmos paises detêm apenas $1 \%$ do Produto Interno Bruto. Os recursos das 200 pessoas mais ricas do mundo são maiores que a renda de $41 \%$ da população de todo o mundo. Os recursos das 3 pessoas mais ricas do mundo ultrapassam a renda de vários paises subdesenvolvidos(PNUD, 1999). 
Nos países em desenvolvimento o trabalho infantil ainda persiste com números alarmantes. Há cerca de 250 milhões de crianças trabalhando (PNUD, 2000).

A situação do preconceito de raça, credo e gênero estão ainda longe de ser resolvida. As estatísticas mostram que em média uma em cada três mulheres, em todo o mundo, foi vítima de violência em uma relação familiar. Em 1995, na África do Sul, 29\% dos negros estavam desempregados, valor superior aos $4 \%$ dos sul-africanos brancos.

A tabela 1, a seguir, apresenta a disparidade entre Produto Interno Bruto per capita nas diversas regiões mundiais.

Tabela 1. Distribuição do PIB per capta - 2000

\begin{tabular}{lcc}
\hline Região & População (milhões) & PIP/cap PPP\$ \\
\hline África Sub-Sahara & 569 & 1607 \\
Paises Árabes & 258 & 4140 \\
Países da Ásia do Leste & 1311 & 3564 \\
Países do Sudeste da Ásia & 509 & 3234 \\
Paises do Sul da Ásia & 1364 & 2112 \\
América Latina e Caribe & 498 & 6510 \\
Países do Leste da Europa & 399 & 6200 \\
Países Industrializados & 1105 & 20357 \\
Mundo & 5820 & 6526 \\
\hline
\end{tabular}

Fonte: PNUD, 2000.

No entanto, o conceito de desenvolvimento humano extrapola a visão unidimensional econômica; mais que renda, riqueza e acúmulo de capital, o desenvolvimento deve propiciar ao indivíduo e à coletividade vidas mais produtivas e naturalmente mais criativas, seja para o trabalho, lazer ou atividades políticas e culturais.

O crescimento econômico é um meio e não um fim; não há um vinculo automático entre Produto Interno Bruto de um país e desenvolvimento humano de seus habitantes (PNUD, 1990). Exemplo cabal desta afirmaçăo pode ser visto nos dados comparativos do primeiro relatório das Nações 
Unidas para o Desenvolvimento Humano. Enquanto o Sri Lanka apresentava uma esperança de vida ao nascer de 71 anos e uma taxa de alfabetização adulta de $87 \%$ com uma renda per capita de $\$ 400,00$, o Brasil com uma renda per capita de $\$ 2020,00$ apresentava uma esperança de vida ao nascer de 65 anos e 78\% de alfabetização adulta. Na Arábia Saudita, onde a renda per capta era de $\$ 6200,00$ a esperança de vida era de apenas 64 anos e a taxa de alfabetização adulta não passava de 55\% (PNUD, 1990).

Neste último século, nas sociedades ocidentais modernas, as diferenças entre pobres e ricos, têm continuamente cedido lugar a formas mais sutis de desigualdade.

Está claro que em paises pobres as diferenças são profundas, determinando preocupantes desigualdades sociais. No entanto, como destaca Nunes e colaboradores, em países ditos emergentes, não apenas a renda, mas as demais condições de vida adquirem importância crescente:

O principio da igualdade tem base no conceito de cidadania, segundo o qual todos os individuos são iguais, tendo, portanto, os mesmos direitos. Mas igualdade não é o mesmo que eqüidade. Esta incorpora em seu conceito algum valor de justiça. Por outro lado, nem toda desigualdade constitui iniqüidade no sentido de injustiça. A iniqüidade pode ser considerada como uma "desigualdade injusta", que poderia ser evitada, dai sua importáncia para os tomadores de decisão. Castellanos, por exemplo, considera que as desigualdades em saúde são as desigualdades redutiveis, isto é, desnecessárias, vinculadas às condições heterogêneas de vida.(Nunes e col.,2001, p.17) 
A partir deste conceito de igualdade, interessa-nos a eqüidade que diz respeito à distribuição eqüitativa de bens e serviços, geradora de justiça social.

Neste sentido, a distribuição eqüitativa em um pais como o Brasil, com uma das mais perversas concentraçōes de renda do mundo, apresenta sérias dificuldades. Para ilustrar esta situação, em 1996, o índice de Gini brasileiro (que expressa a concentração da renda, e será apresentado posteriormente, indicando padrões mais concentrados de renda com valores próximos de 1 e desconcentrados com valores próximos de 0), era de 0,600, encontrando paralelo internacional apenas nos de Serra Leoa $(0,629)$ e da Suazilândia (0,609). Outros países da América Latina apresentavam índices muito mais reduzidos, como Bolivia $(0,420)$, Uruguai $(0,423)$, Venezuela $(0,48)$, México $(0,537)$, Chile $(0,56)$ e Colômbia $(0,57)$. Todos os países desenvolvidos apresentavam índices muito mais baixos, como a França $(0,327)$, a Grã-Bretanha $(0,361)$, a Nova Zelåndia $(0,439)$ e os Estados Unidos $(0,408)$ (SEADE, 2000).

$\mathrm{O}$ conceito de desenvolvimento humano pode ser resumido como um processo de expansão das escolhas dos cidadãos (PNUD, 1990). Este conceito, associado a outros correlatos, como pobreza, eqüidade e exclusão social, vem sendo progressivamente estudado com o objetivo de se obter ferramentas capazes de aferir a eficácia da implementação de políticas públicas. Desta forma, indicadores e indices têm sido utilizados como importantes instrumentos na defesa e promoção dos direitos dos cidadãos. Por esta razão, os sistemas de estatísticas sociais de hoje precisam fortalecer-se em todos os paises em desenvolvimento. Melhorar a cobertura, confiabilidade e desagregação de dados, especialmente por gênero, grupo de renda e área geográfica é fundamental para a melhoria das condições de vida. É necessário também aumentar a velocidade, a regularidade na coleta de dados e a disseminação de informação para os usuários interessados (PNUD, 2000).

Criar uma cultura de avaliação embasada em estatísticas, indicadores e indices é fundamental para o desenvolvimento humano. 
Como a ONU destaca em seu Relatório do Desenvolvimento Humano do ano de 2000:

A informação e as estatísticas são instrumentos poderosos na criação de uma cultura de responsabilidade e na realização dos direitos humanos. Ativistas, juristas, estatísticos e especialistas de desenvolvimento tém de trabalhar em conjunto com as comunidades. O objetivo: gerar informaçס̃es e provas que possam quebrar barreiras da descrença $e$ mobilizem as mudanças de politica e comportamento (PNUD, 2000, p.10).

Não resta dúvida que as estatísticas estão ajudando alguns governos a melhorar suas politicas, criando consensos sociais sobre as prioridades das comunidades e as expectativas dos futuros desempenhos. Neste sentido, agências internacionais vêm estimulando o incremento de novos e melhores indicadores, maior acesso público aos dados, diversificação das fontes de informação, seja por meio de instituições governamentais, seja por instituições da sociedade civil.

Os indicadores estatísticos são instrumentos poderosos para a promoção dos direitos humanos. Ajudam a estabelecer metas e fazer avaliações do desempenho. Os números podem dar respeitabilidade e poder a grupos de pressão.

Como aponta o mencionado Relatório do Desenvolvimento Humano do ano de 2000, a ausência de estatísticas pode ser tão reveladora quanto a sua existência. Como exemplo cita que no governo militar argentino, na década de 1970 , os estatísticos e economistas foram os primeiros a desaparecer, demonstrando assim a preocupação que o governo tinha acerca do vazamento dos dados.

Outro exemplo citado pelo referido relatório é o caso dos dados recolhidos durante a época do apartheid na África do Sul. Estes mostraram que os casos de kwashiorkor, uma doença de subnutrição, foram 300 vezes 
mais elevados entre os negros que entre os brancos. Em vez de enfrentar o problema, o Governo optou por deixar de recolher estatísticas sobre a doença.

As estatisticas e indicadores podem e devem ser utilizados na construção de metas. Reduzir o analfabetismo em um percentual especifico no transcorrer de determinado período de tempo é muito mais produtivo do que a declaração de boas intenções.

O próprio Relatório de Desenvolvimento Humano das Nações Unidas de 2000 destaca, que embora a questão dos direitos não possa ser única e exclusivamente expressa através de estatísticas, estas são essenciais em sua análise (PNUD, 2000). Neste aspecto, é importante esclarecer as diferenças entre as estatísticas utilizadas como instrumento de monitoramento do desenvolvimento humano.

Neste estudo estaremos trabalhando com indicadores, valor numérico selecionado para representar um fenômeno de interesse (COLE e col.,1998) e indicadores compostos, baseados em dois ou mais fenômenos. Estes indicadores compostos, tratados por metodologia específica, são apresentados na forma de índice, o qual provê um resumo conveniente de dados diversos.

Os indicadores sociais são medidas da sociedade que refletem as condições das pessoas em uma dada cultura ou unidade territorial em um determinado segmento temporal. A característica dos indicadores sociais reside na objetividade e aferição estatistica em contraponto com percepções subjetivas individuais.

Uma vasta gama de áreas, como Saúde, Educação, Ecologia entre outras, contribui com variáveis na construção de indicadores sociais. Desta forma, a área de Saúde contribui com indicadores como mortalidade infantil, médicos per capita, partos normais etc. (DIENER e SUH 1997)

Os indicadores sociais são fáceis de definir e de quantificar, trazendo assim confiança em seus resultados. Por estas razões são tecnicamente convenientes para comparações de regiões geográficas e comparações temporais. Os indicadores oferecem um instrumento capaz de comparar 
municípios em um país ou estado, medindo avanços nos níveis sociais. Eles podem expor diferenças nos niveis de saúde, educação, entre subgrupos especificos da população, tais como classes sociais diferentes, zona urbana e rural etc.

Indicadores, como por exemplo a mortalidade infantil, podem medir diretamente uma conjuntura ou ainda serem utilizados como medidas indiretas. Por exemplo, a taxa de mortalidade infantil é uma medida direta do risco de morte que a criança corre durante seu primeiro ano de vida, mas também é uma medida indireta do desenvolvimento de uma sociedade (VAUGHAN e MORROW 1992).

Outro ponto favorável dos indicadores sociais é o de seus valores incluirem medidas sobre uma extensa gama de aspectos sociais, os quais, geralmente não são refletidos por indicadores econômicos. Assim, indicadores sociais possuem capacidade de capturar importantes qualidades sociais não constatadas por medidas econômicas ou subjetivas (DIENER e SUH 1997).

A combinação de vários indicadores por processos matemáticos vem contribuindo nas últimas décadas para a criação de uma série de índices para mensurar o desenvolvimento humano e condições de vida.

Neste sentido, a presente tese tem como objetivo o desenvolvimento de um novo índice denominado Índice de Desenvolvimento Municipal - IDM, que possa aferir o progresso dos municipios paulistas em diversas áreas sociais.

Para tanto, o presente trabalho estará divido em 6 capitulos. As principais medidas de desenvolvimento humano, tais como PIB, GINI, IDH e outras são descritas ainda na Introdução como parte da revisão da literatura. No segundo capitulo apresentamos o objetivo principal e os objetivos especificos.

O terceiro capitulo aborda o arcabouço conceitual do indice proposto, as medidas utilizadas na sua construção, áreas temáticas e indicadores selecionados. Outro importante ponto a ser apresentado neste capítulo é a padronização dos resultados obtidos. 
No Brasil, diversas ações foram empreendidas no sentido de construir indices que pudessem levar em conta a dinâmica nacional. Entre esses índices destacam-se o Índice de Responsabilidade Social -IPRS e o İndice de Exclusão Social - lex. No capítulo 4, são apresentados os resultados da aplicação do índice de Desenvolvimento Municipal - IDM para todos os municipios do Estado de São Paulo em dois momentos distintos, 1991 e 1996. Pode-se observar a evolução do estado em diversas áreas, principalmente na área de educação no que tange a inclusão das crianças e jovens paulistas na escola.

A utilização de índices para mensuração do desenvolvimento humano vem sendo empregada, em muitas ocasiöes, de forma descuidada. Por esta razão, apresenta-se no quinto capitulo a discussão quanto às possibilidades do uso do Índice de Desenvolvimento Municipal - IDM e suas interpretações. As considerações finais são expressas no capitulo 6 .

Além dos capítulos mencionados, a tese conta com a apresentaçăo, em meio magnético (CD ROM), de um sistema simples de informática capaz de visualizar os resultados do Índice de Desenvolvimento Municipal e seus indices por área temática para todos os municipios paulistas nos anos de 1991 e 1996. Propicia o cálculo do IDM geral e por áreas temática para qualquer município em qualquer ano desejado. 


\subsection{MEDIDAS DE DESENVOLVIMENTO HUMANO}

\subsubsection{Produto Interno Bruto}

Esforços para medir a riqueza de um país datam do século XVII quando Willian Petty apresentou uma das primeiras estimativas. Desde então, este conceito vem sendo estudado por economistas com o objetivo de oferecer uma ferramenta para entender parte do sistema econômico de um pais (ENGLAND 1998).

Uma das medidas mais difundidas para aferiçăo da riqueza de um país é o Produto Interno Bruto (PIB), caracterizado pelos valores econômicos da produção interna de bens e serviços menos os valores econômicos da importação de bens e serviços. Desenvolvido nas décadas de 1930 e 1940, inicialmente pela Inglaterra e Estados Unidos, monitorava os problemas econômicos gerados pela recessão, desemprego e guerra (MORRIS 1979). Passou a ser utilizado mundialmente pela maioria dos paises a partir da década de 1950, com estímulo de agências multilaterais como o Banco Mundial. O PIB possuiu características que o colocam como um indice demonstrativo do crescimento econômico, parte do desenvolvimento dos paises (SEADE 2000).

O PIB pode ser ajustado ao tamanho da populaçăo, PIB per capita, facilitando assim a comparação do desempenho de paises ao longo do tempo. No entanto, como instrumento de mensuração do desenvolvimento, o PIB não está livre de imperfeições. Uma das críticas mais difundidas é que o PIB é unidimensional, isto é, não capta outros aspectos importantes do desenvolvimento, tais como saúde, educação, etc. Além deste fator, o PIB é insensivel à verdadeira distribuição de renda de um pais (SEADE 2000). Não há qualquer ligação direta entre níveis de PIB e desempenho nas áreas de saúde, educação entre outras. O crescimento do PIB em um pais não garante uma distribuição de renda justa ou mesmo que os governos venham aplicando recursos em áreas que possam beneficiar sua populaçăo. 
A preocupação excessiva em focalizar medidas como o Produto Interno Bruto - PIB - de um país, obscurecem as verdadeiras perspectivas de desenvolvimento humano.

O crescimento econômico deve ser direcionado para o benefício das pessoas. Pelos números mostrados anteriormente fica claro o contraste e a discrepáncia entre renda per capita e desenvolvimento humano. Paises como Sri Lanka, Chile, Costa Rica, Jamaica, Tanzânia e Tailândia, entre outros, apresentam melhores indicadores de desenvolvimento humano, mostrando assim que seus recursos foram direcionados de forma mais efetiva para esse desenvolvimento. Outros paises como Omã, Gabão, Arábia Saudita, Argélia, entre outros, apresentam resultados piores em seus indicadores, o que mostra que não conseguiram traduzir a renda em progresso humano (PNUD 1990).

Mesmo na ausência de um crescimento econômico satisfatório ou uma distribuição de renda mais igualitária, pode-se alcançar melhorias significativas no desenvolvimento humano por meio de políticas públicas mais bem estruturadas. Exemplos destas políticas podem ser notados em países como o Siri Lanka, Costa Rica e Chile, que obtiveram um crescimento lento em seu PIB nas últimas três décadas, mas que evoluíram no desenvolvimento humano (PNUD 1990).

O que deve estar claro é que o PIB, ou PIB per capita, é uma medida de produção, não de consumo. 


\subsubsection{Curva de Lorez e Índice de Gini}

Existem várias maneiras para expressar o grau de desigualdade da renda em uma sociedade.

A Curva de Lorenz é uma representação gráfica comumente utilizada para representar essa desigualdade. No eixo $x$, representa-se a população em percentagem (pode-se usar o quintil da população). $O$ eixo y espelha a renda acumulada em percentagem. Quanto maior o afastamento da curva em relação à reta ideal de $45^{\circ}$, maior a desigualdade.

Os exemplos a seguir nos apresentam a situação ideal de igualdade, à esquerda e a situação de total desigualdade à direita.

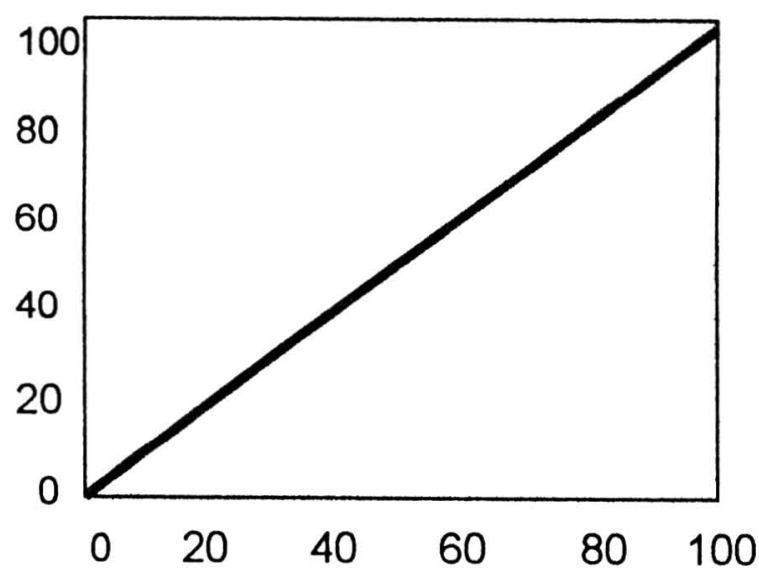

Figura 2. Igualdade de Renda

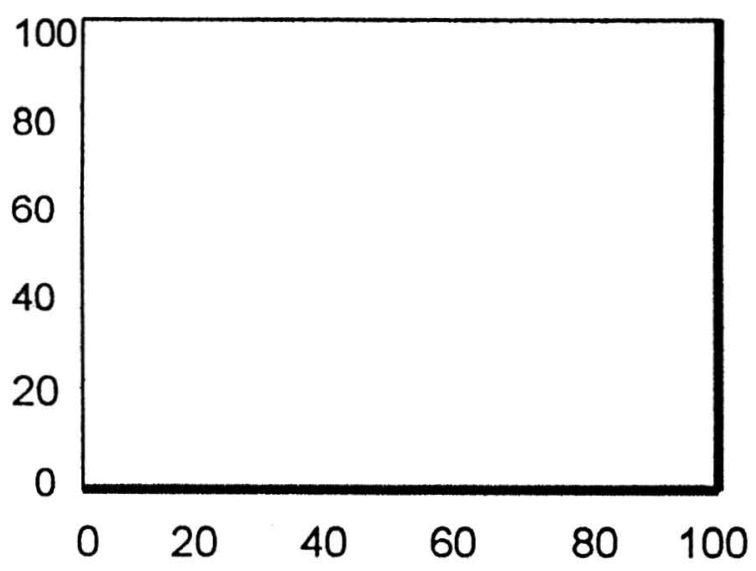

Figura 3. Desigualdade de Renda

A figura 3, mostra claramente, que a medida que a curva se afasta da reta ideal de $45^{\circ}$, maior será a desigualdade de renda da população.

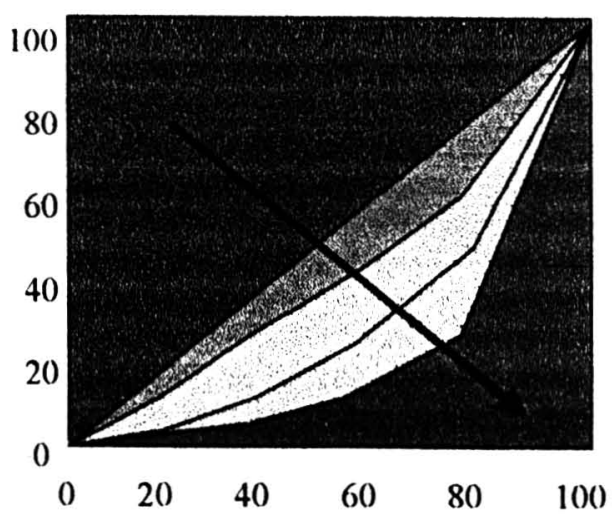

Figura 4. Curvas de Lorenz 
Um exemplo real da curva de Lorenz é apresentado a seguir para dados mundiais de 1997.

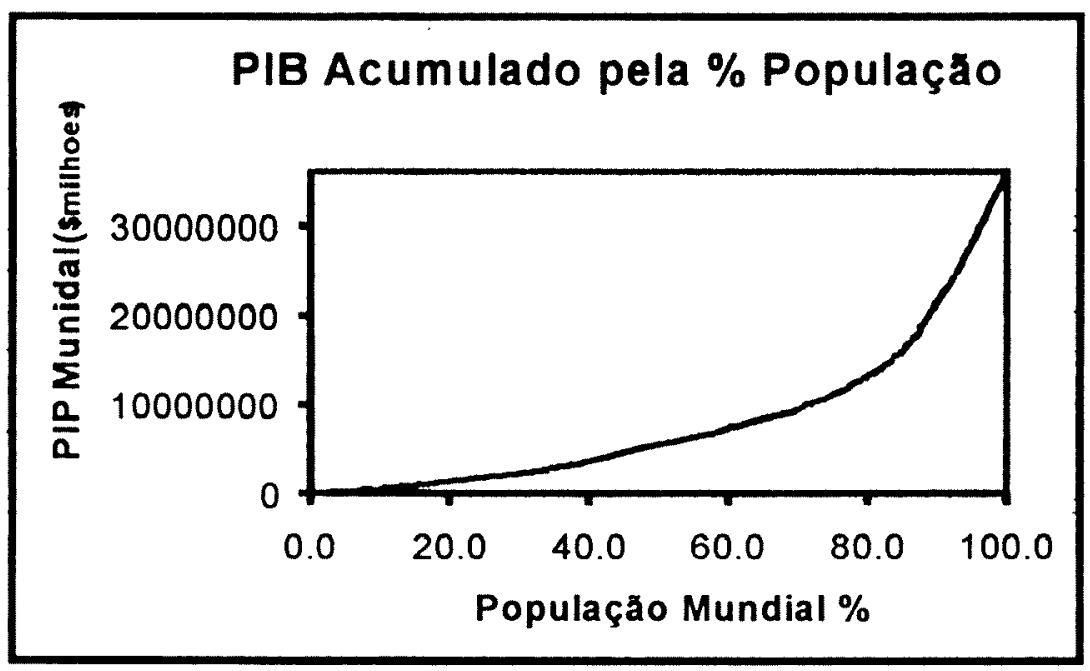

Figura 5. PIB Mundial acumulado - 1997

Fonte: LBOR 1993

Uma maneira simples para apresentar a desigualdade de renda é a organização da unidade escolhida (familias, pessoas, etc., em ordem crescente de renda), do mais pobre para o mais rico. Dividi-se o conjunto de rendas em quintil (ou decil) verificando a parcela retida em cada um desses quintis (geralmente usa-se a razão entre a parcela da renda retida pelos mais pobres e a parcela de renda retida pelos mais ricos Q5/Q1.)

No entanto, como notamos pela figura 5, uma comparação com dois periodos de tempo diferentes pode trazer dificuldades nas conclusōes com relação à precisão fornecida pela Curva de Lorenz.

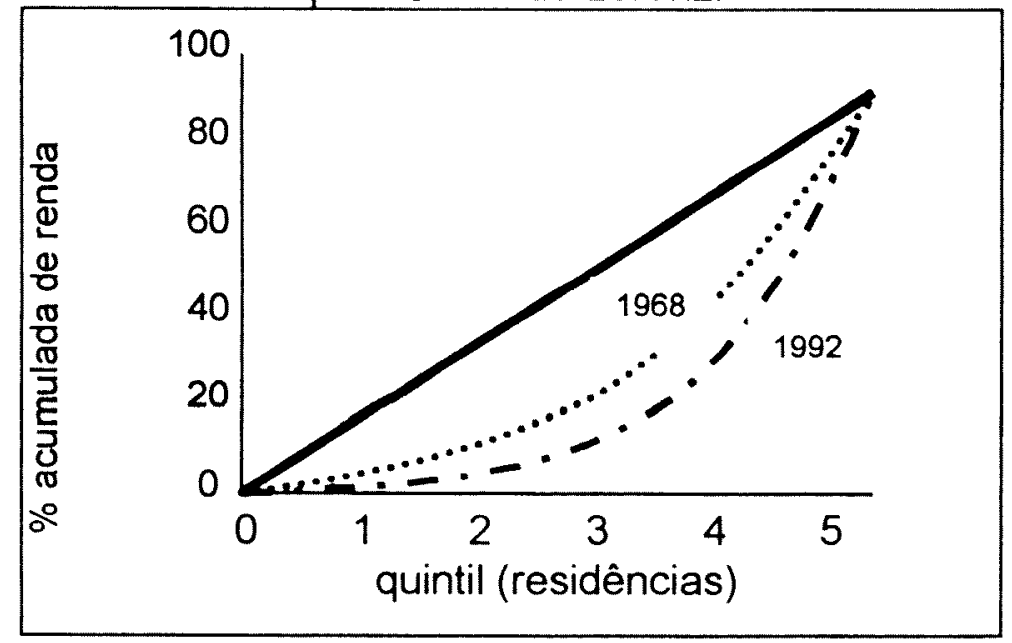

Figura 6. Curva de Lorenz para 1968 e 1992 Fonte: LBOR 1993 
Esta técnica é simples, mas busca-se um único valor que pudesse representar a disparidade de renda de uma sociedade.

$O$ índice de Gini mede a diferença entre a curva real e a linha hipotética ideal de $45^{\circ}$. Vejamos o exemplo mostrado pela figura 6.

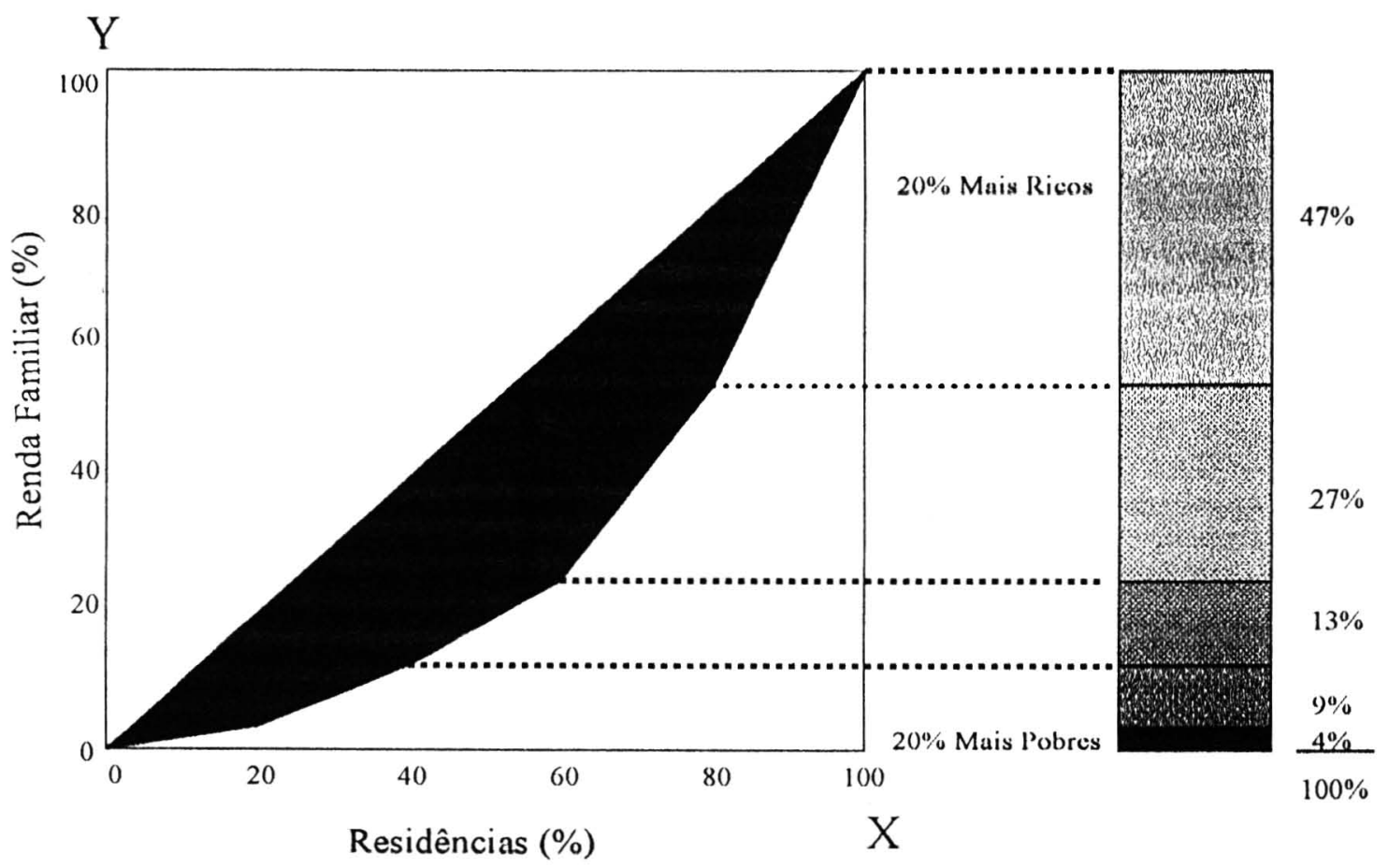

Figura 7. Curvas de Rendimento

A fórmula para obtenção do índice de Gini é dada por:

$$
G=\frac{\sum_{i=1}^{n}\left(x_{i}\right)-\sum_{i=1}^{n}\left(y_{i}\right)}{(n .100)-\sum_{i=1}^{n}\left(x_{i}\right)}
$$

Onde $X_{i}$ representa os valores percentuais das residências.

$Y_{i}$ representa os valores de renda associados aos valores de $X_{i}$. $n$ representa o número de pontos utilizados para o cálculo.

Quanto mais próximo de 0 (zero) o valor do indice de Gini estiver, mais igualitária seria a sociedade e quanto mais próximo de 1 (um) mais desigual seria a sociedade. 


\subsubsection{PQLI (Physical Quality of Life Index)}

$\mathrm{Na}$ década de 1970, alguns índices incorporaram em suas metodologias, variáveis sociais para mensurar o desenvolvimento humano.

O Índice do Progresso Social - IPS, desenvolvido a partir de 1974 por Richard Estes da Universidade da Pensilvânia, nos Estados Unidos e descritos em 1984 e 1988, é um desses indices. Ele mede o desenvolvimento econômico, condições sociais e políticas, e a habilidade das nações produzirem serviços e bem estar aos seus cidadãos (ESTES 2001). O autor utilizou diferentes indicadores e indices para mensurar 0 desenvolvimento humano dos paises. $O$ quadro a seguir mostra alguns dos indicadores utilizados.

Quadro 1. Indicadores sócio-econômicos

\begin{tabular}{|l|l|}
\hline Taxa de mortalidade infantil & Taxa de médicos \\
\hline Percentagem de adultos analfabetos & $\begin{array}{l}\text { Expectativa de vida para pessoas de } \\
1 \text { ano }\end{array}$ \\
\hline $\begin{array}{l}\text { Percentagem do Produto Interno } \\
\text { Bruto aplicado a Educação }\end{array}$ & $\begin{array}{l}\text { Expectativa de vida para pessoas } \\
\text { com menos de 5 anos }\end{array}$ \\
\hline $\begin{array}{l}\text { Percentual de crianças até um ano } \\
\text { imunizadas contra o sarampo }\end{array}$ & $\begin{array}{l}\text { Expectativa ao nascer do sexo } \\
\text { feminino }\end{array}$ \\
\hline $\begin{array}{l}\text { Percentual de mulheres casada que } \\
\text { utilizam contraceptivos }\end{array}$ & $\begin{array}{l}\text { Taxa de alfabetização adulta } \\
\text { feminina }\end{array}$ \\
\hline Taxa de mortalidade materna & $\begin{array}{l}\text { Percentual do Produto Interno Bruto } \\
\text { gasto com despesas militares }\end{array}$ \\
\hline $\begin{array}{l}\text { Indice da produção de alimentos per } \\
\text { capita }\end{array}$ & Divida pública externa (\% do PIB) \\
\hline Taxa de mortalidade & Taxa de crescimento populacional \\
\hline $\begin{array}{l}\text { Percentual da população com menos } \\
\text { que 15 anos }\end{array}$ & $\begin{array}{l}\text { Percentual da população com mais } \\
\text { que 60 anos }\end{array}$ \\
\hline Percentagem das terras agrícolas & $\begin{array}{l}\text { Percentagem de mortes por } \\
\text { desastres naturais }\end{array}$ \\
\hline
\end{tabular}

Além destes indicadores, outros na área de educação e econômicos derivados do Produto Interno Bruto também são utilizados. No entanto, um 
rol tão extenso de indicadores dificulta sua própria aplicação na comparação de paises cuja qualidade de estatística deixa a desejar.

Em seu livro Measuring the Condition of the Wprld's Poor - The Physical Quality of Life Index, Morris David Morris apresenta as características de seu índice para a mensuração das condições de vida, salientado entre outros pontos, a questão do rol de indicadores que irão compor o indice:

\begin{abstract}
Esforços anteriores tentaram incorporar em uma única medida um grande número de indicadores tanto para paises ricos quanto para pobres. Um número excessivo de indicadores tem se mostrado como um obstáculo para o desenvolvimento da mensuração de condições de vida (MORRIS 1979)
\end{abstract}

Morris apresenta seis critérios para a composição de seu índice:

1. Não assumir que existe um único padrão de desenvolvimento.

2. Evitar assumir padrões que refletem sociedades específicas.

3. Deve-se medir resultados.

4. Deve-se poder refletir resultados da sociedade.

5. Deve ser simples de construir e fácil de entender.

6. Deve se prestar para comparação internacional.

Todos os itens apresentados são importantes para a construção de um índice para a mensuração da condição de vida. Não obstante o item cinco merece destaque especial. A simplicidade em construir um índice implica que os dados de cada indicador utilizado devem ser relativamente fáceis de se obter e de processar, que os dados representem informaçōes que todas as sociedades necessitam colecionar para que possam torna-se nações modernas e que os indicadores não requeiram maior precisão que aqueles já usados pelos governos para fins administrativos(MORRIS 1979). 
Como afirma Morris, a facilidade em compreender um indice deve ser uma de suas justificativas principais.

Para compor o PQLI Morris selecionou 3 indicadores: Mortalidade infantil, expectativa de vida e alfabetização. Como ressalta Yeung e Mathieson (YEUNG e MATHIESON 1998), os indicadores selecionados refletem e incorporam importantes aspectos do progresso humano. Por exemplo, a expectativa de vida pode ser um bom indicador dos efeitos da nutrição, saúde pública, renda e meio ambiente em geral. Da mesma forma, a mortalidade infantil reflete as condições da saúde da mãe, da qualidade da água e do lar onde residem. Já o nível de educacional, apresentado pela alfabetização, denota a abilidade do individuo na sociedade e a posição da mulher na mesma.

Para compor o PQLI cada indicador é transformado em uma escala que varia de 0 (zero), a pior condiçáo de desenvolvimento, a 100 (cem) a melhor condição.

No caso da alfabetização, este indicador é transformado pela percentagem de pessoas com 15 (quinze) anos ou mais alfabetizadas. A própria percentagem corresponde a primeira parte do índice.

$\mathrm{O}$ indicador de mortalidade infantil é expresso pelo número de mortes em mil nascidos vivos. Neste caso, a pior situação de desenvolvimento seria aquela em que toda a criança faleceu no primeiro ano de vida, e a melhor situação aquele em que nenhuma criança veio a falecer no primeiro ano de vida.

Como afirma Morris, estas situações descritas no parágrafo anterior são bastante improváveis, visto que desde 1950 nenhum pais ultrapassou 229 mortes infantis por 1000 nascidos vivos. Da mesma maneira, a melhor situação não seria 0 (zero) mas sim 8 (oito) por mil nascidos vivos, caso da Suécia quando da realização do Trabalho de Morris.

Em função desta situação o Índice Físico de Qualidade de Vida estabelece como valor máximo (pior) de mortalidade infantil 229 em mil nascidos vivos e como valor minimo (melhor) $7 \mathrm{em}$ mil nascidos vivos. Usando a amplitude dos valores 229 a 7 (222) teriamos um aumento de 1 
ponto no índice de mortalidade para cada 2,22 na mortalidade infantil, o que nos forneceria a fórmula:

Indice de mortalidade infantil $=\frac{229-\text { taxade mort.infantil(1000nasc. vivos) }}{2,22}$

O mesmo raciocinio se aplica para obtermos o indice da expectativa de vida a um ano de vida, cuja variação apresentada é de 38 anos à 77 anos (39 anos) o que resulta em um aumento de um ponto no índice de expectativa de vida para cada 0,39 anos de aumento:

Indice de expectativa de vida a um ano $=\frac{\text { expectativ a de vida a um ano }-\mathbf{3 8}}{0,39}$

O resultado final do Índice Físico de Qualidade de Vida - IFQV pode ser obtido mediante a média aritmética dos três índices com igual peso.

\subsection{4 İndice de Desenvolvimento Humano - IDH}

A partir de 1990, a Organização das Nações Unidas, por meio do Programa das Nações Unidas para o Desenvolvimento, vem apresentando relatórios anuais sobre o desenvolvimento dos paises. Para isso concebeu o Índice de Desenvolvimento Humano - IDH com a preocupação de incluir dimensões variadas da vida e condição humana.

Para compor o indice, três componentes básicos foram utilizados:

a longevidade, que também reflete, entre outras coisas, as condições de saúde da população; medida pela esperança de vida ao nascer.

a educaçăo; medida por uma combinaçăo da taxa de alfabetização de adultos e a taxa combinada de matrícula nos niveis de ensino fundamental, médio e superior. 
a renda; medida pelo poder de compra da população, baseado no PIB per capita ajustado ao custo de vida local para torná-lo comparável entre países, através da metodologia conhecida como paridade do poder de compra (PPC).

A metodologia de cálculo do IDH envolve a transformaçăo destas trés dimensōes em índices de longevidade, educaçăo e renda, que variam entre 0 (pior) e 1 (melhor), e a combinação destes indices em um indicador síntese. Quanto mais próximo de 10 valor deste indicador, maior será o nivel de desenvolvimento humano do pais ou região.

Da mesma maneira que o IFQV foi estabelecido, a equipe liderada pelo conselheiro especial Dr.Mahbub ul Haq preocupou-se em construir um indice que pudesse fornecer resultados baseados em dados reais. Para isso, recorreu a seguinte solução:

- Longevidade - expectativa de vida ao nascer;

Utilizam-se como valores extremos 25 anos (min. $\left.x_{i} f i x\right)$ e 85 anos (max. $x_{i} f i x$ ).

- Educação - Valores percentuais da combinação de: Alfabetização adulta (peso 2/3) escolaridade 1,2 e 3 graus (peso 1/3); Utilizam-se como valores extremos $0 \%\left(\right.$ min. $\left.x_{i} f i x\right)$ e $100\left(\max . x_{i} f i x\right)$.

- Renda - real PIB per capta (PP\$)

Utilizam-se como valores extremos $\$ 100\left(\min . x_{i} f i x\right)$ e $\$ 40.000$ (max. $x_{i} f f x$ ).

Para cada uma das dimensões, os valores min. $x_{i}$ fix e max. $x_{i}$ fix são valores preestabelecidos, mediante análise estatística da série histórica mundial para cada indicador. Paises podiam apresentar progresso em determinadas áreas, mas o progresso global poderia ser maior, ocultando assim as reais condições desses países.

Com esta alteração na metodologia, adotada a partir de 1994, podese analisar o desenvolvimento de um pais no decorrer do tempo, sem que seus resultados fossem afetados pelos valores mundiais máximos e mínimos que variam de ano para ano. 
Para cada uma das dimensões acima, calcula-se o indice dado por:

$$
\text { Indice }=\frac{x_{i}-\min x_{i} f i x}{\max x_{i} f i x-\min x_{i} f i x}
$$

- Índice do PIB real ajustado per capita (dól. PPC)

A partir de 1994, o resultado do PIB para os paises analisados foi modificado para a fórmula:

$$
W(y)=\frac{\log _{y}-\log _{y \operatorname{mim}}}{\log _{y \max }-\log _{y \operatorname{mim}}}
$$

Esta mudança se deve a preocupação de que um nivel respeitável de desenvolvimento humano não requer renda ilimitada. O resultado dessa Mudança pode ser observado pela figura 8 abaixo.

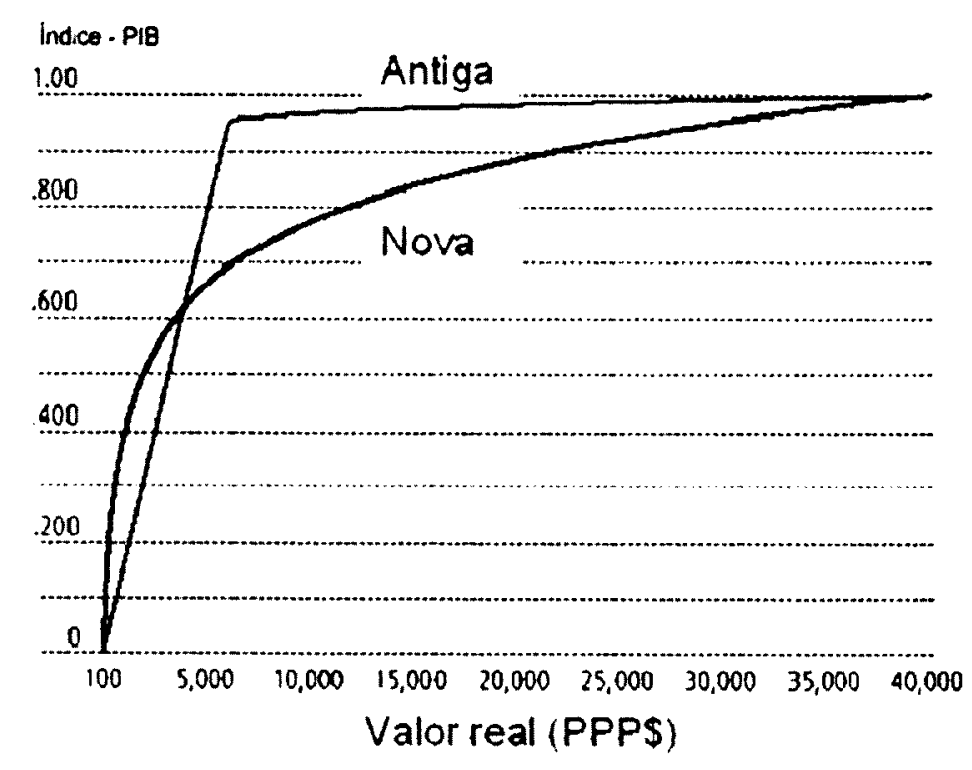

Figura 8. Simulação de PIB com transformação e sem transformação.

O cálculo final do Índice de Desenvolvimento Humano é dado pela média aritmética dos indices de esperança de vida, educacional e PIB. 


\subsection{5 Índice de Desenvolvimento Humano Modificado - IDH-M.}

Proposto em 1998 por Noorbakhsh, o IDH - M utiliza os mesmos componentes do índice original, Renda, Educação e Longevidade. Os dois primeiros componentes são tratados matematicamente incorporando alternativas de peso para os indicadores originais do IDH, enquanto a Longevidade é medida pela esperança de vida ao nascer.

A estrutura utilizada pelo IDH-M é diversa do índice original e traz consigo a principal alternativa para a mensuração do desenvolvimento humano.

A primeira etapa para obtenção do IDH-M é a transformação dos dados para remover o efeito da escala. Para tanto utiliza-se os valores da distribuição Normal Padronizada Z:

$$
Z_{i j}=\frac{x_{i j}-\bar{x}_{j}}{s_{j}}
$$

Após a obtenção dos dados padronizados aplica-se a fórmula:

$$
d_{i}=\left[\sum_{j=1}^{3}\left(z_{i j}-z_{a}\right)^{2}\right]^{1 / 2}
$$

Onde $z_{a}$ é o maior valor padronizado encontrado para o componente $j$ (Renda, Educação e Longevidade).

$O$ resultado final do IDH-M é dado por:

$$
I D H-M_{i}=\frac{d_{i}}{\bar{d}+k s_{d}}
$$

Onde $\bar{d}$ e $s_{d}$ são a média e o desvio padrão de $d_{i}$.

O parâmetro $k$ é determinado de maneira que o intervalo obtido pelo denominador da expressão final do índice possa abarcar todos os valores dos países em análise. 
Se a distribuição é normal, então para $k=295 \%$ dos paises terão seus indices entre 1 e 0 . Para que todos os paises estejam no intervalo desejado o valor resultante de $k=2,2$.

De acordo $\mathrm{cm}$ o próprio autor, o IDH-M reflete a mudança na posição de um país em relação aos demais paises, ano a ano, enquanto o IDH reflete a posição de um país em relação a pontos fixos, independentemente do que ocorre no restante dos países.

A tabela seguinte mostra a comparação entre o IDH e IDH-M para os 14 principais paises segundo o IDH-M (dados de 1995).

Tabela 02. Classificação de países segundo IDH-M. 1995

\begin{tabular}{llccc}
\hline $\begin{array}{l}\text { Posto } \\
\text { (Rank) }\end{array}$ & País & IDH-M & $\begin{array}{c}\text { IDH } \\
\text { (Posto) }\end{array}$ & $\begin{array}{c}\text { IDH - IDH-M } \\
\text { (postos) }\end{array}$ \\
\hline 1 & Canadá & 0,965 & 1 & 0 \\
2 & Holanda & 0,958 & 4 & 2 \\
3 & Islândia & 0,957 & 6 & 3 \\
4 & Japão & 0,955 & 3 & -1 \\
5 & Espanha & 0,952 & 9 & 4 \\
6 & Suécia & 0,952 & 10 & 4 \\
7 & Noruega & 0,952 & 7 & 0 \\
8 & França & 0,950 & 8 & 0 \\
9 & Austrália & 0,948 & 11 & 2 \\
10 & Suiça & 0,943 & 13 & 3 \\
11 & Estados Unidos & 0,942 & 2 & -9 \\
12 & Bélgica & 0,941 & 12 & 0 \\
13 & Austria & 0,938 & 14 & 1 \\
14 & Finlândia & 0,936 & 5 & -9
\end{tabular}

Extraida de A Modified Human Development Index, Noorbakhsk, F. World Developmet, Vol. 26, no 03, pp. $517-528,1998$.

É possivel verificar pela tabela 2, a alteração nas posiçōes dos paises. Segundo dados de 1995, a maior mudança ocorre nos paises chamados de desenvolvimento intermediário. 


\subsection{6. Índice Paulista de Responsabilldade Social - IPRS}

Idealizado pela Fundação SEADE em 2000, o IPRS se apresenta como um instrumento de fiscalização política.

De forma mais abrangente, os componentes utilizados para a confecção do indice são: resultados de curto prazo; esforços realizados pela gestão municipal na direção de melhorar os indicadores de educação e saúde; e participação, que significa sobretudo gerar mecanismos institucionais que permitam a transparência das ações sociais.

Quadro 02. Variáveis utilizadas para composição do IPRS. São Paulo 2000.

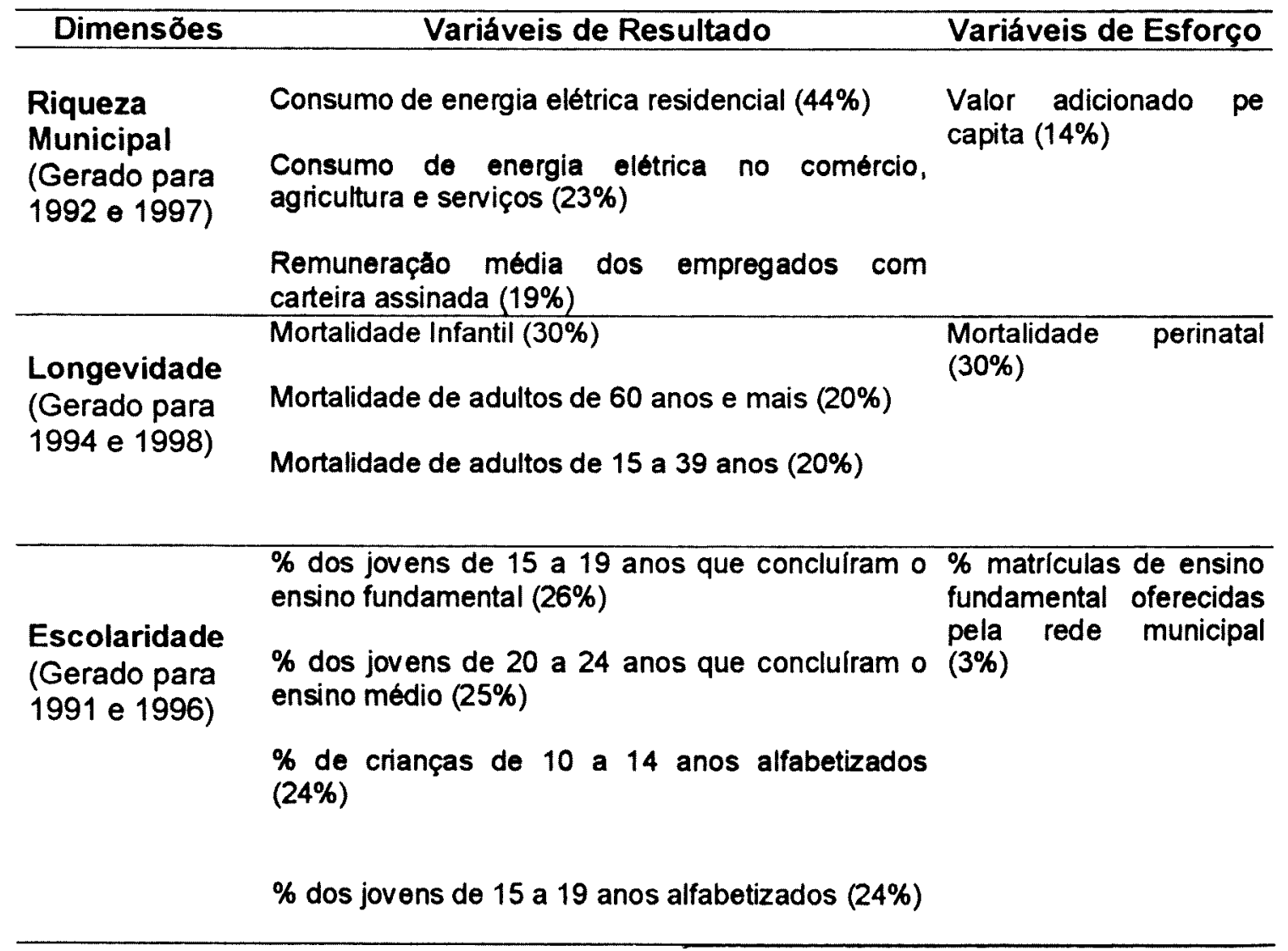

Extraído de Fórum São Paulo Século 21 - Índice Paulista de Responsabilidade Social - IPRS - São Paulo 2000. 
Os indicadores utilizados para a construçăo do índice Paulista de Responsabilidade Social - IPRS, são referentes aos anos-base de 1992 e 1997. etapas:

A metodologia adotada para a criação do IPRS percorre algumas

1) Padronização dos indicadores.

Transformação logarítmica nos dados referentes ao consumo anual de energia elétrica no comércio, agricultura e em serviços por ligação, rendimento médio do emprego formal e valor adicionado fiscal per capita, com o objetivo de corrigir a forte assimetria das distribuições destas variáveis, minimizando assim a influência de observações "aberrantes" (muito grandes ou muito pequenas), que poderiam comprometer os resultados finais.

Os indicadores de Riqueza, Escolaridade e Longevidade são padronizados para que os mesmos possuam a mesma escala de 0 a 1. Para tanto adota-se:

Indicador Padronizado = (indicador - mínimo $) /($ máximo - mínimo $)$

2) Utilização da Análise Fatorial

Os indicadores sintéticos de riqueza, longevidade e escolaridade foram obtidos por meio da análise fatorial, técnica estatística de análise multivariada que se aplica à identificação de fatores que indiquem objetivamente para a agregação de um conjunto de medidas. Os indicadores padronizado foram tratados pela Análise Fatorial originado fatores de Riqueza, Educação e Longevidade.

3) Análise de Agrupamentos

Análise de Agrupamentos é o nome genérico atribuido a uma extensa variedade de métodos que procuram elaborar critérios para agrupar objetos.

São técnicas estatísticas multivariadas, com conotação exploratória. Desta forma, dada uma amostra de $n$ objetos, cada um deles medido segundo $p$ variáveis, procura-se um esquema de classificação que agrupe 
os objetos em k grupos. Os objetos são mensurados nas diversas variáveis de interesse fornecendo uma matriz de dados de $n$ objetos por $p$ variáveis, a qual será manuseada através de algoritmos para a obtenção dos grupos homogêneos. A similaridade entre os objetos é obtida através de coeficientes especificos para cada tipo de variável.

A Análise de Agrupamentos foi utilizada com objetivo de reunir os 645 municipios paulista em grupos homogêneos quanto aos fatores de Renda, Educação e Longevidade. Desta forma, obteve-se 5 grupos cujas caracteristicas são apresentadas a seguir:

Quadro 03. Características dos grupos de municípios paulistas segundo IPRS. São Paulo 2000.

\begin{tabular}{|c|c|c|}
\hline GRUPO & Característica & $\begin{array}{c}N^{\circ} \text { de } \\
\text { Municípios }\end{array}$ \\
\hline 1 & $\begin{array}{l}\text { Alta Riqueza, média longevidade e média escolaridade } \\
\text { Alta Riqueza, média longevidade e alta escolaridade } \\
\text { Alta Riqueza, baixa longevidade e alta escolaridade } \\
\text { Alta Riqueza, alta longevidade e baixa escolaridade } \\
\text { Alta Riqueza, alta longevidade e média escolaridade } \\
\text { Alta Riqueza, alta longevidade e alta escolaridade }\end{array}$ & 84 \\
\hline 2 & $\begin{array}{l}\text { Alta Riqueza, baixa longevidade e baixa escolaridade } \\
\text { Alta Riqueza, média longevidade e baixa escolaridade } \\
\text { Alta Riqueza, baixa longevidade e média escolaridade }\end{array}$ & 50 \\
\hline 3 & $\begin{array}{l}\text { Baixa Riqueza, média longevidade e média escolaridade } \\
\text { Baixa Riqueza, alta longevidade e média escolaridade } \\
\text { Baixa Riqueza, média longevidade e alta escolaridade } \\
\text { Baixa Riqueza, alta longevidade e alta escolaridade }\end{array}$ & 254 \\
\hline 4 & $\begin{array}{l}\text { Baixa Riqueza, baixa longevidade e média escolaridade } \\
\text { Baixa Riqueza, baixa longevidade e alta escolaridade } \\
\text { Baixa Riqueza, média longevidade e baixa escolaridade } \\
\text { Baixa Riqueza, alta longevidade e baixa escolaridade }\end{array}$ & 163 \\
\hline 5 & Baixa Riqueza, baixa longevidade e baixa escolaridade & 94 \\
\hline
\end{tabular}

Extraido de Fórum São Paulo Século 21 - Indice Paulista de Responsabilidade Social - IPRS - São Paulo 2000. 
Os grupos săo denominados:

1 - Pólo

2 - Economicamente Dinâmicos e de Baixo Desenvolvimento Social

3 - Saudáveis e de Baixo Desenvolvimento Econômico

4 - De Baixo Desenvolvimento Econômico e em Transição Social

5 - De Baixo Desenvolvimento Econômico e Social

Cada um dos municipios paulista está classificado em um dos grupos apresentados anteriormente. 


\section{OBJETIVOS}

\subsection{Objetivo geral}

A presente tese tem como objetivo geral o desenvolvimento de um indice denominado Indice de Desenvolvimento Municipal - IDM, para aferição do progresso dos municípios em diversas áreas sociais.

\subsection{Objetivos especificos}

2.2.1 Fornecer índices nas áreas de Saúde, Educação, Saneamento e Segurança.

2.2.2 Apresentar uma descrição do desenvolvimento dos municipios paulistas segundo o índice proposto nos anos de 1991 e 1996.

2.2.3 Apresentar um aplicativo usando a planilha eletrónica Microsoft Excel para facilitar a visualização dos resultados, utilizando gráficos e mapas, bem como proceder a cálculos do índice de desenvolvimento Municipal - IDM proposto, para qualquer municipio, em qualquer data desejada. 


\section{METODOLOGIA}

\subsection{Unidade de análise e dados utilizados}

De acordo com o objetivo deste trabalho, analisa-se o municipio, visto que o mesmo apresenta-se como a menor unidade administrativa brasileira, sendo responsável pela geraçăo da maior parte de dados nas mais diversas áreas.

É importante salientar uma característica dos municipios paulistas, a sua heterogeneidade no que diz respeito ao porte demográfico das diferentes localidades. No estado de São Paulo a população dos municípios varia de 1000 habitantes até 10 milhões (SEADE 2000). Essa propriedade demográfica deve ser levada em consideração quando indicadores e índices são utilizados para a comparação de municipios. Dos 645 municípios constituidos no estado de São Paulo no ano de $2000,70 \%$ possuem menos de 30 mil habitantes. Por outro lado, indicadores e índices em municípios como São Paulo, Campinas e outros de maior porte, podem apresentar resultados que não espelham a diversidade intra-urbana.

Os dados utilizados são provenientes das bases da Fundação SEADE e Instituto Brasileiro de Geografia e Estatistica - IBGE (1991 e 1996), obtidos por meio da internet [URL: http://www.seade.gov.br] e [URL: http://www.ibge.gov.br] respectivamente.

\section{2 Áreas temáticas e seleção dos indicadores}

Pode-se perguntar, como diferentes medidas, tais como mortalidade, educação etc., podem ser combinadas e fornecer um único valor? Destacase que medidas como Produto Interno Bruto, possuem a facilidade de apresentar um único valor expressivo, visto que os indicadores utilizados 
possuem as mesmas unidades, seja para a venda de um automóvel, seja para a compra de uma maçã (MORRIS 1979).

Para a composição de um índice, faz-se necessário que os indicadores utilizados apresentem a mesma escala. Uma das soluções encontradas e que satisfaz o objetivo conceitual do índice apresentado é empregar coeficientes.

Os princípios norteadores para a escolha dos indicadores componentes do Índice de Desenvolvimento Municipal são:

a) Periodicidade anual.

A utilização de indicadores coletados anualmente propicia a atualização do índice proposto. Esta atualização permite a comparação dos resultados ano a ano, verificando o impacto de possíveis políticas públicas. Uma vasta gama de indicadores, cuja importância é reconhecida, apresenta uma defasagem temporal que torna os resultados do índice pouco representativos. Este é o caso dos indicadores produzido por censos decenais.

b) Adequação à estrutura do índice proposto

Como será apresentado posteriormente neste capítulo, a estrutura matemática proposta para a construção do índice de Desenvolvimento Municipal requer que os indicadores possam ser apresentados por meio de coeficientes. Por esta razăo, indicadores de renda, por exemplo, não satisfazem os pressupostos da construção do índice.

c) Representatividade

Procurou-se incorporar Indicadores que pudessem refletir e resumir características sociais de uma população. 


\subsubsection{Coeficientes}

A desigualdade social e econômica nas populações, grupos sociais e áreas geográficas tem sido foco de diversos estudos, sejam filosóficos ou metodológicos. Este último enfoque possui diversas faces, entre elas a questão mensuração da própria desigualdade.

Quando desejamos analisar fenômenos ao longo do tempo, ou comparar esses fenômenos em grupos populacionais distintos ou ainda regiões diversas, o uso de casos absolutos pode conduzir a conclusões equivocadas. Para realizar tais comparações, deve-se levar em conta $\circ$ tamanho das populações a serem analisadas e sua estrutura como idade, sexo, de maneira a expressar os valores analisados por meio de coeficientes de incidência ou prevalência.

Um coeficiente é calculado relacionando os eventos à população que Ihes deu origem, população esta chamada em risco, já que a mesma referese ao conjunto de pessoas que podem desenvolver o evento, e dessa forma passar a fazer parte do número total de casos.

O coeficiente é a freqüência de eventos que ocorrem em um dado período de tempo, dividida pela população aferida na metade do período de tempo estipulado (JEKEL e col. 1999).

Os resultados obtidos pelos diversos coeficientes apresentam valores inferiores a 1 e por esta razão sofrem a multiplicação de uma constante, seja 100 para obtenção de percentagem ou outros valores como 1.000, 10.000, etc, o que leva a uma interpretação do coeficiente sobre esta constante.

Desta forma teriamos o coeficiente de mortalidade geral - Cmg:

$$
\begin{aligned}
& \text { Número de óbitos } \\
& C m g=\frac{(\text { em um local e período de tempo definido })}{\text { População no meio do período }} \times 1.000 \\
& \text { (mesmo local e período de tempo) }
\end{aligned}
$$




\subsubsection{Características operacionais dos coeficientes utilizados}

Em função das características propostas pelo índice e apresentadas posteriormente, os coeficientes a serem utilizados são por nós chamados de positivos. Assim, ao obtermos coeficientes de Mortalidade Infantil, para efeito de cálculo do índice proposto utilizaremos o Complementar do Coeficiente de Mortalidade Infantil:

$$
\mathrm{CCMI}=1-\frac{\begin{array}{l}
\text { Número de óbitos de criança } \\
\text { com menos de } 1 \text { ano de idade } \\
\text { (local e periodo definidos) }
\end{array}}{\begin{array}{l}
\text { Número de nascidos vivos } \\
\text { (mesmo local e período de tempo) }
\end{array}}
$$

No caso da área de educação, por exemplo, os coeficientes são utilizados na sua forma mais comum. Desta maneira, o coeficiente de matriculados no ensino fundamental não sofrerá alterações.

O resultado final desta modificação forneceria a matriz de coeficientes, onde cada municipio é representado por uma linha $(i=1, \ldots, n)$ sendo mensurado em $j$ indicadores $(j=1, \ldots, p)$ :

$$
C_{i j}=\left[\begin{array}{c}
c_{11 \ldots \ldots} \ldots c_{1 j} \ldots \ldots c_{1 p} \\
c_{i 1} \ldots \ldots c_{i j} \ldots \ldots c_{i p} \\
c_{n 1} \ldots \ldots c_{n j} \ldots \ldots c_{n p}
\end{array}\right]
$$




\section{Indicadores Selecionados}

Ao idealizar um novo indice, faz-se necessário a busca de indicadores que possam, na medida do possivel, abranger a riqueza de informação sobre uma variedade de aspectos sociais, econômicos e políticos que influenciam a natureza e a qualidade da vida humana.

Um dos problemas encontrado na composição do IDH e ilustrado no primeiro relatório do Programa das Nações Unidas para o Desenvolvimento (PNUD 1990), em 1990, era justamente aquele derivado da cobertura dos indicadores, ou seja, os dados possuiam (e ainda possuem) uma cobertura incompleta. Em muitos países as estatísticas para determinadas áreas são inexistentes ou ainda de má qualidade. Uma lista considerável desse tipo de variáveis é apresentada pelo PNUD de 1990, entre elas destacamos a distribuição de renda de famílias, desemprego, valores relacionados à alimentação básica necessária à subsistência, além de informações diferenciadas para regiões rurais e urbanas (PNUD 1990). Além disso, as estatísticas relativas a diferentes dimensões adotadas têm que ser padronizadas e combinadas de modo específico em um único indicador.

Diferente da proposta realizada pelo PNUD, a unidade territorial a ser tratada neste trabalho é o município.

\section{Indicadores de Saúde}

\section{Coeficiente de mortalidade Infantil}

Coeficiente de mortalidade de pessoas de 60 anos ou mais

A evolução das estatísticas de saúde tem sido fonte de análise para caracterizar as condições de vida de uma população (SZWARCWALD e col. 1997). Viver mais, desfrutar do acesso aos serviços de saúde são valores cultuados pela sociedade brasileira.

A análise da desigualdade em saúde pode apresentar diversas dimensões. Uma delas é a situação da saúde coletiva expressa pelas características epidemiológicas dos diversos grupos sociais (NUNES 2001). 
Desta forma, os indicadores de saúde possuem grande importância para o monitoramento das condições de vida bem como podem tornar-se poderosos instrumentos para o desenvolvimento de políticas públicas.

Os aspectos da mortalidade infantil são fundamentais para se conhecer o perfil das condições de vida de uma população.

Este coeficiente é um dos mais importantes indicadores de saúde, visto que seus resultados espelham uma série de condições sócioeconômicas, entre elas as condições dos serviços de saúde junto às mães, educação dos pais, condições nutricionais e ambientais.

$O$ indicador de mortalidade infantil mostra uma importante face do desenvolvimento de uma sociedade. Por esta razão, e por possuir periodicidade anual, foi considerado um dos indicadores componentes do Índice de Desenvolvimento Municipal.

O Brasil, cujo envelhecimento etário de sua população se intensificou nas últimas duas décadas, deve dar maior atenção às doenças crônicodegenerativas, de maneira especial às neoplasias.

Os óbitos relacionados às doenças neoplásicas vem aumentando com o decorrer dos anos. No sexo masculino essas cifras passaram de $11,87 \%$ no ano de 1980, para 12,36\% em 1981 e $13,54 \%$ em 1995 . No sexo feminino verificamos 9,66\% em 1980, 10,61\% em 1981 e $11,15 \%$ em 1995 (BARBOSA e PAES 2000). O comportamento etário revelou um descenso da mortalidade proporcional à medida que se avança na idade. Dentre as neoplasias malignas mais comuns no ano de 1995 destacaram-se as da traquéia, brônquios e pulmões, que representaram $1,87 \%$ das mortes gerais para o sexo masculino, e as neoplasias malignas da mama feminina, que representaram 0,94\% das mortes gerais no país (BARBOSA e PAES 2000).

No estado de São Paulo, a população com idade igual ou superior a 60 anos vem crescendo nos últimos anos seguindo a estrutura demográfica geral do país. Em números absolutos, o estado, em 1980, contava com 1.564.974 idosos. Esse número passou para 2.325.726 em $1990 \mathrm{e}$ 3.316.957 em 2000 (SEADE 2001). 
Dar atenção especial a essa faixa populacional, tornando mais eficientes as políticas públicas e aumentando o comprometimento do estado e da sociedade é fundamental para o desenvolvimento dos municipios paulistas. Neste sentido, o indicador de mortalidade de pessoas de 60 anos ou mais vem se constituindo em um importante instrumento para monitorar ações em saúde, sendo assim, selecionado para compor o IDM.

\section{Indicadores de Educação}

\section{Coeficiente de Matriculados na Pré-Escola (total)}

Coeficiente de evasão no ensino fundamental Público

Coeficiente de matriculados no ensino médio

Coeficiente de evasão no ensino médio

A educação é um direito humano fundamental e possui forte impacto sobre as possibilidades de desenvolvimento (UNESCO 2000).

Os indicadores e estatísticas de educação permitem monitorar as tendências e facilitam a avaliação de políticas públicas de maneira a administrar mais eficientemente seus processos educativos (UNESCO 2001).

O estado de São Paulo possui um dos mais baixos percentuais de analfabetismo. Em 1999 o estado de São Paulo possuía 6,2\% de analfabetos, resultado bem abaixo do valor nacional igual a 13,3\%. Quanto ao percentual de escolarização de crianças entre 7 e 14 anos de idade São Paulo apresentava em 1999 um percentual igual a 97,3 (IBGE 1999). No entanto, os bons resultados do estado de São Paulo não são homogêneos. A região de governo de Guaratinguetá apresenta um percentual de evasão no ensino médio, igual a $13,51 \%$, enquanto a região de Jales apresentava 6,15\% no ano de 1998 (Secretaria de Estado da Educação de São Paulo 1999).

O ensino superior não pode ser contemplado na estrutura dos indicadores para composição do IDM, visto que os resultados obtidos por determinados municípios não espelham a realidade local. Pode-se observar, 
que a migração de estudantes para determinados centros educacionais, alteram os resultados dos indicadores de matrículas, superestimando ou subestimando esses indicadores. Por esta razão, priorizaram-se os indicadores do ensino de Pré-Escola, Fundamental e Médio.

\section{Indicadores de Segurança (Violência)}

\section{Coeficiente de homicidios}

Coeficiente de mortalidade devido a acidentes de veículos a motor

As mortes violentas vêm aumentando no Estado de São Paulo desde a década de 1980 , em número absolutos e proporcionalmente às outras causas de morte.

As mortes por causas externas no Estado de São Paulo representavam em 1999 o terceiro maior grupo com 14,3\% do total de óbitos, sendo que a categoria de homicídios (43,9 mortes por cem mil habitantes) é a maior causa entre as causas externas (Secretaria de Saúde do Estado de São Paulo, 2001).

As agressões ou homicídios representam $46,6 \%$ dos óbitos por causa externa em São Paulo em 1999 seguidos pela mortalidade por causa dos acidentes de transporte.

Quando verificamos a distribuição das mortalidades por causas externas, os homicídios são em número absoluto, a primeira entre os diferentes tipos de causa externa, sendo a maior proporção na Diretoria Regional de Saúde (DIR) de Santo André $(60,7 \%)$, seguida de São Paulo $(60,5 \%)$ e Osasco $(58,8 \%)$, sendo a proporção estadual de $46,7 \%$.

As mortalidades por causas violentas representam importante impacto na população paulista, visto que incidem na população jovem produtiva do estado gerando grande perda em anos de vida.

Devido às caracteristicas apresentadas, os indicadores de homicídio e mortalidade devido a acidentes de veículo a motor foram selecionados para a construção do Índice de Desenvolvimento Municipal. 


\section{Indicadores de Meio Ambiente - saneamento}

\section{Coeficiente de residências com abastecimento de água tratada} Coeficiente de residências com coleta de esgoto

$\mathrm{Na}$ área de saneamento básico, os indicadores selecionados foram residências com abastecimento de água tratada e residências com coleta de esgoto.

A associação entre o sistema de saneamento básico e as internações hospitalares é bastante alta. Dados de 1997 mostram que apenas $38 \%$ do total de esgotos produzidos eram tratados no Brasil, ou seja, $62 \%$ são despejados in natura nos solos, rios, córregos e nascentes, constituindo em uma das maiores fontes de degradação do meio ambiente. Um outro fator, desta elevada associação, é o descaso com as famílias que recebem até dois salários mínimos, as quais não possuem acesso à rede de água. De acordo com o BNDES, $65 \%$ das internações hospitalares de crianças com idade inferior a 10 anos estão associados à precariedade das condições de saneamento básico. Esta relação intrínseca entre o sistema de saneamento e a saúde pública também trás prejuizos em termos econômicos, onde para cada unidade monetária investida em saneamento, ocorre uma economia de quatro unidades monetárias dos gastos com custeio em saúde.

As implicações deste cenário são os problemas de saúde enfrentados pela população, tais como a esquistossomose, cólera, e a deteriorização do meio ambiente (COSTA FILHO 2000). 


\subsection{Composição do Índice de Desenvolvimento Municipal (IDM)}

A primeira etapa para a composição de um índice deve estar direcionada para a escolha das ảreas que irão compor o próprio índice, vista anteriormente. Uma segunda etapa consiste na escolha e viabilidade operacionais dos indicadores de cada área.

Esta seção focaliza a construção do índice de Desenvolvimento Municipal, a formulação matemática do índice.

\subsubsection{Utilização da função Antilogaritmo}

Alguns indicadores fornecem resultados matemáticos que podem não espelhar a importância dos mesmos, apresentando assim uma pequena contribuição. Seguindo o mesmo paradigma utilizado pelas Nações Unidas em seu Programa para o Desenvolvimento, através do índice IDH, o qual aplica a função logarítmica para minimizar a influência do indicador renda, utilizamos a função antilogaritmo para ampliar a influência de determinados indicadores, que estariam sub representados, positivamente ou negativamente.

Neste sentido a função antilog causa uma maior dispersão dos dados, minimizando os resultados finais do indice.

A simulação para aplicação da função antilog em coeficientes entre 1 e 0,20 e seus valores originais é apresentada na figura 9 .

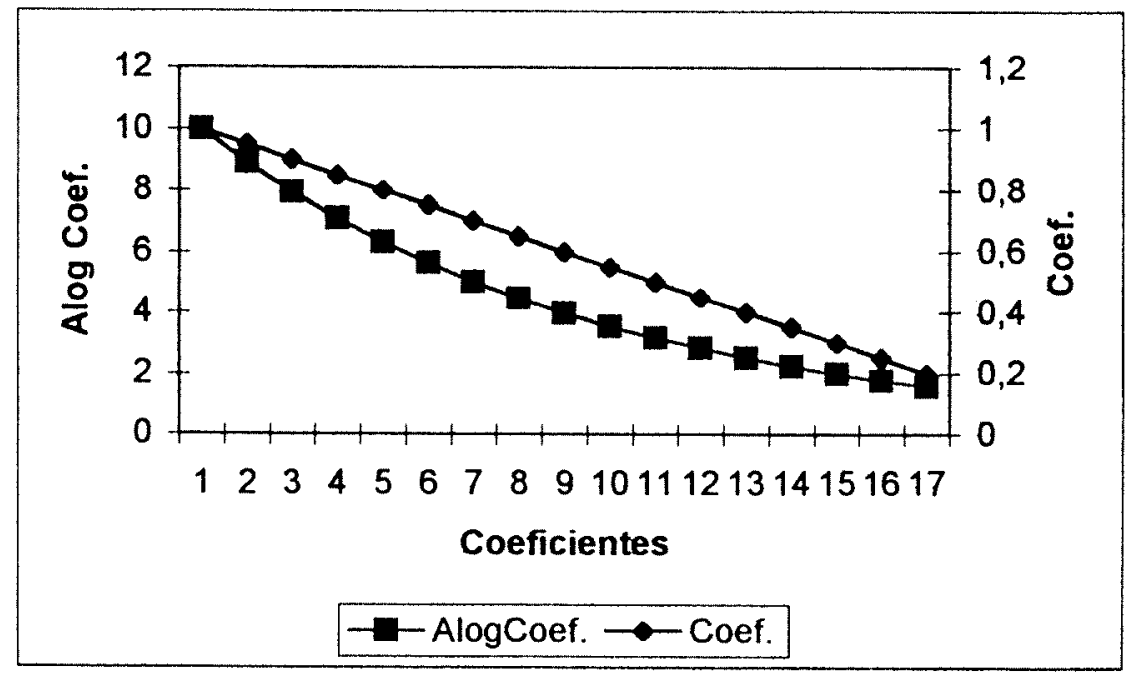

Figura 9. Coeficientes originais e tratados pela função antilog. 
Busca-se assim minimizar os resultados matemáticos do coeficiente em foco.

Quadro 4. Indicadores selecionados e transformação utilizada.

\begin{tabular}{|l|l|c|}
\hline Área & Indicadores & $\begin{array}{c}\text { Transformação } \\
\text { Antilog }\end{array}$ \\
\hline Saúde & Mortalidade Infantil & Sim \\
& Mortalidade de pessoas de 60 anos ou + & Não \\
\hline Educação & Matriculados na Pré-Escola (total) & Sim \\
& Evasão no ensino fundamental Público & Não \\
& Matriculados no ensino médio & Não \\
& Evasão no ensino médio & Sim \\
\hline Segurança & Mortalidade por Homicídios & Sim \\
& Mortalidade devido a acidentes de veículos a & \\
\hline Saneamento & Resider & Não \\
& Residências com coleta de esgoto & Não \\
\hline
\end{tabular}

\subsubsection{Utilização do conceito de distâncias}

A composição do IDM é feita inicialmente mediante o conceito da distância Euclidiana. Situação em que os $n$ municípios são mensurados através de $p$ variáveis contínuas.

Para obter 0 índice proposto, calcula-se a distância euclidiana para cada coeficiente positivo como é apresentado a seguir:

Dado o vetor de coeficientes $C_{i j}$ para cada um dos municípios e fixando $i$ teremos a distância euclidiana para cada um dos n municípios $\left(d_{l}\right.$, $\left.d_{2}, \ldots, d_{n}\right)$

$$
d_{i}=\sqrt{\sum_{j=1}^{p}\left(c_{i j}-c_{j \max }\right)^{2}}
$$

onde $j$ varia de 1 a 10 (dez indicadores). 
A distância de cada coeficiente $c_{i j}$ para o valor máximo $\left(c_{\text {jmax }}\right)$ se justifica pelo conceito da busca do ideal para cada indicador aferido. Desta forma, quanto menor as distâncias alcançadas, melhores as condições de vida, visto que o valor máximo representa o ideal em termos do coeficiente de matrículas nas diversas séries escolares, melhores condições de saneamento e assim por diante.

Conceito semelhante pode ser observado quando o PNDU de 1994 adota uma padronização diferente da que vinha usando em anos anteriores no Índice de Desenvolvimento Humano - IDH. A partir de 1994 o PNDU incorpora valores que possam ser apresentados como metas nas áreas de saúde, renda e educação.

A mesma linha metodológica é seguida pela composição do Índice de Desenvolvimento Infantil - IDI da Unicef que utiliza como base a universalização dos direitos da criança:

Para combinar os indicadores selecionados num único índice é necessário expressá-los em unidades comparáveis. Para isso, os valores de cada indicador foram normalizados numa escala de 0 a 1 , onde 1 corresponde à melhor condição de desenvolvimento infantil e 0 , à pior. Para efeitos de comparação $e$ interpretação, essa é a mesma escala utilizada para o cálculo do IDH.

Outra opção é a substituição do valor 1 pelo valor máximo encontrado em cada coeficiente, adotada até 1994 pelo PNDU em seu IDH e outros indices como o Índice de Qualidade de Vida Urbana - IQVU desenvolvido pela prefeitura de Belo Horizonte, MG, em 1996: 


\begin{abstract}
Considerando-se que o IQVU destina-se à comparação intra-urbana e a hipótese de que, em se tratando de áreas metropolitanas, cada indicador é ofertado em condições ótimas em, pelo menos, uma das unidades espaciais, adota-se a ocupação de tomar o respectivo máximo como referencial de "valor ótimo". Entretanto, o modelo permite que se utilizem referências externas para tal fim.
\end{abstract}

No entanto, o próprio texto apresenta uma alternativa para a utilização de referências externas.

A escolha pelo valor máximo encontrado não permite uma comparação evolutiva no tempo das possíveis melhoras de cada município, visto que o valor máximo pode aumentar no decorrer do tempo, encobrindo a evolução de outros municípios.

Pelo exposto, adotamos como valor ótimo a situação almejada representada pelo valor 10 , quando o coeficiente é tratado pela função antilogaritmo e 1 para os demais coeficientes. Cabe destacar que esta solução traz em si um dos objetivos do IDM, ou seja, a simplicidade matemática.

No entanto, a apresentação do resultado final de um índice deve ser padronizada para facilitar a interpretação e comparação dos valores obtidos.

A forma convencional de apresentação de um índice é dada pelo intervalo que varia entre os valores 0 e 1 , que pode ser transformado em valores percentuais variando entre $0 \%$ e $100 \%$ ou valores de pontuação de 0 a 1000 .

\title{
3.3.3 Padronização de $d_{i}$
}

A padronização de $d_{i}$ é dada por : 


$$
d_{i} \text { padronizado }=\frac{d_{i}}{\operatorname{Max} d_{i} O t}[2]
$$

O valor $\mathrm{Maxd}_{i} \mathrm{Ot}$ é dado pela distância euclidiana dos valores almejados. Desta forma, para cada um dos dez coeficientes selecionados, cada um dos cinco tratados pela função Antilog, pode resultar em uma distância máxima igual $a \sqrt{(1-10)^{2}}$. Os demais coeficientes resultam, cada um, em uma distância máxima igual a $\sqrt{(0-1)^{2}}$. A somatória de todas as possiveis distâncias máximas é dada pela expressão 3 :

$$
\operatorname{Maxd}_{i} O t=\sqrt{410}
$$

\subsection{4 Índice de Desenvolvimento Municipal - IDM}

O resultado final do indice é dado pela fórmula:

$$
I D M=\left[\operatorname{Antilog}\left(1-\frac{d_{i}}{\text { Maxd }_{i} O t}\right)\right] \times 100 \text { [4] }
$$

Para uma melhor interpretação do índice, o resultado da padronização é primeiramente subtraido de 1 e posteriormente aplicado a função antilogaritmo para fazer com que as diferenças entre os municípios possam ser percebidas com maior facilidade. O resultado final é obtido mediante a multiplicação da constante 100 para aumentar a sensibilidade do indice que irá variar entre 1000 pontos - melhor resultado, e 0 ponto, pior resultado.

Para cada uma das áreas temáticas pode-se calcular o valor do IDM utilizando a equação 5 modificada:

$$
I D M_{\text {área }}=\left(1-\frac{d_{i}}{\operatorname{Maxd}_{i} O t}\right) \times 1000[5]
$$


Os resultados da equação 5 variam na mesma escala do IDM geral e a sua interpretação é a mesma.

\subsection{Sistema IDM Informatizado}

O conjunto de informações geradas pela aplicação do índice de Desenvolvimento Municipal - IDM pode ser melhor observado através de um sistema informatizado. Seguindo os mesmo pressupostos de simplicidade assumidos para a criação do IDM, criou-se através da ferramenta Visual Basic do software Microsoft Excel 2000 um sistema que pode ser instalado em computadores cuja configuração inicial é similar ao pentium $133 \mathrm{mhz}$. 0 sistema requer que o computador tenha instalado no mínimo a versão 7 do software Microsoft Excel.

O sistema contempla os resultados comparativos do IDM para todos os municípios paulistas em 1991 e 1996. É possivel visualizar os resultados comparativos de cada município para cada área temática, saúde, educação, segurança e saneamento.

Outro importante aspecto do Sistema IDM é a possibilidade de cálculo do índice. O usuário de posse dos coeficientes para cada uma das áreas temáticas tem a facilidade de calcular o índice mediante tela interativa, proporcionado assim resultados imediatos.

3.5 Características metodológicas do Índice de Exclusão Social - lex e Índice de Exclusão Social Modificado - IEXSOC

Metodologicamente o lex (SPOSATI, 1996) apresenta como característica as seguintes etapas:

$1^{a}$ - Busca de áreas temáticas que possam representar a exclusão/inclusão social da região geográfica em estudo; 
$2^{a}$ - Escolha de indicadores representativos em cada uma das áreas temáticas;

$3^{a}$ - A construção do índice propriamente dita:

a - Para cada indicador selecionado fixa-se padrões básicos de inclusão, aos quais são atribuídos o valor 0 (zero). Uma das maneiras para a definição dos padrões é a utilização do valor da média do indicador como padrão.

b - Transformação dos valores do indicador com intervalo variando de -1 a 1. Para isto leva-se em conta o valor padrão zero. O melhor resultado do indicador receberá o valor 1 , enquanto o pior o valor -1 .

c - Cálculo da média dos valores transformados do referido indice. Cabe salientar que o indice geral (também chamado de indicador) é composto pelos diversos índices temáticos, como por exemplo, o índice de qualidade de domicilio, índice de Inserção Social, etc. A tabela abaixo ilustra o cálculo descrito anteriormente.

Tabela 3 Cálculo do índice temático Inserção Social

\begin{tabular}{ccccc}
\hline $\begin{array}{c}\text { Setor } \\
\text { Censitário }\end{array}$ & $\begin{array}{c}\text { Indice de } \\
\text { Escolaridade }\end{array}$ & $\begin{array}{c}\text { Indice de } \\
\text { Renda } \\
\text { per Capita }\end{array}$ & $\begin{array}{c}\text { Indice de Condição de } \\
\text { ocupação do domicilio }\end{array}$ & $\begin{array}{c}\text { Indicador de Inserção } \\
\text { social (média dos indices) }\end{array}$ \\
\hline 1 & 0,8502 & 0,6781 & 0,9397 & 0,822667 \\
2 & 0,9125 & 0,8372 & 0,9317 & 0,893800 \\
3 & 0,6389 & $-0,2042$ & 1,0000 & 0,478233 \\
8 & $-0,3275$ & $-0,2658$ & 0,8851 & 0,097267 \\
9 & 0,6434 & $-0,2385$ & 0,8798 & 0,428233 \\
10 & $-0,8746$ & $-0,8028$ & $-0,9980$ & $-0,891800$ \\
162 & $-0,3415$ & $-0,3726$ & $-0,8406$ & $-0,518233$ \\
237 & 0,8460 & 1,0000 & 0,8442 & 0,896733 \\
415 & $-1,0000$ & $-0,6793$ & $-1,0000$ & $-0,893100$ \\
\hline
\end{tabular}

Dados parciais retirados de CHIESA, AM. 1999. 
d - O resultado final é obtido pela média ponderada de todos os indices temáticos. O peso de cada indice temático é aferido segundo sugestão dos grupos participantes na pesquisa.

Neste trabalho, a metodologia do índice de Exclusão Social foi aplicada nos mesmos indicadores da área de Saúde, Educação, Segurança e Saneamento utilizados pelo IDM. Para as áreas de Saúde e Segurança foi aplicado o peso 2 em cada uma e peso nas demais áreas da seguinte forma:

$$
\text { Iex }=\frac{2 \times \text { IexSaúde }+ \text { IexEducação }+2 \times \text { IexSeguraça }+ \text { IexSaneame }}{6} \quad[6]
$$

Metodologicamente o IEXSOC apresenta como característica as seguintes etapas:

$1^{a}$ - Busca de áreas temáticas que possam representar a exclusão/inclusão social da região geográfica em estudo;

$2^{\mathrm{a}}$ - Escolha de indicadores representativos em cada uma das áreas temáticas;

$3^{a}-A$ construção do índice propriamente dita:

a - Cada um dos indicadores selecionados é transformado em valores que variam de 0 a 1 , onde 0 indica a maior carência e 1 menor carência. Para tal transformação usa-se a seguinte expressão matemática:

$$
\text { IEXSOC }=\frac{\text { valor obs. }- \text { valor mínimo obs. }}{\text { valor máximo obs. - valor mínimo obs. }}
$$

b - Calcula-se a média dos valores dos indicadores transformados, resultando no IEXSOC. 
Os resultados obtidos são apresentados na forma de postos, desta maneira, o valor do índice é dado pela posição do município em relação aos demais. 


\section{RESULTADOS}

\subsection{Desenvolvimento dos Municipios Paulistas segundo IDM}

Para o ano de 1991, trezentos e sessenta e um (361) municipios apresentaram todos os coeficientes para o cálculo do IDM, o que representa $63 \%$ dos 572 municípios instalados. Os demais municípios, possuem departamento próprio responsável pela área de saneamento básico, não vinculados ao sistema da Companhia de Saneamento Básico do Estado de São Paulo - SABESP. Esta configuração descentralizada dos dados de saneamento inviabilizou a coleta e tratamento dos indicadores de água e esgoto. No entanto entendemos que esta dificuldade possa ser transposta com o compromisso de órgãos públicos municipais em colaborar para confecção do Índice de Desenvolvimento Municipal - IDM.

O município com menor desenvolvimento em 1991 no Estado de São Paulo é Águas da Prata com Índice de Desenvolvimento Municipal - IDM igual a 529,86 para uma escala de desenvolvimento que varia de zero (o menor desenvolvimento) a 1000 (o melhor desenvolvimento). Ao observar os resultados do município de Águas da Prata para as quatro áreas temáticas que compõem o índice, verificamos que o IDM Saúde é igual a 601,12, IDM Educação igual a 746,10, IDM Segurança igual a 999,72 e IDM Saneamento igual a 949,29. A área de saúde é a responsável prioritária pelo baixo índice do municipio. Cabe ainda ressaltar que, o resultado final não é uma simples média dos resultados de cada uma das áreas, mas sim a síntese de todos os indicadores.

$\mathrm{Na}$ outra ponta da escala, o município de Turmalina, na Região de Governo de Fernandópolis apresenta maior desenvolvimento com IDM igual a 854,67 . Para as áreas temáticas, Turmalina apresenta IDM de Saúde igual a 950,48 Educação 887,42, Segurança 999,34 e Saneamento 528,32.

Em 1996, dos 625 municípios existentes 220 apresentam todos os coeficientes necessários para o cálculo do IDM. O município em melhores 
condições de desenvolvimento segundo o IDM é Oscar Bressane com 918,73 pontos.

No entanto, esta análise deve ser realizada levando-se em consideração o tamanho da população. Em municípios com baixa população, os indicadores podem sofrer alterações relevantes de um ano para outro dependendo dos eventos ocorridos. Por esta razão, para efeito de análise dos IDMs, os municípios foram divididos em 05 grupos em função de seu tamanho populacional, de acordo com a tabela a seguir:

Tabela 04. Agrupamento de municipios segundo tamanho populacional

\begin{tabular}{llcccc}
\hline Grupo & $\begin{array}{l}\text { Descrição } \\
\text { (x1000 Habitantes) }\end{array}$ & \multicolumn{2}{c}{$\begin{array}{c}\text { Municípios } \\
(1991)\end{array}$} & \multicolumn{2}{c}{$\begin{array}{c}\text { Municipios } \\
\text { (1996) }\end{array}$} \\
\cline { 3 - 6 } & & No. & $\%$ & No. & $\%$ \\
1 & Até 10 & 245 & 42,83 & 284 & 45,44 \\
2 & 10 até 30 & 172 & 30,07 & 182 & 29,12 \\
3 & 30 até 60 & 70 & 12,24 & 67 & 10,72 \\
4 & 60 até 90 & 30 & 5,24 & 31 & 4,96 \\
5 & Acima de 90 & 55 & 9,62 & 61 & 9,76 \\
\hline & Total & 572 & 100 & 625 & 100 \\
\hline
\end{tabular}

A partir dos grupos de municipios apresentamos os resultados para os anos de 1991 e 1996. Uma visualização completa pode ser obtida no CD ROM IDM (em anexo).

Tabela 5. Resultados do IDM para Grupo 1 - População até 10 mil habitantes - 1991 .

\begin{tabular}{lccccc}
\hline Município & \multicolumn{5}{c}{ IDM } \\
& Saúde & Educação & Segurança & Saneamento & GERAL \\
\hline Turmalina & 950,48 & 887,43 & 999,34 & 528,33 & 854,68 \\
Sebastianópolis do Sul & 932,70 & 878,44 & 1000,00 & 583,74 & 840,92 \\
Paraíso & 945,47 & 853,93 & 1000,00 & 714,04 & 837,32 \\
Bilac & 964,81 & 838,34 & 999,67 & 803,70 & 836,26 \\
Platina & 891,44 & 533,38 & 996,16 & 352,28 & 593,56 \\
Redenção da Serra & 806,69 & 585,70 & 998,99 & 310,63 & 590,77 \\
Jeriquara & 936,35 & 502,12 & 1000,00 & 730,72 & 589,31 \\
Itirapuã & 861,47 & 521,51 & 999,64 & 765,83 & 583,44 \\
Águas da Prata & 601,12 & 746,11 & 999,73 & 949,30 & 529,87 \\
\hline
\end{tabular}


Os resultados apresentados na tabela 5 mostram a situação dos municipios com maior e menor pontuação entre os municípios com menos de 10 mil habitantes. A diferença entre o IDM de Turmalina e Águas da Patra atinge 324,81 pontos na escala de 0 a 1000 pontos.

A tabela seguinte, apresenta os dados dos municípios do grupo 2 , entre 10 mil e 30 mil habitantes. Neste grupo a diferença entre o maior IDM e o menor chega a 253,38 pontos. Nota-se que as áreas de Saneamento, Educação e Saúde contribuem para que o município de Ribeirão Branco apresente um IDM baixo.

Tabela 6. Resultados do IDM para o Grupo 2 - População entre 10 mil e 30 mil habitantes - 1991.

\begin{tabular}{lccccc}
\hline Municipio & & & IDM & \\
Nhandeara & Saúde & Educação & Segurança & Saneamento & GERAL \\
Cerquilho & 950,59 & 869,13 & 999,60 & 667,52 & 849,57 \\
Tupi Paulista & 943,74 & 815,30 & 999,62 & 867,43 & 810,50 \\
Flórida Paulista & 929,63 & 824,76 & 999,87 & 770,94 & 808,69 \\
Guararapes & 938,61 & 821,71 & 999,54 & 528,09 & 802,91 \\
Iracemápolis & 921,67 & 814,91 & 999,29 & 786,92 & 797,43 \\
Monte Azul Paulista & 940,17 & 792,21 & 1000,00 & 984,65 & 791,95 \\
Capela do Alto & 924,50 & 801,32 & 999,48 & 777,32 & 789,10 \\
Bernardino de Campos & 948,45 & 647,47 & 999,83 & 493,70 & 681,37 \\
Itatinga & 867,86 & 682,07 & 999,81 & 757,80 & 680,74 \\
Cabreúva & 931,32 & 641,37 & 999,70 & 696,51 & 677,17 \\
Miracatu & 915,52 & 656,57 & 999,41 & 325,65 & 674,71 \\
Nazaré Paulista & 931,22 & 634,07 & 997,67 & 269,55 & 662,78 \\
Ribeirão Branco & 926,48 & 626,84 & 999,01 & 242,84 & 656,26 \\
\hline
\end{tabular}


Tabela 7. Resultados do IDM para o Grupo 3 - População entre 30 mil e 60 mil habitantes - 1991.

\begin{tabular}{lccccc}
\hline \multirow{2}{*}{ Município } & & \multicolumn{5}{c}{ IDM } \\
\hline Nova Odessa & Saúde & Educação & Segurança & Saneamento & GERAL \\
Barra Bonita & 940,21 & 821,11 & 999,46 & 880,05 & 813,46 \\
Socorro & 936,51 & 820,18 & 999,45 & 1000,00 & 811,61 \\
Pereira Barreto & 930,30 & 818,46 & 999,21 & 516,61 & 796,06 \\
Caraguatatuba & 940,90 & 813,23 & 999,33 & 474,93 & 795,51 \\
Santana de Parnaiba & 900,53 & 682,07 & 999,01 & 443,89 & 689,22 \\
Jacupiranga & 892,50 & 684,78 & 999,65 & 346,16 & 684,95 \\
Apiai & 909,73 & 654,39 & 998,14 & 466,75 & 675,26 \\
\hline & 838,41 & 666,43 & 999,52 & 351,23 & 649,34 \\
\hline
\end{tabular}

Tabela 8. Resultados do IDM para o Grupo 4 - População entre 60 mil e 90 mil habitantes - 1991.

$$
\text { IDM }
$$

\begin{tabular}{lccccc} 
Municipio & Saúde & Educação & Segurança & Saneamento & GERAL \\
\hline São João da Boa Vista & 931,12 & 799,53 & 999,46 & 885,16 & 792,76 \\
Birigui & 946,55 & 788,05 & 999,71 & 897,50 & 790,86 \\
Itatiba & 924,46 & 794,53 & 999,55 & 788,21 & 784,39 \\
Poá & 918,34 & 792,30 & 999,21 & 655,55 & 776,64 \\
São Roque & 924,55 & 710,14 & 999,43 & 481,73 & 717,58 \\
Lorena & 923,81 & 697,07 & 999,53 & 744,56 & 713,95 \\
Itapeva & 881,72 & 701,74 & 999,52 & 594,97 & 697,12 \\
\hline
\end{tabular}

Os resultados das tabelas 7 e 8 , referentes aos grupos populacionais 3 e 4, apresentam resultados semelhantes quanto a pontuação do IDM. $\mathrm{Na}$ área de saúde chama atenção o baixo valor do IDM de Saúde para o município de Itapeva. A mortalidade infantil neste municipio apresentava uma taxa de 55 óbitos por mil nascidos vivos, enquanto no Estado de São Paulo a taxa de mortalidade infantil era de 27 por mil nascidos vivos.

O grupo 5 apresenta Americana com o maior IDM e com maior homogeneidade entre as áreas temáticas. O municipio de São Paulo, cuja população se enquadra no grupo 5 (mais de 9 milhões de habitantes em 
1991) apresenta um IDM igual a 779,91 sendo que a área de saneamento é a mais deficitária.

Tabela 9. Resultados do IDM para o Grupo 5 - População acima de 90 mil habitantes - 1991.

\section{IDM}

\begin{tabular}{lccccc} 
Municipio & Saúde & Educação & Segurança & Saneamento & GERAL \\
\hline Americana & 941,93 & 824,48 & 999,59 & 964,13 & 817,58 \\
São Caetano do Sul & 932,91 & 815,61 & 999,39 & 947,78 & 806,15 \\
Santo André & 933,17 & 797,41 & 999,26 & 1000,00 & 792,75 \\
Araraquara & 933,34 & 788,79 & 999,53 & 912,70 & 786,03 \\
Cubatão & 913,46 & 829,46 & 999,07 & 314,18 & 783,63 \\
São Vicente & 935,51 & 790,10 & 999,60 & 661,43 & 783,49 \\
Itapetininga & 919,32 & 717,81 & 999,51 & 705,15 & 726,17 \\
Itapecerica da Serra & 909,16 & 728,12 & 998,83 & 251,33 & 715,49 \\
São Paulo & 930,10 & 785,30 & 999,00 & 759,10 & 779,90 \\
Itapevi & 910,41 & 704,79 & 998,74 & 441,07 & 707,67 \\
\hline
\end{tabular}

As tabelas 10 e 11 apresentam os resultados dos grupos 1 e 2 para o ano de 1996. Pode-se notar um aumento generalizado dos resultados do IDM, tanto para os municípios em melhores condições, quanto para aqueles em piores condições de desenvolvimento.

Tabela 10. Resultados do IDM para o Grupo 1 - População até 10 mil habitantes - 1996 .

IDM

\begin{tabular}{lcllll} 
Município & Saúde & Educação & Segurança & Saneamento & GERAL \\
\hline Oscar Bressane & 957,27 & 957,39 & 999,68 & 768,32 & 918,73 \\
Bento de Abreu & 991,39 & 914,65 & 999,24 & 887,47 & 912,44 \\
Turiúba & 965,81 & 925,39 & 999,10 & 787,33 & 906,36 \\
Gália & 903,56 & 677,20 & 999,69 & 762,38 & 693,34 \\
Nipoã & 780,79 & 774,24 & 999,41 & 869,54 & 673,30 \\
Planalto & 893,36 & 648,24 & 999,50 & 841,43 & 671,26 \\
Estrela d'Oeste & 770,66 & 778,15 & 1000,00 & 735,47 & 665,80 \\
\hline
\end{tabular}


Tabela 11. Resultados do IDM para o Grupo 2 - População entre 10 mil e 30 mil habitantes -1996.

\begin{tabular}{lccccc}
\hline & \multicolumn{5}{c}{ IDM } \\
Município & Saúde & Educação & Segurança & Saneamento & GERAL \\
\hline Lucélia & 946,80 & 893,65 & 999,58 & 818,56 & 871,03 \\
Bernardino de Campos & 930,33 & 891,50 & 999,12 & 964,97 & 859,31 \\
Ilhabela & 933,95 & 945,28 & 999,44 & 298,24 & 853,41 \\
Piratininga & 914,35 & 906,48 & 999,64 & 829,38 & 852,09 \\
Tarumã & 908,46 & 740,63 & 999,29 & 787,81 & 738,61 \\
Itaporanga & 866,03 & 781,04 & 999,64 & 658,12 & 737,52 \\
Cabreúva & 920,95 & 741,13 & 999,66 & 342,84 & 732,32 \\
São Miguel Arcanjo & 912,16 & 735,77 & 999,55 & 532,41 & 731,61 \\
Areiópolis & 929,17 & 674,37 & 999,60 & 741,99 & 699,81 \\
\hline
\end{tabular}

No grupo 3, chama a atenção os resultados insatisfatórios da área de saneamento básico dos vários municípios que compõem este grupo.

Tabela 12. Resultados do IDM para o Grupo 3 - População entre 30 mil e 60 mil habitantes - 1996.

\section{IDM}

\begin{tabular}{lccccc} 
Município & Saúde & Educação & Segurança & Saneamento & GERAL \\
\hline Fernandópolis & 943,88 & 883,95 & 999,45 & 941,51 & 864,16 \\
Adamantina & 938,18 & 864,08 & 999,49 & 889,54 & 844,94 \\
Jales & 941,74 & 857,12 & 999,48 & 892,87 & 841,98 \\
Registro & 923,17 & 862,27 & 998,99 & 627,43 & 825,96 \\
Paulinia & 941,39 & 837,88 & 999,56 & 756,23 & 824,41 \\
Piedade & 895,52 & 804,73 & 997,64 & 385,99 & 761,76 \\
Presidente Epitácio & 875,24 & 803,92 & 999,72 & 508,08 & 752,80 \\
Peruibe & 929,76 & 754,32 & 999,18 & 428,18 & 747,93 \\
Tremembé & 937,32 & 722,48 & 999,36 & 797,59 & 737,21 \\
Ibiúna & 921,41 & 756,69 & 999,26 & 219,45 & 737,15 \\
\hline
\end{tabular}


Tabela 13. Resultados do IDM para o Grupo 4 - População entre 60 mil e 90 mil habitantes -1996.

IDM

\begin{tabular}{lccccc} 
Município & Saúde & Educação & Segurança & Saneamento & GERAL \\
\hline São João da Boa Vista & 939,47 & 894,14 & 999,56 & 930,11 & 868,20 \\
Caçapava & 930,04 & 882,63 & 999,44 & 847,92 & 851,57 \\
Itatiba & 931,02 & 866,76 & 999,62 & 847,60 & 841,32 \\
Itapeva & 890,02 & 794,08 & 999,48 & 777,67 & 763,69 \\
São Roque & 923,52 & 770,81 & 999,45 & 575,23 & 761,86 \\
Lorena & 916,87 & 755,57 & 999,20 & 883,04 & 754,00
\end{tabular}

A tabela 14 apresenta o grupo 5 cuja população excede a 90 mil habitantes. O município de Santos atinge um IDM igual a 844,67 pontos, com um resultado homogêneo nas diversas áreas. 0 municipio de São Paulo com IDM igual a 831,72 pontos mostra sua maior defasagem na área educacional.

Tabela 14. Resultados do IDM para o Grupo 5 - População acima de 90 mil habitantes - 1996 .

IDM

Municipio Saúde Educação Segurança Saneamento GERAL

\begin{tabular}{lccccc}
\hline Santos & 925,36 & 875,54 & 999,41 & 1000,00 & 844,67 \\
São Paulo & 932,09 & 851,20 & 998,93 & 904,69 & 831,72 \\
São José dos Campos & 933,07 & 843,28 & 998,92 & 897,55 & 826,45 \\
Pindamonhangaba & 920,87 & 793,89 & 999,52 & 836,11 & 782,81 \\
Taubaté & 926,56 & 774,39 & 999,22 & 880,60 & 772,00 \\
Itapetininga & 908,78 & 758,76 & 999,42 & 854,81 & 752,06 \\
\hline
\end{tabular}

Como mostrado nas tabelas anteriores, os resultados da pontuação do IDM aumentaram em quase todos os municipios paulistas. A evolução dos resultados pode ser observada pela figura 10. Em 1991 nota-se a predominância de municipios com IDM entre 630 e 750 pontos (os municípios em branco não apresentaram indicadores suficientes para 0 cálculo do IDM). Esse resultado é alterado em 1996, com o aumento do 
valor do Índice de Desenvolvimento Municipal. A região central do Estado obtém uma pontuação maior, enquanto o sul do estado, apesar do aumento do IDM apresenta valores mais baixos.

A representação do desenvolvimento por meio de mapas é usada em muitos países desenvolvidos como instrumento na tomada de decisão para a alocação de recursos em áreas mais necessitadas (ALDERMAN et. al., 2000). Por esta razão, são apresentados mapas temáticos baseados em cada IDM, para o Estado de São Paulo, nos anos de 1991 e 1996. Os municípios cujos dados são insuficientes para o cálculo do índice são apresentados em branco.

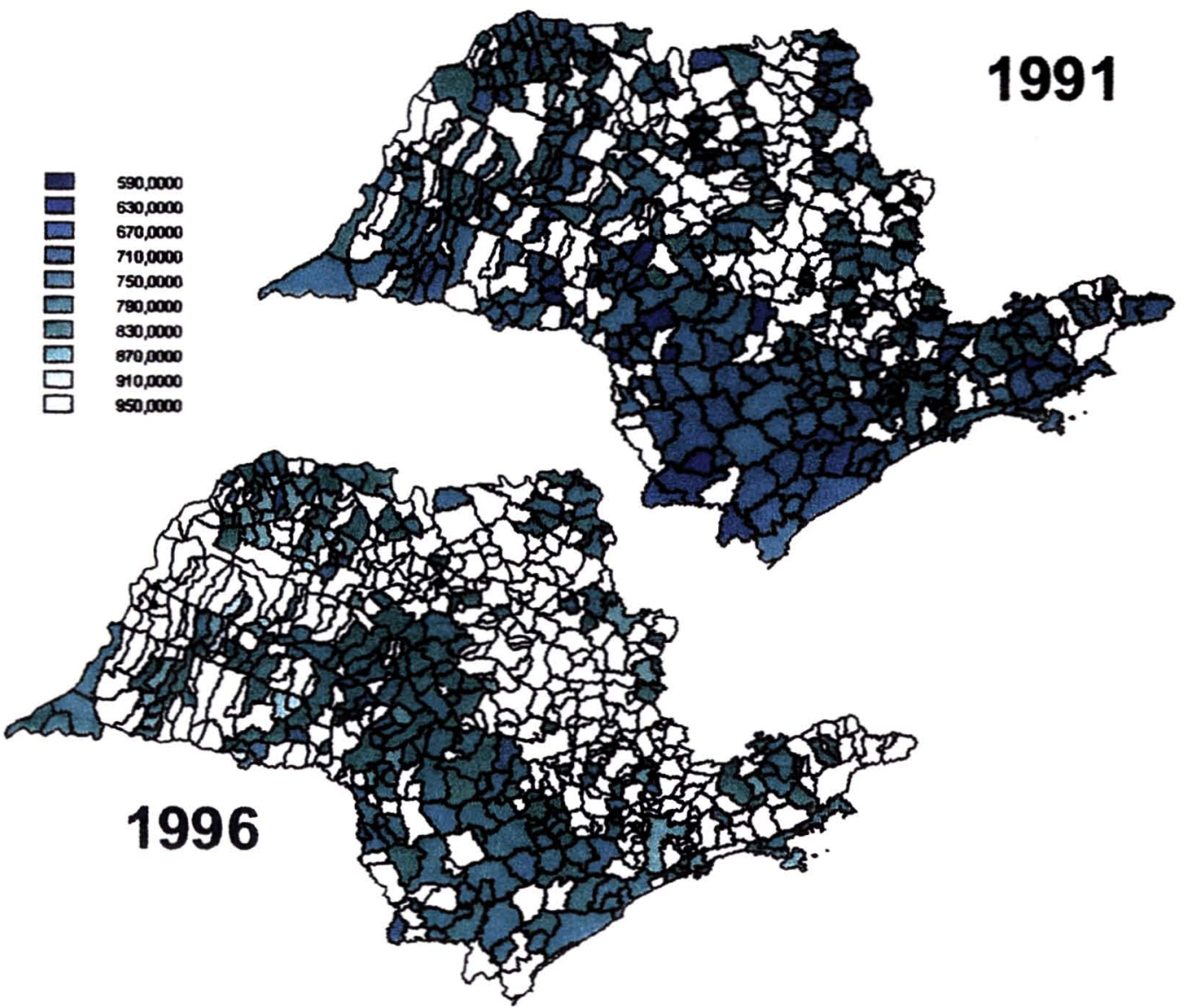

Figura 10. Resultados do IDM para municípios paulistas em 1991 e 1996.

A área de saúde obteve uma pequena melhora na pontuação do IDM de 1991 para 1996. A média do IDM de Saúde em 1991 foi igual a 924,83 pontos com um desvio-padrão de 30 pontos, enquanto em 1996 a média foi 
igual a 929,90 pontos com um desvio-padrão de 25 pontos, mostrando também uma homogeneidade maior em 1996.

A região mais carente é a região sul do estado, como mostra a figura 10. Os municipios com melhor desempenho na área de saúde estão localizados na Região Central do Estado, bem como nas Regiões Noroeste e Oeste.

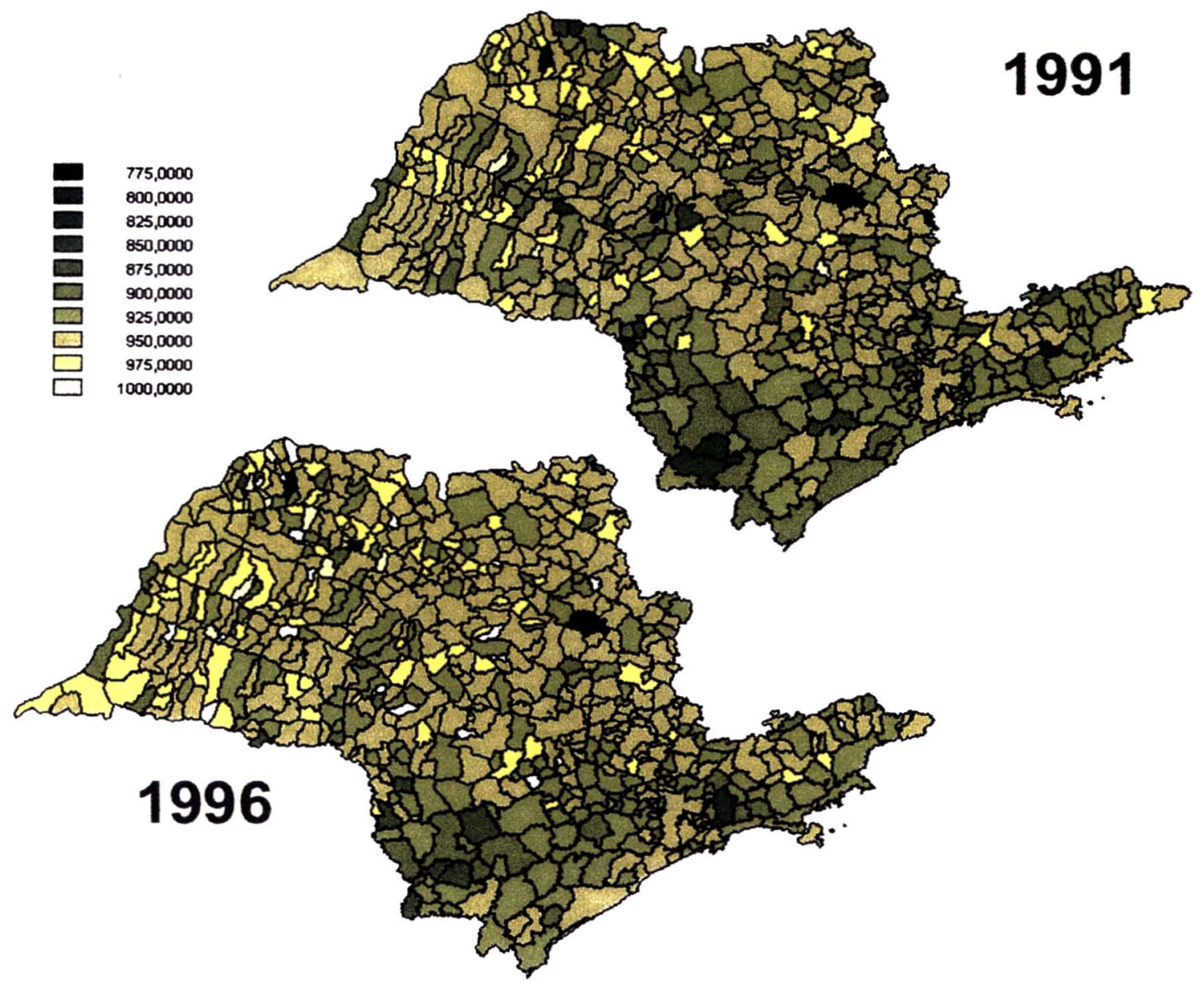

Figura 11. Resultados do IDM de Saúde. Municipios paulistas 1991 e 1996.

Os resultados da área de educação comprovam a tendência de melhoria no atendimento escolar e diminuição da evasão. Os melhores resultados na área de Educação em 1991 ficam por conta dos municípios Uchoa, Nhandeara, Sebastianópolis do Sul e Turmalina. Em 1996, apresentando um aumento médio de 84 pontos os melhores resultados são 
apresentados pelos municípios de Estiva Gerbi, Mauá, Ilhabela, Oscar Bressane.

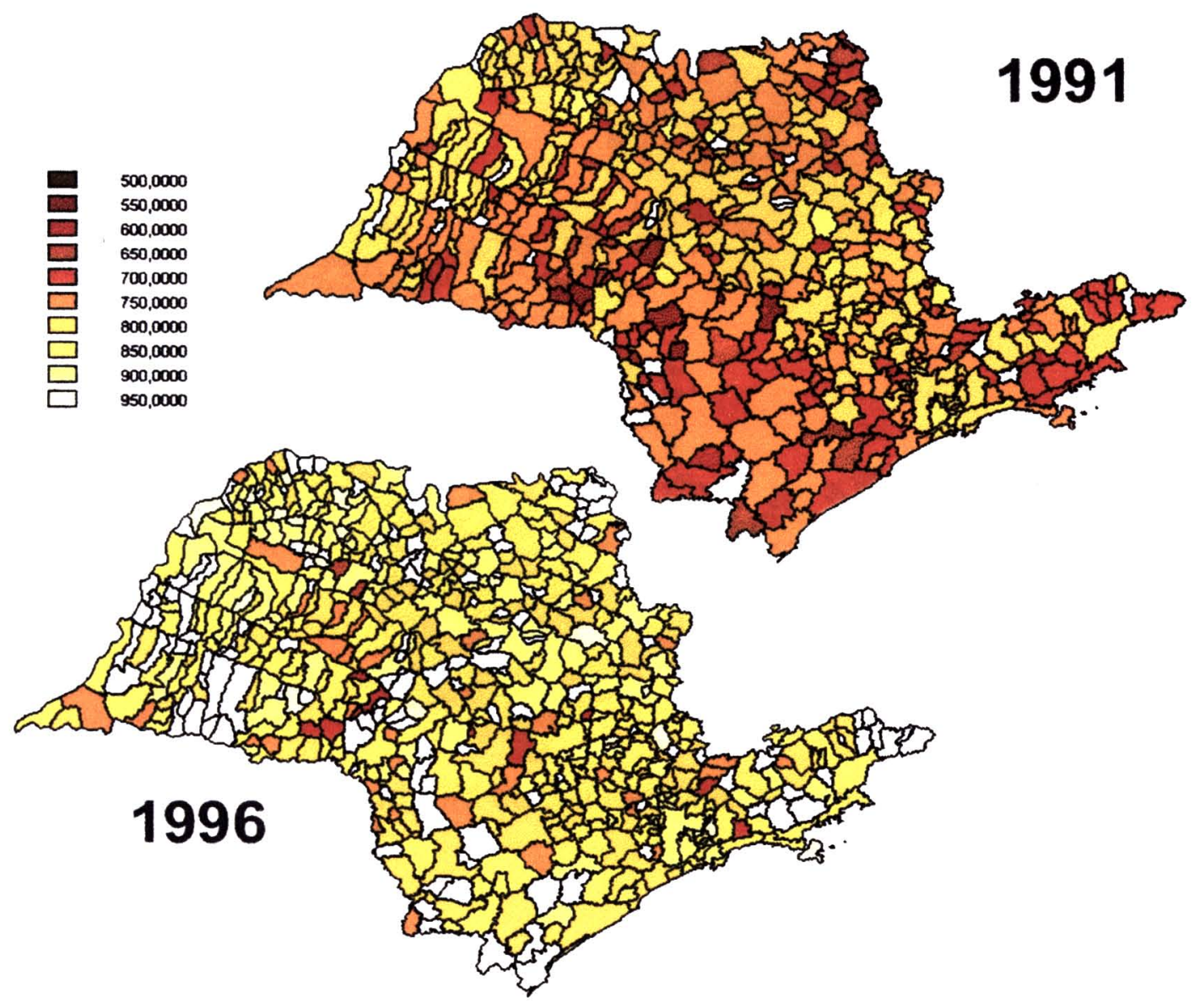

Figura 12. Resultados do IDM de Educação. Municípios paulistas 1991 e 1996.

Apesar da redução dos municípios com disponibilização de resultados, a área de saneamento apresentou melhoras significativas nesta área, principalmente no que diz respeito à cobertura das instalações de água. 


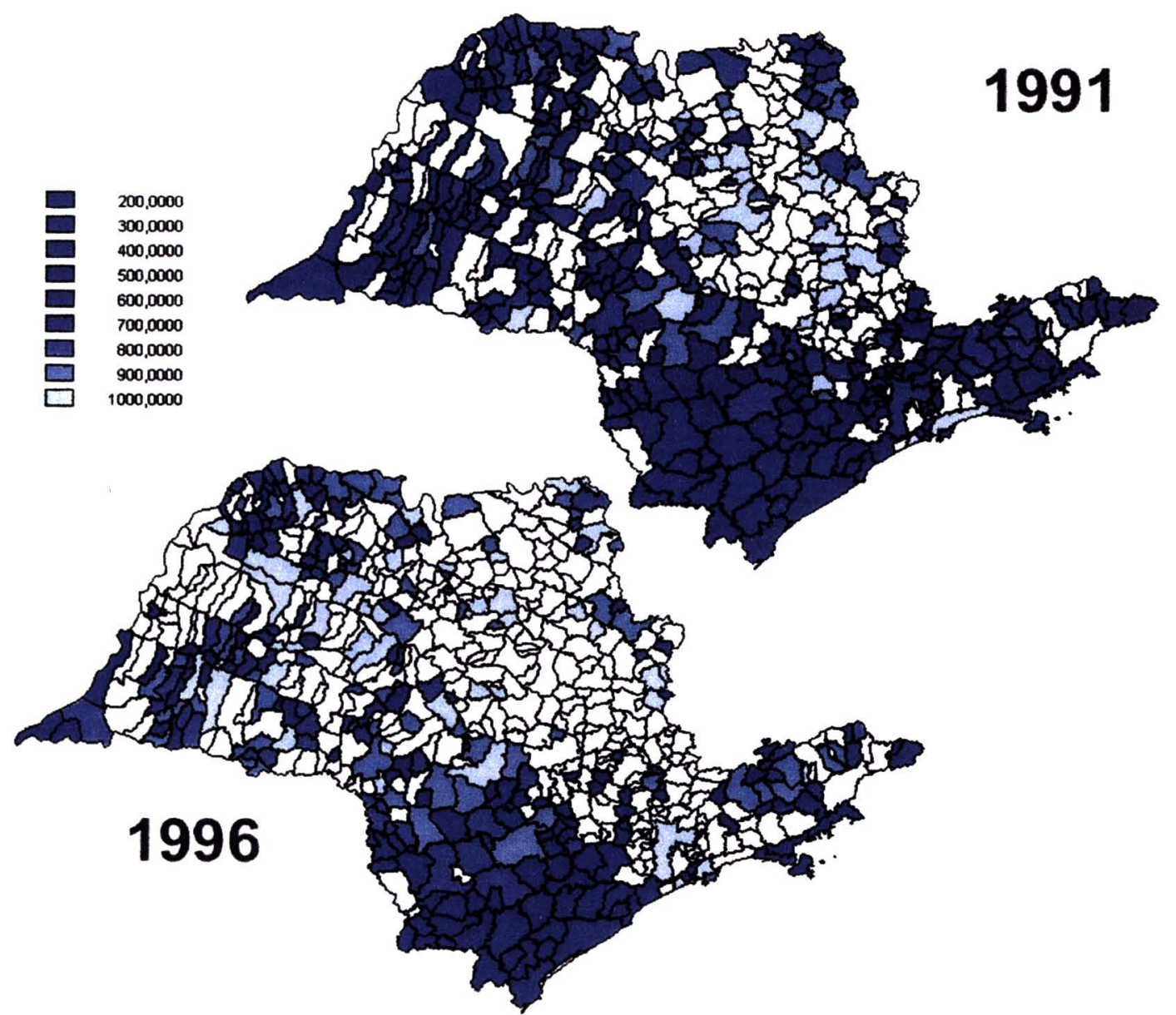

Figura 13. Resultados do IDM de Saneamento para municipios paulistas em 1991 e 1996.

A figura 14 revela uma piora nos níveis de segurança no estado de São Paulo. A cor mais clara indica uma diminuição no valor do IDM Segurança principalmente na região da Grande São Paulo onde o pior resultado é encontrado no município de Diadema com IDM de 997 pontos, este resultado deve ser analisado de maneira a visualizar quais dos indicadores componentes da área temática podem estar influenciando negativamente o resultado geral. No caso de Diadema encontramos uma taxa de homicídios extremamente alta (120 por cem mil habitantes). 


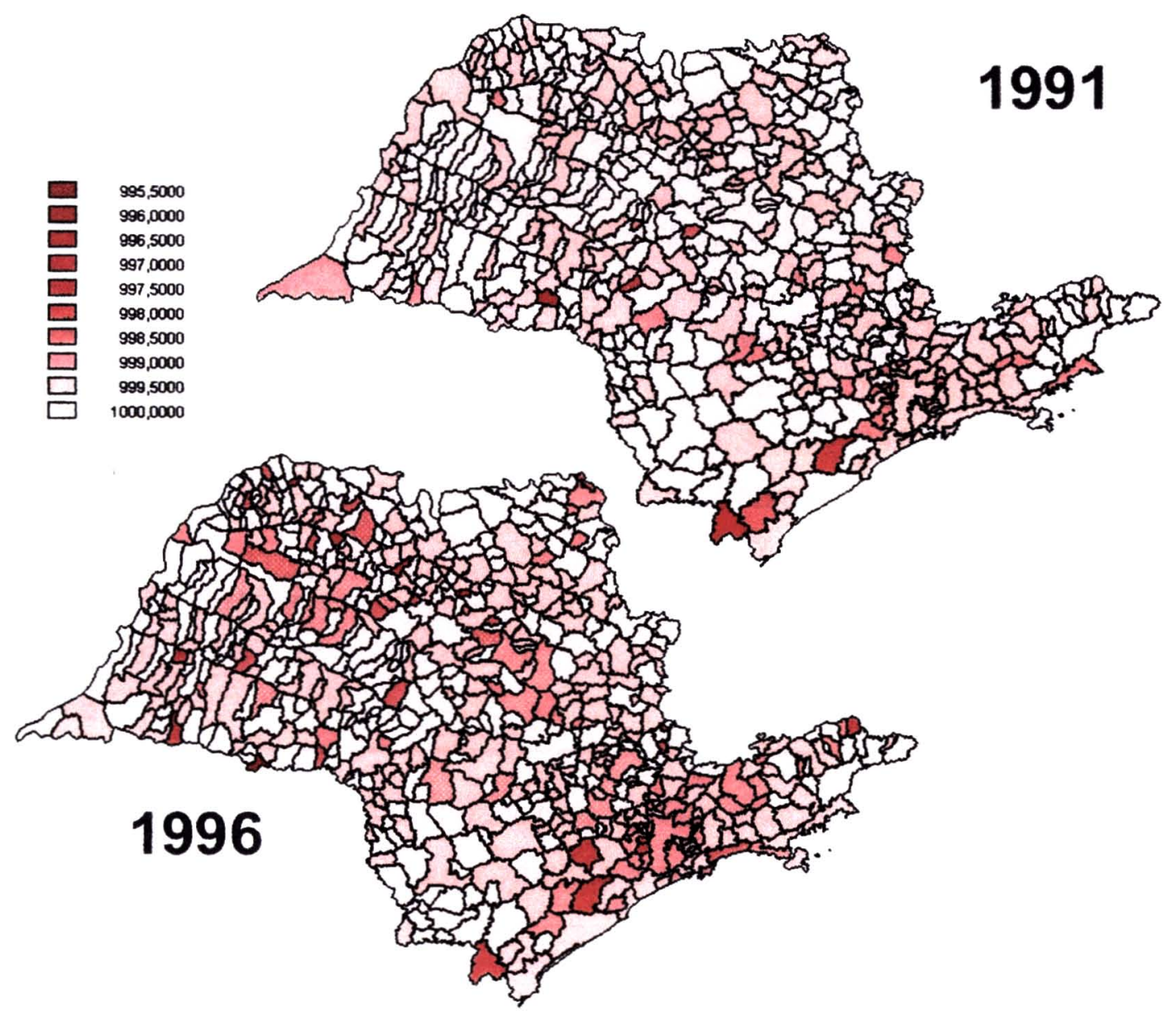

Figura 14. Resultados do IDM de Segurança para municípios paulistas em 1991 e 1996.

Os resultados observados na figura 14 , também atestam que os niveis do IDM Segurança diminuíram em outras regiões do estado.

Analisando temporalmente os resultados do IDM para o Estado de São Paulo, podemos verificar um crescimento generalizado no resultado do Índice de Desenvolvimento Municipal - IDM. Apenas 8 municípios registraram uma diminuição nos valores do IDM de 1991 para 1996. A pior situação para o decréscimo do IDM é encontrada em Coroados (perda de 69 pontos). Os municípios com maior acréscimo da pontuação do IDM foram Águas da Prata e Águas de Santa Bárbara, com ganho de 248 e 242 pontos, respectivamente.

De maneira geral, o Estado de São Paulo apresentou um acréscimo médio no valor do IDM, de 1991 para 1996 da ordem de 68 pontos. 


\begin{tabular}{lccc}
\multicolumn{4}{l}{ Tabela 15. Resultados comparativos do IDM para 1991 e 1996} \\
\hline Municipio & Grupo Populacional & IDM & IDM \\
& 1991 & 1996 \\
\hline Águas da Prata & 1 & 529,86 & 778,09 \\
Três Fronteiras & 2 & 791,31 & 784,40 \\
Bernardino de Campos & 2 & 680,74 & 859,31 \\
São Miguel Arcanjo & 3 & 715,99 & 731,61 \\
Lins & 3 & 764,51 & 799,80 \\
Adamantina & 4 & 783,83 & 844,94 \\
Itapeva & 4 & 697,12 & 763,69 \\
São João Da Boa Vista & 5 & 792,76 & 868,20 \\
São Paulo & 5 & 779,91 & 831,72 \\
Franca & & 729,92 & 816,05 \\
\hline
\end{tabular}

Alguns resultados comparativos são apresentados na tabela 15, para uma comparação detalhada e completa é possivel recorrer ao Aplicativo em CD ROM em anexo.

\subsection{Análise de Correlação}

O Índice de Desenvolvimento Municipal - IDM apresenta uma forte correlação linear entre os coeficientes que o compõe (soma dos coeficientes). Para o ano de 1991 e 1996 os coeficientes de correlação apresentam os valores de 0,91 e 0,89 respectivamente (figura 15 e 16). Mesmo com forte correlação, deve-se estar claro que a relação entre IDM e os indicadores individuais não mudam da mesma maneira para todos os municipios.

Esses resultados mostram que mesmo com forte correlação entre IDM e seus coeficientes, não é possivel a substituição do indice por um dos seus componentes, visto que o resultado da correlação obtida se deve à contribuição conjunta dos coeficientes 


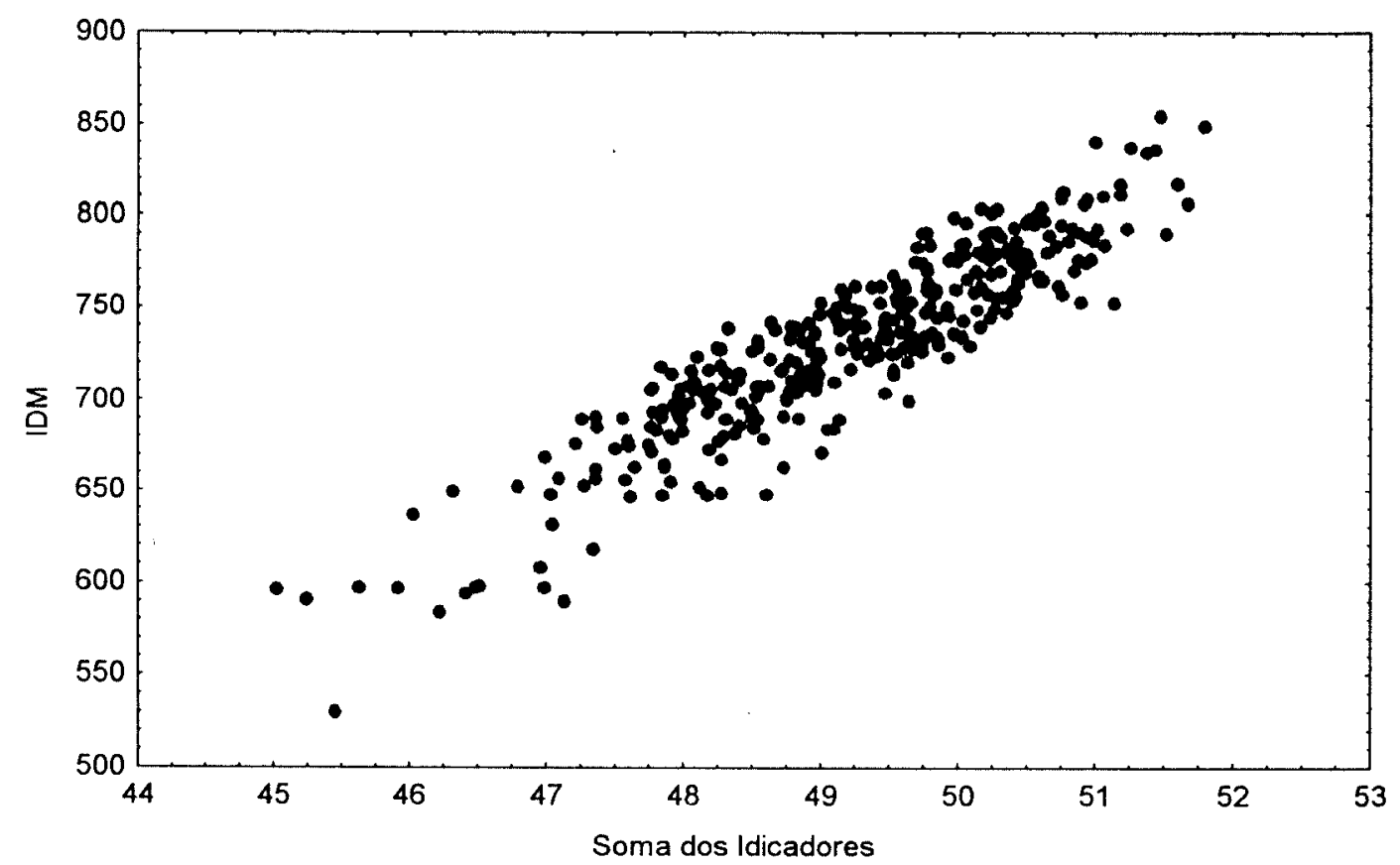

Figura 15. Diagrama de correlação - IDM e Soma de indicadores. 1991 $(\mathrm{N}=360)$.

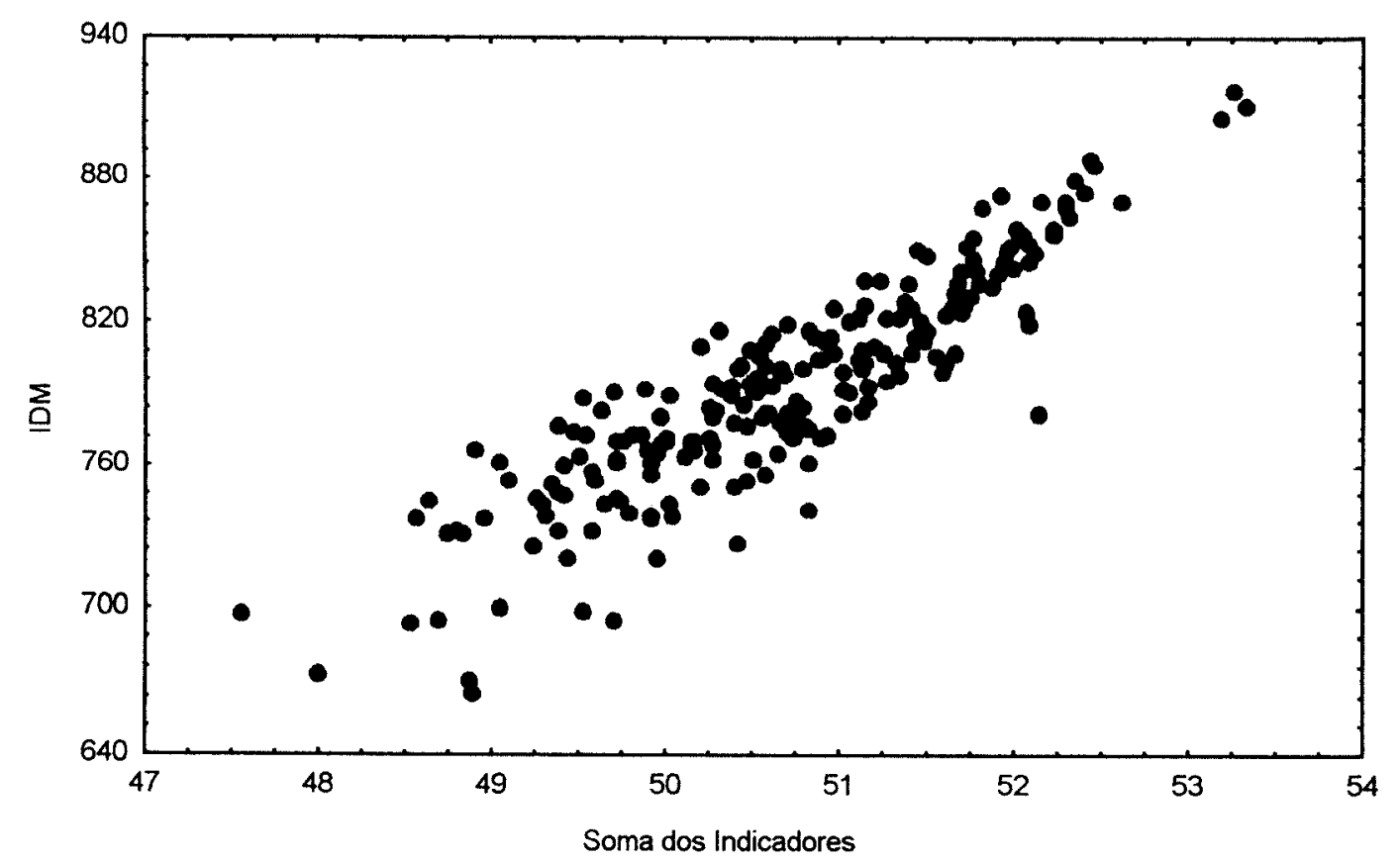

Figura 16. Diagrama de correlação - IDM e Soma de indicadores. 1996 $(\mathrm{N}=220)$. 
Os resultados da correlação de cada indice temático e seus respectivos indicadores (soma dos indicadores) para os anos de $1991 \mathrm{e}$ 1996 respectivamente são apresentados nas tabela 16.

Tabela 16. Coeficientes de Correlação por área temática. 1991 e 1996.

\begin{tabular}{lcc}
\hline \multirow{2}{*}{ IDM } & Coeficiente de correlação & Coeficiente de correlação \\
\hline Saúde & 1991 & 1996 \\
Educação & 0,97 & 0,96 \\
Segurança & 0,96 & 0,94 \\
Saneamento & 1,00 & 0,98 \\
& 0,99 & 0,98 \\
\hline
\end{tabular}

Os resultados apresentados anteriormente indicam que os indices temáticos representam seus indicadores. No entanto, a análise conjunta dos indices temáticos pode apresentar uma maior riqueza de informações, propiciando assim uma visão mais ampla do desenvolvimento do município.

Coeficientes de correlação semelhantes foram obtidos quando os municipios foram agrupados segundo as categorias populacionais sugeridas pela tabela 4. 


\subsection{Comparaçåo entre resultados do Índice de Desenvolvimento Municipal - IDM, Índice de Exclusão Social - lex e Índice de Exclusão Social Modificado- IEXSOC}

A possibilidade de caracterização e apresentação de indicadores e, mais recentemente, a construção de indices que possam sintetizar áreas temáticas, como Saúde, Educação, etc., vem se constituindo em um dos principais objetivos para os cientistas sociais e instrumentos valiosos para os administradores públicos.

Seguindo esta tendéncia, uma série de indices tem surgido com o objetivo de captar o desempenho sócio-económico de países, estados e municípios. No estado de São Paulo, o Índice de Exclusão Social - lex e Índice de Exclusão Social modificado - IEXSOC vem sendo utilizados como instrumentos para aferir condições sociais e estratificar municipios em zonas homogêneas segundo condições de vida* (AKERMAM 1997; ARAÚJO 1999; CHIESA 1999; SPOSATI 1996).

Para os anos de 1991 e 1996 o cálculo do lex e IEXSOC é feito utilizando os mesmo indicadores do IDM, apresentados em 3.2. A metodologia desses índices sugere a adoção de pesos para cada área temática a critério da equipe de pesquisadores. Para efeito de comparação com o IDM, foram adotados pesos iguais e o cálculo da média para cada uma das áreas temáticas (Saúde, Educação, Segurança e Saneamento).

\footnotetext{
- Uma análise do poder discriminatório da estratificação resultante do IEXSOC encontra-se no trabalho de Frei, F. e Silva, N.N. Discriminando desigualdades sociais: Aspectos metodológicos. Revista Plural, 2002; 2:7-25.
} 
Tabela 17. Municípios em melhores condições segundo índices IEXSOC, lex e IDM - 1991.

\begin{tabular}{lclllc}
\hline \multicolumn{1}{c}{ municipio } & IEXSOC & Municipio & lex & municipio & IDM \\
\hline São Francisco & 1,00 & Ag. de S. Pedro & 0,82 & Turmalina & 854,68 \\
Ág. de S. Pedro & 0,93 & Iracemápolis & 0,79 & Nhandeara & 849,57 \\
S. B. do Campo & 0,93 & Bento de Abreu & 0,78 & Sebastian. do Sul & 840,92 \\
Sto. A. de Posse & 0,91 & São Simão & 0,76 & Paraíso** & 837,32 \\
Araras & 0,89 & Americana* & 0,75 & Bilac** & 836,26 \\
Americana* & 0,89 & Sta.Rosa Viterbo & 0,74 & Magda & 835,01 \\
Sumaré & 0,88 & Araras & 0,74 & Americana* & 817,58 \\
Sta. R. de Viterbo & 0,88 & Lins & 0,74 & Cândido Rodr. & 817,21 \\
Araraquara & 0,85 & Bariri & 0,74 & Nova Odessa & 813,47 \\
Jaci & 0,84 & Rio das Pedras & 0,73 & Gabriel Monteiro & 812,01 \\
Pitangueiras & 0,83 & Pirassununga & 0,73 & Barra Bonita & 811,61 \\
Esp. Sto. do Turvo & 0,83 & Fernandópolis & 0,73 & Cerquilho & 810,50 \\
Lins & 0,82 & Cândido Mota & 0,73 & Sta Cl. d'Oeste & 809,36 \\
Cândido Mota & 0,81 & Nova Aliança & 0,72 & Tupi Paulista** & 808,69 \\
Sarapuí & 0,81 & Barra Bonita & 0,72 & S. J. Duas Pontes & 806,15 \\
Adamantina & 0,80 & Bilac** & 0,72 & S. Caet do Sul & 806,15 \\
Assis & 0,80 & Tupi Paulista** & 0,71 & Adolfo & 804,15 \\
Bariri & 0,80 & Adamantina & 0,71 & Sta. Mercedes & 803,72 \\
Lindóia & 0,79 & Paraiso** & 0,71 & Flórida Paulista & 802,91 \\
Ipuã & 0,79 & Icem & 0,71 & Arealva & 801,26 \\
\hline TMuniciplos prem & & &
\end{tabular}

* Municípios presentes simultaneamente nos três grupos

** Municipios presentes simultaneamente no grupo lex e IDM

Não há correspondência entre os resultados obtidos por cada um dos índices. Desta forma, dos 20 municipios em melhores condições de desenvolvimento, apenas um (Americana) está presente simultaneamente nos três grupos. A comparação entre IEXSOC e lex mostra uma concordância maior (oito municípios) em relação a comparação entre lex e IDM (apenas 3 municipios). Já nos grupos caracterizados como em piores condições de desenvolvimento, apenas 2 dos 19 municipios estão presentes simultaneamente nos grupos IEXSOC e IDM, enquanto que quatro 
municipios estão presentes simultaneamente nos grupos lex e IDM. Os municipios presentes nos três grupos são Barra do Turvo e Ribeirão Branco.

Tabela 18. Municípios em piores condições segundo índices IEXSOC, lex e IDM - 1991.

\begin{tabular}{|c|c|c|c|c|c|}
\hline municipio & IEXSOC & municipio & lex & Municipio & IDM \\
\hline Barra do Turvo* & 0,00 & Bar. do Turvo* & $-0,18$ & Ág. da Prata & 529,87 \\
\hline Rib. do Sul & 0,02 & Red. da Serra** & 0,11 & Itirapuã & 583,44 \\
\hline lepê & 0,05 & Miracatu & 0,13 & Jeriquara & 589,31 \\
\hline Rib. Branco* & 0,06 & Embu & 0,13 & Red. da Serra** & 590,77 \\
\hline Guaraçaí & 0,06 & Platina** & 0,14 & Platina** & 593,56 \\
\hline Morungaba & 0,07 & Itaquaq. & 0,19 & Ribeirão Branco* & 596,19 \\
\hline Nhandeara & 0,09 & Diadema & 0,19 & Júlio Mesquita & 596,77 \\
\hline Santóp. Aguapei & 0,10 & Itap. da Serra & 0,20 & Arandu & 597,16 \\
\hline Jeriquara & 0,10 & Franc. Morato & 0,20 & Timburi & 597,17 \\
\hline Álv. de Carvalho & 0,11 & Jacupiranga & 0,22 & Anhembi & 597,29 \\
\hline Reginópolis & 0,11 & Itapevi & 0,22 & Avaí & 597,85 \\
\hline Cruzália & 0,12 & Jandira & 0,24 & Ág. Sta. Bárbara & 607,59 \\
\hline Sorocaba & 0,13 & Nazaré Pta. & 0,26 & Alvinlândia & 617,67 \\
\hline Pedregulho & 0,13 & Tab. da Serra & 0,27 & Sarutaiá & 631,13 \\
\hline Santo André & 0,16 & Rib. Branco* & 0,27 & Bar do Turvo* & 636,17 \\
\hline Jaborandi & 0,17 & Apiaí & 0,29 & Anhumas & 646,62 \\
\hline Gabr. Monteiro & 0,18 & Teod. Sampaio & 0,29 & Jambeiro & 647,25 \\
\hline Apiaí & 0,18 & Itariri & 0,29 & Restinga & 647,34 \\
\hline Itatinga & 0,18 & Carapicuiba & 0,29 & Cabrália Paulista & 647,76 \\
\hline
\end{tabular}

\footnotetext{
${ }^{\star}$ Municipios presentes simultaneamente nos dois grupos

** Municípios presentes simultaneamente no grupo lex e IDM
} 
Tabela 19. Municipios em melhores condições segundo indices IEXSOC, lex e IDM - 1996.

\begin{tabular}{|c|c|c|c|c|c|}
\hline município & IEXSOC & municipio & lex & Municipio & IDM \\
\hline Assis & 0,96 & Ág. de S. Pedro & 0,89 & Oscar Bressane** & 918,73 \\
\hline Ág. de S. Pedro & 0,95 & Bento de Abreu* & 0,82 & Bento de Abreu* & 912,44 \\
\hline Poloni ${ }^{\star}$ & 0,94 & Adolfo & 0,82 & Turiúba* & 906,36 \\
\hline Santos & 0,94 & Oscar Bressane ${ }^{\star *}$ & 0,80 & Lutécia & 888,79 \\
\hline Monte Alto & 0,94 & Monte Alto & 0,80 & Sebast. do Sul & 886,73 \\
\hline Esp. Sto do Pinhal & 0,93 & Pedrinhas Pta* & 0,80 & Turmalina & 880,41 \\
\hline Lins & 0,93 & Lins & 0,79 & Gabriel Monteiro & 874,99 \\
\hline Turiúba* & 0,92 & Poloni ${ }^{\star}$ & 0,79 & São Francisco & 873,33 \\
\hline Mococa & 0,92 & Turiúba* & 0,79 & Lucélia & 871,03 \\
\hline Igarapava & 0,92 & Nhandeara** & 0,79 & Poloni* & 870,64 \\
\hline Jales & 0,92 & Orindiúva & 0,78 & Pedrinhas Pta* & 870,24 \\
\hline Fernandópolis* & 0,91 & Fernandópolis* & 0,78 & S. J. da Boa Vista* & 868,20 \\
\hline Pedrinhas Pta* & 0,91 & Igarapava & 0,78 & Álvares Florence & 867,68 \\
\hline Praia Grande & 0,91 & Monte Aprazivel & 0,77 & Fernandópolis* & 864,16 \\
\hline S. J. da Boa Vista* & 0,91 & S. J. Boa Vista* & 0,77 & Bern. de Campos & 859,31 \\
\hline Piratininga & 0,91 & Franca & 0,76 & Nhandeara** & 859,08 \\
\hline Maracaí & 0,91 & Sant. do Aguapeí & 0,76 & Dirce Reis & 856,98 \\
\hline Bento de Abreu* & 0,91 & Mococa & 0,75 & Gastão Vidigal & 856,35 \\
\hline Adamantina & 0,91 & Tupã & 0,75 & Piacatu & 855,95 \\
\hline Pres. Prudente & 0,91 & Esp. Sto. Pinhal & 0,75 & llhabela & 853,41 \\
\hline
\end{tabular}

* Municipios presentes simultaneamente nos dois grupos

** Municípios presentes simultaneamente no grupo lex e IDM

As tabelas 19 e 20 apresentam os resultados dos municipios em melhores e piores condições de desenvolvimento respectivamente, para o ano de 1996, segundo os índices IEXSOC, lex e IDM.

Pode-se observar que para as duas condições de desenvolvimento 6 municípios estão presentes simultaneamente nos três grupos. 
Tabela 20. Municipios em piores condições segundo indices IEXSOC, lex e IDM - 1996.

\begin{tabular}{lclllc}
\hline Município & IEXSOC & Município & lex & Municipio & IDM \\
\hline Elias Fausto & 0,75 & Itaporanga & 0,47 & Tremembé & 737,21 \\
Rosana & 0,75 & Guar. d'Oeste & 0,46 lbiúna* & 737,15 \\
Cajati & 0,75 & Rib. Grande & 0,45 Colômbia & 732,69 \\
Iporanga & 0,75 & Cabreúva & 0,45 Cabreúva* & 732,32 \\
Itupeva & 0,75 & Peruibe & 0,45 Bofete* & 732,12 \\
S. Mig.l Arcanjo* & 0,75 & Pariquera-Açu & 0,44 S. Mig. Arcanjo* & 731,61 \\
Itaóca & 0,74 & Jambeiro & 0,43 Araçariguama* & 731,10 \\
Pariquera-Açu & 0,74 & Caraguatatuba & 0,43 Mesópolis & 727,25 \\
Ribeirão Grande & 0,74 & Guararema & 0,42 Óleo & 725,76 \\
Itaberá & 0,74 & Tapirai & 0,41 Coroados & 721,45 \\
Bofete* & 0,74 & Nipoã & 0,36 Alvinlândia & 720,83 \\
Piedade & 0,74 & Miracatu & 0,36 Areiópolis & 699,81 \\
Cabreúva* & 0,73 & Guapiara & 0,36 Platina & 698,49 \\
Araçariguama* & 0,72 & Piedade & 0,32 Itapirapuã Pta* & 697,15 \\
Itariri & 0,71 & Araçariguama & 0,32 Anhembi & 695,70 \\
Itapirapuã Pta* & 0,71 & Ibiúna & 0,30 Álv.de Carvalho & 694,97 \\
Cesário Lange & 0,70 & Itapirapuã Pta & 0,30 Gália & 693,34 \\
Jarinu & 0,69 & Itariri & 0,29 & Nipoã & 673,30 \\
Guapiara & 0,68 & Florinia & 0,28 Planalto & 671,26 \\
Ibiúna* & 0,68 & Jarinu & 0,24 Estr. do Norte & 665,80 \\
\hline
\end{tabular}

* Municípios presentes simultaneamente nos dois grupos

Chama a atenção o caso de Planalto, cujo resultado temporal do IDM é oposto ao resultado do IEXSOC (tabela 21). Pela análise, os resultados dos valores médios, utilizados na padronização do IEXSOC, verifica-se a diminuição do intervalo entre o minimo e máximo valores em 1996. Por esta razão um pequeno incremento no valor médio, poderá não causar aumento no valor do IEXSOC. Exemplo desta situação pode ser encontrada nos dados referentes ao município de Cabreúva, que apresenta em 1991 IEXSOC igual a 0,24 e 0,16 em 1996. No entanto, seu valor médio cresceu de 0,62 para 0,72 . 
Tabela 21. Resultados comparativos - IDM e IEXSOC - 1991 e 1996.

\begin{tabular}{lcccc}
\hline & IDM & IDM & IEXSOC & IEXSOC \\
Municipio & 1991 & 1996 & 1991 & 1996 \\
Turmalina & 854,68 & 880,41 & 0,53 & 0,67 \\
Sebastianópolis do Sul & 840,92 & 886,73 & 0,47 & 0,63 \\
Águas da Prata & 529,87 & 778,09 & 0,49 & 0,62 \\
Capela do Alto & 681,37 & 749,47 & 0,31 & 0,33 \\
Registro & 707,24 & 825,96 & 0,43 & 0,54 \\
São Roque & 717,58 & 761,86 & 0,47 & 0,48 \\
São Paulo & 779,91 & 831,72 & 0,67 & 0,79 \\
Taubaté & 758,11 & 772,00 & 0,66 & 0,72 \\
Planalto & 727,96 & 671,26 & 0,49 & 0,62 \\
\hline
\end{tabular}




\section{DISCUSSÃO}

A utilização de medidas sintéticas deve ser vista com cuidado por seus usuários. É por esta razão que os relatórios do Programa das Nações Unidas para o Desenvolvimento - PNUD (ONU) apresentam anualmente o Índice de Desenvolvimento Humano (IDH) em conjunto com a série de indicadores componentes deste índice, bem como uma extensa análise dos resultados estatísticos obtidos.

A escolha dos indicadores que irăo compor o índice, deve ser norteada por critérios tão específicos quanto possivel, a fim de que esta escolha seja a mais próxima dos objetivos pretendidos, ou seja, caracterizar, com máxima precisão, uma população nos mais diversos aspectos sociais. Neste sentido, as áreas de saúde, educação, segurança e saneamento foram priorizadas por se adequarem a esses critérios.

O conceito de distância vem orientando trabalhos que abordam questões relativas à construção de índices.

O Unicef, utiliza as distâncias de vários indicadores para um máximo desejável, com o objetivo de construir seu Índice de Desenvolvimento Infantil - IDI Assim, valores máximos de cobertura vacinal de sarampo, escolarização bruta na pré-escola e creche, percentual de gestantes com cobertura pré-natal adequada entre outros, são incorporados ao cálculo IDI.

$O$ Índice de Desenvolvimento Humano Modificado - IDHM (NOORBAKHSH 1998), incorpora em sua metodologia a noção de distância Euclidiana. Inicialmente os indicadores são padronizados utilizando a distribuição Normal reduzida Z. Em seguida, é obtido o valor da distância Euclidiana $d_{i}$ para cada componente padronizado em relação ao máximo valor do mesmo componente padronizado.

O Indice de Desenvolvimento Municipal - IDM adota o mesmo conceito de distância Euclidiana, sem que os indicadores sejam padronizados pela distribuição Normal reduzida Z. Desta forma, o IDM possui a capacidade de avaliar o crescimento de cada município, 
independentemente do que ocorre com os demais. Qualquer evolução ou involução nos resultados dos coeficientes é discriminada pelo Índice de Desenvolvimento Municipal. Este quesito deve ser salientado, visto que o mesmo não ocorre em índices como o IDH-M, lex e IEXSOC,cujos resultados são sempre referentes ao conjunto em que o município está inserido, sendo assim, pouco sensivel a determinadas mudanças nos indicadores.

Neste sentido, determinados resultados, como o apresentado pelo município Cabreúva servem de alerta para a especificidade do modelo metodológico adotado pelo índice. O município de Cabreúva apresenta uma diminuição do IEXSOC de 1991 para 1996, este resultado se deve a uma menor dispersão da série estatística analisada. No entanto os valores obtidos por Cabreúva mostram uma evolução nas condições de vida.

Dois objetivos nortearam a escolha da padronização de $d_{i}$. $O$ primeiro, diz respeito à busca de simplicidade matemática. O segundo objetivo está relacionado com a sensibilidade do índice, o que possibilitará a verificação de mudanças dos municipios ao longo do tempo.

O Índice de Desenvolvimento Municipal - IDM caracteriza-se pela incorporação dos coeficientes $C_{i j}$ em relação a um ótimo almejado, utilizando a noção de distância, como mostrado anteriormente.

Esse resultado está de acordo com os pressupostos apresentados anteriormente, visto que o resultado máximo de $\mathrm{d}_{\mathrm{i}}$ Ótimo não se altera no decorrer dos anos, o que propicia uma análise do desempenho de um municipio temporalmente e apresenta uma solução simples matematicamente.

Outras padronizações poderiam ser utilizadas, mas apresentam restriçōes impostas pelos objetivos. Exemplo disto é a padronização utilizando a aplicação da distribuição Normal Reduzida aos valores de $\mathrm{d}_{\mathrm{i}}$. Para casos onde a distribuição se apresenta de forma assimétrica esta padronização não produz efeitos desejados visto que o intervalo resultante pode estar acima de 1 e abaixo de 0 , o que inviabiliza sua aplicação. 
Outro inconveniente deste tipo de padronização é o efeito que pode ocasionar no índice. Desta forma, uma melhoria dos indicadores de um município podem não ser revelados pelo índice, que leva em consideração todos os valores dos outros municipios para o cálculo.

Situação semelhante pode ser encontrada pela padronização que utiliza no denominador das equações que constituem o índice a diferença entre 0 valor máximo observado e o mínimo observado no conjunto de dados analisados, como é constituido o IEXSOC.

Quanto à padronização utilizada pelo lex, esta produz as mesmas caracteristicas dos modelos adotados pelo IDH-M e IEXSOC. Assim, os resultados da padronização, cuja variação se insere no intervalo numérico $[-1 ; 1]$, resultam em indices dependentes da distribuição geral dos municipios analisados.

A baixa concordância entre os resultados obtidos para os três indices IDM, IEXSOC e lex se deve ao tipo de padronização adotada. No caso do IEXSOC e lex, a padronização atua de forma preponderante no resultado final do índice, elevando ou rebaixando o valor destes.

No que se refere ao desenvolvimento municipal o IDM apresentou resultados que possibilitam mapear regiōes em melhores e piores condiçōes.

De modo geral, o Estado de São Paulo apresentou melhora considerável nos resultados do IDM, apenas 8 municípios registraram queda nos valores de 1991 para 1996, em um total de 220 municipios, o que representa $3,6 \%$ do estado. As áreas de Educação e Saneamento são as que apresentam maior aumento nos valores do IDM, responsáveis pela melhoria do desenvolvimento no estado.

Apenas $7 \%$ dos municipios paulistas apresentam queda no IDM de Educação. O municipio de Coroados, na Região de Governo de Araçatuba, apresentou uma queda de 96 pontos. A maior alta é encontrada no município de Águas de Santa Bárbara, Região de Governo de Avaré, com um acréscimo 332 pontos. Observa-se ainda que $30 \%$ dos municipios aumentaram sua pontuação no IDM educacional em 100 ou mais pontos. 
Os resultados da área de Saneamento também apresentam um aumento da pontuação do IDM. Cabe ressaltar que o número de municípios que dispunham de dados para esta área é reduzido. No entanto, dos 256, apenas $3 \%$ apresentam uma diminuição dos valores do IDM.

A área de Saúde apresenta resultado positivo, mas $42 \%$ dos municipios registram queda entre 1991 e 1996 no valor do IDM. A maior queda é registrada em Nipoã (164 pontos) e a maior alta em Águas da Prata (333 pontos).

O IDM de Segurança apresenta queda generalizada, de 1991 para 1996. Em 323 municípios, o que representa $56 \%$ dos municípios que dispunham de dados para o cálculo, os valores do indice recuaram.

A aferiçăo das condições do desenvolvimento de regiões do estado, municipio ou mesma intra-urbanamente permite aos órgãos governamentais de planejamento o estabelecimento de prioridades na gestão dos recursos, em bases objetivas. Portanto, é um bom instrumento para orientar o fluxo de investimentos estaduais e municipais. Além disto, pode ser útil no monitoramento do Plano Diretor, podendo indicar as áreas em que 0 adensamento populacional foi excessivo e onde se fazem necessárias alterações nos parâmetros urbanísticos estabelecidos.

Da forma como é elaborado e calculado, o Índice de Desenvolvimento Municipal - IDM pode se tornar um dos instrumentos importantes também para uma gestăo regional, realizando comparaçठ̌es internas, podendo ser de grande utilidade, por exemplo, em programas como no Orçamento Participativo. Além disto, mostra-se interessante como instrumento de gestão setorial, já que permite avaliar a necessidade de investimentos nas diversas áreas.

É importante destacar ainda que, sendo calculado periodicamente, o Índice de Desenvolvimento Municipal - IDM permitirá a avaliação temporal das condições de vida nas cidades, funcionando como um dos instrumentos de monitoramento da gestão. Finalmente, a pesquisa de informações gerará um extenso Banco de Dados do município, que poderá ser utilizado por diversos grupos da sociedade civil, servindo inclusive para subsidiar a 
elaboração de projetos destinados à melhoria de áreas marginalizadas da cidade.

Atualmente, as administrações públicas também têm se interessado por medidas de desenvolvimento, entendidas como instrumentos de planejamento local e regional, destacando-se no caso brasileiro, os diversos exercícios de simulação e produção de estatísticas de PIB regional realizadas pelo IBGE e por conceituadas agéncias estaduais, como a as Fundações Seade (em São Paulo) e João Pinheiro (em Minas Gerais). Por outro lado, o PNUD e o IPEA passaram a produzir estatísticas de desenvolvimento humano em escala estadual e municipal, a partir de 1996.

Com vistas a complementar o conjunto de instrumentos para monitoramento do desenvolvimento no Estado de São Paulo, o IDM se apresenta como uma ferramenta, cuja simplicidade de manuseio e construção pode contribuir para a criação e disseminação de uma cultura de avaliação embasada em estatísticas, indicadores e índices. 


\section{CONCLUSÕES}

Os coeficientes utilizados na elaboração do índice proposto possuem boa qualidade e estão disponíveis na própria localidade, facilitando sua coleta e manuseio estatístico. Destaca-se que a periodicidade de tais coeficientes são anuais, possibilitando assim, uma avaliação das políticas desenvolvidas ao longo do tempo.

A utilização de índices deve ser feita com parcimônia, levando-se em consideração um conjunto amplo de análises. No caso do índice de Desenvolvimento Municipal - IDM, a análise dos índices temáticos deve ser realizada em conjunto com o índice geral.

A simplicidade na construção do IDM está associada ao desenvolvimento do sistema de informática, que poderá propiciar a disseminação de informações em prefeituras e outros órgãos públicos.

Resultados mais refinados podem ser obtidos mediante a estratificação de municípios em zonas homogêneas, possibilitando assim uma acurácia maior nos resultado do Índice de Desenvolvimento Municipal. Sistemas de informática mais sofisticados podem garantir maior agilidade no acesso e manipulação dos dados e resultados.

A sensibilidade de índices como 0 Índice de Desenvolvimento Humano - IDH, pode ser comprometida quando o contexto mundial passa a ser regiões mais homogêneas como municipios ou ainda setores censitários.

Ao propor um novo índice, busca-se implementar a cultura da informação, para tanto, deve-se buscar coletar novos indicadores permitindo que o acesso a eles seja fácil e rápido. Neste sentido, organizaçס̋es 
governamentais e não governamentais devem juntar-se com o objetivo de propiciar aos mais pobres o direito às informações.

Os resultados obtidos pelo Índice de Desenvolvimento Municipal IDM, mostram-se sensiveis à mudanças ao longo do tempo, visto que estabelece em sua estrutura metodológica a busca do ideal para cada indicador aferido, ou seja, valores fixos. Outros índices, como o IEXSOC, lex e IDH-M não trazem em sua estrutura este conceito, visto que além de fornecer como resultado a posição do municipio em relação aos demais, possuem componente que leva em consideração o resultado do município em relação à série que este está inserido, o que pode não permitir avaliar o progresso de seus indicadores.

A interpretação do IDM deve ser feita em conjunto com os resultados obtidos nas áreas temáticas que compõem o índice e cada um dos índices temáticos.

Deve-se tomar cuidado ao se analisar o IDM, pois este não tem como objetivo ordenar os municípios em função do desenvolvimento. Desta forma, a utilização do IDM visa estabelecer uma aferição do progresso do município em relação a um ótimo desejável, bem como analisar os resultados obtidos deste município ao longo do tempo.

A divisão dos municipios paulistas em cinco grupos, de acordo com suas populaçōes, é mais um exercicio para tornar o Índice de Desenvolvimento Municipal mais adequado às realidades que nos deparamos. Não é pretensão, ao adotar esta divisão populacional, resolver em sua totalidade as possiveis distorções nos indicadores, como as taxas de mortalidade. Esta preocupação pode ser observada, quando a Fundação SEADE, em sua metodologia para o cálculo do IPRS (SEADE 2000), adota estratégias estatísticas, como a média aritmética, para o cálculo da 
mortalidade de pessoas na faixa etária entre 15 e 39 anos. Outras estratégias devem ser incorporadas, enriquecendo a gama de opções.

A utilização do IDM, associado ao sistema informatizado proposto, proporcionará o gerenciamento de entrada dos indicadores, tratamento e apresentação dos resultados dos índices temáticos e IDM. Por meio deste procedimento, pode-se também realizar simulações com os diversos indicadores, proporcionando visualizações das possiveis ações a serem desencadeadas nas diversas áreas temáticas.

A proposta de um novo índice que possa aferir o desenvolvimento de municípios deve ser vista como mais um instrumento no diversificado rol de ferramentas de avaliação sócio-econômicas, cujo aprimoramento deve ser constante. Neste sentido, a análise de contextos específicos de determinadas regiões pode e deve ser pano de fundo para propostas mais realistas quanto aos objetivos almejados. É neste sentido que a metodologia do IDM pode receber contribuições futuras, com escolhas de máximos desejáveis mais próximos da realidade regional, instigando suas comunidades a superá-los.

Os resultados apresentados pelo índice de Desenvolvimento Municipal - IDM indicam o avanço do Estado de São Paulo nas áreas de Educação, Saúde e Saneamento. No entanto, a área de Segurança representada pelos indicadores de homicídios e mortalidade devido a acidentes de veículo a motor mostram uma situação preocupante em 1996. 


\section{REFERÊNCIAS}

ALDERMAN $H$. et. al. Measuring Poverty in South Africa, Pretoria: Statistics South Africa, 2000.

AKERMAN M. Definição e Mensuração da Pobreza na Região Metropolitana de São Paulo: uma abordagem multissetorial. Condições de vida e situação de saúde, Rio de Janeiro 1997; ABRASCO, p. 95 - 113.

ARAÚJO, NSA. Contribuições ao gerenciamento local de informações em saúde para o programa de saúde infantil do Município de Embu. São Paulo; 1999. [Tese de Mestrado - Faculdade de Saúde Pública da USP].

BARBOSA DL, PAES NA. Perfil da mortalidade brasileira por neoplasmas dos idosos do Brasil. [Apresentado no VIII Encontro de Iniciação Científica da Universidade Federal da Paraíba;2000 João Pessoa (PB), Brasil].

CHIESA AM. A eqüidade como princípio norteador da identificação de necessidades relativas ao controle dos agravos respiratórios na infância. São Paulo; 1999. [Tese de Doutorado - Faculdade de Saúde Pública da USP].

COLE DC, EYLES J, GIBSON BL. Indicatros of Human health in ecosystems: what do we measure? The Science of the Total Enviromment 1998; 224: $201-213$.

COSTA FILHO E. Saneamento básico: direito de todos os cidadãos. Gazeta Mercantil, Goiás, 2000 novembro 13

DIENER E, SUH E. Measuring quality of life: Economic, social, and subjective indicators. Social Indicators Research 1997; 40: $189-216$. 
ENGLAND RW. Measurement social well-being: alternatives to gross domestic product. Ecological Economics 1998; 25: 89- 103.

ESTES R. The International Index of Social Progress, 1974 Disponivel em http://uww.globalideasbank.org/BOV/BV-377.html [2001 março].

FREI F, SILVA NN. Discriminando desigualdades sociais: Aspectos metodológicos. Revista Plural, 2002; 2:7-25.

Fundação IBGE. Pesquisa nacional por amostra domiciliar: 1999, Rio de Janeiro; 2000.

Fundação IBGE. Censo demográfico do Brasil. Rio de Janeiro; 1991

FUNDAÇÃO SEADE . Informações dos Municípios Paulistas. Informações existentes no site: www. seade.gov.br 2001 [fevereiro 2002].

Fundação SEADE. Fórum São Paulo Século 21: Índice Paulista de Responsabilidade Social - IPRS. São Paulo; 2000.

JEKEL JF, ELMORE JG, KATZ DL. Epidemiologia, Bioestatística e Medicina Preventiva. Porto Alegre: Artmed; 1999.

LBOR- Left Business Observer Report.Gini says: measuring income inequality. 1993. Informações existentes no site:

http://www.panix.com/ dhenwood/Gini_supplement.html [ 2000 setembro].

MORRIS DM. Measuring the condition of the World's Poor, New York: Overseas Development Council; 1979.

NOORBAKHSH F. A Modified Human Development Index. World Development 1998; 26 (03): $517-528$. 
NUNES A, SANTOS JRS, BARATA RB, VIANNA SM. Medindo as desigualdades em saúde no Brasil: Uma proposta de monitoramento. Brasília 2001: Organização Pan-Americana da Saúde, Instituto de Pesquisa

PNUD - Programa das Nações Unidas para o Desenvolvimento. Human Development Report (Disponivel em CD ROM). New York; 1990.

- Programa das Nações Unidas para o Desenvolvimento. Human Development Report (Disponível em CD ROM). New York; 1994.

- Programa das Nações Unidas para o Desenvolvimento. Human Development Report (Disponivel em CD ROM). New York; 1997.

- Programa das Nações Unidas para o Desenvolvimento. Relatório do Desenvolvimento Humano. New York; 1999.

- Programa das Nações Unidas para o Desenvolvimento. Relatório do Desenvolvimento Humano. Portugal; 2000.

Secretaria Estadual de Saúde de São Paulo. Informações existentes nos site:mww.saude.sp.gov.Br/html/fr_dados.htm [2001 setembro].

SPOSATI, A. Mapa da Exclusão/Inclusão Social da cidade de São Paulo. São Paulo: Educ; 1996

SZWARCWALD CL, LEAL MC, ANDRADE CLT. Mortalidade infantil no Brasil: Belíndia ou Bulgária? Cadernos de Saúde Pública 1997; 13(3):503516, jul-set.

UNESCO - Organização das Nações Unidas para a Educação, Ciência e a Cultura. Foro Consultivo Internacional sobre Educación para Todos, 
2000. Informações existentes no site:

http://www.oei.es/efa2000sdomingo.htm [ 2001 junho]

UNESCO - Organização das Nações Unidas para a Educação, Ciência e a Cultura. Education Statistics 2001. Regional Reports (América Latina y el Caribe). Informações existentes no site http://www.uis.unesco.org/ en/ pub /pubO.htm [ 2002 janeiro].

VAUGHAN, JP, MORROW, RH. Epidemiologia para municípios. São Paulo: Hucitec; 1992.

YEUNG OM, MATHIESON JA.Global benchmarks: Comprehensive measure of development. Washington: Brookings Institute press; 1998. 
Tabela 1. Índice de Desenvolvimento Municipal - IDM - municipios do Estado de São Paulo - 1991 e 1996.

\begin{tabular}{|c|c|c|c|c|c|c|c|c|c|c|}
\hline \multirow[b]{2}{*}{ Municipio } & \multicolumn{2}{|c|}{$\begin{array}{l}\text { IDM } \\
\text { Saúde }\end{array}$} & \multicolumn{2}{|c|}{$\begin{array}{c}\text { IDM } \\
\text { Educação }\end{array}$} & \multicolumn{2}{|c|}{$\begin{array}{c}\text { IDM } \\
\text { Segurança }\end{array}$} & \multicolumn{2}{|c|}{$\begin{array}{c}\text { IDM } \\
\text { Saneamento }\end{array}$} & \multicolumn{2}{|c|}{$\begin{array}{c}\text { IDM } \\
\text { GERAL }\end{array}$} \\
\hline & 1991 & 1996 & 1991 & 1996 & 1991 & 1996 & 1991 & 1996 & 1991 & 1996 \\
\hline Adamantina & 946.78 & 938.18 & 781,26 & 864,08 & 999,75 & 999,49 & 766,12 & 889,54 & 783,83 & 844,94 \\
\hline Adolfo & 947,25 & 928,34 & 807.73 & 879,11 & 1000,00 & 1000,00 & 756,93 & 921,06 & 804,15 & 849,01 \\
\hline Aguaí & 926,12 & 926,76 & 718,11 & 773,78 & 999,30 & 999,36 & - & - & - & - \\
\hline Aguas de Prata & 601,12 & 934,30 & 746,11 & 777.21 & 999,73 & 999,48 & 949,30 & 1000,00 & 529,87 & 778.09 \\
\hline Águas de Lindoia & 922,10 & 944,02 & 684.55 & 824,38 & 999,32 & 999,64 & - & - & - & $=$ \\
\hline Aguas de Santa Barbara & 921,74 & 945,34 & 540,39 & 873,56 & 998,61 & 999,12 & 519,57 & 665,20 & 607,59 & 849.71 \\
\hline Águas de Săo Pedro & 918.55 & 967,67 & 757,92 & 768,09 & 1000,00 & 1000,00 & 1000,00 & 1000,00 & 756,93 & 781.78 \\
\hline Agudos & 925,68 & 932,71 & 711,74 & 812,75 & 998,61 & 999,55 & 828,82 & * & 725,93 & $=$ \\
\hline Alambari & - & 954,53 & - & 810,41 & - & 999,48 & - & 371,89 & - & 793,37 \\
\hline Alfredo Marcondes & 933,76 & 948,66 & - & 797,58 & 1000,00 & 999,50 & 670,30 & 737,08 & $*$ & 796,41 \\
\hline Altair & 889,29 & 927,68 & 665,97 & 778,06 & 999,44 & 1000,00 & 615,69 & 684,80 & 678,28 & 771,90 \\
\hline Altinópolis & 951,10 & 944,23 & 713,49 & 806,38 & 999,81 & 999,49 & - & * & * & - \\
\hline Alto Alegre & 941,19 & 939,59 & 707.54 & 781.23 & 1000,00 & 1000,00 & 474,76 & 645,20 & 720,69 & 778,19 \\
\hline Aluminio & - & 939,83 & - & 856,93 & * & 999,75 & - & - & - & - \\
\hline Álvares Florence & 947,09 & 938,34 & 778,70 & 912,34 & 999,64 & 1000,00 & 497,53 & 615,00 & 774,06 & 867,68 \\
\hline Alvares Machedo & 907,77 & 936,57 & 702,05 & 811,45 & 999,60 & 999,45 & 529,24 & 657,03 & 707,24 & 799,47 \\
\hline Álvaro de Carvalho & 931,83 & 887,59 & 619,38 & 688,84 & 1000,00 & 999,01 & 242,89 & 826,89 & 652,77 & 694,97 \\
\hline Alviniandia & 915,82 & 957,26 & 556,43 & 692,65 & 1000,00 & 1000,00 & 628,92 & 833,18 & 617,67 & 720.83 \\
\hline Americana & 941,93 & 939,02 & 824,48 & 901,16 & 999,59 & 999,45 & 964,13 & - & 817,58 & - \\
\hline Américo Brasiliense & 933,35 & 916,63 & - & - & 999,63 & 999,69 & 731,94 & $\cdot$ & $\cdot$ & - \\
\hline Américo de Campos & 929,38 & 924,96 & 789.14 & 886,18 & 999,36 & 998,39 & 637,29 & - & 779,35 & - \\
\hline Amparo & 926,27 & 927.77 & 782,93 & 903.62 & 999,70 & 999,57 & - & $\cdot$ & $\cdot$ & - \\
\hline Analándia & 964,64 & 876,29 & 663,74 & 763,67 & 1000,00 & 999,45 & * & - & . & - \\
\hline Andradina & 932,38 & 946,69 & 765.55 & 888,52 & 999,61 & 999,55 & - & - & $*$ & $*$ \\
\hline Angatuba & 927,03 & 933,59 & 683,69 & 780,04 & 999,33 & 999.21 & 533,22 & 741,07 & 701,72 & 777,20 \\
\hline Anhembi & 878,37 & 918,51 & 538,27 & 671,81 & 1000,00 & 999,11 & 658,58 & 830,39 & 597,29 & 695,70 \\
\hline Anhumas & 947,87 & 910,55 & 596.14 & - & 1000,00 & 999,46 & 471,18 & 754,73 & 646,62 & - \\
\hline Aparecida & 918,82 & 922,88 & 728,27 & 814,97 & 999,56 & 999,57 & - & - & * & - \\
\hline Aparecida d'Oeste & 923,09 & 959,72 & 803,61 & 789,79 & 1000,00 & 999,19 & 526,01 & 690,56 & 782,59 & 792,85 \\
\hline Apial & 938,41 & 905,48 & 666.43 & 793,91 & 999.52 & 999.72 & 351,23 & 622,42 & 649,34 & 769,65 \\
\hline Araçariguama & $\because$ & 914.50 & - & 747,78 & 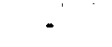 & 999,00 & - & 272,74 & 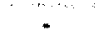 & 731,10 \\
\hline Araçatuba & 938,99 & 942,36 & 745,79 & 831,39 & 999,51 & 999,54 & - & - & * & i. \\
\hline Araçoiaba da Serra & 919,93 & 930,23 & 690.25 & 780,22 & 999,37 & 999,34 & 301,90 & 453,75 & 697,04 & 766,97 \\
\hline Aramina & 972,32 & 938,54 & 729,25 & - & 999,55 & 999,60 & $\cdot$ & - & - & $=$ \\
\hline Arandu & 951,15 & 932,61 & 516.03 & - & 999,35 & 999.69 & 503,30 & 636,87 & 597,16 & $\cdot$ \\
\hline Arapel & $* \quad:$ & 946,85 & - & * & 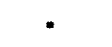 & 909.27 & $*$ & 538,41 & * & $\cdot$ \\
\hline Araraquara & 933,34 & 938,93 & 788,79 & 850.83 & 999,53 & 999.42 & 912,70 & $\because$ & 786,03 & - \\
\hline Arerae & 932,67 & 934,05 & 775.24 & 846,19 & 999,63 & 999,30 & 981.98 & * & 775,86 & - \\
\hline Arealva & 950,06 & 964,64 & 809,54 & - & 1000,00 & 999,64 & 584,42 & 737,23 & 801,26 & - \\
\hline Arelas & 912,98 & 939.51 & - & - & 1000,00 & 1000,00 & 578,07 & - & - & - \\
\hline Areiópolis & 919,48 & 929,17 & 666,07 & 674,37 & 1000,00 & 999,60 & 662,74 & 741,99 & 690,04 & 699,81 \\
\hline Ariranha & 946,08 & 938,92 & 643,88 & 808,60 & 999,69 & 1000,00 & 854,43 & - & 683,87 & - \\
\hline Artur Nogueira & 927,25 & 948,45 & 716,12 & 818,63 & 998,89 & 999,05 & * & - & - & - \\
\hline Aruje & 908,45 & 903,38 & 775,82 & 808,73 & 999,48 & 999,08 & - & * & - & $=$ \\
\hline Aspásia & - & 879,78 & - & 876,25 & - & 1000,00 & . & 525,09 & - & 794,81 \\
\hline
\end{tabular}


Tabela 1. Índice de Desenvolvimento Municipal - IDM - municipios do Estado de São Paulo - 1991 e 1996.

\begin{tabular}{|c|c|c|c|c|c|c|c|c|c|c|c|}
\hline \multirow{2}{*}{\multicolumn{2}{|c|}{ Municipio }} & \multicolumn{2}{|c|}{$\begin{array}{c}\text { IDM } \\
\text { Saúde }\end{array}$} & \multicolumn{2}{|c|}{$\begin{array}{c}\text { IDM } \\
\text { Educação }\end{array}$} & \multicolumn{2}{|c|}{$\begin{array}{c}\text { IDM } \\
\text { Segurança }\end{array}$} & \multicolumn{2}{|c|}{$\begin{array}{c}\text { IDM } \\
\text { Saneamento }\end{array}$} & \multicolumn{2}{|c|}{$\begin{array}{c}\text { IDM } \\
\text { GERAL }\end{array}$} \\
\hline & & 1991 & 1996 & 1991 & 1996 & 1991 & 1996 & 1991 & 1996 & 1991 & 1996 \\
\hline Assis & & 925,68 & 938,29 & 731,46 & 829,34 & 999,36 & 999,05 & 798,58 & 962,75 & 739,64 & 819,45 \\
\hline Atibaia & & 926,33 & 926,57 & 744,43 & 775,56 & 999,29 & 999,32 & - & - & - & - \\
\hline Auriflama & & 950,66 & 946,86 & 780,64 & 862,15 & 999,86 & 998,91 & 576,81 & 783,33 & 779,58 & 846,49 \\
\hline Avai & & 914,43 & 950,15 & 526,79 & - & 1000,00 & 998,39 & 516,45 & 631.34 & 597,85 & - \\
\hline Avanhandava & & 903,87 & 917,45 & 733,12 & 718,28 & 999,77 & 999,57 & 785,40 & - & 731,31 & - \\
\hline Avarè & & 924,06 & 919,25 & 725,95 & 801,53 & 999,58 & 999,65 & 836,50 & 888,08 & 735,53 & 787.99 \\
\hline Bady Bassitt & & 934,29 & 950,89 & 716,78 & 788,74 & 999,36 & 999.59 & 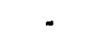 & - & - & - \\
\hline Balbinos & & 702,90 & 962,69 & - & - & 998,52 & 1000,00 & 611,89 & 868,99 & - & - \\
\hline Bálsamo & & 961,21 & 959,85 & 726,65 & 902,40 & 999,62 & 999,49 & - & - & - & - \\
\hline Bananal & & 943,23 & 945,58 & 678,91 & $\cdot$ & 999,72 & 999,81 & 472,20 & 561,18 & 701,25 & - \\
\hline Baržo de Antonina & & 924,56 & 960,67 & $\cdot$ & 727,68 & 999,40 & 999,38 & 475,50 & 629.61 & - & 744.13 \\
\hline Barbosa & & 905,12 & 943,87 & 637,52 & 807,93 & 999,33 & 999,68 & 698,07 & - & 667,04 & - \\
\hline Bariri & 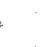 & 922,09 & 946,84 & 759,22 & 842,24 & 999,77 & 999,52 & 1000,00 & - & 759,48 & $=$ \\
\hline Barra Bonita & & 936,51 & 929.89 & 820,18 & 834,03 & 999.46 & 999,78 & 1000.00 & - & 811.61 & - \\
\hline Barra do Chapeu & & - & 913,49 & $\cdot$ & - & - & 1000,00 & - & 201,34 & - & - \\
\hline Barra do Turvo & & 884,30 & 911,19 & 617,70 & - & 997,20 & 997.97 & 171.65 & 237.80 & 636,17 & - \\
\hline Berretos & & 919,45 & 905,13 & 743,82 & 807,46 & 999,56 & 999,53 & $=$ & - & $\cdot$ & - \\
\hline Barrinha & & 922,68 & 917,49 & 699,18 & - & 999,78 & 999,09 & - & - & - & - \\
\hline Barueri & & 918,78 & 915,91 & 750,69 & 851,98 & 998,92 & 998,98 & 447,18 & - & 741,76 & - \\
\hline Bastos & & 920.28 & 931,60 & 726,30 & 817,08 & 999,42 & 999,18 & 706,65 & 824,89 & 732,49 & 805.21 \\
\hline Batatais & & 941,34 & 942,44 & 761,19 & 820,01 & 999,59 & 999,58 & 936,79 & $\cdot$ & 768,61 & - \\
\hline Bauru & & 929,47 & 930,86 & 774,44 & 848.44 & 999,46 & 999,59 & - & - & - & - \\
\hline Bebedouro & & 941,42 & 936,73 & 758,69 & 852,99 & 999,49 & 999,49 & - & 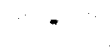 & - & - \\
\hline Bento de Abreu & & 988,84 & 991,39 & 776,29 & 914,65 & 1000,00 & 999,24 & 805,02 & 887,47 & 789,93 & 912,44 \\
\hline Bernardino de Campos & & 867,86 & 930,33 & 682,07 & 891,50 & 999,82 & 999,12 & 757,80 & 964,97 & 680,75 & 859,31 \\
\hline Bertioga & & $\cdot$ & 901,69 & $\cdot$ & 800,84 & $\cdot$ & 998,36 & - & - & - & $\cdot$ \\
\hline Bilec & & 964,81 & 949,55 & 838.34 & 791,32 & 999,67 & 1000.00 & 803,70 & - & 836,26 & $=$ \\
\hline Birigui & & 946,55 & 942,80 & 788,05 & 874,02 & 999,71 & 999,22 & 897,50 & $=$ & 790,86 & - \\
\hline Biritiba Mirim & & 911,29 & 899.15 & 741,24 & 676,19 & 999,49 & 999,46 & - & - & - & - \\
\hline Boe Esperança do Sul & & 924,32 & 920,18 & 714.89 & $\cdot$ & 1000.00 & 999,30 & 803.27 & - & 727.41 & - \\
\hline Boceina & & 938,10 & 960,17 & 756,00 & 799,13 & 999,75 & 999,32 & 887,85 & 974,41 & 763,20 & 804,78 \\
\hline Bofete & & 943,97 & 954,75 & 662,18 & 722,99 & 998,99 & 1000,00 & - & 391,39 & - & 732,12 \\
\hline Boituva & & 933,20 & 926,86 & 701,37 & 815.14 & 999,45 & 999,33 & 579.39 & 657,44 & 716,87 & 797.21 \\
\hline Bom Jesus dos Perdōes & & 939,46 & 927,38 & - & 782,40 & 999,74 & 998,91 & 482,53 & - & - & $\cdot$ \\
\hline Bom Sucesso de ltararé & & $\therefore \quad-$ & 880,84 & - & 772,70 & $*$ & 1000,00 & - & $\cdot$ & - & - \\
\hline Borá & & 1000,00 & 949,98 & $\cdot$ & $\cdot$ & 1000,00 & 1000,00 & 614,75 & 644,28 & - & - \\
\hline Boractia & & 900,55 & 943,89 & 678,53 & $\cdot$ & 1000,00 & 999,50 & 742,70 & 773,63 & 692,81 & 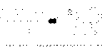 \\
\hline Borborema & & 940.55 & 931,82 & 780,08 & 783,17 & 999,24 & 999,49 & - & - & - & - \\
\hline Borebi & : & $\because \cdot$ & 936,24 & $\cdot$ & 803,27 & $\cdot$ & 1000,00 & - & $=$ & - & 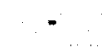 \\
\hline Botucatu & & 930,01 & 936,86 & 741,02 & 796,25 & 999,09 & 999,32 & 845,15 & 915,40 & 748.73 & 793,27 \\
\hline Bragança Paulista & & 912,63 & 927,79 & 725.72 & 774,31 & 999,32 & 999.41 & 689.75 & - & 728,66 & $=$ \\
\hline Braúna & & 939,49 & 946,84 & 787,69 & 800,60 & 1000,00 & 1000,00 & 639,04 & - & 782,74 & - \\
\hline Brodowski & & 950,92 & 937,04 & 649,81 & 855,12 & 999,47 & 999,41 & 884,54 & - & 689,16 & - \\
\hline Brotas & & 926.28 & 931,59 & 783.46 & 859.86 & 999,60 & 999,35 & $\cdot$ & - & - & - \\
\hline Buri & & 889,78 & 860,45 & 688,11 & $\cdot$ & 999,60 & 999,66 & 488,11 & 721,95 & 689,81 & $\cdots$ \\
\hline
\end{tabular}


Tabela 1. Índice de Desenvolvimento Municipal - IDM - municipios do Estado de São Paulo - 1991 e 1996.

\begin{tabular}{|c|c|c|c|c|c|c|c|c|c|c|}
\hline \multirow[b]{2}{*}{ Municipio } & \multicolumn{2}{|c|}{$\begin{array}{l}\text { IDM } \\
\text { Saúde }\end{array}$} & \multicolumn{2}{|c|}{$\begin{array}{c}\text { IDM } \\
\text { Educação }\end{array}$} & \multicolumn{2}{|c|}{$\begin{array}{c}\text { IDM } \\
\text { Segurança }\end{array}$} & \multicolumn{2}{|c|}{$\begin{array}{c}\text { IDM } \\
\text { Saneamento }\end{array}$} & \multicolumn{2}{|c|}{$\begin{array}{c}\text { IDM } \\
\text { GERAL }\end{array}$} \\
\hline & 1991 & 1996 & 1991 & 1996 & 1991 & 1996 & 1991 & 1996 & 1991 & 1996 \\
\hline Buritama & 914,58 & 933,39 & 773,65 & 846,12 & 999,43 & 999,70 & 864,70 & - & 765,50 & - \\
\hline Buritzal & 973,22 & 973,54 & - & - & 999,52 & 999,52 & 663,20 & 841,24 & - & - \\
\hline Cabrália Paulista & 966,46 & 915,79 & 590,50 & $\cdot$ & 997,66 & 999,58 & 604,37 & - & 647,76 & - \\
\hline Cabreúva & 915,53 & 920,95 & 656,58 & 741,13 & 999,42 & 999,66 & 325,66 & 342,84 & 674,71 & 732,32 \\
\hline Caçapava & 931,68 & 930,04 & 755,66 & 882,63 & 999,39 & 999,44 & 773,65 & 847.92 & 759,12 & 851,57 \\
\hline Cachooira Paulleta & 916,00 & 927,36 & 697,59 & 788,88 & 899,60 & 908,92 & 775,13 & 848,90 & 711,98 & 782,68 \\
\hline Caconde & 926.72 & 919,85 & 718,06 & 783.14 & 999,48 & 999.77 & - & - & - & - \\
\hline Cafolandia & 941,64 & 919.27 & 740,02 & 808,04 & 999,52 & 999,58 & 428,53 & - & 742,06 & - \\
\hline Caiabu & 947,41 & 935,48 & 710,47 & $\cdot$ & 1000,00 & 999,55 & 422,47 & 610.86 & 722,69 & - \\
\hline Caleiras & 903,09 & 942,42 & 801,76 & 868,06 & 999,39 & 999.13 & 714.11 & - & 775,75 & - \\
\hline Caiuá & 936,58 & 955,76 & - & - & 999,46 & 1000,00 & - & - & - & - \\
\hline Cajamar & 920,53 & 912,85 & 744,81 & 863,62 & 998,96 & 999,09 & 468,45 & - & 739,25 & - \\
\hline Cajati & $\cdot$ & 937,61 & $\cdot$ & 761.69 & - & 999.12 & - & 477,42 & - & 757,81 \\
\hline Cajobi & 957,19 & 959,59 & 692,46 & 814,26 & 999,38 & 999,20 & 824,62 & 938,87 & 720,60 & 816,71 \\
\hline Cajuru & 926,51 & 941,59 & 722.74 & 753,22 & 999,69 & 999,22 & 755.80 & 881.81 & 733,14 & 762,31 \\
\hline Campina do Monte Alegre & $\cdot$ & 923,20 & $\cdot$ & 811,14 & - & 1000,00 & - & 680,33 & - & 793,08 \\
\hline Campinas & 935,64 & 940,48 & 770,34 & 839,11 & 999,49 & 999,20 & - & - & - & - \\
\hline Campo Límpo Paulista & 920,05 & 920,51 & 735,01 & 845,39 & 999,65 & 999,49 & - & - & - & - \\
\hline Campos do Jordão & 870,79 & 893,48 & 701,41 & 802,64 & 999.41 & 999,40 & 548,23 & 735,58 & 690,54 & 770,63 \\
\hline Campos Novos Paulista & 926,06 & 920,94 & 544,38 & 653,40 & 1000,00 & 998,61 & $\cdot$ & $*$ & - & - \\
\hline Cananéia & 898,56 & 903,30 & 724,51 & - & 999,30 & 999,17 & 418,73 & 526,41 & 714,79 & - \\
\hline Candido Mota & 945,71 & 935,13 & 749,53 & 782,47 & 999,64 & 999.52 & 933,07 & $\cdot$ & 761,22 & $-\cdots$ \\
\hline Cândido Rodrigues & 959,34 & 888,12 & 818.90 & - & 999,22 & 998.55 & 747.01 & 920.74 & 817,21 & - \\
\hline Canitor & - & 925,73 & $=$ & $\cdot$ & - & 999,39 & - & - & $\cdot$ & - \\
\hline Capazo Bonito & 898,82 & 890,40 & 743,80 & 836,28 & 999,09 & 999,36 & 576,99 & 752,35 & 731,95 & 789,49 \\
\hline Capela do Alto & 948,45 & 911,96 & 647,48 & 757.84 & 999,83 & 999,27 & 493,71 & 646,65 & 681,37 & 749,47 \\
\hline Capivari & 930,81 & 916,34 & 750.72 & 800.71 & 999.79 & 999,66 & - & - & - & - \\
\hline Caraguatatuba & 900,53 & 902,54 & 682,07 & 809,89 & 999,01 & 999,07 & 443,89 & 417,09 & 689,22 & 770,54 \\
\hline Carapicuiba & 920,88 & 934,27 & 730,93 & 811.73 & 998,95 & 999,05 & 421,36 & - & 728,41 & - \\
\hline Cardoso & 894,11 & 927,25 & 763,85 & 841,63 & 999,85 & 999,52 & 698,24 & 806,48 & 745,30 & 820,17 \\
\hline Casa Branca & 939,84 & 914,55 & 805,00 & 786,35 & 999,61 & 999,41 & - & - & - & - \\
\hline Csssia dos Coquelros & 977,24 & 945,06 & 679,45 & 821,89 & 999,33 & 999,36 & 414,76 & 595,39 & 705,64 & 808,82 \\
\hline Castilho & 945,87 & 949,09 & 726,32 & 805,73 & 999,49 & 999,73 & - & - & $\cdot$ & $\cdot$ \\
\hline Catanduva & 933,06 & 942,74 & 719,11 & 812,30 & 999,59 & 999,50 & 885,06 & - & 734,24 & - \\
\hline Catiguà & 934,18 & 960,00 & 634,02 & 793,01 & 999.42 & 999,72 & - & - & - & $\cdot$ \\
\hline Codral & 938,69 & 935,89 & 712,70 & - & 999,05 & 997.65 & - & * & - & - \\
\hline Cerqueira Cesar & 916,94 & 932,48 & 665,03 & - & 999.72 & 999,59 & - & - & - & $\cdot$ \\
\hline Cerquilho & 943.74 & 942.28 & 815.30 & 868,16 & 999,63 & 999,13 & 867,44 & - & 810,51 & - \\
\hline Cesário Lange & 936,58 & 905,78 & 694,93 & 825,55 & 999.67 & 999,85 & 601,22 & 563,85 & 713,84 & 788,31 \\
\hline Cherqueeda & 918,46 & 910,15 & 754,41 & 821,24 & 999,47 & 999,85 & 748,70 & 862,34 & 752,21 & 795,90 \\
\hline Chavantes & 918,22 & 938,79 & - & 867,32 & 999,31 & 999,79 & - & - & - & $\cdot$ \\
\hline Clementina & 910.47 & 946,69 & 782,97 & 814,45 & 999,48 & 999,65 & - & * & - & - \\
\hline Colina & 929,28 & 935,02 & 793,23 & 842,35 & 999,49 & 999,89 & - & - & - & - \\
\hline Colómbia & 929,62 & 925.65 & 602,84 & 721,59 & 1000,00 & 999,68 & 734,90 & 807,09 & 651,55 & 732,69 \\
\hline Conchal & 916,40 & 917.58 & 741.00 & 805.45 & 999,60 & 999.21 & 659.74 & - & 740,20 & - \\
\hline
\end{tabular}


Tabela 1. Indice de Desenvolvimento Municipal - IDM - municipios do Estado de São Paulo - 1991 e 1996.

\begin{tabular}{|c|c|c|c|c|c|c|c|c|c|c|}
\hline \multirow[b]{2}{*}{ Municipio } & \multicolumn{2}{|c|}{$\begin{array}{l}\text { IDM } \\
\text { Saúde }\end{array}$} & \multicolumn{2}{|c|}{$\begin{array}{c}\text { IDM } \\
\text { Educaçäo }\end{array}$} & \multicolumn{2}{|c|}{$\begin{array}{c}\text { IDM } \\
\text { Segurança }\end{array}$} & \multicolumn{2}{|c|}{$\begin{array}{c}\text { IDM } \\
\text { Saneamento }\end{array}$} & \multicolumn{2}{|c|}{$\begin{array}{c}\text { IDM } \\
\text { GERAL }\end{array}$} \\
\hline & 1991 & 1996 & 1991 & 1996 & 1991 & 1996 & 1991 & 1996 & 1991 & 1996 \\
\hline Conchas & 944,20 & 950,14 & 784,60 & 756,68 & 999,70 & 999,73 & - & 740,44 & - & 765,71 \\
\hline Cordeirópolis & 876,36 & 932,59 & 795,92 & 850,02 & 999,81 & 999,42 & - & - & - & - \\
\hline Coroados & 955,76 & 947,60 & 796,40 & 700,07 & 999,53 & 1000,00 & 526,30 & 652,04 & 791,07 & 721.45 \\
\hline Coronel Macedo & 887.78 & 932,28 & - & 775,24 & 1000,00 & 1000,00 & 427.32 & 627,10 & - & 770,34 \\
\hline Corumbetal & 929,29 & 902,71 & 830,65 & $\cdot$ & 999,43 & 999,48 & - & - & $=$ & - \\
\hline Cosmópolis & 932,90 & 936,34 & 736.11 & 790,89 & 999,35 & 999,61 & - & - & 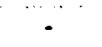 & - \\
\hline Cosmorama & 885,72 & 905,38 & 804,45 & 864,37 & 999,54 & 1000,00 & 493,47 & $=$ & 759,70 & - \\
\hline Cotia & 911,33 & 912,77 & 753,69 & 825,50 & 999,04 & 999,22 & 369,90 & $=$ & 737,59 & - \\
\hline Cravinhos & 931,01 & 923,79 & 712,73 & 898,19 & 999,27 & 999.15 & - & - & - & - \\
\hline Cristais Paulista & 898,36 & 940,86 & 662.13 & - & 1000,00 & 999.41 & 453,97 & - & 675.97 & $=$ \\
\hline Cruzália & 972,79 & 928,98 & 707,06 & 748,07 & 1000,00 & $1000, \infty 0$ & 551,64 & 703,82 & 728,93 & 751,29 \\
\hline Cruzeiro & 915,41 & 927,26 & 698,25 & 762,62 & 999,61 & 999,51 & - & $\begin{array}{c}\cdots \\
-\end{array}$ & $\therefore$ & - \\
\hline Cubatio & 913,40 & 929,32 & 829,46 & 825,87 & $\$ 99,07$ & 009.03 & 314,18 & 389,24 & 703.63 & 794,27 \\
\hline Cunha & 916.74 & 912.39 & 752,71 & 819,57 & 999.53 & 999.83 & - & - & - & - \\
\hline Descalvado & 931,36 & 940,34 & 853,12 & 872,51 & 999,86 & 999.73 & - & - & - & - \\
\hline Diadema & 915,72 & 926,05 & 772.17 & 875.14 & 998,37 & 997.65 & 501,98 & - & 756.75 & - \\
\hline Dirce Reis & - & 1000,00 & . & 868,95 & - & 1000,00 & - & 553,08 & - & 856.98 \\
\hline Divinolândia & 935,17 & 940,06 & 761,11 & 789,30 & 999.54 & 999.70 & 445,24 & 548,12 & 755,31 & 781.11 \\
\hline Dobrada & 902,93 & 949.16 & 689,65 & 780,13 & 999,47 & 999.74 & - & $*$ & - & - \\
\hline Dois Corregos & 935,11 & 924,15 & 773,58 & 814,70 & 999,81 & 999,64 & - & . & - & - \\
\hline Dolcinópolis & 948,55 & 945,99 & 757,94 & 843,53 & 1000,00 & 999,15 & 711,27 & 767,73 & 765,59 & 831,38 \\
\hline Dourado & 939,41 & 936,41 & 785,65 & 871.15 & 999,48 & 998,91 & 866.51 & 972,28 & 785,68 & 849,70 \\
\hline Dracens & 936,30 & 942,48 & 798,16 & 842,58 & 999,13 & 999.48 & 634,17 & - & 788,91 & - \\
\hline Duartina & 904,13 & 926,31 & 747,94 & 868,60 & 999,39 & 999,56 & 674,36 & - & 739,57 & - \\
\hline Dumont & 926,29 & 961,20 & - & - & 999,63 & 1000,00 & - & - & - & - \\
\hline Echaporà & 945.16 & 944,05 & 607,12 & 793,22 & 999,36 & 999,61 & 537,02 & 721,03 & 654,63 & 790.92 \\
\hline Eldorado & 910.67 & 922.17 & 711,06 & 783,35 & 999.61 & 999.58 & 368.94 & 597,48 & 709.58 & 770,66 \\
\hline Elias Fausto & 932,88 & 921,28 & 707.02 & 747,30 & 999,69 & 999.56 & $=$ & 566,60 & - & 744,31 \\
\hline Elisibrio & $=$ & 963.45 & $*$ & - & . & 1000,00 & - & $\cdot$ & - & - \\
\hline Embaúba & - & 939,61 & $*$ & 808,36 & - & 999.26 & - & 757,56 & $\cdot$ & 801,33 \\
\hline Embu & 897,80 & 916,89 & 727.35 & 789,04 & 998,50 & 997,93 & 355,75 & - & 714,12 & - \\
\hline Embu-Guaçu & 918,30 & 886,69 & 744,44 & 708,09 & 999,01 & 998,91 & - & - & - & - \\
\hline Emilianopolis & - & 972,34 & $*$ & - & $*$ & 997,50 & - & 848,43 & - & - \\
\hline Engenheiro Coelho & - & 922,73 & - & 793,39 & - & 999,58 & - & - & - & - \\
\hline Espirito Santo do Pinhal & 913,52 & 927,38 & 779,92 & 820,82 & 999,54 & 999,30 & 887.85 & 956,99 & 769,57 & 807,02 \\
\hline Espirito Santo do Turvo & $=$ & 925,15 & $\cdot$ & 732,86 & $\cdot$ & 998,92 & $=$ & 930,57 & - & 741,58 \\
\hline Estiva Gerbi & - & 926,59 & - & 927,06 & - & 999,30 & $\cdot$ & $\cdot$ & - & - \\
\hline Estrela do Norte & 776,93 & 770,66 & 749,86 & 778,15 & 1000,00 & 1000,00 & 560,42 & 735.47 & 656,42 & 665,80 \\
\hline Estrela d'Oeste & 941,52 & 968,95 & 815,96 & 845,94 & 999,57 & 999,78 & 459,61 & 604,66 & 796,95 & 836,57 \\
\hline Euclides da Cunha Paulista & $\because$ & 939,23 & $\cdot$ & 758,89 & - & 999,45 & - & 411,83 & - & 753,86 \\
\hline Fartura & 920.63 & $\$ 32,13$ & 793.14 & 762,22 & 999,62 & 999.49 & $\cdot$ & 702,42 & - & 762,74 \\
\hline Fernando Prestes & 907,97 & 926,58 & 792,50 & 784,72 & 1000,00 & 999,66 & 812,46 & 822,36 & 774,32 & 778,88 \\
\hline Fernandopolis & 939,19 & 943,88 & 758,72 & 883,95 & 999,80 & 999,45 & 822,87 & 841,51 & 764,95 & 864,16 \\
\hline Ferraz de Vasconcelos & 892,84 & 920,30 & 764,53 & 866,03 & 999,34 & 999,23 & 552,73 & - & 741,48 & $\cdot$ \\
\hline Flora Rica & 929,46 & 944,62 & - & - & 1000,00 & 999,21 & 414,54 & 494,37 & 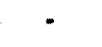 & - \\
\hline
\end{tabular}


Tabela 1. Índice de Desenvolvimento Municipal - IDM - municípios do Estado de São Paulo-1991 e 1996.

\begin{tabular}{|c|c|c|c|c|c|c|c|c|c|c|}
\hline \multirow[b]{2}{*}{ Municipio } & \multicolumn{2}{|c|}{$\begin{array}{c}\text { IDM } \\
\text { Saúde }\end{array}$} & \multicolumn{2}{|c|}{$\begin{array}{c}\text { IDM } \\
\text { Educação }\end{array}$} & \multicolumn{2}{|c|}{$\begin{array}{c}\text { IDM } \\
\text { Segurança }\end{array}$} & \multicolumn{2}{|c|}{$\begin{array}{c}\text { IDM } \\
\text { Saneamento }\end{array}$} & \multicolumn{2}{|c|}{$\begin{array}{c}\text { IDM } \\
\text { GERAL }\end{array}$} \\
\hline & 1991 & 1996 & 1991 & 1996 & 1991 & 1996 & 1991 & 1996 & 1991 & 1996 \\
\hline Floreal & 937,31 & 946.57 & 833,26 & 831,81 & 1000,00 & 998.39 & - & 797.63 & - & 823,37 \\
\hline Flórida Paulista & 938,61 & 917,83 & 821.71 & 808,70 & 999,54 & 999.85 & 528.09 & 735,82 & 802,92 & 789,78 \\
\hline Florinia & 947,05 & 854,89 & 667,51 & 800,80 & 999.40 & 995,30 & 736,84 & 879,09 & 699,48 & 743,75 \\
\hline Franca & 936,01 & 934,37 & 712,01 & 827,69 & 999,76 & 999,57 & 868,90 & 959,13 & 729,92 & 816,05 \\
\hline Francisco Morato & 889.81 & 906,25 & 743,81 & 802,70 & 998,94 & 999,08 & 289,37 & - & 717,95 & $\cdot$ \\
\hline Franco da Rocha & 912,85 & 924,93 & 765,13 & 856,61 & 999,43 & 998,72 & 489,62 & * & 750,25 & 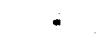 \\
\hline Gabriel Monteiro & 959,94 & 951,13 & 823,98 & 899,82 & 999.27 & 999,31 & 504,53 & 726,87 & 812,01 & 874,99 \\
\hline Ob́lia & 943,66 & 903.57 & 660.14 & 677.20 & 1000,00 & 999.69 & 494,35 & 762.39 & 689.04 & 693,34 \\
\hline Garça & 919,94 & 916,80 & 715,02 & 819,50 & 999,43 & 999,67 & 746,44 & $\cdot$ & 725,13 & - \\
\hline Gast3o Vidigal & 906,24 & 921,47 & 837,69 & 907,38 & 999,06 & 999,51 & 635,11 & 735,40 & 798,77 & 856,35 \\
\hline General Salgado & 928,91 & 913,98 & 775,55 & 869,95 & 1000,00 & 999,66 & $\cdot$ & - & - & $\cdot$ \\
\hline Getulina & 938,03 & 936,24 & 778,90 & 720,18 & 999,75 & 999,61 & 742,13 & - & 778,23 & $\because$ \\
\hline Glicério & 899,07 & 959,44 & 660,51 & 797,43 & 1000,00 & 999,58 & 554,37 & - & 677,43 & - \\
\hline Guaiçara & $\mathbf{9 1 7 , 3 1}$ & 947,70 & 651,84 & 732,81 & 999,71 & 999,67 & - & 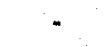 & - & $\therefore$ \\
\hline Guaimbê & 904,71 & 954,29 & 664,18 & 730.68 & 999,50 & 1000,00 & - & - & - & - \\
\hline Guaira & 947,56 & 928,45 & 763,10 & 806,84 & 999,74 & 999,63 & 730,51 & - & 769,57 & - \\
\hline Guapiaçu & 941,35 & 945,88 & 724,88 & - & 999,83 & 999,28 & - & - & $\cdot$ & $\because$ \\
\hline Guapiara & 902,90 & 885,17 & 693,41 & 832,66 & 999,56 & 999,70 & 200,78 & 306,50 & 689,36 & 766.84 \\
\hline Guará & 933,42 & 925,97 & 660,03 & 792,80 & 999,26 & 999,58 & - & - & - & - \\
\hline Guaraçai & 949,05 & 952,27 & 805,10 & - & 999,51 & 999,58 & 669,56 & $\therefore$ & 800,49 & - \\
\hline Guaraci & 921,12 & 948,67 & 719,25 & 858,52 & 999,54 & 999,70 & - & - & 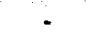 & $\because$ \\
\hline Guarani d'Oeste & 929,32 & 930.64 & 732,91 & 847.76 & 999,03 & 996.28 & 722,54 & 830.55 & 740,88 & 827,12 \\
\hline Guarantā & 926,33 & 902,54 & 619.43 & 720,88 & 999,35 & 1000,00 & - & - & $=$ & - \\
\hline Guararapes & 921,67 & 954,46 & 814,92 & 880,52 & 999,29 & 999.08 & 786,93 & . & 797,43 & $=$ \\
\hline Guararema & 917,12 & 900,58 & 683,07 & 768,95 & 999,36 & 999,03 & 408,05 & 496,37 & 694,83 & 746,78 \\
\hline Guaratinguetá & 915,53 & 925,24 & 772,64 & 809,62 & 999,64 & 999.44 & - & - & - & - \\
\hline Guarei & 916,76 & 929,03 & 686,87 & 783,27 & 999,57 & 999.61 & 430,15 & 595,61 & 697,85 & 773,74 \\
\hline Guariba & 922,79 & 934,62 & 722,03 & 757,65 & 999,40 & 999,62 & 1000,00 & 1000,00 & 733,07 & 763,59 \\
\hline Guarujá & 915,55 & 914,52 & 769,20 & 818.14 & 999,35 & 998,92 & 716.12 & 808,94 & 760,59 & 795,79 \\
\hline Guarulhos & 913,08 & 912,88 & 780,88 & 833,44 & 999,12 & 998,84 & 509,12 & - & 761,53 & - \\
\hline Guatapará & - & 928,28 & - & 762,19 & - & 999,58 & 0,00 & - & - & - \\
\hline Guzolándia & 974,03 & 923,21 & 621,64 & 894,90 & 998,87 & 999.14 & 321,79 & 467,86 & 663,08 & 836,96 \\
\hline Herculândia & 942,54 & 939,91 & 653,24 & 813,20 & 999,23 & 999,76 & 510,82 & - & 684,48 & - \\
\hline Holambra & 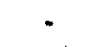 & 947,71 & - & - & - & 999,15 & $\cdot$ & - & - & - \\
\hline Hortolândia & - & 928,57 & - & 843,27 & - & 999,16 & - & - & - & - \\
\hline lacanga & 860,43 & 936,45 & 761,32 & 813,49 & 999,76 & 999.55 & $*$ & - & $\therefore$ & 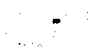 \\
\hline lacri & 897,58 & 945,71 & 719,38 & 813,47 & 1000,00 & 999,63 & 574,27 & 743,93 & 715,36 & 807,60 \\
\hline laras & $\therefore$ & 953,04 & - & - & - & 999,31 & - & 712,22 & - & - \\
\hline Ibato & 940,65 & 931,08 & 782,23 & 809,58 & 999,13 & 999,43 & $\cdot$ & - & $\cdot$ & - \\
\hline lbird & 940,42 & 928,56 & 748,22 & 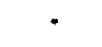 & 999,79 & 999,41 & 783,35 & 878,82 & 766,99 & - \\
\hline Ibirarema & 934,31 & 926,64 & 682,74 & 811,65 & 999,53 & 998,37 & 764,26 & - & 707,41 & - \\
\hline lbitinga & 930,82 & 928,72 & 663,11 & 776,36 & 999,72 & 999,49 & - & - & - & - \\
\hline Ibiúna & 915.16 & 921,41 & 688.79 & 756,69 & 999.61 & 999,26 & 181,73 & 219,45 & 690,08 & 737.15 \\
\hline lcem & 959,20 & 913,36 & 739,68 & - & 1000,00 & 1000,00 & 811,11 & 919,58 & 756,30 & - \\
\hline lepê & 944,73 & 950,81 & 733,99 & $\ddot{-}$ & 999,75 & 999,50 & - & - & - & - \\
\hline
\end{tabular}


Tabela 1. Índice de Desenvolvimento Municipal - IDM - municipios do Estado de São Paulo - 1991 e 1996.

\begin{tabular}{|c|c|c|c|c|c|c|c|c|c|c|}
\hline \multirow[b]{2}{*}{ Municipio } & \multicolumn{2}{|c|}{$\begin{array}{l}\text { IDM } \\
\text { Saúde }\end{array}$} & \multicolumn{2}{|c|}{$\begin{array}{c}\text { IDM } \\
\text { Educaçåo }\end{array}$} & \multicolumn{2}{|c|}{$\begin{array}{c}\text { IDM } \\
\text { Segurança }\end{array}$} & \multicolumn{2}{|c|}{$\begin{array}{c}\text { IDM } \\
\text { Saneamento }\end{array}$} & \multicolumn{2}{|c|}{$\begin{array}{c}\text { IDM } \\
\text { GERAL }\end{array}$} \\
\hline & 1991 & 1996 & 1991 & 1996 & 1991 & 1996 & 1991 & 1996 & 1991 & 1996 \\
\hline Igaraçu do Tiete & 924,54 & 926,10 & 787,21 & 860,93 & 999,44 & 999.75 & - & - & - & - \\
\hline Igarapava & 947,74 & 938,38 & 723.70 & 813,86 & 999.48 & 999,60 & 569,57 & 951,24 & 736,63 & 807,62 \\
\hline Igaratá & 955,17 & 933,86 & - & - & 999,71 & 999,45 & 306,70 & 408,00 & $=$ & - \\
\hline Iguape & 894,76 & 936.16 & 698,66 & 793,57 & 999,55 & 999,45 & 485,06 & 595,52 & 698,55 & 784,26 \\
\hline Itha Comprida & $\cdot$ & 933,36 & $\therefore$ & 849,40 & - & 999,63 & 0,00 & - & - & - \\
\hline Ilha Solteira & - & 942,92 & - & 910.65 & - & 999,84 & 0,00 & - & - & - \\
\hline llhabela & 930,48 & 933,95 & 723.12 & 945,28 & 999,87 & 999.44 & 296,84 & 298,24 & 721,90 & 853,41 \\
\hline Indaiatuba & 922,21 & 936,62 & 771,07 & 836,27 & 999,63 & 999,50 & - & - & - & - \\
\hline Indiana & 915,07 & 925,45 & 766,64 & " & 1000,00 & 998,87 & $*$ & - & - & - \\
\hline Indiaporã & 874,49 & 927.60 & 790,84 & - & 999,62 & 999.09 & 721,76 & 777.89 & 750,31 & - \\
\hline Inúbia Paulista & $941 ; 20$ & 924,02 & 785,10 & - & 1000,00 & 1000,00 & 581,63 & 797,27 & 779,68 & - \\
\hline Ipaussu & 897,38 & 924,84 & 677,04 & 815,99 & 999,65 & 999.79 & 773,25 & - & 690,93 & - \\
\hline Ipero & 931,62 & 941,20 & 729,36 & 772,96 & 999,45 & 999.13 & 412.32 & 447,05 & 730.88 & 765,88 \\
\hline Ipeúna & 977,24 & 939,59 & 733,02 & 827,60 & 998,65 & 998,99 & 702,13 & - & 752,57 & - \\
\hline Iporanga & 897,72 & 925,06 & - & 822.10 & 1000,00 & 1000,00 & 351,74 & 447,50 & - & 792,58 \\
\hline Ipuä & 921,62 & 935,13 & 716,16 & 828,98 & 999.47 & 999.64 & - & - & - & - \\
\hline Iracemápolis & 940,17 & 941,08 & 792,21 & 866,52 & 1000,00 & 999.61 & 984,65 & $\cdot$ & 791,96 & - \\
\hline Irapuã & 954,00 & 941,95 & 706,63 & 780,33 & 999,70 & 1000,00 & 694,42 & 791,92 & 728,51 & 781,79 \\
\hline Irapuru & 944,89 & 898,93 & 770,13 & 853,53 & 999,78 & 999,77 & - & - & - & $\because$ \\
\hline Itaberá & 913,65 & 914,29 & 701,38 & 823,94 & 999,77 & 999,58 & 441,67 & 541,36 & 706,66 & 791,79 \\
\hline Itai & 890,15 & 917,22 & 675,48 & $\cdot$ & 999,63 & 999,79 & 615,05 & 808,28 & 684,67 & - \\
\hline Itajobi & 910,44 & 932,88 & 771.76 & 854,03 & 999,61 & 999,74 & - & - & - & - \\
\hline Itaju & 946,85 & 972,86 & 722,88 & - & 998,47 & 1000,00 & - & - & - & - \\
\hline Itanhaém & 907,54 & 927,83 & 737,39 & 792,31 & 999,44 & 999,13 & 385,83 & 368,29 & 725,95 & 770,33 \\
\hline Itabca & . & 906,79 & - & 820.37 & $=$ & 1000,00 & 0,00 & 308,52 & - & 774,02 \\
\hline Itapecerica da Serra & 909,16 & 909,57 & 728,12 & 827,80 & 998,83 & 997,86 & 251,33 & - & 715,49 & - \\
\hline Itapetininga & 919,32 & 908,78 & 717.81 & 758,76 & 999.51 & 999,42 & 705,15 & 854,81 & 726.17 & 752,06 \\
\hline Itapeva & 881,72 & 890,02 & 701,74 & 794,08 & 999,52 & 999,48 & 594,97 & 777,67 & 697,12 & 763,69 \\
\hline ItapevI & 910,41 & 911,76 & 704,79 & 812,52 & 998,74 & 998,92 & 441,07 & - & 707,67 & - \\
\hline Itapira & 915,61 & 941,19 & 777,00 & 807.87 & 999,68 & 999,23 & - & - & - & - \\
\hline Itapirapua Paullata & $\cdot$ & 857,81 & $*$ & 733,07 & - & 999,47 & - & 366,12 & - & 697,15 \\
\hline Itápolis & 943,00 & 942,33 & 780,16 & 854,71 & 999,72 & 999,59 & - & - & - & - \\
\hline ltaporanga & 895,42 & 866,03 & 737,77 & 781,04 & 999,75 & 999,64 & 574,32 & 658,12 & 726,27 & 737,52 \\
\hline Itapui & 945,77 & 941,45 & 676,89 & 700,62 & 999,80 & 1000,00 & - & - & - & - \\
\hline Itapura & 914,63 & 939,87 & 701,68 & $\cdot$ & 999,03 & 998,93 & - & - & $\cdot$ & - \\
\hline Itaquaquecetuba & 901,52 & 901,87 & 749.01 & 859,48 & 998,74 & 998,67 & 314,83 & - & 727,87 & - \\
\hline Hararé & 891,15 & 897,33 & 726,51 & 783,61 & 999,65 & 999.76 & - & - : & $\because \cdots$ & - \\
\hline Itariri & 899,35 & 921,22 & 716,27 & 805,10 & 999.22 & 998,59 & 323,42 & 404,21 & 706,71 & 777,33 \\
\hline Itatiba & 924,46 & 931,02 & 794,53 & 866,76 & 999,55 & 999,62 & 788,21 & 847,60 & 784,39 & 841,32 \\
\hline Itatinga & 931,32 & 931,05 & 641,37 & 808,39 & 999,70 & 999,22 & 696,51 & 828,76 & 677,17 & 798,56 \\
\hline Itirapina & 929,24 & 923,86 & 784,93 & 881.16 & 999,01 & 998.99 & - & - & * & - \\
\hline Itirapuã & 861,47 & 945,75 & 521,51 & - & 999,64 & 1000,00 & 765,83 & 842,28 & 583,44 & - \\
\hline Itobi & 955,10 & 904.46 & 680,68 & - & 999,73 & 999,49 & 654,43 & 768,90 & 709,20 & - \\
\hline Itu & 927,70 & 922,52 & 780,84 & 816.16 & 999.32 & 999,40 & 790,28 & - & 776,08 & - \\
\hline Itupeva & 920,55 & 954,82 & 733.22 & 820,66 & 999,19 & 999,92 & 351,19 & 503,29 & 727,26 & 807,73 \\
\hline
\end{tabular}


Tabela 1. Índice de Desenvolvimento Municipal - IDM - municipios do Estado de São Paulo - 1991 e 1996.

\begin{tabular}{|c|c|c|c|c|c|c|c|c|c|c|}
\hline \multirow[b]{2}{*}{ Municipio } & \multicolumn{2}{|c|}{$\begin{array}{c}\text { IDM } \\
\text { Saúde }\end{array}$} & \multicolumn{2}{|c|}{$\begin{array}{c}\text { IDM } \\
\text { Educação }\end{array}$} & \multicolumn{2}{|c|}{$\begin{array}{c}\text { IDM } \\
\text { Segurança }\end{array}$} & \multicolumn{2}{|c|}{$\begin{array}{c}\text { IDM } \\
\text { Saneamento }\end{array}$} & \multicolumn{2}{|c|}{$\begin{array}{c}\text { IDM } \\
\text { GERAL }\end{array}$} \\
\hline & 1991 & 1996 & 1991 & 1996 & 1991 & 1996 & 1991 & 1996 & 1991 & 1996 \\
\hline Ituverava & 932,25 & 941,21 & 714,49 & 806,11 & 999,70 & 999,60 & - & - & * & - \\
\hline Jaborandi & 924,67 & 951,15 & 783.77 & * & 999,71 & 999,72 & 889,58 & 875,76 & 778,04 & " \\
\hline Jaboticabal & 923,57 & 929,87 & 741,09 & 883,12 & 999,52 & 999,43 & 937,75 & - & 746,91 & - \\
\hline Jacarel & 926,40 & 922,10 & 771,62 & 857,75 & 999,36 & 999,06 & 766,27 & $\bullet$ & 768,38 & - \\
\hline Jeci & 908,36 & 902,70 & 788,84 & - & 1000,00 & 080,51 & * & - & - & $\cdot$ \\
\hline Jacupiranga & 909,73 & 949,35 & 654,39 & - & 998,14 & 999,29 & 466,75 & 606,02 & 675,26 & - \\
\hline Jaguariúna & 942,64 & 936,32 & 707,18 & 781,23 & 999,61 & 999,52 & 798,13 & - & 727,64 & - \\
\hline Jales & 926,21 & 941,74 & 781,34 & 857,12 & 999,33 & 099,48 & 781,71 & 892,87 & 775,60 & 841,98 \\
\hline Jambeiro & 930,66 & 942,73 & 602,94 & 807,06 & 998,90 & 998,89 & 446,97 & 522,68 & 647,25 & 794,02 \\
\hline Jandira & 895,32 & 913,30 & 742,14 & 827,70 & 998,94 & 999,05 & 391,04 & - & 723,47 & - \\
\hline Jardinópolis & 922,97 & 934,38 & 776,47 & 832.15 & 999,17 & 999.47 & - & - & - & - \\
\hline Jarinu & 915,93 & 912,95 & 712,60 & 772,77 & 1000,00 & 998,94 & 183,72 & 245,06 & 705,43 & 744,94 \\
\hline Jaú & 936,54 & 927,40 & 787,81 & 798,76 & 999,63 & 999,39 & - & - & $\cdots$ & - \\
\hline Jeriquara & 936,35 & 933,22 & 502,12 & $\cdots$ & 1000,00 & 998,89 & 730,72 & 845,25 & 589,31 & $\because$ \\
\hline Joanopolis & 928,19 & 916,14 & 655,00 & 715.05 & 1000,00 & 999,57 & 535,44 & - & 682.72 & - \\
\hline Joso Ramalho & 958,66 & 935,79 & 744,07 & 771,80 & 999,16 & 1000,00 & - & - & - & - \\
\hline José Bonifácio & 939,85 & 932,86 & 714,91 & 856,16 & 999,61 & 999,30 & - & - & - & - \\
\hline Jülio Mesquita & 862,79 & 921,45 & 550,03 & 787.14 & 999,35 & 1000,00 & 475,65 & - & 596,77 & - \\
\hline Jundiai & 931,61 & 933,29 & 789,88 & 843,68 & 999,65 & 999,45 & - & - & - & - \\
\hline Junqueiropolis & 950,53 & 942,79 & 759,37 & 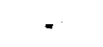 & 999,80 & 999,85 & - & - & - & - \\
\hline Juquid & 912,77 & 920,89 & 703,04 & - & 999,28 & 098,57 & 430,09 & 488,85 & 707,09 & 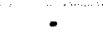 \\
\hline Juquitiba & 924,39 & 908,32 & 650,84 & 765,82 & 998,70 & 998,72 & $\cdot$ & $\cdots$ & 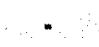 & 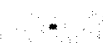 \\
\hline Lagoinha & 920,63 & 958.67 & 715,68 & - & 999.61 & 999,63 & - & 545,39 & 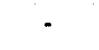 & - \\
\hline Laranjal Paulista & 950,62 & 945,94 & 743,14 & 845,50 & 999.43 & 999,06 & 733,32 & - & 755,49 & - \\
\hline Lavinia & 886,77 & 915,19 & 803,78 & 854,00 & 999,67 & 1000,00 & 537,58 & - & 761,53 & - \\
\hline Lavrinhas & 921,47 & 913,52 & 667,67 & - & 999,61 & 998,65 & - & 551,09 & - & - \\
\hline Leme & 921,21 & 917.59 & 738,56 & 851,35 & 999,62 & 999,38 & 929,82 & - & 744.09 & - \\
\hline Lençóis Paulista & 929,39 & 941,82 & 747,22 & 861,48 & 999,40 & 999,45 & 978,52 & - & 753,82 & - \\
\hline Limeira & 925,89 & 931,35 & 767,00 & 833,08 & 999,46 & 999,56 & 998,53 & - & 766,84 & - \\
\hline Lindoia & 972,71 & 929,20 & 609,08 & 768,36 & 999,12 & 998,11 & - & - & $\therefore \quad-$ & - \\
\hline Lins & 933,88 & 933,47 & 759,67 & 806,59 & 999,79 & 999,78 & 910.81 & 998.88 & 764,51 & 799,80 \\
\hline Lorena & 923,81 & 916,87 & 697,07 & 755.57 & 999,53 & 999,20 & 744,56 & 883,04 & 713,95 & 754,00 \\
\hline Lourdes & - & 916,04 & - & - & - & 999,03 & - & 746,05 & - & - \\
\hline Louveira & 936,19 & 916,99 & 811,26 & 790,62 & 999,10 & 999,24 & - & $\because$ & 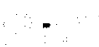 & $\therefore$ \\
\hline Lucélia & 932,77 & 946,80 & 788,66 & 893,65 & 999,90 & 999,58 & 692,89 & 818,56 & 782,07 & 871,03 \\
\hline Lucianopolis & 930,87 & 892,89 & 746,25 & - & 999,23 & 1000,00 & 473,17 & 802,97 & 744,39 & - \\
\hline Luis António & 924,19 & 909,16 & 768,97 & 784,96 & 999,69 & 999,72 & • & • & $=$ & $\cdot$ \\
\hline Luiziánia & 909,22 & 951.59 & 809,05 & 767,52 & 999,56 & 999,57 & 729,85 & 900,69 & 784,74 & 776,68 \\
\hline Lupbrcio & 909,05 & 940.02 & 620,94 & 748,05 & 1000,00 & 1000,00 & 578,63 & 764,15 & 655,80 & 756,42 \\
\hline Lutocia & 938,50 & 962.04 & 660,72 & 917.96 & 1000,00 & 1000,00 & 553,49 & 628,44 & 689,60 & 888,79 \\
\hline Macatuba & 930,91 & 933,90 & 738,36 & 811,12 & 999,51 & 999,61 & 706,46 & 831,74 & 745,08 & 802,08 \\
\hline Macaubal & 928,30 & 945,39 & 812,51 & 837,48 & 999,75 & 999,51 & - & - & - & $\cdot$ \\
\hline Macedónia & 906,46 & 969,68 & 750,47 & 846,01 & 1000,00 & 1000,00 & 508,73 & 603,53 & 738,12 & 836,79 \\
\hline Magda & 964,50 & 983,01 & 840,85 & 879,56 & 999,02 & 999,49 & 698,28 & . & 835,01 & $\cdot$ \\
\hline Mairinque & 911,87 & 899,67 & 737,50 & 807,08 & 998,92 & 999,45 & - & - & - & - \\
\hline
\end{tabular}


Tabela 1. Índice de Desenvolvimento Municipal - IDM - municípios do Estado de São Paulo - 1991 e 1996.

\begin{tabular}{|c|c|c|c|c|c|c|c|c|c|c|}
\hline \multirow[b]{2}{*}{ Municipio } & \multicolumn{2}{|c|}{$\begin{array}{l}\text { IDM } \\
\text { Saúde }\end{array}$} & \multicolumn{2}{|c|}{$\begin{array}{c}\text { IDM } \\
\text { Educação }\end{array}$} & \multicolumn{2}{|c|}{$\begin{array}{c}\text { IDM } \\
\text { Segurança }\end{array}$} & \multicolumn{2}{|c|}{$\begin{array}{c}\text { IDM } \\
\text { Saneamento }\end{array}$} & \multicolumn{2}{|c|}{$\begin{array}{c}\text { IDM } \\
\text { GERAL }\end{array}$} \\
\hline & 1991 & 1996 & 1991 & 1996 & 1991 & 1996 & 1991 & 1996 & 1991 & 1996 \\
\hline Mairipora & 929,05 & 913,73 & 712,33 & 803,46 & 999,18 & 998,83 & 310,34 & - & 714,79 & - \\
\hline Manduri & 911,82 & 900,20 & 737,75 & 859,85 & 999,65 & 999,31 & 873,34 & $\cdot$ & 739,08 & - \\
\hline Marabá Paulista & 948,74 & 969,37 & 802,01 & - & 1000,00 & 999,50 & - & $\cdot$ & - & $\cdot$ \\
\hline Maracai & 929.22 & 924,09 & 745,86 & 848,70 & 999.27 & 999.42 & 731,75 & 850,04 & 750,33 & 823,91 \\
\hline Marapoama & $\cdot$ & 942,26 & $\cdot$ & 856,83 & $\cdot$ & 998,22 & 0,00 & $\cdot$ & $\cdot$ & - \\
\hline Mariapolis & 950.35 & 975.10 & 795.39 & 815.12 & 1000,00 & 1000,00 & 341,91 & 398,92 & 779.83 & 803,67 \\
\hline Marilia & 930,66 & 933,05 & 738,74 & 826,86 & 999,36 & 999,35 & - & - & - & - \\
\hline Marinópolis & 946,42 & 931,32 & 711,28 & 836.27 & 1000,00 & 1000,00 & 495,20 & 693.74 & 725,30 & 815,85 \\
\hline Martinopolis & 928.05 & 951,07 & 727.64 & $\cdot$ & 999,74 & 999,48 & 691,65 & $\cdot$ & 736,09 & $\because$ \\
\hline Matão & 937,48 & 938,12 & 798,00 & 867,09 & 999,63 & 999,65 & $\cdot$ & - & $\cdot$ & - \\
\hline Mauá & 918,12 & 920,37 & 756,75 & 929,64 & 998,91 & 998,87 & 577,57 & * & 749,77 & - \\
\hline Mendonça & 974,86 & 946.13 & 771,65 & 895,99 & 1000.00 & 999.50 & - & - & $\cdot$ & - \\
\hline Meridieno & 969,93 & 952.72 & 774.80 & 854,39 & 1000,00 & 999,08 & 577.01 & . & 780,19 & - \\
\hline Mesdpolis & - & 983,04 & - & 701,79 & - & 998,17 & - & 595,77 & - & 727,25 \\
\hline Miguelópolis & 933,68 & 928,63 & 717,97 & 787,83 & 999,67 & 999,69 & - & - & $\cdot$ & $=$ \\
\hline Mineiros do Tieté & 926,85 & 945,72 & 729,26 & - & 999,62 & 999,62 & - & - & - & - \\
\hline Mira Estrola & 837,94 & 930,07 & 760,18 & - & 1000,00 & 999,32 & 614,02 & 748,55 & 705,85 & - \\
\hline Miracatu & 931.22 & 921,34 & 634.07 & 849,12 & 997,68 & 997,80 & 269,56 & 347,33 & 662,79 & 801,94 \\
\hline Mirandópolis & 923.76 & 940,35 & 767,88 & 860,93 & 999.67 & 999.52 & - & - & - & - \\
\hline Mirante do Paranapanema & 940,01 & 957,07 & 721,14 & 808,02 & 999,73 & 999,89 & 697,19 & $\cdot$ & 735,49 & - \\
\hline Mirassol & 946,21 & 945,19 & 793,82 & 863,68 & 999,72 & 999.71 & $\cdot$ & $\cdot$ & $\cdot$ & • \\
\hline Mirassolândia & 916,79 & 931,95 & $\cdot$ & 856,37 & 1000,00 & 1000,00 & $\cdot$ & - & - & $\cdot$ \\
\hline Mococa & 931,39 & 932,71 & 774,54 & 862,29 & 999,73 & 999,55 & 855,41 & 892,03 & 774,02 & 840,03 \\
\hline Mogi das Cruzes & 916,17 & 845,23 & 776,87 & 831,12 & 999,45 & 999,17 & - & - & $\cdots$ & - \\
\hline Mogl Guaçu & 921,56 & 955,55 & 772,38 & 850,15 & 999,44 & 999.51 & 1000,00 & - & 768.74 & - \\
\hline Moji Mirim & 931,21 & 937,80 & 736,45 & 813,04 & 999,47 & 999,40 & - & - & $\cdot$ & - \\
\hline Mombuce & 931,21 & 944.25 & 810.41 & 808,24 & $\infty 00,30$ & 909,37 & - & 539,78 & - & 796,21 \\
\hline Monçס̄es & 916,97 & 888,80 & 777,63 & $\cdot$ & 1000,00 & 1000,00 & 506,71 & 759,04 & 761,20 & $\cdot$ \\
\hline Mongague & 911,90 & 936,26 & 735,67 & 761,25 & 999.17 & 999,08 & - & - & - & - \\
\hline Monte Alegre do Sul & 941,43 & 929,15 & 695,68 & 799,65 & 999,67 & 998,48 & $\cdot$ & $\cdot$ & - & - \\
\hline Monte Alto & 930,56 & 949,31 & 739,96 & 828,77 & 999,40 & 999,56 & 934,27 & 948,33 & 748,82 & 824,37 \\
\hline Monte Aprazivel & 940,61 & 950.51 & 783,32 & 842.72 & 999.67 & 999,86 & 779,26 & 878.67 & 783.31 & 835,31 \\
\hline Monte Azul Paulista & 924,50 & 924,76 & 801,32 & 879,06 & 999,49 & 999,23 & 777,33 & $\cdot$ & 789,10 & - \\
\hline Monte Castelo & 958,80 & 959,70 & 728,98 & $\cdot$ & 1000,00 & 999,18 & 571,65 & - & 743,19 & - \\
\hline Monte Mor & 921,57 & 921,36 & 751.76 & 799,66 & 999,64 & 999.22 & - & 566,87 & - & 780,51 \\
\hline Monteiro Lobato & 912,37 & 946,04 & 738,58 & $\cdot$ & 1000,00 & 999,48 & 335,65 & 519,28 & 726.91 & $\cdot$ \\
\hline Morro Agudo & 934,15 & 920,97 & 707,65 & 833,07 & 999,45 & 999,10 & - & - & - & - \\
\hline Morungaba & 891,69 & 948,45 & 754,09 & 767.12 & 999,12 & 999,72 & 706,23 & 701,49 & 737.77 & 772,27 \\
\hline Motuca & - & 967,35 & - & - & - & 999,01 & $=$ & - & - & - \\
\hline Murutinga do Sul & 931,06 & 958,95 & 758.31 & - & 999.52 & 1000,00 & - & - & - & - \\
\hline Narandiba & 922.22 & 930.77 & 691,41 & - & 998,85 & 997.93 & 391,44 & 569,59 & 701,50 & - \\
\hline Natividade da Serra & 920.83 & 900,23 & 672.12 & $\cdot$ & 999.72 & 999,40 & 530,76 & - & 691,95 & $\cdot$ \\
\hline Naxare Paullat & 028,48 & 928,73 & 626,05 & 658,03 & $\infty \infty .01$ & 000.10 & 242,84 & - & 656,26 & $=$ \\
\hline Neves Paulista & 932,53 & 953,94 & 797,43 & 808,81 & 999,56 & 999.79 & $\cdot$ & - & • & $\cdot$ \\
\hline Nhandeara & 950,59 & 943,15 & 869,14 & 881,94 & 899,61 & 999,82 & 667,53 & 787,89 & 849,58 & 858,08 \\
\hline
\end{tabular}


Tabela 1. Índice de Desenvolvimento Municipal - IDM - municipios do Estado de São Paulo - 1991 e 1996.

\begin{tabular}{|c|c|c|c|c|c|c|c|c|c|c|}
\hline \multirow[b]{2}{*}{ Município } & \multicolumn{2}{|c|}{$\begin{array}{l}\text { IDM } \\
\text { Saúde }\end{array}$} & \multicolumn{2}{|c|}{$\begin{array}{c}\text { IDM } \\
\text { Educação }\end{array}$} & \multicolumn{2}{|c|}{$\begin{array}{c}\text { IDM } \\
\text { Segurança }\end{array}$} & \multicolumn{2}{|c|}{$\begin{array}{c}\text { IDM } \\
\text { Saneamento }\end{array}$} & \multicolumn{2}{|c|}{$\begin{array}{c}\text { IDM } \\
\text { GERAL }\end{array}$} \\
\hline & 1991 & 1996 & 1991 & 1996 & 1991 & 1996 & 1991 & 1996 & 1991 & 1996 \\
\hline Nipoã & 945,45 & 780,79 & 674,18 & 774,24 & 999,35 & 999,41 & 723,42 & 869,54 & 703,66 & 673,30 \\
\hline Nova Alianga & 965,32 & 976,29 & 776.15 & 850,01 & 1000,00 & 1000,00 & 772,28 & - & 785.50 & $\cdot$ \\
\hline Nova Campina & - & 861,69 & - & - & • & 999,71 & 0,00 & 253,21 & - & - \\
\hline Nova Canad Paulista & - & 928,60 & $\cdot$ & 879.98 & - & 1000,00 & 0,00 & - & $\cdot$ & - \\
\hline Nova Europa & 919,60 & 950,88 & 717.03 & 831,92 & 999,66 & 999,16 & - & - & $\cdot$ & - \\
\hline Nova Granada & 928,52 & 936,60 & 758,25 & 806,78 & 999,50 & 999,29 & 790,39 & 882,64 & 759,99 & 800,83 \\
\hline Nova Guataporanga & 964,11 & 958,72 & 766,37 & 764,18 & 999,16 & 999,14 & 448,58 & 704.28 & 767.75 & 773,08 \\
\hline Nova Independencia & 940,50 & 906,33 & 639,12 & $\cdot$ & 1000,00 & 1000,00 & $\cdot$ & • & $\cdot$ & - \\
\hline Nova Luzitảnia & 944,33 & 926,61 & 730,93 & - & 1000,00 & 1000,00 & 426,98 & 777,52 & 736.40 & - \\
\hline Nova Odessa & 940,21 & 919,37 & 821.11 & 902,55 & 999.47 & 999.15 & 880.05 & $\cdot$ & 813,47 & - \\
\hline Novais & - & 908,85 & $\cdot$ & 761,88 & $\cdot$ & 1000,00 & - & - & - & - \\
\hline Novo Horizonte & 935,16 & 948,62 & 756,39 & 816,46 & 999,52 & 999,60 & 779,23 & 874,58 & 761,09 & 813,64 \\
\hline Nuporanga & 911.54 & 934,68 & 747.09 & 777,26 & 1000,00 & 1000,00 & $\cdot$ & * & - & - \\
\hline Ocauçu & 943,74 & 914,89 & 667,44 & 826,05 & 999,58 & 1000,00 & - & - & - & - \\
\hline Óleo & 951,48 & 917,52 & 594,10 & 720,39 & 1000,00 & 999,38 & 614.61 & 628,32 & 648,38 & 725,76 \\
\hline Olimpia & 923,13 & 942,42 & 789.67 & 821,80 & 999,53 & 999.50 & - & $\bullet$ & $\therefore$ & $\therefore$ \\
\hline Onda Verde & 974,46 & 934,09 & 622,41 & 839,21 & 1000,00 & 1000,00 & 648,80 & 693,05 & 670,80 & 819,51 \\
\hline Oriente & 914,88 & 946,06 & 626,25 & 829,68 & 1000,00 & 999.14 & - & $\cdot$ & - & - \\
\hline Orindiúva & 944,28 & 961,64 & - & 838,56 & 1000,00 & 1000,00 & 728,14 & 845,86 & - & 836,19 \\
\hline Orlandia & 936,59 & 927,06 & 773,32 & 877,97 & 999,65 & 099,20 & $*$ & - & - & - \\
\hline Osasco & 909,80 & 921,02 & 758,24 & 818,72 & 998,94 & 998,86 & - & - & - & - \\
\hline Oscar Bressane & 945.71 & 957.27 & 736,72 & 957,39 & 1000,00 & 999.68 & 032,38 & 768,32 & 747,13 & 918,73 \\
\hline Osvaldo Cruz & 931.18 & 950,76 & 731,80 & 787,57 & 999.91 & 999,47 & 756,92 & 875.53 & 741,33 & 791,80 \\
\hline Ourinhos & 931,52 & 929,42 & 770.71 & 800,44 & 999.45 & 999.19 & 860,46 & * & 771.29 & $*$ \\
\hline Ouro Verde & 955,87 & 951,63 & 727,73 & - & 999.74 & 999,43 & - & $\cdot$ & - & - \\
\hline Pacaembü & 949,33 & 950,96 & 756,44 & 806,31 & 999,71 & 999,27 & 513,18 & $\cdot$ & 759,13 & - \\
\hline Palestina & 955,86 & 950,05 & 745,18 & 817,05 & 999.43 & 999.80 & - & - & $\cdot$ & - \\
\hline Palmares Paulista & 914,81 & 933,55 & 711,08 & 808,93 & 999,75 & 1000,00 & 767,70 & 889,62 & 720,71 & 801,03 \\
\hline Palmeira d'Oeste & 949,88 & 934,92 & 786,12 & 881,56 & 999,83 & 999,83 & 460,31 & 639,83 & 778,82 & 847,28 \\
\hline Palmital & 908,76 & 931,51 & 710,11 & 755,32 & 999,20 & 999,59 & $\bullet$ & $\cdot$ & $\bullet$ & 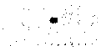 \\
\hline Panorama & 899,78 & 919,14 & 749,06 & - & 999,37 & 999,56 & 471,82 & - & 732,79 & - \\
\hline Paraguaçu Paulista & 919,75 & 939,70 & 740,55 & 869,68 & 999,59 & 999,59 & - & $\cdot$ & $\cdot$ & $-\cdots$ \\
\hline Paraibuna & 899,07 & 919,32 & 691,38 & $\cdot$ & 999.03 & 999,04 & 395,58 & $\cdot$ & 693,22 & $\cdot$ \\
\hline Paraiso & 945,47 & 945,35 & 853,93 & 784,83 & 1000,00 & 999,65 & 714,04 & $\bullet$ & 837,32 & $\because$ \\
\hline Paranapanema & 923,12 & 916,73 & 701,23 & 739,19 & 999,86 & 999,62 & 477,62 & 660,90 & 710,93 & 739.11 \\
\hline Paranapua & 949,33 & 935,89 & 725,27 & 840,25 & 990,62 & 1000,00 & 435,47 & 680,93 & 734,03 & 820,80 \\
\hline Parapuã & 968.71 & 935,85 & 700,26 & 801,88 & 999,84 & 998,17 & 562,13 & 746,51 & 723,67 & 794,49 \\
\hline Pardinho & 932,69 & 904,68 & 668,43 & 780,00 & 999,47 & 909,50 & 578,99 & 628,70 & 693,94 & 780,79 \\
\hline Pariquera-Açu & 931,77 & 884,70 & 706,96 & 796,86 & 999,45 & 999,51 & 416,46 & 475,30 & 715,75 & 753,91 \\
\hline Parial & $\cdot$ & 912.26 & $\cdot$ & 776,39 & $\cdot$ & 1000.00 & $\cdot$ & - & $\cdot$ & $\cdot$ \\
\hline Patrocínio Paulista & 938,41 & 956.28 & 638,50 & 720,60 & 1000.00 & 999,83 & 840,29 & $\cdot$ & 678,40 & $\cdot$ \\
\hline Paulicêtia & 930,33 & 885,79 & - & - & 999,12 & 999,47 & $\cdot$ & $\cdot$ & $\therefore$ & $\therefore$ \\
\hline Paulinia & 939,32 & 941,39 & 751,26 & 837,88 & 999,33 & 999,56 & $\cdot$ & 756.23 & • & 824,41 \\
\hline Paulo do Faria & 946,79 & 925.90 & 794,16 & 852,60 & 999,56 & 999,39 & 803,62 & 889,66 & 794,44 & 828,46 \\
\hline Pederneiras & 944,55 & 924.42 & 716,46 & 778,60 & 999.13 & 999,50 & 763,56 & 933,46 & 734,50 & 774,46 \\
\hline
\end{tabular}


Tabela 1. Índice de Desenvolvimento Municipal - IDM - municipios do Estado de São Paulo - 1991 e 1996.

\begin{tabular}{|c|c|c|c|c|c|c|c|c|c|c|}
\hline \multirow[b]{2}{*}{ Município } & \multicolumn{2}{|c|}{$\begin{array}{l}\text { IDM } \\
\text { Saúde }\end{array}$} & \multicolumn{2}{|c|}{$\begin{array}{c}\text { IDM } \\
\text { Educação }\end{array}$} & \multicolumn{2}{|c|}{$\begin{array}{c}\text { IDM } \\
\text { Segurança }\end{array}$} & \multicolumn{2}{|c|}{$\begin{array}{c}\text { IDM } \\
\text { Saneamento }\end{array}$} & \multicolumn{2}{|c|}{$\begin{array}{c}\text { IDM } \\
\text { GERAL }\end{array}$} \\
\hline & 1991 & 1996 & 1991 & 1996 & 1991 & 1996 & 1991 & 1996 & 1991 & 1996 \\
\hline Pedra Bela & 938,02 & 910,87 & 703,48 & 784,75 & 1000,00 & 1000,00 & 141,00 & . & 704,55 & - \\
\hline Pedranópolis & 915,50 & 892,40 & 756,42 & 833,57 & 1000,00 & 1000,00 & 538,19 & 617,90 & 747,21 & 785,78 \\
\hline Pedregulho & 929,40 & 942,02 & 649,56 & $\cdot$ & 999,34 & 998,74 & 660,86 & 707,21 & 681,70 & $\cdot$ \\
\hline Pedreira & 940,81 & 941,58 & 759,58 & 784,09 & 999,85 & 999,68 & $\cdot$ & - & $\because$ & - \\
\hline Podrinhas Paulista & - & 944,25 & - & 894,31 & - & 1000,00 & 0,00 & 838,78 & - & 870,24 \\
\hline Pedro de Toledo & 888,66 & 931,28 & 665,06 & 794,62 & 999,53 & 999,24 & 413,12 & 555,69 & 673,07 & 781.44 \\
\hline Penápolis & 931,04 & 941,66 & 734,08 & 776,87 & 998,50 & 999,43 & 865,88 & $\cdot$ & 744,26 & - \\
\hline Pereira Barroto & 940,91 & 936,10 & 813,23 & 852,22 & 999,33 & 999,55 & 474,94 & $\because$ & 795,51 & $\cdot$ \\
\hline Pereiras & 887,51 & 906,21 & 775,25 & 826,67 & 999,18 & 999,33 & 720,87 & - & 749,18 & $\cdot$ \\
\hline Peruibe & 922,65 & 929.76 & 696,77 & 754,32 & 999,00 & 999,18 & 407,21 & 428,18 & 705,69 & 747.93 \\
\hline Piacalu & 907,62 & 939,12 & 743,79 & 881,51 & 1000,00 & 999,21 & 556,29 & 786,40 & 735,62 & 855.95 \\
\hline Piedade & 900,63 & 895,52 & 767,60 & 804,73 & 999,64 & 997,64 & 294,39 & 385,99 & 738,08 & 761,76 \\
\hline Pilar do Sul & 917.76 & 902,23 & 743,64 & 802,37 & 999.58 & 999.23 & 586.79 & 607,80 & 740.85 & 772,79 \\
\hline Pindamonhangaba & 921,97 & 920,87 & 744,74 & 793,89 & 999,27 & 999,52 & 736,81 & 836,11 & 746,69 & 782,81 \\
\hline Pindorama & 930,63 & 941,50 & 735,84 & 810,60 & 999,85 & 999,55 & - & $\cdot$ & - & - \\
\hline Pinhalzinho & 935,82 & 913,01 & 628,36 & 837,16 & 999,39 & 999,24 & 370,99 & 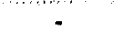 & 663,01 & - \\
\hline Piquerobi & 937,97 & 931,96 & 805,30 & - & 1000,00 & 1000,00 & 505,64 & 575,35 & 790,01 & $\cdot$ \\
\hline Piquete & 909,96 & 916,14 & 676,54 & 762,89 & 1000,00 & 999,52 & 648,35 & $\cdot$ & 693,62 & - \\
\hline Piracaia & 893,75 & 904,12 & 693,91 & 741,78 & 999,44 & 998,96 & 563,53 & - & 696,96 & - \\
\hline Piracicaba & 929,05 & 932.74 & 753,40 & 829,50 & 999.56 & 999,50 & - & $\because$ & - & $\because$ \\
\hline Piraju & 920,05 & 919,30 & 701,98 & 768,37 & 999,75 & 999,25 & 716,61 & 864,17 & 715,64 & 764,09 \\
\hline Pirajui & 915,86 & 904,61 & 782,96 & 891,58 & 999,57 & 999,59 & $\cdot$ & - & $\cdot$ & - \\
\hline Pirangl & 953,31 & 956,35 & $\cdot$ & $\cdot$ & 999,34 & 999,45 & $\cdot$ & - & $\cdot$ & • \\
\hline Pirapora do Bom Jesus & 899,30 & 940,45 & 558,45 & $\cdot$ & 999,49 & 999,05 & $\therefore$ & $\because$ & $\cdot$ & $\cdot$ \\
\hline Pirapozinho & 939,82 & 949,48 & 748,81 & 828,80 & 999,64 & 999,49 & 609,53 & 803,91 & 753,55 & 822,51 \\
\hline Pirassununga & 941,59 & 933,91 & 762,31 & 835.75 & 999.63 & 999.44 & 941.53 & $\therefore$ & 769.56 & $\cdot$ \\
\hline Piratininga & 918.23 & 914,35 & 816,63 & 906,48 & 999,23 & 999.64 & 751.49 & 829,38 & 795,87 & 852,09 \\
\hline Pitangueiras & 936,67 & 935,41 & 708,84 & 779,40 & 999,61 & 999,30 & 673,57 & $-\cdots$ & 725,19 & - \\
\hline Planalto & 952,16 & 893,36 & 712,30 & 648,24 & 999,48 & 999,50 & 514,08 & 841,43 & 727,96 & 671,26 \\
\hline Platina & 891,44 & 955,87 & 533,38 & 664,20 & 996,16 & 999,36 & 352,28 & 708,73 & 593,56 & 698,49 \\
\hline Póá & 918,34 & 910,03 & 792,30 & 926,18 & 999,21 & 999,36 & 655,55 & $\therefore$ & 776,64 & $\cdot$ \\
\hline Poloni & 941,57 & 949,24 & 727,60 & 888,26 & 999,60 & 999,23 & 824,99 & 906,23 & 742,63 & 870,64 \\
\hline Pomptia & 913,90 & 927,64 & 787,94 & 875,92 & 999,46 & 999,28 & $\cdot$ & - & - & - \\
\hline Pongaí & 918,89 & 947,70 & 775.50 & 821,40 & 1000,00 & 1000,00 & 727,39 & 745,08 & 766.88 & 814.57 \\
\hline Pontal & 923,66 & 927,01 & 701,94 & 789,17 & 999,28 & 999,35 & - & $\cdot$ & - & $\because$ \\
\hline Pontalinda & - & 914,93 & $\because$ & 915,35 & $\cdot$ & 999,47 & - & 429,32 & - & 837,69 \\
\hline Pontes Gestal & 967,35 & 945,92 & 696,10 & $\cdot$ & 1000,00 & 1000,00 & 694,38 & 867,60 & 723,26 & $\cdot$ \\
\hline Populina & 930,15 & 941,17 & 699.47 & 784,21 & 1000,00 & 1000,00 & 566,14 & 717,83 & 714,30 & 782,92 \\
\hline Porangaba & 901,24 & 920.18 & 728,51 & 850,29 & 998,71 & 999,12 & • & 658,27 & : & 817,27 \\
\hline Porto Feliz & 915,69 & 917,04 & 714,10 & 819,28 & 999,75 & 999,60 & 777,01 & 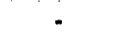 & 723,26 & - \\
\hline Porto Forroira & 934.70 & 931.58 & 747.57 & 849,31 & 999,31 & 999,49 & 839,67 & - & 755.22 & $\cdot$ \\
\hline Potim & - & 924,01 & - & 808,05 & 0.00 & 999,66 & - & $\because$ & $\therefore$ & - \\
\hline Potirendaba & 945,44 & 947.97 & 745,33 & 836,16 & 999,84 & 999,71 & 618,34 & $\cdot$ & 753,04 & - \\
\hline Pradópolis & 932,62 & 932,12 & 765,11 & 786,54 & 999,82 & 999,37 & - & - & - & $\cdot$ \\
\hline Prala Grande & 918,67 & 912,87 & 788,80 & 835,73 & 999,00 & 998,95 & 982,78 & 1000,00 & 779,08 & 808,44 \\
\hline
\end{tabular}


Tabela 1. Índice de Desenvolvimento Municipal - IDM - municípios do Estado de São Paulo - 1991 e 1996.

\begin{tabular}{|c|c|c|c|c|c|c|c|c|c|c|}
\hline \multirow[b]{2}{*}{ Municipio } & \multicolumn{2}{|c|}{$\begin{array}{l}\text { IDM } \\
\text { Saúde }\end{array}$} & \multicolumn{2}{|c|}{$\begin{array}{c}\text { IDM } \\
\text { Educação }\end{array}$} & \multicolumn{2}{|c|}{$\begin{array}{c}\text { IDM } \\
\text { Segurança }\end{array}$} & \multicolumn{2}{|c|}{$\begin{array}{c}\mathrm{IDM} \\
\text { Saneamento }\end{array}$} & \multicolumn{2}{|c|}{$\begin{array}{c}\text { IDM } \\
\text { GERAL }\end{array}$} \\
\hline & 1991 & 1996 & 1991 & 1996 & 1991 & 1996 & 1991 & 1996 & 1991 & 1996 \\
\hline Presidente Alves & 892,50 & 932,22 & 640,02 & - & 999,20 & 999,59 & 712,67 & 847,84 & 664,46 & - \\
\hline Presidente Bernardes & 939,42 & 931,99 & 717.51 & 870,31 & 999,73 & 999,10 & 502,56 & 746,97 & 728.01 & 841,90 \\
\hline Presidente Epitácio & 897,07 & 875,24 & 848,54 & 803,92 & 999,68 & 999,72 & 440,62 & 508,08 & 790,60 & 752,80 \\
\hline Presidente Prudente & 940,98 & 932.48 & 710.17 & 805.54 & 999,39 & 999,53 & 801,17 & 958.42 & 729,39 & 798.43 \\
\hline Presidente Venceslau & 931,06 & 946,83 & 781,41 & 760,94 & 999,68 & 999,43 & - & $\cdot$ & - & 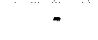 \\
\hline Promissão & 936,24 & 916,77 & 785,63 & 779,73 & 999,71 & 999,42 & - & - & $\bullet$ & - \\
\hline Quatá & 942,52 & 920,48 & 717,92 & 850,13 & 999,84 & 999,65 & 663,30 & 863,50 & 733,23 & 822,62 \\
\hline Queiroz & 838,47 & 919,62 & 658,45 & 796,37 & 999,07 & 999,11 & 480,75 & 837,73 & 647,92 & 783,93 \\
\hline Queluz & 929,48 & 899,01 & 761,26 & $\cdot$ & 999,06 & 997,62 & 654,57 & 702,70 & 759,86 & - \\
\hline Quintana & 952,50 & 931,20 & 713.48 & 844,38 & 999,65 & 999,32 & - & - & - & $=$ \\
\hline Rafard & 926,34 & 939,53 & 689.71 & 822.93 & 1000,00 & 999,52 & - & - & $\cdot$ & - \\
\hline Rancharia & 915,95 & 901,49 & 759,35 & - & 999,66 & 999,06 & - & - & $=$ & - \\
\hline Redenção da Serra & 806,69 & 950,89 & 585,70 & - & 998.98 & 999.55 & 310,63 & 330,37 & 590.77 & - \\
\hline Regente Feijo & 922,43 & 957,34 & 689,84 & 779,51 & 999,56 & 999,44 & 706,64 & 851,03 & 707,91 & 787,29 \\
\hline Reginópolis & 915.10 & 902,68 & 776,48 & 783,77 & 1000,00 & 999,15 & 607,17 & - & 762,73 & - \\
\hline Registro & 913,49 & 923,17 & 702.17 & 862,27 & 999,30 & 998,99 & 445,60 & 627,43 & 707,24 & 825,96 \\
\hline Restinga & 937,98 & 893,35 & 595,55 & - & 1000,00 & 998.92 & 639,10 & 767,06 & 647,34 & - \\
\hline Ribelra & 907,54 & 921.70 & 659,78 & - & 999,11 & 999.52 & 146,00 & 278,44 & 668,23 & - \\
\hline Ribeirão Bonito & 951,21 & 949.14 & 703,80 & 844,33 & 999,82 & 1000,00 & $\cdot$ & - & - & - \\
\hline Ribeiråo Branco & 829,03 & 870,13 & 580.74 & $:$ & 999,82 & 999,63 & 230,89 & 316,70 & 596,20 & $\cdot$ \\
\hline Ribeirão Corrente & 889,35 & 902,22 & 681,47 & - & 1000,00 & 1000,00 & 684,52 & 785,14 & 689,31 & $\cdot$ \\
\hline Ribeirão do Sul & 967,57 & 918,24 & 643.79 & 832,46 & 1000,00 & 1000,00 & 599,27 & 633,40 & 684,05 & 803,31 \\
\hline Ribeirão Grande & - & 917,99 & - & 819,64 & - & 999,62 & 0,00 & 367,18 & - & 783,10 \\
\hline Ribeiråo Pires & 921.09 & 929.03 & 776,96 & 829,45 & 999,21 & 999,29 & 492,82 & - & 762,20 & $=$ \\
\hline Ribeirão Preto & 937.51 & 936,35 & 738,47 & 823,16 & 999,38 & 999,04 & - & - & - & - \\
\hline Rifaina & 928,39 & 891,33 & 673,97 & - & 999,12 & 998,27 & 812,69 & 950,27 & 700,10 & $\because$ \\
\hline Rincão & 898,59 & 935,63 & 726,55 & 866,37 & 999,82 & 999,30 & 824,72 & - & 724,83 & $\bullet$ \\
\hline Rinópolis & 913,05 & 944,95 & 713,05 & 798,04 & 999,64 & 999,50 & $\cdot$ & - & $\because$ & $\therefore$ \\
\hline Rio Claro & 932,74 & 930,29 & 805,81 & 838,78 & 999,34 & 999,31 & $\cdot$ & $\cdot$ & - & - \\
\hline Rio das Pedras & 930,54 & 937,60 & 778,48 & 850,89 & 999,81 & 999,57 & 1000,00 & " & 777,39 & $=$ \\
\hline Rio Grande da Serra & 928.03 & 905,18 & 709,96 & 770,67 & 999,42 & 999,04 & 292,34 & • & 712,21 & - \\
\hline Riolândia & 909,38 & 935.42 & - & 763,51 & 999,30 & 999,69 & 787,70 & 863,78 & $=$ & 767,58 \\
\hline Riversul & 918.42 & 918,60 & - & $\cdot$ & 999.42 & 999,35 & 485,80 & 588,84 & - & - \\
\hline Rosana & - & 953,86 & - & 842,99 & $\cdot$ & 999,75 & * & 279,87 & * & 809,53 \\
\hline Roseira & 924,45 & 938,78 & 748,60 & 771,36 & 999,41 & 998,76 & 842,32 & 943,36 & 751,97 & 775,37 \\
\hline Rubiácea & 889,83 & 888,09 & $\therefore$ & 805,57 & 1000,00 & 1000,00 & 417,68 & 572,34 & - & 764,62 \\
\hline Rubinéia & 949,78 & 930,17 & - & - & 1000,00 & 1000,00 & 525,12 & 700,70 & - & - \\
\hline Sabino & 940,84 & 943,20 & 748,02 & 758,85 & 1000,00 & 999,25 & - & $\therefore$ & - & - \\
\hline Sagres & 969,16 & 943,92 & - & $\cdot$ & 1000,00 & 1000,00 & 342.18 & 588,34 & - & - \\
\hline Sales & 908,64 & 931,42 & 821,98 & 793,80 & 999,52 & 998.29 & 616,35 & - & 789.75 & - \\
\hline Sales Oliveira & 950,96 & 948,97 & 771,02 & 872,75 & 999,66 & 998,95 & - & - & - & - \\
\hline Salesópolis & 911,97 & 898,57 & 747,63 & 834,26 & 999,19 & 999,43 & 470,84 & - & 737,56 & - \\
\hline Salmourão & 892,43 & 921,56 & 680,49 & $\cdot$ & 999,60 & 999,59 & 388,81 & 612,96 & 683,51 & - \\
\hline Saltinho & 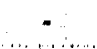 & 938,81 & - & 878,94 & - & 999,27 & - & - & - & - \\
\hline Salto & 931,68 & 932,06 & 753,89 & 843,91 & 999,54 & 999,43 & - & - & - & - \\
\hline
\end{tabular}


Tabela 1. Indice de Desenvolvimento Municipal - IDM - municipios do Estado de São Paulo - 1991 e 1996.

\begin{tabular}{|c|c|c|c|c|c|c|c|c|c|c|}
\hline \multirow[b]{2}{*}{ Município } & \multicolumn{2}{|c|}{$\begin{array}{l}\text { IDM } \\
\text { Saúde }\end{array}$} & \multicolumn{2}{|c|}{$\begin{array}{c}\text { IDM } \\
\text { Educação }\end{array}$} & \multicolumn{2}{|c|}{$\begin{array}{c}\text { IDM } \\
\text { Segurança }\end{array}$} & \multicolumn{2}{|c|}{$\begin{array}{c}\text { IDM } \\
\text { Saneamento }\end{array}$} & \multicolumn{2}{|c|}{$\begin{array}{c}\text { IDM } \\
\text { GERAL }\end{array}$} \\
\hline & 1991 & 1996 & 1991 & 1996 & 1991 & 1996 & 1991 & 1996 & 1991 & 1996 \\
\hline Salto da Pirapóra & 914,89 & 923,40 & 786,56 & 838,20 & 999,74 & 999,45 & 690,82 & 765,16 & 771,75 & 814,39 \\
\hline Salto Grande & 929,73 & 893,56 & 701,78 & 800,14 & 999,53 & 999.68 & - & - & - & - \\
\hline Sandovalina & 938,33 & 891,61 & 728,85 & 727,52 & 999,25 & 999,35 & - & - & - & - \\
\hline Santa Adélia & 949,07 & 915,71 & 701,00 & 751,76 & 999,71 & 999,45 & 254,57 & - & 710,40 & - \\
\hline Santa Albertina & 928,33 & 959,55 & 708,92 & 831,46 & 999,69 & 1000,00 & 440,24 & 712,73 & 716,76 & 826,27 \\
\hline Santa Barbara d'Oeste & 938,37 & 939,70 & 805,90 & 873,76 & 999,70 & 999,45 & - & - & - & - \\
\hline Santa Branca & 913,76 & 923,51 & - & $\bullet$ & 999,44 & 999,11 & - & - & - & - \\
\hline Santa Clara d'Oeste & 973,33 & 922,47 & 825,92 & 746,80 & 999,28 & 1000,00 & 367,95 & 589,10 & 809,36 & 745,07 \\
\hline Santa Cruz da Concelçălo & 855,42 & 938,30 & 763,52 & 884,69 & 1000,00 & 999,21 & 770,94 & - & 722.23 & - \\
\hline Santa Cruz das Palmeiras & 928,15 & 943,27 & 716,78 & 857,81 & 999,51 & 999,39 & - & - & - & - \\
\hline Santa Cruz do Rio Pardo & 914,08 & 943.86 & 724,30 & 806,67 & 999,14 & 999,35 & 704,12 & 850,06 & 728.55 & 803.65 \\
\hline Santa Ernestina & 923,54 & 962,55 & - & - & 999,35 & 998,37 & 672,14 & 857,67 & - & - \\
\hline Santa Fo do Sul. & 916,50 & 944,02 & 781,24 & 857,89 & 999,50 & 999,51 & - & - & - & $\because$ \\
\hline Santa Gertrudes & 955,33 & 925,16 & 750,23 & 680,72 & 999,45 & 998,64 & - & - & - & - \\
\hline Santa Isabel & 917,01 & 890,84 & 718,28 & 765.63 & 999,32 & 999,18 & 418,07 & - & 718,39 & - \\
\hline Santa Lucia & 939,07 & 959,57 & - & 882,73 & 1000,00 & 999,43 & - & * & - & - \\
\hline Santa Maria da Serra & 943,29 & 939,41 & 678,15 & 780,23 & 999,05 & 999,43 & - & - & - & $\therefore$ \\
\hline Santa Mercedes & 930,27 & 943,79 & 835,83 & $\cdot$ & 999,40 & 1000,00 & 434,05 & 605,80 & 803,72 & - \\
\hline Santa Rita do Passa Quatro & 960,05 & 974,51 & 802,66 & 840,30 & 999,62 & 999,27 & - & - & - & $\because$ \\
\hline Santa Rita d'Oeste & 673,69 & 638,59 & 791,20 & 925,15 & 999,48 & 1000,00 & - & - & $=$ & - \\
\hline Santa Rosa do Viterbo & 946,34 & 943,17 & 738.13 & 811,22 & 999,66 & 999,60 & 983.61 & 996,67 & 752,94 & 807,95 \\
\hline Santana da Ponte Pensa & 908,46 & 977,05 & 791,63 & 914,99 & 1000,00 & 998,29 & * & $\cdot$ & 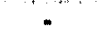 & - \\
\hline Santana de Parnalba & 892,50 & 934,08 & 684,78 & 771,95 & 999,65 & 999,32 & 346,16 & - & 684,95 & $\therefore$ \\
\hline Santo Anastacio & 931.46 & 945,62 & 755,85 & 808,20 & 999.27 & 999,43 & 725,15 & 851,51 & 758,31 & 805,60 \\
\hline Santo Andró & 933,17 & 934,41 & 797,41 & 873.61 & 999,26 & 999,10 & 1000,00 & - $\cdot$ & 792.75 & $*$ \\
\hline Santo Antonio da Alegria & 909,07 & 926,74 & 611.72 & - & 1000,00 & 999,67 & - & $\cdot$ & - & - \\
\hline Santo Antonio de Posse & 922,58 & 940.44 & 702,02 & 837,11 & 999,51 & 999,20 & - & - & - & * \\
\hline Santo Antonio do Aracanguá & $\cdot$ & 943,32 & - & 739,35 & - & 999,22 & - & - & - & - \\
\hline Santo Antonio do Jardim & 936,37 & 941,95 & 709,87 & 830,24 & 998,99 & 999,32 & 550,49 & 547.46 & 723,06 & 811,44 \\
\hline Santo Antonio do Pinhal & 937,10 & 913,02 & 629,60 & - & 1000,00 & 998,77 & 289,26 & 362,06 & 661,81 & - \\
\hline Santo Expedito & 965,32 & 943,96 & 768,66 & $*$ & 1000,00 & 999,24 & 548.13 & 690,93 & 773,54 & - \\
\hline Santópolis do Aguapei & 944,32 & 926,20 & 725,05 & 818,34 & 1000,00 & 1000,00 & 461,46 & 914,03 & 733,43 & 804,26 \\
\hline Santos & 919,79 & 925,36 & 780,90 & 875,54 & 999,45 & 999,41 & 1000,00 & 1000,00 & 774,01 & 844,67 \\
\hline Såo Bento do Sapucaí & 923,21 & 930,11 & 655,44 & 827,69 & 999,79 & 999,06 & 464,90 & 530,91 & 680,01 & 802,92 \\
\hline Salo Bernardo do Campo & 926,06 & 933,12 & 834,96 & 894,77 & 999,06 & 998,87 & $\cdot$ & - & - & - \\
\hline São Caetano do Sul & 932,91 & 935,16 & 815,61 & 852,29 & 999,39 & 999,58 & 947,78 & - & 806,15 & $\cdot$ \\
\hline S3ao Carlos & 944,38 & 943,24 & 818,18 & 850,79 & 999,55 & 999,39 . & - & $\cdot$ & 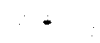 & - \\
\hline Sảo Francisco & 963,93 & 954,27 & 799,65 & 897,30 & 1000,00 & 999,33 & 368,81 & 688,84 & 788,23 & 873,33 \\
\hline São João da Boa Vista & $\$ 31,12$ & 939,47 & 799,53 & 894.14 & 999,46 & 999.56 & 885.16 & 930,11 & 792,76 & 868.20 \\
\hline Sto Joso das Duas Pontes & 954,27 & 924,97 & 815,78 & 827,98 & 999,35 & 1000,00 & 552,11 & 693,44 & 806,15 & 808,28 \\
\hline Sto Joso de Iracema & $=$ & 950,32 & - & 923,98 & - & 1000,00 & - & * & - & - \\
\hline Sảo Joảo do Pau D'Alho & 971,24 & 934,17 & 759,99 & 894,94 & 1000,00 & 1000,00 & - & $\cdot$ & - & 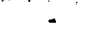 \\
\hline Săo Joaquim da Barra & 922,90 & 930.29 & 700,62 & 829,09 & 999,62 & 999,54 & 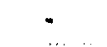 & $\cdot$ & $=$ & - \\
\hline São José da Bela Vista & 914,89 & 955,16 & 688,54 & $\cdot$ & 999,64 & 999,53 & 758,88 & - & 705,14 & $\cdot$ \\
\hline Saxo José do Barreiro & 962,48 & 906,49 & 682,42 & - & 1000,00 & 1000,00 & 563.04 & $=$ & 709,85 & - \\
\hline
\end{tabular}


Tabela 1. Índice de Desenvolvimento Municipal - IDM - municipios do Estado de São Paulo - 1991 e 1996.

$\begin{array}{ccccc}\text { IDM } & \text { IDM } & \text { IDM } & \text { IDM } & \text { IDM } \\ \text { Saúde } & \text { Educação } & \text { Segurança } & \text { Saneamento } & \text { GERAL }\end{array}$

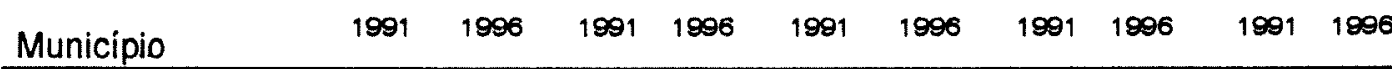

\begin{tabular}{|c|c|c|c|c|c|c|c|c|c|c|}
\hline São José do Rio Pardo & 929,51 & 937,74 & 728,67 & 816,17 & 999,73 & 999,52 & - & - & - & - \\
\hline Sao Jos6 do Rlo Preto & 938,18 & 941,02 & 744,43 & 841,48 & 999,45 & 999,41 & - & - & - & - \\
\hline São José dos Campos & 937,40 & 933,07 & 766,74 & 843,28 & 999,31 & 998,92 & 773,18 & 897.55 & 769,51 & 826,45 \\
\hline Såo Lourenço da Serra & - & 925,99 & - & $\cdot$ & - & 998,94 & - & - & - & - \\
\hline Sảo Luís do Paraitinga & 908,60 & 921,19 & 677,08 & 860,40 & 999,82 & 999.10 & 456,12 & 494,29 & 689,32 & 817,11 \\
\hline Såo Manuel & 938,58 & 931,06 & 701,31 & 788,14 & 999,59 & 999,21 & 760,36 & 890,71 & 721,78 & 784,31 \\
\hline Sāo Miguel Arcanjo & 905,92 & 912,16 & 720,36 & 735,77 & 999,71 & 999,55 & 439,27 & 532.41 & 715.99 & 731,61 \\
\hline Săo Paulo & 930,16 & 932,09 & 785,31 & 851,20 & 999,09 & 998,93 & 759,13 & 904,69 & 779,91 & 831,72 \\
\hline São Pedro & 924,67 & 935,18 & 729,23 & 703,60 & 999.51 & 999,69 & - & $\cdot$ & - & $\cdot$ \\
\hline Sto Pedro do Turvo & 934,41 & 921,99 & 808,44 & 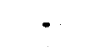 & 999,27 & 999.63 & - & $\cdot$ & $=$ & - \\
\hline Sảo Roque & 924,55 & 923,52 & 710,14 & 770,81 & 999,43 & 999,45 & 481,73 & 575,23 & 717.58 & 761,86 \\
\hline São Sebastião & 927,97 & 922,58 & 723,54 & 846,02 & 999,04 & 998,90 & 562,11 & 574,51 & 730,22 & 812,73 \\
\hline São Sebastião da Grama & 934,64 & 921,03 & 673,28 & 729,68 & 999,54 & 999,26 & - & - & - & - \\
\hline Sżo Simão & 927,73 & 944,44 & 795,14 & 779,65 & 999,70 & 999,42 & 1000,00 & $=$ & 788,39 & - \\
\hline São Vicente & 935,51 & 923,28 & 790,10 & 810,81 & 999.60 & 999,20 & 661,43 & 686,54 & 783,49 & 793,07 \\
\hline Sarapul "... & 869,52 & 900,83 & 673,43 & 757,16 & 899,72 & 999,64 & 469,29 & 592,35 & 671,33 & 746,61 \\
\hline Sarutaí & 902,27 & 940,69 & 581,81 & $\cdot$ & 1000,00 & 999,47 & 732,56 & 738,66 & 631,13 & $\cdot$ \\
\hline Sebastianópolis do Sul & 932,70 & 959,03 & 878,44 & 910,88 & 1000,00 & 997,86 & 583,74 & 701,87 & 840,92 & 886.73 \\
\hline Serra Azul & 890,05 & 912,96 & 651,34 & 736,46 & 999,12 & 999,47 & 936.30 & 1000,00 & 672,44 & 739,20 \\
\hline Serra Negra & 941.12 & 928,67 & 747,59 & 841,35 & 999.81 & 999,66 & - & - & - & $-\cdots$ \\
\hline Serrana & 939,36 & 920,72 & 747.13 & 825,93 & 999,60 & 999,14 & 908,68 & - & 757,17 & - \\
\hline Sertazozinho & 936,17 & 942,19 & 737,91 & 841.71 & 999,59 & 999,32 & 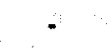 & - & $\cdots$ & $\because$ \\
\hline Sete Barras & 930,19 & 906,50 & 683,18 & $\cdot$ & 999,48 & 999,30 & 297,06 & 432,97 & 695,35 & $\cdot$ \\
\hline Soverinia & 911.72 & 942,91 & 755.96 & 861,64 & 999,82 & 999,53 & 1000,00 & $\cdot$ & 752,29 & - \\
\hline Silveiras & 937,17 & 946,93 & 696,64 & - & 999,48 & 999,50 & 291,10 & 381,18 & 705,97 & $\because$ \\
\hline Socorro & 930,30 & 927,91 & 818,47 & 827,83 & 999,21 & 999,77 & 516,62 & $\cdot$ & 796,07 & 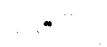 \\
\hline Sorocabe & 926.51 & 924,64 & 778,75 & 832.73 & 999.49 & 999.53 & 991.41 & - & 775.73 & - \\
\hline Sud Mennucel & 944,93 & 942,72 & 693,47 & 834,37 & 1000,00 & 998,51 & 338,13 & 731,66 & 707,48 & 821,75 \\
\hline Sumare & 934,79 & 931,20 & 749,99 & 850,84 & 999,11 & 999,08 & 460,34 & $*$ & 747,96 & - \\
\hline Suzandpolle & - & 040,80 & $\because$ & 822,16 & $\bullet$ & 1000,00 & 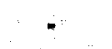 & - & $\cdots$ & + \\
\hline Suzano & 893,62 & 912,54 & 784,24 & 909,68 & 999,45 & 999,30 & 495,80 & 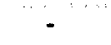 & 752,51 & - \\
\hline Tabapua & 936,51 & 924,10 & 774,31 & 874,81 & 999,07 & 999,12 & - & - & *. & - \\
\hline Tabatinga & 882,08 & 934,24 & 790,37 & 726,95 & 999,83 & 999,25 & $\cdot$ & - & - & - \\
\hline Taboso de Serra & 907,73 & 914,18 & 762,21 & 833,41 & 998,68 & 998,70 & 494,87 & - & 746,01 & - \\
\hline Taciba & 897.49 & 933,87 & 671,99 & - & 999,24 & 999,64 & 658,67 & 769,60 & 686.13 & - \\
\hline Taguaí & 887,17 & 915,76 & 699,12 & 742,67 & 999,72 & 999,74 & 694,74 & 798,37 & 699,81 & 743,50 \\
\hline Taiaçu & 878,92 & 956,56 & 738,72 & 872,00 & 1000,00 & 999,33 & - & - & - & - \\
\hline Talúva & 944,37 & 932,31 & 839.13 & 908,20 & 1000,00 & 1000,00 & - & - & $\because$ & 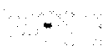 \\
\hline Tambaú & 923,37 & 933,99 & 796,35 & 864,32 & 999,44 & 999,62 & - & - & - & - \\
\hline Tanabi & 945,13 & 948,03 & - & 846,70 & 999,33 & 999,10 & - & $=$ & - & - \\
\hline Tapirai & 859.73 & 918,42 & 649,93 & 856,86 & 1000,00 & 999.09 & 419.14 & 444,09 & 651.90 & 810,40 \\
\hline Tapiratibn & 919,67 & 913,95 & 739,26 & 811,40 & 999,69 & 999,71 & - & - & - & $=$ \\
\hline Taquaritinga & 924,61 & 936.19 & 781,48 & 848,02 & 999,60 & 999,32 & - & - & - & - \\
\hline Taquarituba & 924,24 & 915,38 & 678,88 & 770,16 & 999,32 & 999,44 & 569,88 & 756,61 & 698,43 & 761,94 \\
\hline Taquarival & - & 918,75 & - & - & - & 999,52 & 0,00 & - & - & - \\
\hline
\end{tabular}


Tabela 1. Índice de Desenvolvimento Municipal - IDM - municípios do Estado de São Paulo - 1991 e 1996.

\begin{tabular}{|c|c|c|c|c|c|c|c|c|c|c|}
\hline \multirow[b]{2}{*}{ Municipio } & \multicolumn{2}{|c|}{$\begin{array}{l}\text { IDM } \\
\text { Saúde }\end{array}$} & \multicolumn{2}{|c|}{$\begin{array}{c}\text { IDM } \\
\text { Educação }\end{array}$} & \multicolumn{2}{|c|}{$\begin{array}{c}\text { IDM } \\
\text { Segurança }\end{array}$} & \multicolumn{2}{|c|}{$\begin{array}{c}\text { IDM } \\
\text { Saneamento }\end{array}$} & \multicolumn{2}{|c|}{$\begin{array}{l}\text { IDM } \\
\text { GERAL }\end{array}$} \\
\hline & 1991 & 1996 & 1991 & 1996 & 1991 & 1996 & 1991 & 1996 & 1991 & 1996 \\
\hline Tarabai & 931,78 & 968,27 & 762,68 & 757,56 & 1000,00 & 999,66 & 707,92 & 843,12 & 763,05 & 772,55 \\
\hline Tarumã & - & 908,46 & - & 740,63 & - & 999,29 & 0,00 & 787,81 & - & 738,61 \\
\hline Tatul & 925,98 & 919,64 & 698,80 & 826,98 & 999,53 & 999,56 & 786,82 & 822,43 & 716,44 & 805,35 \\
\hline Taubaté & 933,62 & 926,56 & 753,95 & 774,39 & 999,35 & 999,22 & 744,07 & 880,60 & 758,11 & 772,00 \\
\hline Tojupá & 898,36 & 874,96 & - & 803,75 & 1000,00 & 999,84 & - & - & - & - \\
\hline Teodoro Sampaio & 938,42 & 956.45 & 719,09 & 741,57 & 998,74 & 999,00 & 300,87 & 763,79 & 721,77 & 756,37 \\
\hline Terra Roxa & 930,09 & 927,36 & 800,74 & - & 999,39 & 1000,00 & 928,21 & 974,92 & 793,49 & 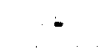 \\
\hline Tietẽ & 937,91 & 930.73 & 783,53 & 837,81 & 999,70 & 999,04 & 775,61 & - & 782,30 & - \\
\hline Timburi & 815,85 & 929,09 & 582,29 & 732,42 & 1000,00 & 999,36 & 550,58 & 721,69 & 597,17 & 740,44 \\
\hline Torre de Pedra & - & 919,73 & - & 779,96 & - & 1000,00 & - & 693,59 & - & 769,69 \\
\hline Torrinhe & 923,39 & 939,30 & 779,74 & - & 999,60 & 999,78 & * & - & - & - \\
\hline Tremembé & 904,71 & 937,32 & 691,63 & 722,48 & 999,53 & 999,36 & 811,34 & 797.59 & 703,95 & 737.21 \\
\hline Tres Frontelres & 957.43 & 869.31 & 797.55 & 856,88 & 999,29 & 999,29 & 499,91 & 809,63 & 791,31 & 704.40 \\
\hline Tuiuti & - & 960,97 & - & - & - & 1000,00 & - & $\cdot$ & - & 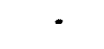 \\
\hline Tupa & 935,78 & 939,55 & 738,70 & 839,31 & 999,62 & 999,55 & - & 910,76 & - & 827.37 \\
\hline Tupi Paulista & 929,63 & 956.43 & 824,76 & 871,30 & 999,87 & 999,47 & 770,95 & • & 808,69 & - \\
\hline Turiuba & 940,62 & 965,81 & 735,23 & 925,39 & 999,13 & 999,10 & 629,74 & 787,33 & 744,46 & 906,36 \\
\hline Tumalina & 950,48 & 939,49 & 887.43 & 920,90 & 999,34 & 1000,00 & 528,33 & 739,54 & 854,68 & 880,41 \\
\hline Ubarana $\quad \cdots$ & $\cdot$ & 904,53 & $\cdot$ & 638,34 & - & 1000,00 & - & $=$ & $\cdot$ & $\because$ \\
\hline Ubatuba & 928,36 & 905,78 & 691,28 & 809,69 & 999,00 & 999,44 & 429,01 & 431,97 & 704,47 & 773,02 \\
\hline Ubirajara & 962,81 & 944,68 & 771,93 & $\cdot$ & 999,57 & 999,57 & 538,08 & 719,91 & 775,08 & $\therefore$ \\
\hline Uchỏa & 946,97 & 964,49 & 855,68 & - & 999,35 & 999,79 & - & $\cdot$ & - & - \\
\hline Uniao Paulista & 910,33 & 951,97 & 737,66 & 818,31 & 1000,00 & 998,66 & 626,43 & 770,77 & 734,50 & 814,59 \\
\hline Uränia & 932,69 & 955,22 & 776,53 & 814,64 & 999,13 & 999,41 & 560,35 & 698,35 & 769,37 & 811,02 \\
\hline Uru & 871,95 & 948,26 & $=$ & - & 1000,00 & 1000,00 & 569,13 & 754,45 & - & 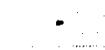 \\
\hline Urupes & 942,24 & 947.14 & 759.79 & 794,40 & 1000,00 & 999,06 & - & - & 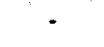 & - \\
\hline Valentim Centll & 938,83 & 242,12 & 786,54 & 814,60 & 1000,00 & 98,74 & 722,33 & 840,00 & 783,83 & 808,89 \\
\hline Valinhos & 939,92 & 941,01 & 749.10 & 818.60 & 999,62 & 999,67 & - & - & - & - \\
\hline Volparalso & 939,06 & 955,60 & 681.78 & 891,25 & 999.69 & 999.77 & - & - & - & 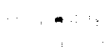 \\
\hline Vargom & - & 911.67 & - & - & - & 999,70 & - & - & - & - \\
\hline Vargem Grande do Sul & 930,26 & 935,41 & 784,58 & 758,70 & 999,31 & 999,44 & - & $\cdot$ & - & $=$ \\
\hline Vargem Grande Paulista & 908,33 & 920,30 & 702,37 & 808,68 & 999,30 & 999,10 & 352,22 & - & 702,51 & $\cdot$ \\
\hline Varzea Paulista & 932,26 & 917,06 & 760,42 & 852,01 & 999,65 & 999,41 & - & - & - & - \\
\hline Vera Cruz & 948,62 & 941,72 & 761,27 & 797,34 & 999,48 & 999,18 & - & - & - & - \\
\hline Vinhedo & 936,86 & 936,92 & 769,81 & 790,18 & 999,78 & 999,34 & - & $\cdot$ & $\cdot$ & $=$ \\
\hline Viradouro & 932.44 & 947.63 & 714,53 & 835.05 & 999,80 & 999,61 & $\cdot$ & $\cdot$ & $\cdot$ & $\cdot$ \\
\hline Vista Alegre do Alto & 933,21 & 948,02 & 779,98 & 890,43 & 999,50 & 996,99 & 848,33 & $\cdot$ & 778,76 & $\because$ \\
\hline Votorantim & 920,66 & 924,53 & 749,11 & 837,91 & 999,68 & 999,64 & 816,96 & $\cdot$ & 750,44 & $\cdot$ \\
\hline Votuporanga & 940,25 & 942,91 & 795,33 & 856,43 & 999,62 & 999,37 & - & $\cdot$ & - & - \\
\hline Zacarias & - & 979,93 & - & 869,42 & - & 999,08 & - & $\cdot$ & - & - \\
\hline
\end{tabular}

- Dado inexistente 
Tabela 2. Indicadores de Educação e Coleta de Esgoto - municípios do Estado de São Paulo - 1991 e 1996.

\begin{tabular}{cccccccc}
$\begin{array}{c}\text { Coef. } \\
\text { Matricula } \\
\text { Pré-escola }\end{array}$ & \multicolumn{2}{c}{$\begin{array}{c}\text { Coef. } \\
\text { Matrícula } \\
\text { Ensino Médio }\end{array}$} & \multicolumn{2}{c}{$\begin{array}{c}\text { Coef. } \\
\text { Evasão } \\
\text { Ensino Fund. }\end{array}$} & $\begin{array}{c}\text { Coef. } \\
\text { Evasão } \\
\text { Ensino Médio }\end{array}$ & \multicolumn{2}{c}{ Coef. } \\
Col. Esgoto
\end{tabular}

Município

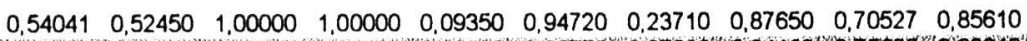

Adamantina

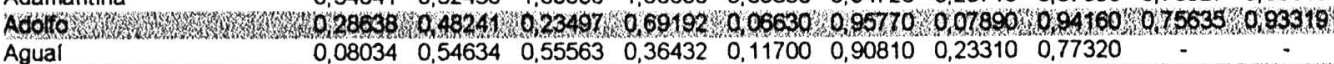

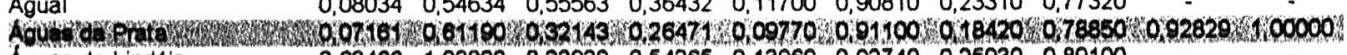

Águas de Lindoia $\begin{array}{lllllllllllll}0.62466 & 1,00000 & 0,22929 & 0,54265 & 0,13960 & 0,92740 & 0,25930 & 0,89100 & -\end{array}$

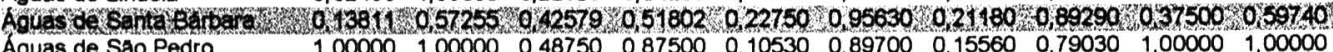

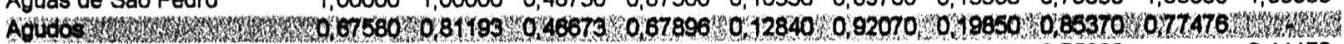

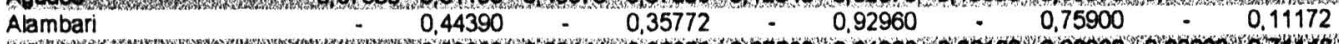
Altedo Narcondes s. $\begin{array}{llllllllllllll}\text { Altair } & 0,15385 & 0,29515 & 0,47802 & 0,58879 & 0,14840 & 0,91060 & 0,07870 & 0,89740 & 0,56164 & 0,62723\end{array}$ Alin'po:

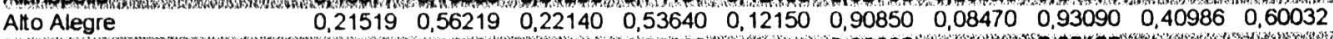
Alintho

$\begin{array}{lllllllllllllll}\text { Älvares Forence } & 0,09615 & 0,35354 & 0,50182 & 0,73801 & 0,08290 & 0,98240 & 0,17050 & 0,96510 & 0,48159 & 0.60743\end{array}$

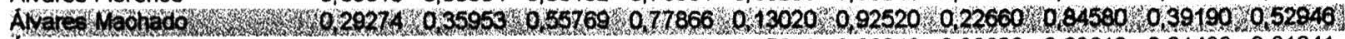

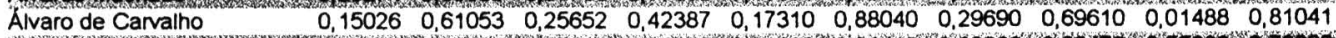

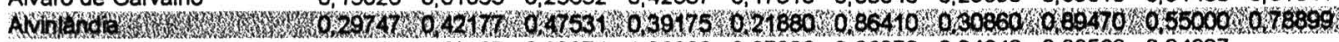
$\begin{array}{lllllllllllllll}\text { Americana } & 0,61755 & 0,59437 & 0,82974 & 1,00000 & 0.07230 & 0,96370 & 0.24640 & 0.88560 & 0.94927\end{array}$

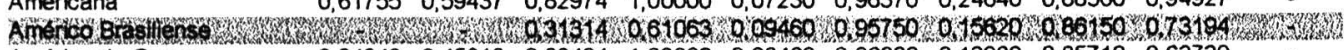
$\begin{array}{llllllllllllll}\text { Américo de Campos } & 0,24242 & 0,45818 & 0,89404 & 1,00000 & 0,08460 & 0,96000 & 0,12980 & 0,85710 & 0,63729\end{array}$

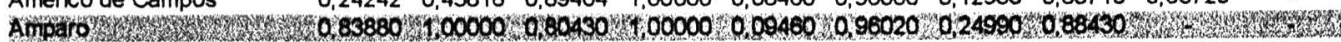
$\begin{array}{llllllllllll}\text { Analándia } & 0,25128 & 0,30583 & 0,25281 & 0,37445 & 0,14840 & 0,90600 & 0,04080 & 0,82560\end{array}$

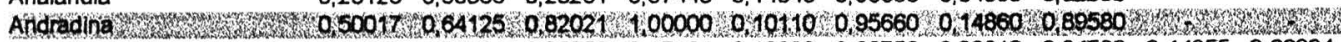
$\begin{array}{llllllllllllllllllllll}\text { Angatuba } & 0,44068 & 0,71491 & 0,28259 & 0,47164 & 0,13920 & 0,90750 & 0,23810 & 0,84580 & 0,44255 & 0,66094\end{array}$ Anhembir. $\begin{array}{llllllllllllll}\text { Anhumas } & 0,21182 & 0.25628 & 0.62827 & 0.18840 & 0,89180 & 0,37250 & 0.82790 & 0.40428 & 0.70309\end{array}$ Apareoida

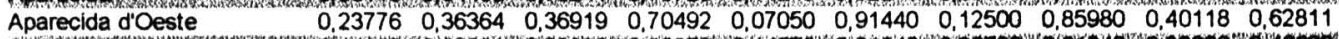

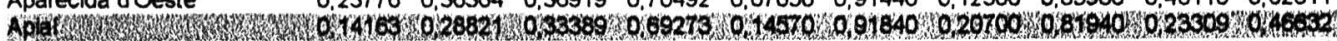
$\begin{array}{llllllll}\text { Araçariguama } & 0,38852 & - & 0,89270 & 0 & 0,83950 & 0,17635\end{array}$

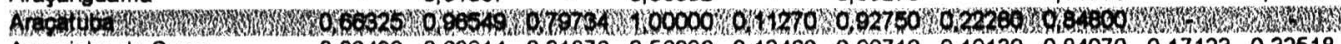

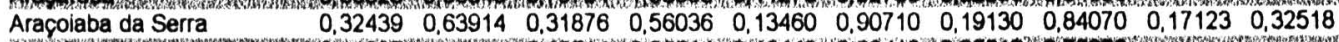

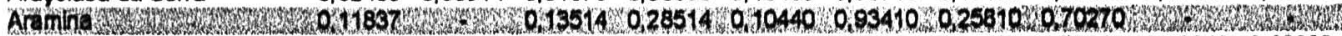
$\begin{array}{lllllllllllll}\text { Arandu } & 0,13421 & 0,21818 & 0,42090 & 0,23210 & 0,87380 & 0,22890 & 0,79290 & 0,49240 & 0,62893\end{array}$ Araper $\begin{array}{lllllllllll}\text { Araraquara } & 0,76637 & 0,95838 & 0,72136 & 0,91373 & 0,09060 & 0,93710 & 0,26410 & 0,79490 & 0,89304\end{array}$

Afalts's $\begin{array}{lllllllllllllll}\text { Arealva } & 0,18509 & 0,27411 & 0,58501 & 0,06290 & 0,97190 & 0,19510 & 0,84240 & 0,52702 & 0.69901\end{array}$ Arejas $\begin{array}{lllllllllllll}\text { Areiópolis } & 0,34878 & 0,56769 & 0,32782 & 0,45440 & 0,14920 & 0,86420 & 0,19350 & 0,72660 & 0,65172 & 0,73412\end{array}$

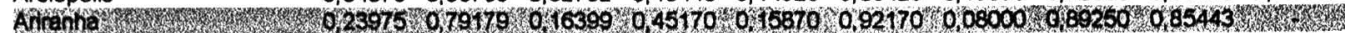

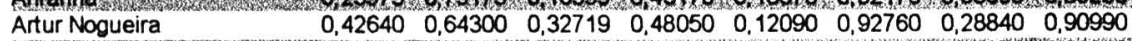
Antof Aspásia $\quad-0,67500-0,67500-0,95280 \quad-0,87950$ - 0.48182 Ass's $\begin{array}{lllllllll}\text { Atibaia } & 0,63892 & 0,79105 & 0,46135 & 0,54716 & 0,11000 & 0,90350 & 0,24430 & 0,88690\end{array}$

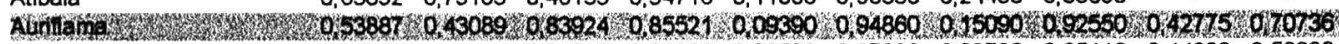

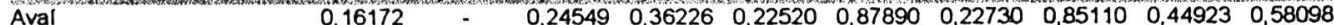
Avanhardar $\begin{array}{lllllllllllllll}\text { Avaré } & 0,71376 & 0,58480 & 0,59234 & 0.75482 & 0,12230 & 0,91680 & 0,19250 & 0,80790 & 0,80789 & 0.87345\end{array}$

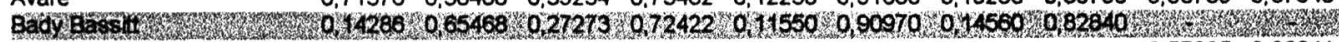

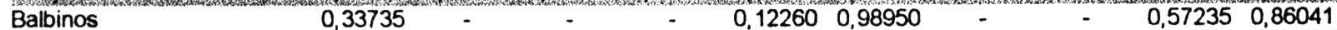

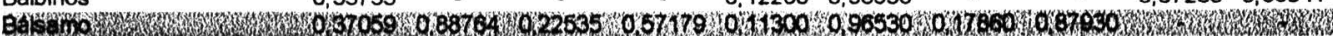

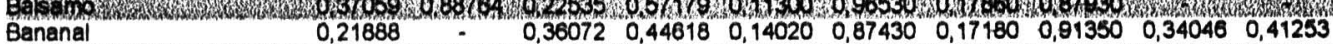

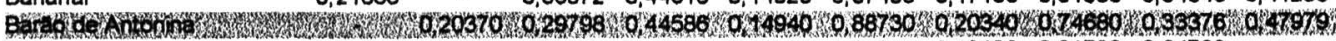
$\begin{array}{llllllllllllll}\text { Barbosa } & 0,19382 & 0,56383 & 0,36667 & 0,46407 & 0,16480 & 0,92340 & 0,12120 & 0.91720 & 0.64789\end{array}$

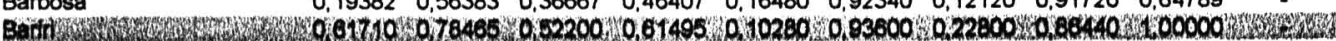
$\begin{array}{llllllllllll}\text { Barra Bonita } & 0,41902 & 0,64130 & 0,55862 & 0,70490 & 0,06870 & 0,93290 & 0,20760 & 0,77950 & 1,00000\end{array}$

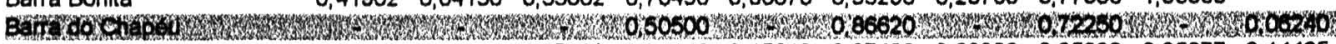

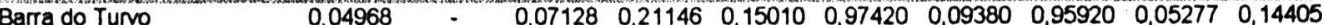
Bartery. $\begin{array}{llllllllll}\text { Barrinha } & 0,04295 \quad 0,12825 & 0,42083 & 0,12070 & 0,93230 & 0,19420 & 0,85930\end{array}$

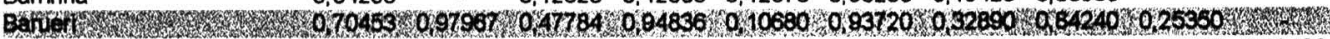
$\begin{array}{lllllllllllllll}\text { Bastos } & 0,43134 & 0,47432 & 0,44024 & 0,63170 & 0,11720 & 0,92750 & 0,24870 & 0,81340 & 0,69327 & 0,82136\end{array}$

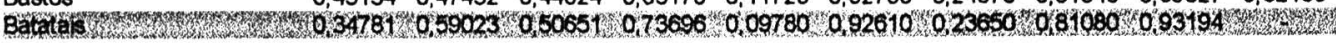


Tabela 2. Indicadores de Educação e Coleta de Esgoto - municipios do Estado de São Paulo - 1991 e 1996.

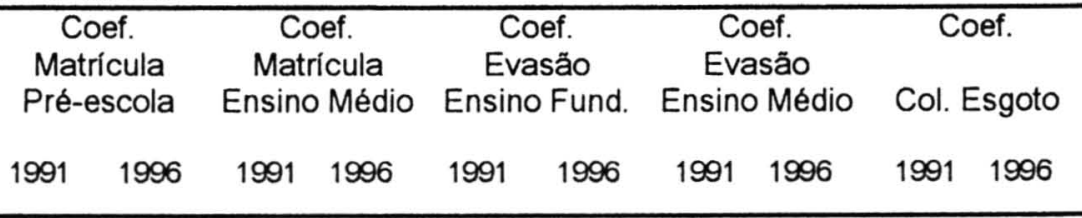

Municipio

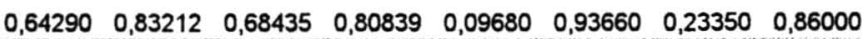

Bauru

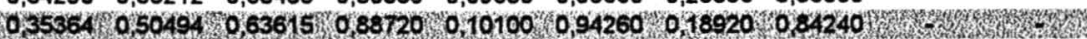

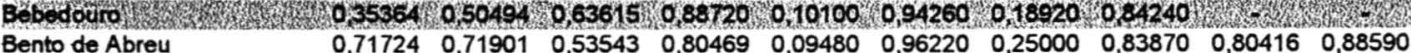

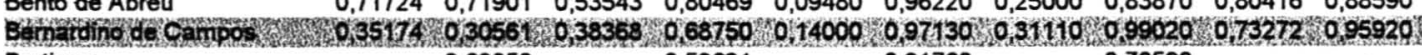
Bertioga $0,69050-0,59631-0,91760-0,70590$ Bitac $\begin{array}{llllllllll}\text { Birigui } & 0,39850 & 0,46154 & 0,54543 & 0,83608 & 0,08510 & 0,95420 & 0,19640 & 0,87910 & 0,85532\end{array}$ Blitibayim

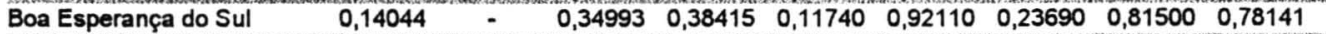

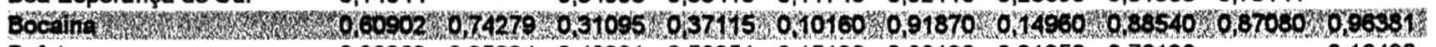
$\begin{array}{llllllllllllllllll}\text { Bofete } & 0,28362 & 0,35024 & 0,48991 & 0,50251 & 0,15190 & 0,88130 & 0,31950 & 0,76120 & - & 0,16490\end{array}$

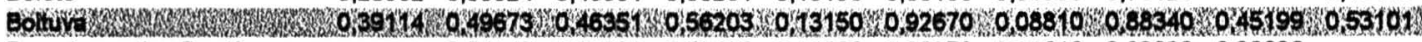

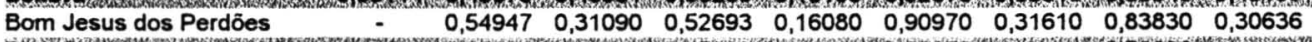

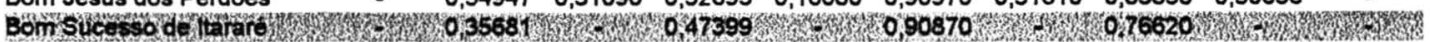
Borá $\quad 0,387760,41304 \quad-\quad-\quad 0,10700 \quad 0,99010 \quad-\quad 0,00577$

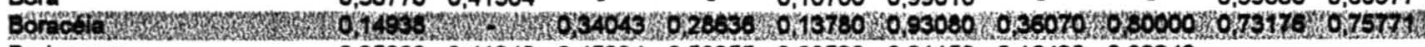
$\begin{array}{llllllllll}\text { Borborema } & 0,25000 & 0,41248 & 0,45224 & 0,58255 & 0,08520 & 0,91150 & 0,16430 & 0,82340\end{array}$

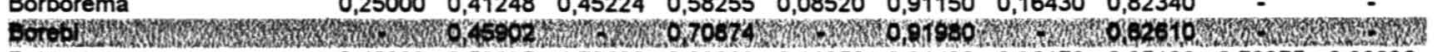
$\begin{array}{lllllllllllllllll}\text { Botucatu } & 0,46822 & 0,52897 & 0,72630 & 0,80939 & 0,11250 & 0,91430 & 0,26170 & 0,85190 & 0,79275 & 0.88036\end{array}$

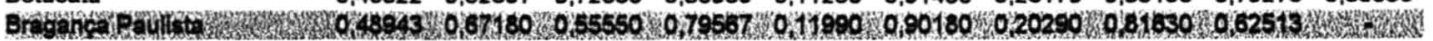
$\begin{array}{llllllllllllll}\text { Braúna } & 0,35685 & 0,51598 & 0,53285 & 0,88608 & 0,08470 & 0,91640 & 0,12240 & 0,83730 & 0,63904\end{array}$ Brodowlow

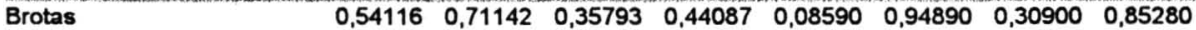

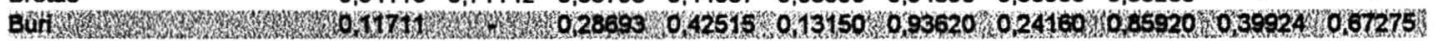
$\begin{array}{lllllllllllllllll}\text { Buritama } & 0,42169 & 0,50866 & 0,55026 & 0,80199 & 0,09330 & 0,93970 & 0,17180 & 0,83310 & 0,83227\end{array}$ Buritszf $\begin{array}{llllllllllllllllllllllll}\text { Cabrália Paulista } & 0,19065 & - & 0,60643 & 0,77891 & 0,19650 & 0,94500 & 0,17570 & 0,94710 & 0,50491\end{array}$ Cabrouram $\begin{array}{lllllllllllll}\text { Cacapava } & 0,28655 & 0,43961 & 0,50179 & 0,81790 & 0,09880 & 0,95990 & 0,34310 & 0,82120 & 0,74653 & 0,80609\end{array}$

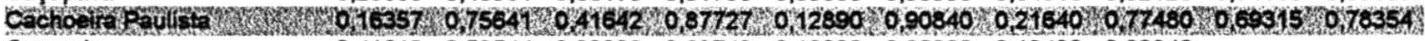
$\begin{array}{llllllllllllllll}\text { Caconde } & 0,41613 & 0,53544 & 0,33333 & 0,63742 & 0,12030 & 0,90900 & 0,19490 & 0,82840\end{array}$

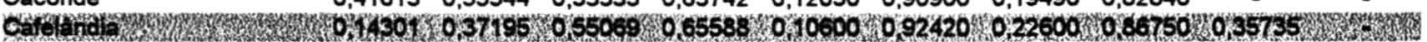
$\begin{array}{lllllllllllllllllllll}\text { Caiabu } & 0,09502 & - & 0,41538 & 0,96891 & 0,12060 & 0,94060 & 0,03810 & 0,85330 & 0,31136 & 0,53723\end{array}$

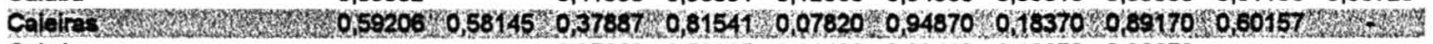

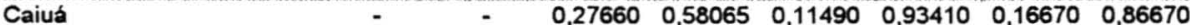

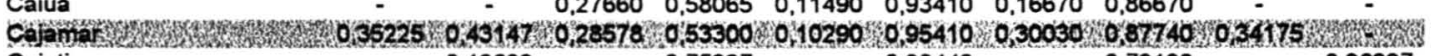
$\begin{array}{llllllllll}\text { Cajati } & -0,12693 & - & 0,75337 & - & 0,90440 & - & 0,79190 & - & 0,36327\end{array}$ Gajobs $\begin{array}{llllllllllllllllll}\text { Cajuru } & 0,49965 & 0,71741 & 0,50217 & 0,66287 & 0,12040 & 0,89160 & 0,31120 & 0,79290 & 0,70147 & 0,83296\end{array}$

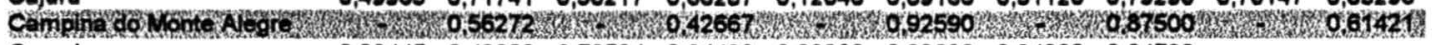
Campinas $\begin{array}{lllllllll}0,28445 & 0,49000 & 0,70584 & 0,84422 & 0,09380 & 0,93620 & 0,24220 & 0,84720\end{array}$

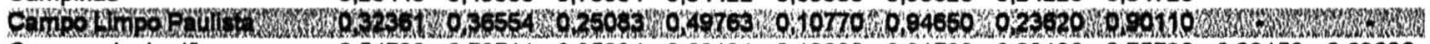
$\begin{array}{llllllllllllllllll}\text { Campos do Jordåo } & 0,54728 & 0,79711 & 0,35324 & 0,60131 & 0,13080 & 0,91720 & 0,32130 & 0,75790 & 0,39159 & 0,62606\end{array}$

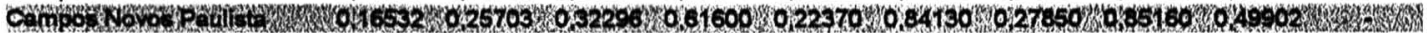
$\begin{array}{lllllllllllllllllllll}\text { Cananéia } & 0,10832 & - & 0,43302 & 0,52821 & 0,11240 & 0,90960 & 0,24230 & 0,74190 & 0,17997 & 0,33024\end{array}$

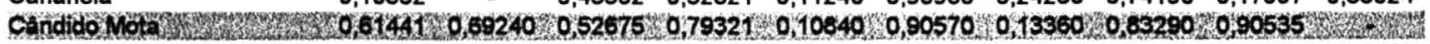

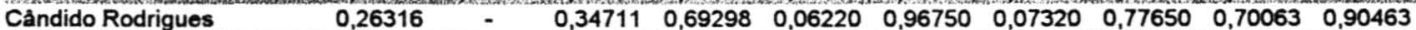

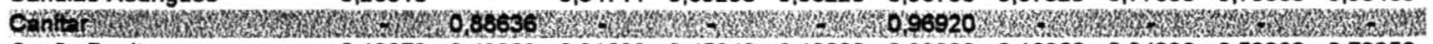
$\begin{array}{lllllllllllllll}\text { Capão Bonito } & 0,12079 & 0,49309 & 0,31688 & 0,45240 & 0,10020 & 0,93990 & 0,16960 & 0,84320 & 0,53382 & 0,72350\end{array}$ Capeza Ato Capivari $\begin{array}{llllllllll}0,54020 & 0,38483 & 0,43422 & 0,62307 & 0,10530 & 0,92090 & 0,22900 & 0,79260 & - & -\end{array}$

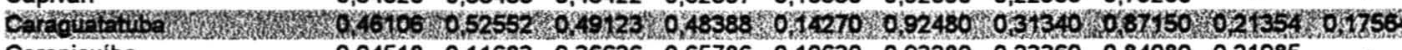

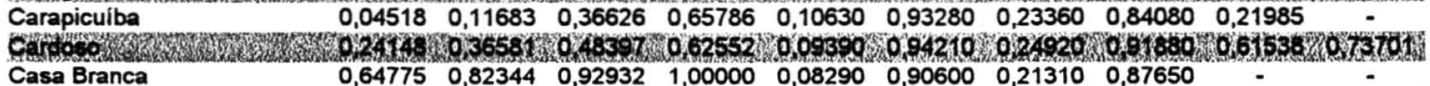

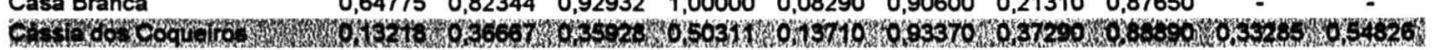
$\begin{array}{lllllllllll}\text { Castilho } & 0,45931 & 0,56069 & 0,31755 & 0,65105 & 0,11590 & 0,92020 & 0,21780 & 0,80510\end{array}$

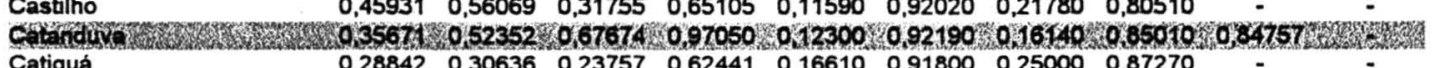
$\begin{array}{llllllllll}0,28842 & 0,30636 & 0,23757 & 0,62441 & 0,16610 & 0,91800 & 0,25000 & 0,87270\end{array}$

Codrats $\begin{array}{lllllllllllllllll}\text { Cerqueira Cesar } & 0,10349 & - & 0,60211 & 0,97716 & 0,14910 & 0,89900 & 0,13850 & 0,80910\end{array}$

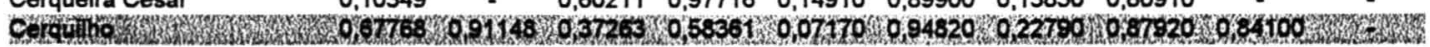
$\begin{array}{llllllllllllllll}\text { Cesario Lange } & 0,03571 & 0,46889 & 0,42746 & 0,51973 & 0,12790 & 0,95320 & 0,22910 & - & 0,49073 & 0,49311\end{array}$

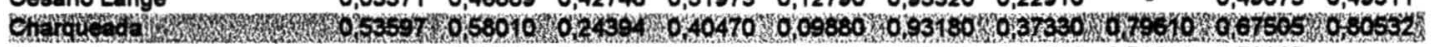

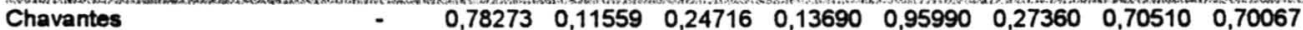

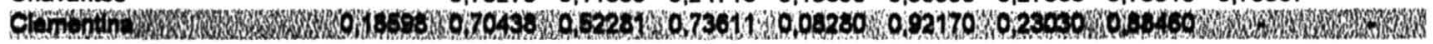


Tabela 2. Indicadores de Educação e Coleta de Esgoto - municipios do Estado de São Paulo - 1991 e 1996.

\begin{tabular}{|c|c|c|c|c|c|c|c|c|c|}
\hline \multicolumn{2}{|c|}{$\begin{array}{c}\text { Coef. } \\
\text { Matrícula } \\
\text { Pré-escola }\end{array}$} & \multicolumn{2}{|c|}{$\begin{array}{c}\text { Coef. } \\
\text { Matrícula } \\
\text { Ensino Médio }\end{array}$} & \multicolumn{2}{|c|}{$\begin{array}{c}\text { Coef. } \\
\text { Evasäo } \\
\text { Ensino Fund. }\end{array}$} & \multicolumn{2}{|c|}{$\begin{array}{c}\text { Coef. } \\
\text { Evasão } \\
\text { Ensino Médio }\end{array}$} & \multicolumn{2}{|c|}{ Coef. } \\
\hline 991 & 1996 & 1991 & 1996 & 1991 & 1996 & 1991 & 1996 & 1991 & 1996 \\
\hline
\end{tabular}

Municipio

$\begin{array}{llllllll}0,82303 & 0,41126 & 0,42682 & 0,74634 & 0,08590 & 0,94060 & 0,10470 & 0,79340\end{array}$

Colina

$\begin{array}{llllllll}0,82303 & 0,41126 & 0,42682 & 0,74634 & 0,08590 & 0,94060 & 0,10470 & 0,79340\end{array}$

Colomb

$\begin{array}{llllllllll}0,44784 & 0,47480 & 0,24493 & 0,33310 & 0,10660 & 0,92640 & 0,14960 & 0,83100 & 0,65974\end{array}$

Cond hop

Cordeiropolis

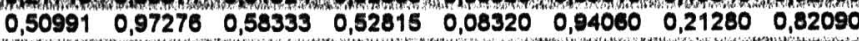

corowdoj

$\begin{array}{llllllllllllll}\text { Coronel Macodo } & - & 0,38810 & 0,28691 & 0,40857 & 0,11040 & 0,91020 & 0,21880 & 0,82640 & 0,29412 & 0,54345\end{array}$

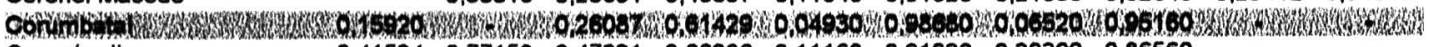

Cosmbpolis

$\begin{array}{llllllll}0,41534 & 0,77158 & 0,47021 & 0,66286 & 0,11160 & 0,91020 & 0,30300 & 0,86560\end{array}$

Cosmoma

Cotia $\begin{array}{llllllllll}0,40327 & 0,49307 & 0,51562 & 0,82909 & 0,10290 & 0,92930 & 0,23500 & 0,87870 & 0,15453\end{array}$

Crvithos

$\begin{array}{llllllllllll}\text { Cristais Paulista } & 0,05745 & - & 0,18519 & 0,40496 & 0,14300 & 0,90530 & 0,40740 & 0,83220 & 0,45397\end{array}$

craszis -

$\begin{array}{llllllll}\text { Cruzeiro } & 0,59934 & 0,67174 & 0,75532 & 0,90176 & 0,13710 & 0,90840 & 0,31600\end{array}$

Cubatow

$\begin{array}{lllllllllll}\text { Cunha } & 0,12699 & 0,26529 & 0,22866 & 0,38834 & 0,09310 & 0,93760 & 0,23820 & 0,82850\end{array}$

Doscatrado

Diadema

$\begin{array}{llllllllllll}0.44887 & 0.77646 & 0.41308 & 0.67578 & 0.09170 & 0.95110 & 0.29820 & 0.85710 & 0,37020\end{array}$

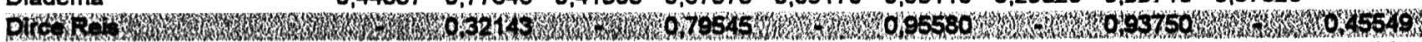

$\begin{array}{lllllllllll}\text { Divinolândia } & 0,48808 & 0,63289 & 0,26030 & 0,46884 & 0,09670 & 0,91300 & 0,87070 & 0,42748 & 0,53004\end{array}$

Dobrofarty

$\begin{array}{llllllllll}\text { Dois Córregos } & 0,11262 & 0,33194 & 0,39400 & 0,50202 & 0,08460 & 0,93120 & 0,13680 & 0,79130\end{array}$

Dolctroports

$\begin{array}{lllllllllllllllllll}\text { Dourado } & 0,29176 & 0,38073 & 0,36867 & 0,68672 & 0,08150 & 0,95680 & 0,17760 & 0,87200 & 0,84226 & 0,96080\end{array}$

Dracena - w

$\begin{array}{lllllllllll}\text { Duartina } & 0,50660 & 0,49643 & 0,62055 & 0,65683 & 0,10850 & 0,95280 & 0,25000 & 0,86410 & 0,67436\end{array}$

p) owont

$\begin{array}{llllllllllll}\text { Echaporá } & 0,32581 & 0,49292 & 0,35068 & 0,47017 & 0,18360 & 0,91700 & 0,45120 & 0,83410 & 0,50851 & 0,70526\end{array}$

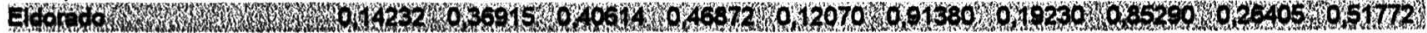

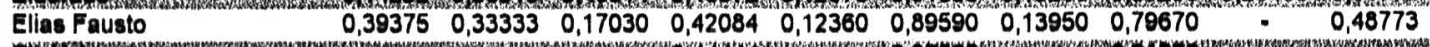

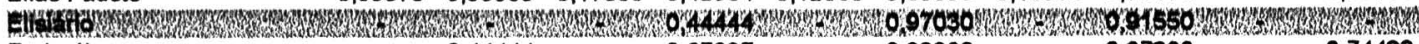

$\begin{array}{lllllllll}\text { Embaúba } & -0,44444-0,97097-0,87380 & 0,74433\end{array}$

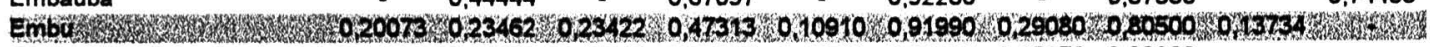

$\begin{array}{llllllll}\text { Embu-Guacu } \quad 0,41988 & 0,29302 & 0,40949 & 0,73156 & 0,10710 & 0,88290 & 0,15670 & 0,00000\end{array}$

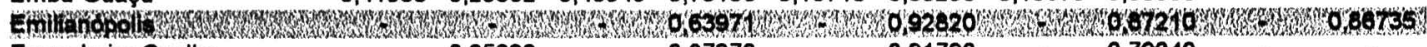

Engenheiro Coelho $\quad 0,25239-0,87370-0,91790-0,79040$

Espfito ssonto do

Espirito Santo do Turvo - $0,88646-0,60209-0,88050-0,80730-0,90229$

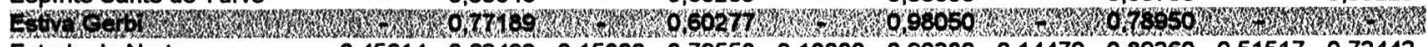

$\begin{array}{lllllllllll}\text { Estrela do Norte } & 0,45614 & 0,63492 & 0,15800 & 0,79558 & 0,10000 & 0,90380 & 0,14470 & 0,89260 & 0,51517 & 0,72442\end{array}$

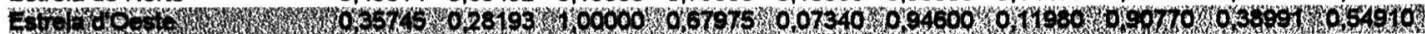

Euclides da Cunha Paulista - $0,44225-0,60693 \quad 0,89790-0,83080-0,23959$

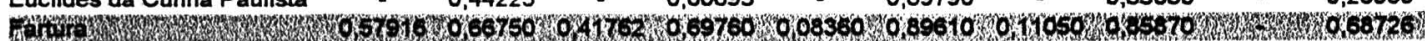

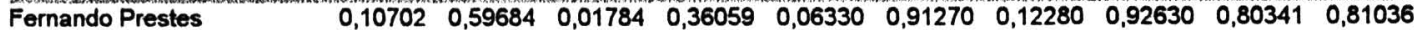

EGrinad

$\begin{array}{llllllllll}\text { Ferraz de Vasconcelos } & 0,04403 & 0,00922 & 0,36908 & 0,68466 & 0,08710 & 0,97070 & 0,20800 & 0,96980 & 0,41464\end{array}$

Hor R

$\begin{array}{lllllllllll}\text { Floreal } & 0,28877 & 0,42038 & 0,43578 & 0,81522 & 0,05680 & 0,93390 & 0,09000 & 0,88740 & - & 0,78389\end{array}$

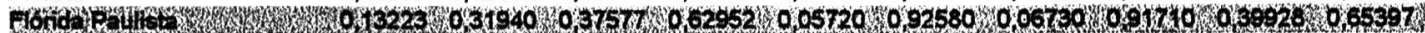

$\begin{array}{lllllllllllll}\text { Florínia } & 0,64881 & 0,73958 & 0,38542 & 0,67633 & 0,15200 & 0,91530 & 0,25350 & 0,85510 & 0,67358 & 0,85063\end{array}$

Fray

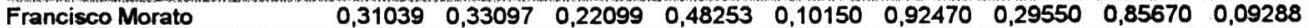

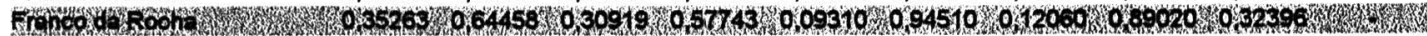

$\begin{array}{llllllllllllll}\text { Gabriel Monteiro } & 0,23140 & 0,69600 & 0,44172 & 0,76154 & 0,06040 & 0,96230 & 0,12000 & 0,95100 & 0,48706 & 0,71237\end{array}$

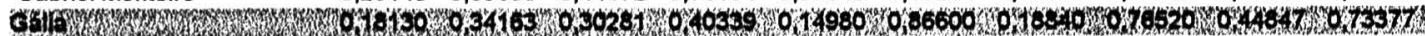

$\begin{array}{llllllllllll}\text { Garça } & 0,60733 & 0,89042 & 0,71013 & 0,99295 & 0,12790 & 0,92200 & 0,27590 & 0,85140 & 0,71718\end{array}$

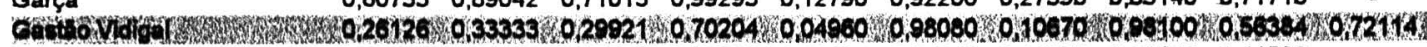

General Salgado $\quad \begin{array}{lllllllll}0,48902 & 0,61639 & 0,62760 & 0,89307 & 0,09430 & 0,94840 & 0,14970 & 0,91540 & 0,41506\end{array}$

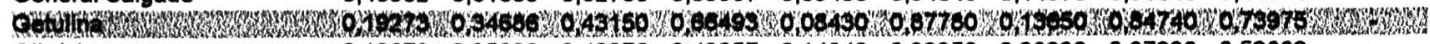

$\begin{array}{llllllllllllllll}\text { Glicério } & 0,10672 & 0,25000 & 0,40076 & 0,49057 & 0,14840 & 0,92350 & 0,38320 & 0,87220 & 0,53883\end{array}$

cintich

$\begin{array}{llllllllllll}\text { Guaimbé } & 0,17784 & 0,50325 & 0,28197 & 0,47059 & 0,14710 & 0,88360 & 0,16460 & 0,80420\end{array}$

chaprow

Guapiacu

0,10801

$\begin{array}{lllllll}0 & 19897 & 0,59649 & 0,10750 & 0,95310 & 0,33610 & 0.81570\end{array}$

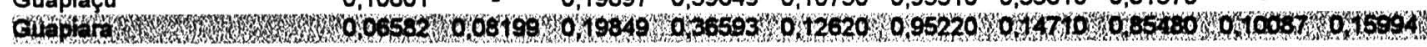


Tabela 2. Indicadores de Educação e Coleta de Esgoto - municipios do Estado de São Paulo - 1991 e 1996.

\begin{tabular}{|c|c|c|c|c|c|c|c|c|c|}
\hline \multirow[b]{2}{*}{ Municipio } & \multicolumn{2}{|c|}{$\begin{array}{c}\text { Coef. } \\
\text { Matricula } \\
\text { Pré-escola }\end{array}$} & \multicolumn{2}{|c|}{$\begin{array}{c}\text { Coef. } \\
\text { Matricula } \\
\text { Ensino Médio }\end{array}$} & \multicolumn{2}{|c|}{$\begin{array}{c}\text { Coef. } \\
\text { Evasão } \\
\text { Ensino Fund. }\end{array}$} & \multicolumn{2}{|c|}{$\begin{array}{c}\text { Coef. } \\
\text { Evasão } \\
\text { Ensino Médio }\end{array}$} & $\begin{array}{c}\text { Coef. } \\
\text { Col. Esgoto }\end{array}$ \\
\hline & 1991 & 1996 & 1901 & 1996 & 1991 & 1996 & 1991 & 1996 & $1991 \quad 1996$ \\
\hline
\end{tabular}

\begin{tabular}{|c|c|c|c|c|c|c|c|c|c|c|}
\hline $\begin{array}{l}\text { Guará } \\
\text { Guaraçal }\end{array}$ & $\begin{array}{l}0,11453 \\
0,20339\end{array}$ & 0,39865 & $\begin{array}{l}0,49708 \\
0,57647\end{array}$ & $\begin{array}{l}0,56488 \\
0,69342\end{array}$ & $\begin{array}{l}0,15070 \\
0,07250\end{array}$ & $\begin{array}{l}0,91720 \\
0,94130\end{array}$ & $\begin{array}{l}0,27510 \\
0,11380\end{array}$ & $\begin{array}{l}0,79430 \\
0,85670\end{array}$ & 0,66956 & . \\
\hline Guaraci & 0,27789 & 0,37232 & 0,45067 & 0,45143 & 0,11920 & 0,95470 & 0,19170 & 0,92620 & - & - \\
\hline i d'Oeste. & 23018 & 0,47487 & 0,39563 & 0,56054 & $0,1.1010$ & 0,94380 & $0,141,10$ & 0,93250 & 0,65094 & 0,7818 \\
\hline uarantã & 0,14493 & 0,18286 & 0.18663 & 0,27614 & 0.17220 & 0,88600 & 0,24240 & 0,85000 & & - \\
\hline pes & 43411 & 55733 & & 0,82158 & 0,07300 & 0,95520 & 0.16630 & 0,89650 & 0,76125 & \\
\hline na & 04671 & 62333 & 34237 & 0.67139 & 0,13400 & 0,90050 & 0,21830 & 0,79550 & 0,33774 & ,40198 \\
\hline Ietá & 167 & 50019 & 0.69955 & 0,99336 & .09510 & 2090 & 0,16220 & 0,85180 & - & $\approx$ \\
\hline & & 33272 & 52720 & 0.45187 & 800 & 1460 & & 0,88460 & 0,40913 & .5215 \\
\hline $\begin{array}{l}\text { uariba } \\
\text { uarujá }\end{array}$ & $\begin{array}{l}0,39811 \\
0,26286\end{array}$ & $\begin{array}{l}0,48657 \\
0,34252\end{array}$ & $\begin{array}{l}0,43157 \\
0,38623\end{array}$ & $\begin{array}{l}0.44903 \\
0.61906\end{array}$ & $\begin{array}{l}0,11930 \\
0,08990\end{array}$ & $\begin{array}{l}0,89880 \\
0,93090\end{array}$ & $\begin{array}{l}0.18800 \\
0,24150\end{array}$ & $\begin{array}{l}0,78660 \\
0,80760\end{array}$ & $\begin{array}{l}1,00000 \\
0,59853\end{array}$ & $\begin{array}{l}1,00000 \\
0,72980\end{array}$ \\
\hline hos & 0,23506 & 0,35558 & 0.50359 & 0,65989 & 0,08510 & 0,93780 & 0.18710 & 0.86290 & 0,40308 & $\cdots$ \\
\hline & 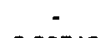 & .73028 & - & & 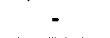 & 0,90020 & - & 0.86470 & 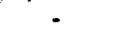 & - \\
\hline & 0,32716 & 67984 & .57188 & 429 & 0,17870 & 090 & 0,10000 & 5110 & 0,09083 & 2565 \\
\hline india &, 17802 & 22197 & 0,29336 & 0,38514 & 0,15360 & 0,93510 & 0,22560 & 0,85550 & 0,33202 & 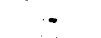 \\
\hline & $\cdot$ & 1,00000 & - & 0,60765 & - & & - & • & $\cdot$ & \\
\hline dia & - & 39162 & - & .63140 & - & & - & 0,87910 & - & - \\
\hline $\begin{array}{l}\text { lacanga } \\
\text { lacri }\end{array}$ & $\begin{array}{l}0,12077 \\
0,09302\end{array}$ & $\begin{array}{l}0,69287 \\
0,29670\end{array}$ & $\begin{array}{l}0,45011 \\
0,33696\end{array}$ & $\begin{array}{l}0,60526 \\
0.47805\end{array}$ & $\begin{array}{l}0,09280 \\
0,11390\end{array}$ & & $\begin{array}{l}0,09170 \\
0,17530\end{array}$ & & 0.53054 & 0,73161 \\
\hline 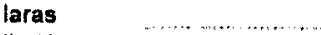 & & - & $-\ldots$ & 0,44571 & $\cdot$ & 0,84010 & - & 0,59260 & & 0,66726 \\
\hline & .02315 & 31250 & 0,26208 & & 1,07450 & & & 1990 & $\cdot$ & - \\
\hline $\begin{array}{l}\text { Ibirá } \\
\text { |birarema }\end{array}$ & & $\begin{array}{l}0.28252 \\
0,39935\end{array}$ & & & & & & 86220 & $\begin{array}{l}0.74851 \\
0.76326\end{array}$ & $\begin{array}{c}0.85397 \\
-\end{array}$ \\
\hline & & 0.58101 & & & & & & & 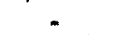 & . \\
\hline 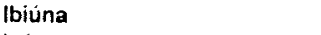 & & 26568 & 177 & & 130 & & & 0,88020 & 0,13508 & 3730 \\
\hline 6 & & 0,63014 & 525 & & & & & & 0,79779 & 91053 \\
\hline & & 0,37759 & & & & & & - & - & - \\
\hline do Tieté & & $0,49677$. & 0,34363 & 165 & 910 & & & 0,78410 & - & - \\
\hline ava & 00863 & 0,74539 & & & & & & & 0,51121 & 0,93105 \\
\hline & $-\infty$ & - & & & & & & & 0,20508 & 0,25547 \\
\hline & 07317 & 0,03054 & 0,41124 & & 12630 & & 260 & 090 & 0,27423 & 0,42823 \\
\hline mprida & & & $\cdot$ & & & & & & & \\
\hline olteira & & 77859 & & & - & & - & & - & - \\
\hline & & 93870 & & & & & & & 00589 & .0075 \\
\hline & & 52151 & & & & & & & - & - \\
\hline & & - & 593 & & & & & & $\therefore$ & - \\
\hline & & - & & & & & & &, 64805 & 708 \\
\hline Paulista & & - & & & & & & & 0888 & .77946 \\
\hline & & 25702 & & & & & & & 0,75035 & \\
\hline & & 4002 & & & & & & & 0,21539 & 24 \\
\hline Ipe & 1,00000 & 0.79487 & & & & & & & 0,70213 & - \\
\hline$g a$ & & 0,31714 & & & & & & & 0,24397 & 0,37088 \\
\hline ipu & & 76936 & & & & & & & - & - \\
\hline mápolis & & 0,75577 & & & & & & & & $=$ \\
\hline & & & & & & & & & 56753 & 773 \\
\hline & & 1595 & & & & & & & $\therefore$ & $-\cdots$ \\
\hline & & & & & & & & & 0,38487 & 0,47405 \\
\hline Itail & & - & & & & & & & 0,57086 & 0.79365 \\
\hline & & 28659 & & & & & & & & - \\
\hline Itaj & & - & & & & & & & - & - \\
\hline Itan & 0,42978 & 5122 & 52316 & & 0,11240 & & 20120 & & 0,13144 & 0.10663 \\
\hline & & & & & & & - & & & $0,1.1378$ \\
\hline Itape & & 2026 & & & & & & & & $-x_{0}$ \\
\hline & & & & & & & & & & \\
\hline & & & & & & & & & 0.54832 & 0.71907 \\
\hline Itap & 2253 & 05343 & 0,29555 & & & & & & 0,26142 & \\
\hline & & 0,60417 & 0,42441 & & 0,09210 & & 0,11460 & & - & - \\
\hline Itapi & & & & & & & & & & 2776 \\
\hline Itápolis & & & & & & & & & " & 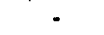 \\
\hline Itaporanga & & & & & & & & & 0.48102 & 0,58565 \\
\hline & & & & & & & & & & \\
\hline Itapura & & - & & & 340 & & 070 & & $x_{2}+2$ & - \\
\hline Itaquaqu & & & & & & & & & 4.100 & - \\
\hline & & & & & & & & & & \\
\hline & & & & & & & & & 0,22937 & \\
\hline & & & & & $0 ; 08410$ & & 590 & 0,803320 & 0,73983 & 0,8123 \\
\hline
\end{tabular}


Tabela 2. Indicadores de Educação e Coleta de Esgoto - municipios do Estado de São Paulo - 1991 e 1996.

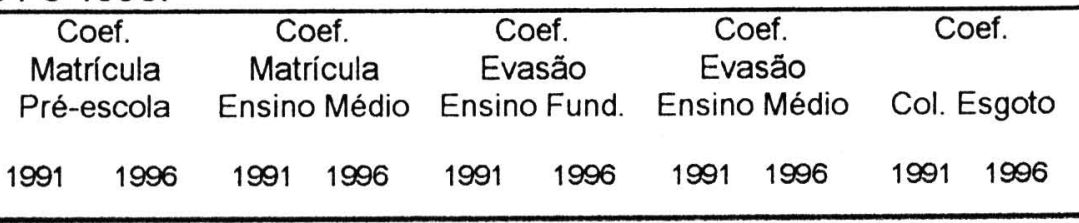

Município

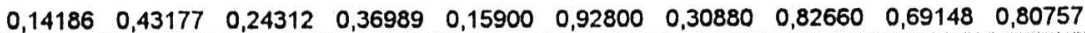

Itatinga

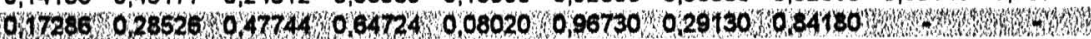

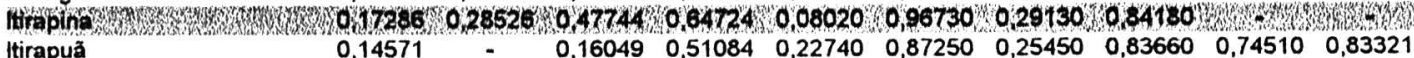

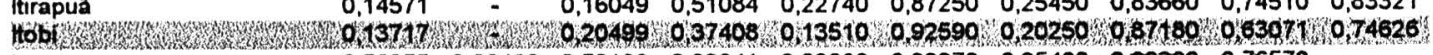
Itu $\begin{array}{llllllllll}0,56255 & 0,66466 & 0,53189 & 0,82841 & 0,09080 & 0,92270 & 0,25400 & 0,80380 & 0,76578\end{array}$ Hupeva $\begin{array}{llllllllll}\text { Ituverava } & 0,54764 & 0,82619 & 0,67408 & 0,76149 & 0,12780 & 0,91690 & 0,19390 & 0,80550\end{array}$

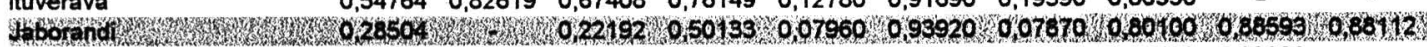
$\begin{array}{lllllllllll}\text { Jaboticabal } & 0,63989 & 0,85127 & 0,71615 & 0,95222 & 0,11470 & 0,95190 & 0,18180 & 0,84520 & 0,93223\end{array}$ Jacorf $\begin{array}{lllllllllll}\text { Jaci } & 0,37113 & - & 0,24590 & 0,45876 & 0,07910 & 0,93490 & 0,09300 & 0,97780\end{array}$

Jacuplrenga $\begin{array}{llllllllllllllllllll}\text { Jaguariúna } & 0,45951 & 0,50662 & 0,47884 & 0,72606 & 0,12810 & 0,90730 & 0,33760 & 0,91330 & 0,73875\end{array}$ gates $\begin{array}{llllllllllllll}\text { Jambeiro } & 0,57143 & 0,74074 & 0,37791 & 0,41872 & 0,19040 & 0,92210 & 0,27270 & 0,84040 & 0,39708 & 0,48610\end{array}$

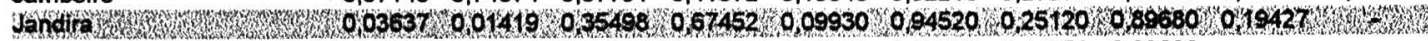
$\begin{array}{llllllllll}\text { Jardinópolis } & 0,09632 & 0,57754 & 0,38812 & 0,40612 & 0,08250 & 0,93700 & 0,11350 & 0,89030\end{array}$ Jantinus $\begin{array}{llllllllllllllll}\text { Jaú } & 0.48231 & 0,65187 & 0.80739 & 0,91114 & 0,08920 & 0,91370 & 0,17220 & 0.84210\end{array}$

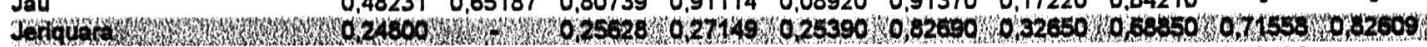
$\begin{array}{lllllllllllll}\text { Joanópolis } & 0,13320 & 0,26054 & 0,23747 & 0,42330 & 0,15080 & 0,87930 & 0,24350 & 0,76820 & 0,49436\end{array}$

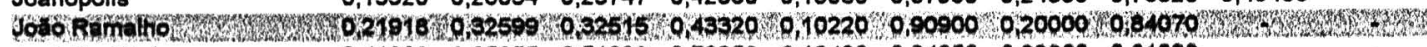
$\begin{array}{lllllllll}\text { José Bonifácio } & 0,41388 & 0,85855 & 0,51023 & 0,79359 & 0,12420 & 0,94050 & 0,23960 & 0,81030\end{array}$

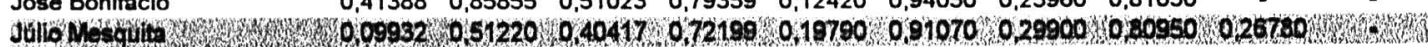
$\begin{array}{llllllllll}\text { Jundiai } & 0,39723 & 0,70059 & 0,67998 & 1,00000 & 0,08560 & 0,93480 & 0,20650 & 0,86000\end{array}$

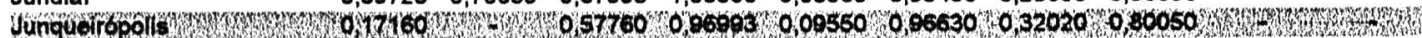
$\begin{array}{llllllllllllll}\text { Juquiá } & 0,18499 & - & 0,58474 & 0,67341 & 0,12800 & 0,93720 & 0,23360 & 0,84490 & 0,30364 & 0,36792\end{array}$

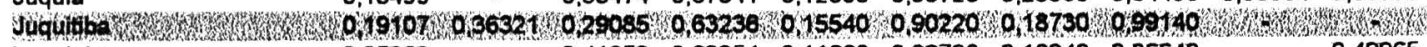
$\begin{array}{llllllllllllllllll}\text { Lagoinha } & 0,05263 & - & 0,41853 & 0,69254 & 0,11660 & 0,92790 & 0,10240 & 0,86640 & - & 0,49965\end{array}$ Laranfatpulfeth $\begin{array}{llllllllllllll}\text { Lavinia } & 0,51768 & 0,62456 & 0,79100 & 0,74834 & 0,08120 & 0,94200 & 0,22310 & 0,84720 & 0,45599\end{array}$ Lavinhas $\begin{array}{lllllllllllllll}\text { Leme } & 0,46498 & 0,55467 & 0,42143 & 0,49698 & 0,11070 & 0,94590 & 0,24020 & 0,81830 & 0,92389\end{array}$

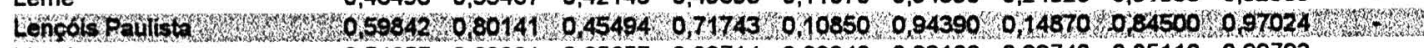
$\begin{array}{lllllllllllll}\text { Limeira } & 0,54657 & 0,63901 & 0,65657 & 0,82714 & 0,09940 & 0,93100 & 0,22740 & 0,85110 & 0,99792\end{array}$

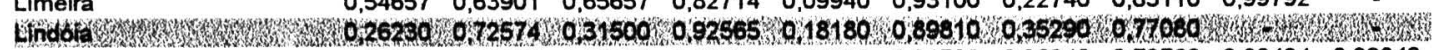
$\begin{array}{llllllllllllllll}\text { Lins } & 0,25690 & 0,64268 & 1,00000 & 1,00000 & 0,10000 & 0,91780 & 0,26340 & 0,79760 & 0,88404 & 0,99842\end{array}$

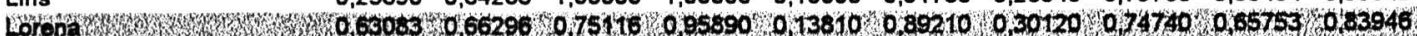
Lourdes $\quad-0,56693-0.83720 \quad-\quad 0.70240 \quad-0.73158$

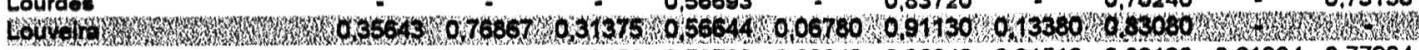
$\begin{array}{lllllllllllll}\text { Lucélia } & 0,58452 & 0,62871 & 0,62456 & 0,79780 & 0,08840 & 0,96040 & 0,21510 & 0,89130 & 0,61284 & 0,77904\end{array}$

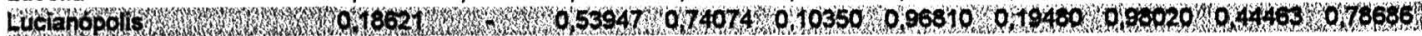
$\begin{array}{lllllllll}\text { Luis António } & 0,08043 & 0,52846 & 0,28807 & 0,88095 & 0,08260 & 0,90860 & 0,36230 & 0,78590\end{array}$

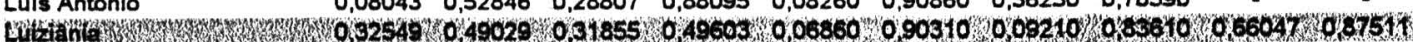
$\begin{array}{lllllllllllllll}\text { Lupercio } & 0,28417 & 0,24280 & 0,37591 & 0,42705 & 0,17580 & 0,89760 & 0,29410 & 0,86360 & 0,51959 & 0,72619\end{array}$ Lutola $\begin{array}{lllllllllllll}\text { Macatuba } & 0,74129 & 0,89761 & 0,59004 & 0,63590 & 0,11520 & 0,92060 & 0,29440 & 0,75090 & 0,70013 & 0,82506\end{array}$

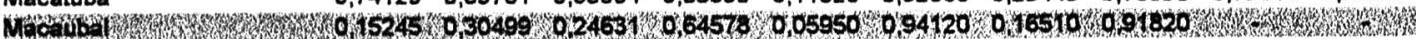

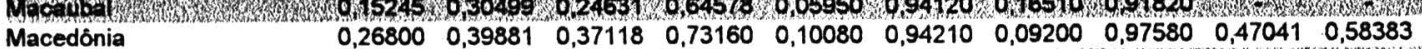

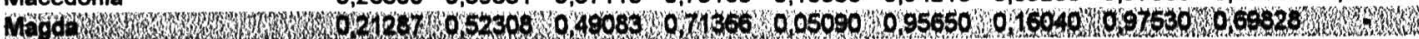
$\begin{array}{llllllllll}\text { Mairinque } & 0,07816 & 0,77433 & 0,46983 & 0,62790 & 0,10500 & 0,91880 & 0,21200 & 0,83050\end{array}$ Mairport) $\begin{array}{llllllllllllllll}\text { Manduri } & 0,13959 & 0,31990 & 0,20690 & 0,57757 & 0,10210 & 0,95560 & 0,13680 & 0,74590 & 0,87334\end{array}$

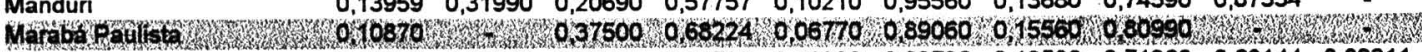
$\begin{array}{llllllllllllllllllll}\text { Maracai } & 0,47804 & 0,99096 & 0,56684 & 0,81701 & 0,10900 & 0,93730 & 0,19580 & 0,71360 & 0,68144 & 0,82311\end{array}$

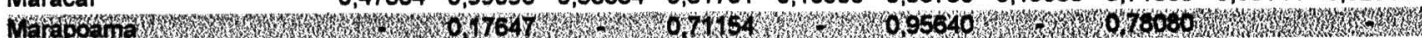
$\begin{array}{llllllllllllllll}\text { Mariápolis } & 0,16606 & 0,75732 & 0,42491 & 0,52564 & 0,07430 & 0,92430 & 0,13390 & 0,83060 & 0,15724 & 0,18605\end{array}$

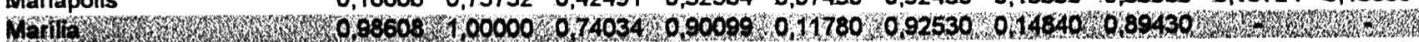
$\begin{array}{llllllllllllll}\text { Marinópolis } & 0,23585 & 0,41600 & 0,27200 & 0,38571 & 0,12020 & 0,94300 & 0,20690 & 0,85710 & 0,34884 & 0,61706\end{array}$

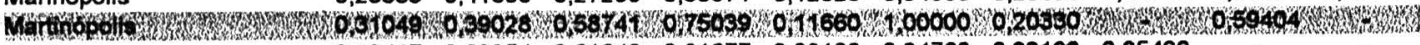
$\begin{array}{lllllllllll}\text { Matảo } & 0,42417 & 0,62954 & 0,61640 & 0,81677 & 0,08100 & 0,94760 & 0,23180 & 0,85420\end{array}$

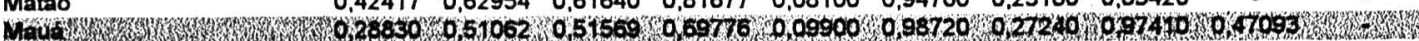
$\begin{array}{llllllllllll}\text { Mendonça } & 0,12953 & 0,55758 & 0,48000 & 0,96875 & 0,08620 & 0,96230 & 0,33330 & 0,85640\end{array}$

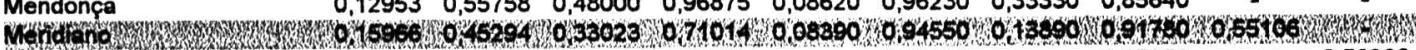
Mesópolis $\quad-\quad 0,59615 \quad-0,63077-0,86480 \quad-0,87950$ - 0,50980 Moutopolis 
Tabela 2. Indicadores de Educação e Coleta de Esgoto - municipios do Estado de São Paulo - 1991 e 1996

$\begin{array}{ccccc}\text { Coef. } & \text { Coef. } & \text { Coef. } & \text { Coef. } & \text { Coef. } \\ \text { Matricula } & \text { Matricula } & \text { Evasão } & \text { Evasão } & \\ \text { Pré-escola } & \text { Ensino Médio } & \text { Ensino Fund. } & \text { Ensino Médio } & \text { Col. Esgoto }\end{array}$

Municipio

$1991 \quad 1996$

19911996

19911996

$1991 \quad 1996 \quad 1991 \quad 1996$

\begin{tabular}{|c|c|c|c|c|c|c|c|c|c|c|}
\hline Mineiros do Tieté & 0,10847 & $=$ & 0,17423 & 0,37231 & 0,10470 & 0,96310 & 0,30210 & 0,91530 & - & 7 \\
\hline Mira Estrela & 0,34194 & 0,03610 & 0,05956 & 0,60976 & 0,09000 & 0,98670 & 0,10260 & - & 0.57665 & 0,72944 \\
\hline Miracatu & 0.13092 & 1,00000 & 1,00000 & 0,45686 & 0,16870 & 0,94120 & 0,36220 & 0,88270 & 0,11556 & 0,16131 \\
\hline Mirandópolis & 0,37726 & 0,49738 & 0,64852 & 0,91571 & $.0,09690$ & 0,94640 & 0,12370 & 0,87050 & $\cdot$ & $\cdot$ \\
\hline Mirante do Paranapanema & 0.47267 & 0,56600 & 0,68186 & 0,86865 & 0,12340 & 0,91940 & 0,18740 & 0,85490 & 0,69719 & $\cdot$ \\
\hline Mirassol & 0,39856 & 0,36563 & 0,59156 & 0,92013 & 0,08260 & 0,95110 & 0.20590 & 0.86490 & - & - \\
\hline Mirassolândia & $\cdot$ & 0,31667 & 0,33333 & 0,68750 & 0,08370 & 0,95150 & 0,03770 & 0.77270 & - & - \\
\hline Mococa & 0,49509 & 0.78352 & 0,68804 & 0,83872 & 0,09530 & 0,94300 & 0.18910 & 0,91550 & 0,84065 & 0,88148 \\
\hline Mogi das Cruzes & 0,43111 & 0,59201 & 0,74291 & 0,88700 & 0,09350 & 0,93030 & 0,20200 & 0,86570 & - & $\cdot$ \\
\hline Mogi Ouaçu & 0.50610 & 0,58644 & 0.58903 & 0,81250 & 0,09530 & 0,94010 & 0,23920 & 0,85810 & 1,00000 & - \\
\hline Moji Mirim & 0,55780 & 0,80623 & 0.62961 & 0,75249 & 0.11570 & 0,92030 & 0,17890 & 0,83800 & - & $\cdot$ \\
\hline Mombuca & 0.41618 & 0.36747 & 0.22287 & 0.32571 & 0,06740 & 0.92990 & 0.09090 & 0,88890 & $\because$ & 0.41728 \\
\hline Monçōes & 0,25455 & 0,64444 & 0,33333 & 0,86538 & 0,08480 & 1,00000 & 0,08510 & $*$ & 0,33106 & 0,67928 \\
\hline Mongaguá & 0,45867 & 0,88653 & 0,38302 & 0,78723 & 0,11180 & 0,89360 & 0,21060 & 0,90750 & $\cdot$ & - \\
\hline Monte Alegre do Sul & 0,26148 & 0,86111 & 0,76703 & 1,00000 & 0,13470 & 0,91250 & 0,26170 & 0,84980 & - & - \\
\hline Monte Alto & 0,54615 & 1,00000 & 0,58691 & 0,75570 & 0,11320 & 0,92750 & 0,19730 & 0,80190 & 0,92216 & 0,93343 \\
\hline Monte Aprazivel & 0.25055 & 0,37028 & 1,00000 & 1,00000 & 0,08750 & 0,94000 & 0,22860 & 0,87260 & 0.72447 & 84213 \\
\hline Monte Azul Pautista & 0,40397 & 0,46406 & 0,32421 & 0,62623 & 0,07410 & 0,95940 & 0,20820 & 0,92790 & 0,77733 & $=$ \\
\hline Monte Castelo & 0,08 & - & 0.41892 & 0.79715 & 0,10940 & 0,92170 & 0.17360 & 0.85970 & 0.50530 & - \\
\hline Monte Mor & 0,16941 & 1,00000 & 1,00000 & 0,52014 & 0,10210 & 0,91590 & 0,31210 & 0.79570 & $\cdot$ & 0,38752 \\
\hline Monteiro Lobato & 0,13420 & - & 0,05125 & 0,98618 & 0,09620 & 0,91810 & 0,37800 & 0,87380 & 0,21335 & 0,42173 \\
\hline Morro Agudo & 0,36 & 0,38289 & 3234 & 0,42165 & 0,12560 & 4150 & 0,14160 & 0,80700 & - & $=\cdots$ \\
\hline Morungaba & $.0,42096$ & 0,40316 & 0,19325 & 0,44337 & 09760 & 480 & 0,20590 & 0,87860 & 0,69188 & 0,68580 \\
\hline Motuca & $*$ & $*$ & $\cdot$ & - & - & 0.96370 & - & - & & $\cdot$ \\
\hline Murutinga do Sul & 0,24490 & - & 0,87963 & 0,96277 & 0,10010 & 0,93130 & 0,29100 & 0,80110 & $\cdot$ & - \\
\hline Narandiba & 0,20283 & * & 0,25000 & 0,44048 & 050 & & 490 & 0,85710 & 0,24900 & 0.50263 \\
\hline Natividade da Serra & 0,10233 & - & 0,17962 & 0,29639 & 0,13890 & 550 & 0,24240 & 0,87800 & 0,53076 & - \\
\hline Nazarb Paylista & $.0,06091$ & 0,12419 & 0,35057 & 0,50000 & 0,16830 & 0,84740 & 0,26780 & 0,83200 & 0,22182 & - \\
\hline Neves Paulista & 0,21767 & 0,80226 & 0,34914 & 0,68326 & 0,07300 & 0,91860 & 0.13240 & 0.90030 & - & - \\
\hline Nhandeara & 0,29714 & 0,68159 & 0,99469 & 1,00000 & 0,04400 & 0,95300 & 0,12680 & 0,86870 & 0,60118 & 0,74453 \\
\hline Nipoã & 967 & 0,30539 & 0,29651 & 0,42574 & 0,14400 & 0,91070 & 0,09620 & 0.87910 & 0,67235 & 0,84615 \\
\hline Nova Aliança & 0,32701 & 0,95313 & 0.32157 & 0.62771 & 58670 & & 0,14460 & 0,87330 & 0.76786 & - \\
\hline Nova Campina & $\ldots$ & - & $\cdot$ & 0,34400 & - & 0,94830 & $\div$ & i & . & 11538 \\
\hline Nova Canaă Paulista & 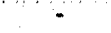 & 0.18803 & $*$ & 0,62987 & - & 0.97190 & - & 0,85420 & - & $m$ \\
\hline Nova Europa & 0,09972 & 0,57143 & 0,24104 & 0,62838 & 0,11260 & 0,93330 & 0,35140 & 0.84360 & - & $\therefore$ \\
\hline $\begin{array}{l}\text { Nova Grangda } . . . \\
\text { Nova Guataporanga }\end{array}$ & $\begin{array}{l}0.16140 \\
0.19841\end{array}$ & $\begin{array}{l}0.43013 \\
0.52174\end{array}$ & & & & & $\begin{array}{l}0.20550 \\
0.09230\end{array}$ & & $\begin{array}{l}0.74837 \\
0.25783\end{array}$ & \\
\hline Nova Independoncia & 0.19231 & 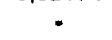 & 0,41667 & 0,64430 & 0,16360 & 0,90090 & 0,30770 & 0,86170 & 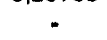 & 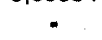 \\
\hline Nova Luzitánia & 0,32759 & 0,38281 & 0,35979 & 0,69189 & 0,11230 & 610 & 0,16670 & - & 0,26706 & 0,75032 \\
\hline Nova Odessa & 0,43779 & 0,72445 & 0,36275 & 0,67890 & 0,06300 & 570 & 0,37760 & 0,79520 & 0,85829 & $\cdot$ \\
\hline Novais & - & 0,64921 & - & 0,38350 & - & 0,90030 & - & 0,77110 & - & - \\
\hline Novo Horizonte & 0,54561 & 0,57362 & 0,54971 & 0,79341 & 0,10380 & 400 & 0,23720 & 0,83250 & 0,76170 & 0,86795 \\
\hline Nuporanga & 602 & 0.48753 & 0.29553 & 0,33708 & 0,10160 & 0.91100 & 0,29070 & 0,82110 & - & - \\
\hline Ocauçu. & 0,20522 & 0.42029 & 0,32328 & 0,57977 & 0.14640 & 0,93330 & 0,10670 & 0,95240 & - & - \\
\hline Óleo & 0,19298 & 0,37059 & 0,27273 & 0,62637 & 0,19010 & 0,87800 & 0,30430 & 0,81740 & 0,50401 & 0,52055 \\
\hline Olimpia & 985 & 988 & 0,61622 & 0,81468 & 0,08320 & 0,92990 & 0,19790 & 0,88030 & - & - \\
\hline Onda Verde & 0,16754 & 0,30055 & $.0,32530$ & 0,48864 & 0,17300 & 510 & 0,18000 & 0,89530 & 0,63352 & 0,67969 \\
\hline Oriente & 0,54248 & 0,67442 & 0,51345 & 0,71471 & 0,17740 & 0,92980 & 0,20670 & 0,85280 & - & - \\
\hline Orindiúva & - & 0,33032 & 0,37278 & 0,63784 & 0,11870 & 0,94130 & 2310 & 0,89430 & 0,67799 & 0,85000 \\
\hline Orlândia & 0.72422 & 561 & 0,53289 & & 680 & & & 18110 & . & $\therefore$ \\
\hline Osasco & 0,32467 & 0,36839 & 0,68581 & 0,84692 & 0,10070 & 0,92840 & 0,26820 & 0,83330 & - & - \\
\hline Oscar Bressano & 0.44615 & 0.70635 & 0,45223 & $.0,80124$ & 0,11230 & 0,97950 & 0,15490 & 0,91270 & 0,60968 & 0.75104 \\
\hline Osvaldo Cruz & 0.12848 & 0,01627 & 0,72296 & 0,99603 & 0.11180 & 0,92060 & 0,23370 & 0,82330 & 0,69942 & 0,84534 \\
\hline Ourinhos & & 0,75743 & & & & & & & 0,82455 & - \\
\hline Ouro Verde & 660 & - & 0,27968 & 0,42117 & 0.10780 & 0,87270 & 0,15450 & 0,82290 & - & - \\
\hline $\begin{array}{l}\text { Pocaembú } \\
\text { Palestina }\end{array}$ & $\begin{array}{l}0,20327 \\
0,27756\end{array}$ & $\begin{array}{l}0,49257 \\
0,64324\end{array}$ & $\begin{array}{l}0,62839 \\
0,49133\end{array}$ & $\begin{array}{l}0,66766 \\
0,77282\end{array}$ & $\begin{array}{l}0,09950 \\
0,10540\end{array}$ & $\begin{array}{l}0,92100 \\
0,92320\end{array}$ & $\begin{array}{l}0,13200 \\
0,17390\end{array}$ & $\begin{array}{l}0,86890 \\
0,92500\end{array}$ & 0,30585 & 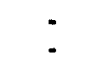 \\
\hline Palmares Paulista & 0,13953 & 0,27397 & 0,18625 & 0,39543 & 0,11700 & 0,93110 & 0,17860 & 0,85270 & 0,75363 & 0,88599 \\
\hline Palmeira d'Oosto & & & & & & & & & 0,33969 & 56627 \\
\hline Palmital $\ldots .$. & 0,45723 & 0,72921 & 0,59225 & 0.57300 & 0,12860 & 0,89310 & 0,17080 & 0.88810 & - & - \\
\hline Panorama & & - & & & & & 0,19870 & 0,88660 & 0,29649 & - \\
\hline Paraguaçu Paulista & & 0,65964 & 0,65558 & 0,87886 & 0,11370 & 0.94810 & 0,21330 & 0,83410 & $=$ & - \\
\hline Paraibuna & 0,28004 & $\cdot$ & 0,33109 & 0,80022 & 0,13290 & 0,92390 & 0,29200 & 0,90090 & 0,39558 & - \\
\hline & & & & & & & . & & 0,71404 & - \\
\hline Paranapanema & 0,19957 & 0,33545 & 0,30445 & 0,56133 & 0.12580 & 0,88940 & 0,22180 & 0,84160 & 0,43997 & 0,64232 \\
\hline Paranapuã & 0,45858 & 0,72193 & 0,44898 & 0,88433 & 0,11890 & 0,93290 & 0,08430 & 0,93970 & 0,24765 & 0,57796 \\
\hline
\end{tabular}


Tabela 2. Indicadores de Educação e Coleta de Esgoto - municipios do Estado de São Paulo - 1991 e 1996.

\begin{tabular}{|c|c|c|c|c|}
\hline $\begin{array}{l}\text { Coef. } \\
\text { Matrícula }\end{array}$ & $\begin{array}{l}\text { Coef. } \\
\text { Matricula }\end{array}$ & $\begin{array}{l}\text { Coef. } \\
\text { Evasăo }\end{array}$ & $\begin{array}{l}\text { Coef. } \\
\text { Evasăo }\end{array}$ & Coef. \\
\hline Pré-escola & Ensino Medio & Ensino Fund. & Ensino Médío & Col. Esgoto \\
\hline
\end{tabular}

Municipio

$\begin{array}{llllllll}1991 & 1996 & 1991 & 1996 & 1991 & 1996 & 1991 & 1996\end{array}$

19911996

Parapuả

Pardinho

Pariquera-Açu

Parisi

Patrocinio Paulista

Paulicéia

Paulínia

Paulo de Faria

Pederneiras

Pedra Bela

Pedranópolis

Pedregulho

Pedreira

Pedrinhas Paulista

Pedro de Toledo

Pentápolis

Pereira Barreto

Pereiras

Peruibe

Piacatu

Piedade

Pilar do Sul

Pindamonhangaba

Pindorama !

Pinhalzinho

Piquerobi

Piquete

Piracaia

Piracicaba

Piraju

Pirajui

Pirangi

Pirapora do Bom Jesus

Pirapozinho

Pirassununga

Piratininga .....

Pitangueiras

Planalto

Platina

Pod

Poloni

Pompoia

Pongai

Pontal

Pontalinda

Pontes Gestal

Populina

Porangaba

Porto Feliz

Porto Forroira

Potim

Potirendaba

Pradópolis

Praia Grande

Presidente Atres

Prosidente Bernardes

Presidente Epitácio

Presidente Prudente

Presidente Venceslau

Promissão,

Quatá

Quelroz

Queluz

Quintana

Rafard

Rancharia

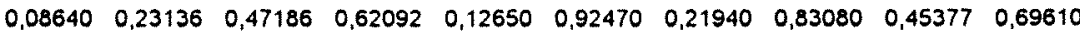
$\begin{array}{llllllllll}0,15686 & 0,35115 & 0,22078 & 0,52917 & 0,14330 & 0,91220 & 0,13460 & 0,80160 & 0,54643 & 0,60244\end{array}$

$\begin{array}{llllllllll}0,20000 & 0,16037 & 0,56442 & 0,55518 & 0,12580 & 0,92450 & 0,24320 & 0,86870 & 0,26780 & 0,34092\end{array}$ $\because 0,62353 \div 0,55660+0,90530 \div 0,84750$

$\begin{array}{lllllllll}0,10099 & 0,60731 & 0,24474 & 0,41194 & 0,16030 & 0,87770 & 0,26920 & 0,81570 & 0,80446\end{array}$

$\begin{array}{ccccccccccc}* & - & 0,25704 & 0,67883 & 0,11720 & 0,94030 & 0,18060 & 0,89670 & - & -\end{array}$

$\begin{array}{llllllllll}0,18672 & 0,41851 & 0,83402 & 0,78745 & 0,07960 & 0,94480 & 0,25600 & 0,86950 & 0,76826 & 0,86109\end{array}$

$\begin{array}{llllllllll}0,47343 & 0,66220 & 0,42153 & 0,56901 & 0,12320 & 0,90590 & 0,20200 & 0,84960 & 0,69723 & 0,90746\end{array}$

$\begin{array}{lllllllll}0,14241 & 0,17647 & 0,41077 & 0,30892 & 0,12540 & 0,92180 & 0,11480 & 0,85570 & 0,09716\end{array}$

$\begin{array}{llllllllll}0,42045 & 0,67424 & 0,33659 & 0,74011 & 0,09920 & 0,93140 & 0,19400 & 0,86510 & 0,49622 & 0,56770\end{array}$

$\begin{array}{lllllllllll}0.11620 & * & 0.35866 & 0,52004 & 0,15600 & 0,93600 & 0,13150 & 0,87920 & 0,63072 & 0.67893\end{array}$

$\begin{array}{llllllll}0,51458 & 0,64839 & 0,40625 & 0,44972 & 0,10000 & 0,91050 & 0,19230 & 0,85490\end{array}$

- $0,72143 \quad-0,88000-0,95830=0,90990 \quad-0,78603$

$\begin{array}{llllllllll}0,15625 & 0.19368 & 0,42323 & 0,59470 & 0,14770 & 0,92200 & 0,26010 & 0,83880 & 0,30386 & 0,41885\end{array}$

$\begin{array}{llllllllll}0,55877 & 0,69783 & 0,70000 & 0,82719 & 0,11720 & 0,90270 & 0,24770 & 0,82060 & 0,81144\end{array}$.

$\begin{array}{lllllllll}0,66586 & 0,91639 & 0,81647 & 0,97880 & 0,07860 & 0,93730 & 0,20990 & 0,85910 & 0,43957\end{array}$

$\begin{array}{llllllllllll}0,07931 & 0,26493 & 0,60965 & 0,57491 & 0,08610 & 0,93760 & 0,09490 & 0,89350 & 0,70364\end{array}$

$\begin{array}{llllllllll}0,07292 & 0,12301 & 0,37402 & 0,62794 & 0,12610 & 0,90150 & 0,34930 & 0,78790 & 0.16166 & 0,19133\end{array}$

$\begin{array}{lllllllllll}0,18531 & 0,58403 & 0,60448 & 0,73477 & 0,10570 & 0,95590 & 0,16460 & 0,94030 & 0,45486 & 0,76063\end{array}$

$\begin{array}{lllllllllll}0,21797 & 0,31177 & 0,32491 & 0,53243 & 0,08910 & 0,92530 & 0,17080 & 0,88340 & 0,23259 & 0,28458\end{array}$

$\begin{array}{llllllllll}0,17192 & 0,34694 & 0,32013 & 0,54107 & 0,10140 & 0,92350 & 0,19170 & 0,81170 & 0,56776 & 0,59716\end{array}$

$\begin{array}{lllllllllll}0,42309 & 0,55240 & 0,55011 & 0,77935 & 0,10820 & 0,91320 & 0,27330 & 0,80590 & 0,65490 & 0,77011\end{array}$

$\begin{array}{llllllllll}0,26012 & 0.42472 & 0,40807 & 0,61286 & 0,10880 & 0,92530 & 0.21180 & 0,81210 & \text { * }\end{array}$

$\begin{array}{llllllllll}0,13894 & 0,68333 & 0,45796 & 0,41593 & 0,16980 & 0,93770 & 0,30770 & 0,99170 & 0,30408\end{array}$

$\begin{array}{llllllllll}0,25000 & * & 0,26941 & 0,53216 & 0,06560 & 0,91220 & 0,35000 & 0,64520 & 0,39200 & 0,45744\end{array}$

$\begin{array}{lllllllllll}0,18997 & 0,11187 & 0,75181 & 0,84281 & 0,14410 & 0,90540 & 0,31230 & 0,72060 & 0,59681 & \text { - }\end{array}$

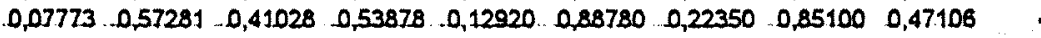

$\begin{array}{llllllllll}0,44315 & 0,45728 & 0,60644 & 0,76389 & 0,10480 & 0,93270 & 0,21510 & 0,82460\end{array}$

$\begin{array}{llllllllll}0,27074 & 0,26708 & 0,52239 & 0,73897 & 0,12890 & 0,90510 & 0,32490 & 0,77990 & 0,69151 & 0,85023\end{array}$

$\begin{array}{llllllll}0,39279 & 0,52564 & 0,72710 & 1,00000 & 0,08960 & 0,96100 & 0,19660 & 0,84290\end{array}$

$\begin{array}{lllllll}0,40185 & 0,56627 & 0,07710 & 0,95390 & 0,13900 & 0,88310\end{array}$

$\begin{array}{lllllllll}0,09953 & - & 0,24800 & 0,49317 & 0,21190 & 0,88870 & 0,30650 & 0,71780\end{array}$

$\begin{array}{llllllllll}0,17319 & 0,01896 & 0,39969 & 0,66325 & 0,09970 & 0,94660 & 0,22050 & 0,78180 & 0,47385 & 0,73926\end{array}$

$\begin{array}{llllllllll}0,57723 & 0,60305 & 0,78636 & 0,87997 & 0,10270 & 0,93330 & 0,29410 & 0,74040 & 0,91731\end{array}$

$\begin{array}{llllllllll}0,72277 & 1,00000 & 0,47495 & 0,65258 & 0,07380 & 0,96490 & 0,17240 & 0,89430 & 0,73418 & 0,80812\end{array}$

$\begin{array}{llllllllll}0,02892 & 0,49709 & 0,26916 & 0,38203 & 0,11740 & 0,91110 & 0,18270 & 0,83670 & 0,63996\end{array}$

$\begin{array}{llllllllll}0,29706 & 0,28000 & 0,66770 & 0,97087 & 0,12570 & 0,83650 & 0,18060 & 0,81960 & 0,36047 & 0,79388\end{array}$

$\begin{array}{lllllllllll}0,11616 & 0,32653 & 0,36872 & 0,40064 & 0,23170 & 0,85870 & 0,12500 & 0,87300 & 0,15826 & 0,66708\end{array}$

$\begin{array}{llllllllll}0,34537 & 0,53145 & 0,65031 & 1,00000 & 0,08290 & 0,97830 & 0,23070 & 0,97460 & 0,53304\end{array}$

$\begin{array}{lllllllllll}0,55224 & 0,92718 & 0,53043 & 0,86531 & 0,11900 & 0,95380 & 0,25980 & 0,91710 & 0,79419 & 0,89599\end{array}$

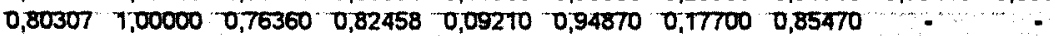

$\begin{array}{llllllllll}0,36232 & 0,48521 & 0,22791 & 0,47679 & 0,08480 & 0,93160 & 0,29090 & 0,86840 & 0,71784 & 0,73178\end{array}$

$\begin{array}{cccccccccccc}0.71016 & 0,34410 & 0,48461 & 0,47641 & 0,13410 & 0,81750 & 0,23540 & 0,81030 & - & - \\ - & 0,44670 & - & 0,59735 & * & 0,98400 & - & 0,94700 & - & 0,22301\end{array}$

$\begin{array}{lllllllllll}0,36846 & 0,44670 & 0,46226 & 0,52381 & 0,13380 & 0,93480 & 0,23470 & 0,87010 & 0,65134 & 0,83079\end{array}$

$\begin{array}{llllllllll}0,33333 & 0,50450 & 0,33452 & 0,68797 & 0,12990 & 0,90950 & 0,12770 & 0,82610 & 0,48319 & 0,64839\end{array}$

$\begin{array}{lllllllllll}0,09409 & 0,30241 & 0,59350 & 0,80495 & 0,11200 & 0,94630 & 0,19470 & 0,92700 & \cdots & 0,57247\end{array}$

$\begin{array}{llllllllll}0,12500 & 0.57261 & 0.31577 & 0.58507 & 0.11730 & 0,92730 & 0,17360 & 0,88760 & 0,75614\end{array}$

$\begin{array}{lllllllll}0,62587 & 0,78220 & 0,62396 & 0,71109 & 0,11010 & 0,93830 & 0,23820 & 0,84960 & 0,80792\end{array}$

$\begin{array}{ccccccccccc}- & 0,43915 & - & 0,38278 & - & 0,92780 & - & 0,76830 & - \\ 0,12648 & 0,74775 & 0,60360 & 0,67612 & 0,10320 & 0,93240 & 0,23350 & 0,90690 & 0,61834\end{array}$

$\begin{array}{lllllllll}0,90896 & 0,93786 & 0,40575 & 0,56556 & 0,09980 & 0,90860 & 0,24120 & 0,81860 & \text { - }\end{array}$

$\begin{array}{llllllllll}0,48562 & 0,79162 & 0,39101 & 0,64034 & 0,08390 & 0,93260 & 0,15940 & 0,83420 & 0,97564 & 1,00000\end{array}$

$\begin{array}{llllllllll}0,30303 & - & 0,37919 & 0,37879 & 0,16500 & 0,87590 & 0,15040 & 0,77550 & 0,66995 & 0,81317\end{array}$

$\begin{array}{llllllllll}0,20833 & 0,71082 & 0,78827 & 1,00000 & 0,12210 & 0,94730 & 0,15820 & 0,84740 & 0,37607 & 0,68947\end{array}$

$\begin{array}{lllllllllll}0,32707 & 0,47818 & 0,55152 & 0,77337 & 0,05120 & 0,94940 & 0,19040 & 0,88030 & 0,23834 & 0,31561\end{array}$

$\begin{array}{llllllllllll}0,46585 & 0,44755 & 0,88534 & 1,00076 & 0,13000 & 0,91980 & 0,25600 & 0,83300 & 0,73868 & 0,94119\end{array}$

$\begin{array}{llllllll}0,46886 & 0,68799 & 0,65137 & 0,93290 & 0,09120 & 0,89410 & 0,14910 & 0,87250\end{array}$

$\begin{array}{llllllllllll}0,47864 & 0.58606 & 0,38054 & 0.59802 & 0,08490 & 0,90710 & 0,22680 & 0,81580 & 0,69922 & .\end{array}$

$\begin{array}{lllllllllll}0,21419 & 0,26412 & 0,46131 & 1,00000 & 0,11910 & 0,94690 & 0,15360 & 0,85650 & 0,59399 & 0,85516\end{array}$

$\begin{array}{llllllllll}0,28829 & 0,89691 & 0,47619 & 0,56552 & 0,15430 & 0,91370 & 0,21740 & 0,81010 & 0,30898 & 0,81705\end{array}$

$\begin{array}{lllllllllll}0,59048 & 0,66797 & 0,39520 & 0,53501 & 0,09950 & 0,90960 & 0,24860 & - & 0,52732 & 0,58321 \\ 0,18362 & 0,28235 & 0,27405 & 0,54867 & 0,11790 & 0,94790 & 0,22430 & 0,80650 & * & \end{array}$

$\begin{array}{llllllllll}0,52034 & 0,59566 & 0,55144 & 0,76407 & 0,14040 & 0,92720 & 0,16060 & 0,81890 & - \\ 0,42788 & 0,56691 & 0,62662 & 0,82369 & 0,10190 & 1,00000 & 0,15440 & \ddots & -\end{array}$ 
Tabela 2. Indicadores de Educação e Coleta de Esgoto - municipios do Estado de São Paulo - 1991 e 1996

$\begin{array}{ccccc}\text { Coef. } & \text { Coef. } & \text { Coef } & \text { Coef. } & \text { Coef. } \\ \text { Matrícula } & \text { Matrícula } & \text { Evasão } & \text { Evasão } & \\ \text { Pré-escola } & \text { Ensino Médio } & \text { Ensino Fund. } & \text { Ensino Médio } & \text { Col. Esgoto }\end{array}$

Municipio

$\begin{array}{llllllll}1991 & 1996 & 1991 & 1996 & 1991 & 1996 & 1991 & 1996\end{array}$

19911996

Redençäo da Serra Regente Feijó

Reginópolis

Registro

Restinga

Ribeira

Ribeirão Bonito

Ribeirăo Bránco

Ribeirăo Corrente

Ribeiråo do Sul

Ribeirāo Grande

Ribeiråo Pires

Ribeiräo Preto

Rifaine

Rincäo

Rinópolis

Rio Claro

Rio des Pedras

Rio Grande da Serra

Riolàndia

Riversul

Rosana

Roseira

Rubiácea

Rubinéa

Sabino

Sagres

Sales

Sales Oliveira

Salesópolis

Salmourão

Saltinho

Salto

Salto de Pirapóra

Salto Grande

Sandovalina

Santa Adélia

Santa Albertina

Santa Barbera d'Oesto

Santa Branca

Santa Clara d'Oeste

Santa Cruz da Concéiçảo

Santa Cruz das Palmeiras

Santa Cruz do Rio Pardo

Santa Ernestina

Santa Fe do Sul

Santa Gertrudes

Santa Isabel

Santa Lucia

Santa Maria da Serra

Santa Mercedes

Sant Rita do.Passa Quatro

Santa Rita d'Oeste

Santa Rosa do Viterbo

Santana da Ponte Pensa

Santena de Parnaibe

Santo Anastácio

Santo Andró

Santo Antonio da Alogria

Santo Antopla da Posse.

Santo Antonio do Aracanguá

Santo Antonio do Jardim

Santo Antonio do Pinhal

Santo Expedito

Santópolis do Aguapei

Santos $\begin{array}{llllllllll}0,10684 & - & 0,32906 & 0,52016 & 0,19530 & 0,83660 & 0,22970 & 0,77690 & 0,30019 & 0,31481\end{array}$ $\begin{array}{lllllllllll}0,24887 & 0,58596 & 0,55943 & 0,72328 & 0,13630 & 0,90570 & 0,25780 & 0,83840 & 0,61366 & 0,80529\end{array}$ $\begin{array}{llllllllll}0,37121 & 0,39847 & 0,56934 & 0,52711 & 0,09090 & 0,91260 & 0,22220 & 0,86130 & 0,58833\end{array}$

$\begin{array}{llllllllllll}0,29077 & 0,49595 & 0,61764 & 0,72321 & 0,13110 & 0,94840 & 0,11130 & 0,91240 & 0,30572 & 0,52407\end{array}$

$\begin{array}{lllllllllll}0,07536 & - & 0,24111 & 0,35224 & 0,18750 & 0,89090 & 0,12960 & 0,78570 & 0,61067 & 0,74604\end{array}$

$\begin{array}{lllllllllll}0,05109 & - & 0,30214 & 1,00000 & 0,14780 & 0,91950 & 0,12100 & 0,85960 & 0,08856 & 0,18950\end{array}$

$\begin{array}{llllllll}0,07803 & 0,21348 & 0,55349 & 0,77591 & 0,12520 & 0,94640 & 0,21810 & 0,86310\end{array}$

$\begin{array}{llllllllll}0,05672 & - & 0,12731 & 0,35561 & 0,17910 & 0,88880 & 0,13480 & 0,84840 & 0,14172 & 0,18921\end{array}$

$\begin{array}{llllllllll}0,13734 & - & 0,29665 & 0,39912 & 0,13650 & 0,85810 & 0,10000 & 0,82760 & 0,65348 & 0,74327\end{array}$

$\begin{array}{lllllllllll}0,29224 & 0,77551 & 0,37712 & 0,54613 & 0,16260 & 0,93220 & 0,12900 & 0,88890 & 0,57242 & 0,62272\end{array}$ $0,49068-0,38618$ - 0.93230 - 0.88720 - 0.20923

$\begin{array}{llllllllll}0,43233 & 0,50560 & 0,64913 & 0,92043 & 0,09260 & 0,93080 & 0,21530 & 0,84790 & 0,32190 & \text { - }\end{array}$

$\begin{array}{llllllllll}0,38683 & 0,55401 & 0,71282 & 0,88497 & 0,11300 & 0,92690 & 0,19660 & 0,87770 & \ldots\end{array}$

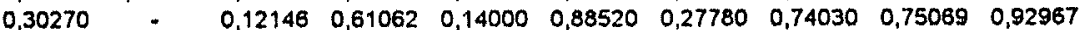

$\begin{array}{llllllllll}0,06897 & 0,41654 & 1,00000 & 0,83955 & 0,11480 & 0,95150 & 0,13720 & 0,86820 & 0,82472 & \text { - }\end{array}$

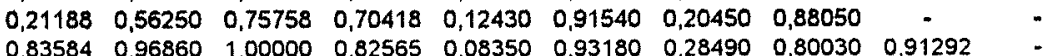

$\begin{array}{llllllllllll}0,51392 & 0,54586 & 0,09858 & 0,86033 & 0,08300 & 0,94080 & 0,21660 & 0,86600 & 1,00000\end{array}$

$\begin{array}{llllllllll}0,15864 & 0,16883 & 0,62552 & 0,63255 & 0,12340 & 0,90930 & 0,31690 & 0,80130 & 0,06923 & -\end{array}$

$\begin{array}{llllllllll}- & 0,16115 & 0,14187 & 0,60442 & 0,14390 & 0,90620 & 0,18880 & 0,74600 & 0,71201 & 0,81873\end{array}$

$\begin{array}{llllllllll}0,39479 & 0,53804 & 0,12920 & 0,89820 & 0,15460 & 0,83160 & 0,34950 & 0,47557\end{array}$

$\begin{array}{lllllllll}0,45980 & - & 0,83141 & - & 0,93940 & - & 0,76690 & - & 0,23545\end{array}$

$\begin{array}{llllllllll}0,13702 & 0,48364 & 0,47354 & 0,68190 & 0,09990 & 0,90300 & 0,25410 & 0,86980 & 0,83553 & 0,93955\end{array}$

$\begin{array}{llllllllllll}0,12291 & 0,16552 & 0,43089 & 0,73684 & 0,09150 & 0,92730 & - & 0,81580 & 0,36447 & 0,43906\end{array}$

$\begin{array}{cccccccccc}0,35484 & - & - & 0,80420 & 0,07270 & 0,96040 & 0,14890 & 0,88600 & 0,43239 & 0,62993\end{array}$

$\begin{array}{llllllllll}0,23273 & 0,24901 & 0,29236 & 0,42767 & 0,09990 & 0,90330 & 0,14610 & 0,90580\end{array}$

$\begin{array}{llllllllll}0,39877 & 0,66456 & 0,10950 & 0,92510 & 0,11110 & 0,84470 & 0,25266 & 0,55142\end{array}$

$\begin{array}{llllllllllllllll}0,21491 & 0,88038 & 1,00000 & 0,99065 & 0,06690 & 0,90950 & 0,08590 & 0,86260 & 0,58573\end{array}$

$\begin{array}{lllllllllll}0,65795 & 0,75574 & 0,31933 & 0,27495 & 0,09330 & 0,96040 & 0,29410 & 0,87590 & \text { - }\end{array}$

$\begin{array}{llllllllll}0,23229 & 0,40571 & 0,43277 & 0,61187 & 0,10160 & 0,93780 & 0,29640 & 0,84780 & 0,36565 & \text { - }\end{array}$

$\begin{array}{llllllllll}0,23776 & - & 0,55594 & 0,82353 & 0,14190 & 0,88320 & 0,16770 & 0,87610 & 0,20980 & 0,50211\end{array}$

* $0.50000-0.86084-0.95540$ * 0.90480 .

$\begin{array}{llllllllll}0,48588 & 0,48703 & 0,48059 & 0,65415 & 0,10340 & 0,94070 & 0,25480 & 0,81350 & * & * \\ 0,46047 & 0,52637 & 0,38420 & 0,47543 & 0,08420 & 0,93970 & 0,22400 & 0,86210 & 0,59071 & 0,67158\end{array}$

(1) $0,272730,558190,12750 \quad 0,91640 \quad 0,227000,83040$

$\begin{array}{llllllllll}0.61184 & 0.93023 & 0.71348 & 0.73446 & 0.12020 & 0.87630 & 0.31250 & 0.86610 & \ldots & \ldots\end{array}$

$\begin{array}{llllllllll}0,34286 & 0,37631 & 0,44895 & 0,61172 & 0,13050 & 0,89500 & 0,19510 & 0,84450 & 0,00898\end{array}$

$\begin{array}{llllllllll}0,39103 & 0,29259 & 0,29377 & 0,59248 & 0,12460 & 0,93920 & 0,16300 & 0,88650 & 0,25993 & 0,64352\end{array}$

$\begin{array}{llllllll}0,31128 & 0,42520 & 0,33175 & 0,56477 & 0,06980 & 0,95920 & 0,10860 & 0,87850\end{array}$

$\begin{array}{llllllllll}\text { - } & * & 0,34769 & 0,48082 & 0,09290 & 0,94150 & 0,19820 & 0,82460 & \text {. }\end{array}$

$\begin{array}{llllllllll}0,24658 & 0,76389 & 0,41096 & 0,56934 & 0,05920 & 0,88860 & 0,08330 & 0,84210 & 0,20674 & 0,52294\end{array}$

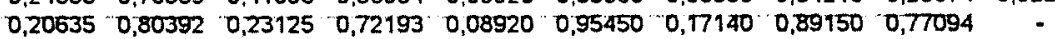

$\begin{array}{llllllll}0,31401 & 0,52836 & 0,40123 & 0,49364 & 0,12040 & 0,94960 & 0,21590 & 0,86230\end{array}$

$\begin{array}{llllllllll}0,54625 & 0,72776 & 0,53229 & 0,72220 & 0,12090 & 0,91800 & 0,23590 & 0,83330 & 0,65022 & 0,80284\end{array}$

$\begin{array}{lllllllllll}- & - & 0,32082 & 0,56863 & 0,04640 & 0,96600 & 0,24470 & 0,84920 & 0,66508 & 0,84779\end{array}$

$\begin{array}{lllllllll}0,24084 & 0,58843 & 0,86901 & 1,00000 & 0,08870 & 0,94310 & 0,11700 & 0,86170\end{array}$

$\begin{array}{llllllllllll}0,70523 & 0,70718 & 0,26343 & 0,36066 & 0,10470 & 0,85510 & 0,14740 & 0,85710 & \text { - }\end{array}$

$\begin{array}{llllllllll}0,03231 & 0,58162 & 0,34481 & 0,63468 & 0,11330 & 0,89920 & 0,16730 & 0,87780 & 0,38422 & \text { - }\end{array}$

$\begin{array}{lllllllllll}- & 0,55157 & 0,26702 & 0,56274 & 0,11230 & 0,96130 & 0,36270 & 0,81030 & -\end{array}$

$\begin{array}{lllllllll}0,61728 & 0,70833 & 0,25641 & 0,37549 & 0,14430 & 0,91070 & 0,09840 & 0,64290\end{array}$

$\begin{array}{llllllllll}0,24171 & - & 0,51282 & 1,00000 & 0,05510 & 0,97700 & 0,17820 & 0,85450 & 0,23087 & 0,44251\end{array}$

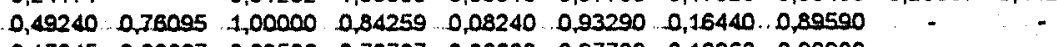

$\begin{array}{lllllllll}0,17045 & 0,66667 & 0,03506 & 0,70787 & 0,06680 & 0,97700 & 0,10260 & 0,90980\end{array}$

$\begin{array}{llllllllll}0,45380 & 0,53797 & 1,00000 & 0,59265 & 0,11470 & 0,92380 & 0,27290 & 0,84410 & 0,97683 & 0,99529\end{array}$

$\begin{array}{lllllllll}0,22727 & 0,91250 & 0,03864 & 0,72093 & 0,06820 & 0,96760 & 0,11760 & 0,93100\end{array}$

$\begin{array}{llllllllll}0,05268 & 0,01325 & 0,34811 & 0,39266 & 0,13300 & 0,91730 & 0,25600 & 0,85950 & 0,21369\end{array}$

$\begin{array}{lllllllllll}0,08478 & 0,00479 & 0,67929 & 0,80837 & 0,09750 & 0,93300 & 0,15180 & 0,86120 & 0,65653 & 0,80833\end{array}$

$\begin{array}{lllllllllll}0,55149 & 0,64182 & 0,88625 & 1,00000 & 0,08540 & 0,94990 & 0,21600 & 0,83740 & 1,00000\end{array}$

$\begin{array}{llllllllll}0,18182 & - & 0,62455 & 0,71709 & 0,18290 & 0,86300 & 0,20120 & 0,79460 & \text { - }\end{array}$

$\begin{array}{lllllllll}0.06949 & 0.48861 & 0.22861 & 0.40870 & 0,12050 & 0,94150 & 0,35840 & 0.83420 & \ldots\end{array}$

$\begin{array}{llllllllll}0,43865 & 0,53823 & 0,31367 & 0,53665 & 0,12510 & 0,83440 & 0,14290 & 0,83500 & 0,52454 & 0,53027\end{array}$

$\begin{array}{lllllllllll}0,09429 & - & 0,27103 & 0,42268 & 0,16590 & 0,92210 & 0,30340 & 0,70190 & 0,21219 & 0,24621\end{array}$

$\begin{array}{lllllllllll}0,20930 & - & 0,50667 & 0,76823 & 0,09160 & 0,93670 & 0,10530 & 0,87500 & 0,41208 & 0,56682\end{array}$

$\begin{array}{lllllllllll}0,25000 & 0,71429 & 0,72414 & 0,58130 & 0,11850 & 0,92520 & 0,09630 & 0,89120 & 0,24546 & 0,88390\end{array}$

$\begin{array}{lllllllllllll}0,53826 & 0,61390 & 1,00000 & 1,00000 & 0,09380 & 0,95110 & 0,21460 & 0,86570 & 1,00000 & 1,00000\end{array}$ 
Tabela 2. Indicadores de Educação e Coleta de Esgoto - municipios do Estado de São Paulo - 1991 e 1996.

$\begin{array}{ccccc}\text { Coef. } & \text { Coef. } & \text { Coef. } & \text { Coef. } & \text { Coef. } \\ \text { Matrícula } & \text { Matrícula } & \text { Evasão } & \text { Evasão } & \\ \text { Pré-escola } & \text { Ensino Médio } & \text { Ensino Fund. } & \text { Ensino Médio } & \text { Col. Esgoto }\end{array}$

Municipio

19911996

19911996

1991

$19961991 \quad 1996$

19911996

São Bento do Sapucaí Sao Bernardo do Campo São Caetano do Sul São Carlos

São Francisco

São João da Boa Vista

São João das Duras Pontes

Sảo Joảo de lracema

São João do Pau D'Alho

Sảo Joaquim da Barra

São José da Bela Vista

Sảo José do Barrairo.

São José do Rio Pardo

Sżo José do Rio Preto

São José dos Campos

São Lourenço da Serra

São Luís do Paraitinga

Sảo Manuel

São Miguel Arcanjo

Sáo Paulo

Sảo Pedro

sto Podro do Turvo

Săo Roque

Såo Sebastião

São Sebastiāo da Grama

São Simảo

São Vicente

Sarapuí

Sarutaiá

Sebastianópolis do Sul

Serra Azul

Serra Negra

Serrana

Sertảozinho

Sete Barras

Severinia

Silveiras

Socorro

Sorocaba

Sud Mennucei

Sumaré

Suzanápolis

Suzano

Tabapuã

Tabatinga

Taboso da Serra

Taciba

Tagual

Taiaçu

Taiủva

Tambaú

Tanabi

Tapiraí

Tapiratiba

Taquaritinga

Taquarituba

Taquarivai

Tarabai

Tarumà

Tatul

Taubaté

Tejupá

Teodoro Sampaio

Terra Roxa

Tietê

Timburi

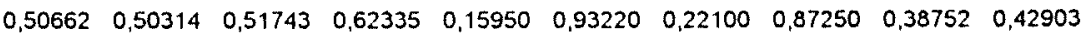

$\begin{array}{lllllllll}0,71143 & 0,70677 & 0,74777 & 0,88718 & 0,06810 & 0,95890 & 0,18640 & 0,87330\end{array}$

$\begin{array}{lllllllll}0,87600 & 1,00000 & 1,00000 & 1,00000 & 0,07920 & 0,93720 & 0,24830 & 0,85780 & 0,94778\end{array}$

$\begin{array}{lllllllllll}0,66000 & 0,86587 & 0,72451 & 0,93262 & 0,07520 & 0,93680 & 0,23990 & 0,88440 & - & . \\ 0,19838 & 0,50365 & 0,41869 & 0,51515 & 0,07280 & 0,97150 & 0,09650 & 0,96670 & 0,22465 & 0,63810\end{array}$

$\begin{array}{llllllllll}0,57506 & 0,63948 & 0,65736 & 0,87135 & 0,08310 & 0,96030 & 0,21180 & 0,82190 & 0,86280 & 0,90826\end{array}$

$\begin{array}{lllllllllll}0,41447 & 0,33898 & 0,56024 & 0,61486 & 0,07160 & 0,93590 & 0,06670 & 0,88810 & 0,48939 & 0,66440\end{array}$

- $0,70000-0,95294 \quad-0,97190 \quad 00,97300$

$\begin{array}{llllllll}0,22289 & 0,72477 & 0,60674 & 1,00000 & 0,09690 & 0,95840 & 0,28440 & 0,86960\end{array}$

$\begin{array}{lllllllll}0,47848 & 0,51799 & 0,62948 & 0,72545 & 0,13400 & 0,93140 & 0,26720 & 0,89550\end{array}$

$\begin{array}{lllllllll}0,13427 & - & 0,20804 & 0,45283 & 0,13050 & 0,85780 & 0,18890 & 0,88990 & 0,75085\end{array}$

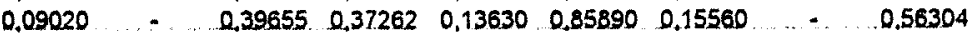

$\begin{array}{lllllllll}0,72860 & 0,53876 & 0,56547 & 0,69252 & 0,12070 & 0,92490 & 0,18410 & 0,90160\end{array}$

$\begin{array}{llllllll}0,59984 & 0,72742 & 0,68254 & 0,85181 & 0,11240 & 0,93380 & 0,16110 & 0,87470\end{array}$

$\begin{array}{llllllllll}0,37824 & 0,50220 & 0,72174 & 1,00000 & 0,09750 & 0,93770 & 0,25050 & 0,82870 & 0,70028 & 0,85867\end{array}$

\begin{tabular}{ccccccccccc}
\hline & 0,45780 & - & 0,54660 & - & 0,92940 & - & $*$ & $*$
\end{tabular}

$\begin{array}{llllllllllll}0,28975 & 0,43476 & 0,48184 & 0,77033 & 0,12950 & 0,91230 & 0,27070 & 0,76670 & 0,72065 & 0,86416\end{array}$

$\begin{array}{llllllllll}0,28595 & 0,38114 & 0,29175 & 0,41798 & 0,11600 & 0,88880 & 0,25000 & 0,79970 & 0,37243 & 0,47723\end{array}$

$\begin{array}{llllllllll}0,45372 & 0,52266 & 0,68726 & 0,90052 & 0,08880 & 0,94130 & 0,23680 & 0,84600 & 0,68343 & 0,86522\end{array}$

$\begin{array}{llllllllllll}0,52249 & 0,70321 & 0,43511 & 0,56366 & 0,11690 & 0,86610 & 0,20620 & 0,75120 & \text { * }\end{array}$

$\begin{array}{lllllllll}0,07207 & 0,32891 & 0,33698 & 0,54713 & 0,06170 & 0,99730 & 0,16870 & * & 0,47909\end{array}$

$\begin{array}{llllllllll}0,65476 & 0,72013 & 0,43501 & 0,60798 & 0,12860 & 0,90110 & 0,22500 & 0,81890 & 0,40161 & 0,49274\end{array}$

$\begin{array}{lllllllllll}0,47724 & 0,78121 & 0,45373 & 0,57716 & 0,11940 & 0,93860 & 0,26590 & 0,83660 & 0,38072 & 0,39826\end{array}$

$\begin{array}{lllllllll}0,36883 & 0,67597 & 0,29613 & 0,44851 & 0,14500 & 0,88160 & 0,12440 & 0,81320\end{array}$

$\begin{array}{lllllllll}0,39157 & 0,43478 & 0,74164 & 1,00000 & 0,08320 & 0,90670 & 0,22110 & 0,85270 & 1,00000\end{array}$

$\begin{array}{llllllllll}0,37405 & 0,44645 & 0,48374 & 0,65531 & 0,08200 & 0,92450 & 0,28650 & 0,81270 & 0,52119 & 0,55669\end{array}$

$\begin{array}{lllllllllllll}0,36819 & 0,75598 & 0,26076 & 0,51667 & 0,14440 & 0,89470 & 0,10680 & 0,84270 & 0,32380 & 0,43103\end{array}$

$\begin{array}{lllllllllll}0,10233 & - & 0,22360 & 0,35616 & 0,19560 & 0,86660 & 0,36360 & 0,78750 & 0,71053 & 0,71174\end{array}$

$\begin{array}{llllllllll}0,21192 & 0,63200 & 0,43284 & 0,61074 & 0,02420 & 0,97240 & 0,06900 & 0,96630 & 0,57221 & 0,69548\end{array}$

$\begin{array}{llllllllll}0,19355 & 0,27818 & 0,19780 & 0,52533 & 0,15370 & 0,88910 & 0,18310 & 0,90590 & 0,90992 & 1,00000\end{array}$

$\begin{array}{lllllllll}0,68608 & 0,95688 & 0,46692 & 0,71681 & 0,10910 & 0,93360 & 0,18560 & 0,85110\end{array}$

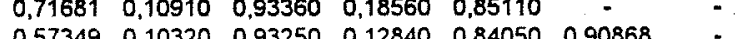

$\begin{array}{llllllllll}0,55203 & 0,72033 & 0,41774 & 0,56570 & 0,11190 & 0,93750 & 0,26620 & 0,79710 & \text { - }\end{array}$

$\begin{array}{llllllllll}0,13113 & - & 0,46045 & 0,50097 & 0,13690 & 0,95360 & 0,27410 & 0,83720 & 0,16288 & 0,34600\end{array}$

$\begin{array}{lllllllllll}0.08546 & 0.32977 & 0.14168 & 0.40025 & 0.08810 & 0.95960 & 0.24140 & 0.89970 & 1.00000\end{array}$

$\begin{array}{lllllllllll}0,07258 & - & 0,33083 & 0,43949 & 0,12600 & 0,83080 & 0,28410 & 0,75000 & 0,22487 & 0,31876\end{array}$

$\begin{array}{llllllllll}0,48503 & 0,64666 & 0,32932 & 0,57937 & 0,06670 & 0,93070 & 0,16170 & 0,88680 & 0,47129 & \text { - }\end{array}$

$\begin{array}{llllllllllll}0,60184 & 0,75052 & 0,74246 & 0,83245 & 0,09480 & 0,82910 & 0,18470 & 0,87830 & 0,98786 & \text { - }\end{array}$

$\begin{array}{llllllllll}0,23061 & 0,44773 & 0,28425 & 0,66048 & 0,13030 & 0,93590 & 0,26430 & 0,96540 & 0,07675 & 0,63623\end{array}$

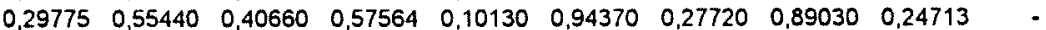

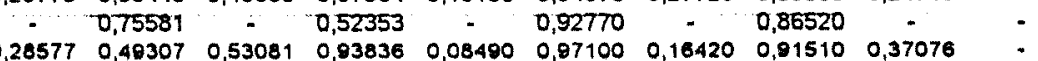

$\begin{array}{lllllllllll}0,30371 & 0,47222 & 0,13912 & 0,51687 & 0,08300 & 0,95940 & 0,16220 & 0,91110\end{array}$

$\begin{array}{llllllllll}0,11457 & 0,30409 & 0,37957 & 0,47876 & 0,07470 & 0,88430 & 0,15940 & 0,80740 & \text { - }\end{array}$

$\begin{array}{llllllllll}0,37607 & 0,53348 & 0,39850 & 0,67475 & 0,09620 & 0,93400 & 0,22520 & 0,85840 & 0,31845\end{array}$

$\begin{array}{llllllllll}0,21695 & - & 0,27824 & 0,56106 & 0,14330 & 0,88240 & 0,06800 & 0,87130 & 0,58467 & 0,73942\end{array}$

$\begin{array}{lllllllllll}0,24889 & 0,46269 & 0,21311 & 0,48602 & 0,12640 & 0,89050 & 0,21050 & 0,79300 & 0,68219 & 0,79245\end{array}$

$\begin{array}{llllllll}0,47130 & 0.76289 & 0.25524 & 0,60145 & 0,10790 & 0,95110 & 0,24660 & 0,83530\end{array}$

$\begin{array}{lllllllllll}0.49853 & 0.61479 & 0,40698 & 0.70979 & 0.05760 & 0.96940 & 0.16670 & 0.88890\end{array}$

$\begin{array}{llllllllll}0,49117 & 0,68639 & 0,39669 & 0,51843 & 0,07990 & 0,95000 & 0,19240 & 0,81690 & \text { - }\end{array}$

$\begin{array}{llllllllllll}0,52324 & 0,55796 & - & 0,00000 & 0,09190 & 0,96030 & 0,19710 & 0,87510 & -\end{array}$

$\begin{array}{llllllllll}0,36547 & 0,52747 & 0,38005 & 0,42562 & 0,15960 & 0,95060 & 0,22300 & 0,89110 & 0,31957 & 0,35763\end{array}$

$\begin{array}{lllllllll}0,46026 & 0,71199 & 0,29003 & 0,42194 & 0,10730 & 0,92440 & 0,35110 & 0,86460\end{array}$

$\begin{array}{llllllll}0,28305 & 0,49553 & 0,58542 & 0,84360 & 0,08720 & 0,94040 & 0,12690 & 0,86960\end{array}$

$\begin{array}{llllllllll}0,32406 & 0,38554 & 0,32295 & 0,43485 & 0,14110 & 0,90700 & 0,22730 & 0,84250 & 0,51734 & 0,73572\end{array}$

\begin{tabular}{ccccccccccc}
\hline & - & - & 0,92500 & - & 0,93010 & $*$ & 0,89090 & - & - \\
0,20724 & 0,30725 & 0,35826 & 0,65495 & 0,09230 & 0,89900 & 0,15790 & 0,81860 & 0,60232 & 0,78214
\end{tabular} $\begin{array}{lllllllll}0,30725 & 0,35826 & 0,65495 & 0,09230 & 0,89900 & 0,15790 & 0,81860 & 0,60232 & 0,78214\end{array}$ $\begin{array}{llllllllllll}0,51074 & 0,57090 & 0,58362 & 0,68623 & 0,13540 & 0,92990 & 0,18300 & 0,89880 & 0,73917 & 0,78509\end{array}$ $\begin{array}{lllllllllll}0,48935 & 0,39853 & 0,72986 & 1,00000 & 0,10580 & 0,90490 & 0,27720 & 0,78460 & 0,68438 & 0,83714\end{array}$ * $\begin{array}{lllllllllll}0,28571 & 0,21927 & 0,32131 & 0,16160 & 0,92930 & 0,19350 & 0,91450 & \text {. }\end{array}$ $\begin{array}{lllllllllll}0,32448 & 0,50241 & 0,53593 & 0,66377 & 0,12100 & 0,88740 & 0,20950 & 0,81760 & 0,13612 & 0,66596\end{array}$ $\begin{array}{llllllllll}0,14706 & - & 0,24927 & 0,51544 & 0,06650 & 0,92680 & 0,16890 & 0,87100 & 0,92366 & 0,97117\end{array}$ $\begin{array}{llllllllll}0,08140 & 0,59622 & 0,83223 & 0,36783 & 0,08250 & 0.94060 & 0,26650 & 0,88670 & 0.70044\end{array}$ $\begin{array}{lllllllllllll}0,13298 & 0,51389 & 0,27545 & 0,54545 & 0,18250 & 0,88340 & 0,16670 & 0,83560 & 0,53261 & 0,70745\end{array}$ 
Tabela 2. Indicadores de Educação e Coleta de Esgoto - municipios do Estado de São Paulo - 1991 e 1996.

\begin{tabular}{|c|c|c|c|c|c|c|c|c|c|c|}
\hline \multirow[b]{2}{*}{ Municipio } & \multicolumn{2}{|c|}{$\begin{array}{c}\text { Coef. } \\
\text { Matrícula } \\
\text { Pré-escola }\end{array}$} & \multicolumn{2}{|c|}{$\begin{array}{c}\text { Coef } \\
\text { Matrícula } \\
\text { Ensino Médio }\end{array}$} & \multicolumn{2}{|c|}{$\begin{array}{c}\text { Coef. } \\
\text { Evasão } \\
\text { Ensino Fund. }\end{array}$} & \multicolumn{2}{|c|}{$\begin{array}{c}\text { Coef. } \\
\text { Evasão } \\
\text { Ensino Médio }\end{array}$} & \multicolumn{2}{|c|}{$\begin{array}{c}\text { Coef. } \\
\text { Col. Esgoto }\end{array}$} \\
\hline & 1991 & 1996 & 1991 & 1996 & 1991 & 1996 & 1991 & 1996 & 1991 & 1996 \\
\hline Torre de Pedra & - & 0,60759 & - & 0,83673 & - & 0,90610 & - & 0,67440 & - & 0,56838 \\
\hline Torrinha & 0.25056 & $=$ & 0,44531 & 0,70167 & 0,08550 & 0,97010 & 0,11180 & 0,84920 & - & - \\
\hline Tremembé & 0,37009 & 0,55259 & 0,52827 & 0.59865 & 0,13640 & 0,87760 & 0,32180 & 0,72410 & 0,76355 & 0,74588 \\
\hline Trés Fronteiras & 0,20305 & 0,32766 & 0,35009 & 0,56090 & 0,07290 & 0,95290 & & 0,86050 & 0,40561 & 0,73636 \\
\hline Tuiuti & - & 0,28509 & - & 0,38672 & - & 0,98100 & - & - & - & - \\
\hline Tupa & 0,39383 & 0,44254 & 0,82112 & 1,00000 & 0,11350 & 0,93670 & 0,21630 & 0,86290 & 0,72711 & 0,88243 \\
\hline $\begin{array}{l}\text { Tupi Paulista } \\
\text { Turiuba } \\
\text { Turmalina }\end{array}$ & $\begin{array}{l}0,26667 \\
0,25389 \\
0,18831\end{array}$ & $\begin{array}{l}0,05841 \\
1,00000 \\
0,34532\end{array}$ & $\begin{array}{l}1,00000 \\
0,38583 \\
0,75758\end{array}$ & $\begin{array}{l}1,00000 \\
0,79439 \\
1,00000\end{array}$ & $\begin{array}{l}0,06630 \\
0,10930 \\
0,02610\end{array}$ & $\begin{array}{l}0,96860 \\
0,96100 \\
0,98670\end{array}$ & $\begin{array}{l}0,19310 \\
0,06320 \\
0,08200\end{array}$ & $\begin{array}{l}0,86450 \\
0,91010 \\
0,92210\end{array}$ & $\begin{array}{l}0,76354 \\
0,58614 \\
0,49860\end{array}$ & $\begin{array}{l}0, \overline{7686} \\
0,73041\end{array}$ \\
\hline Ubarana & $\therefore=$ & 0,72269 & 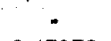 & 0,44800 & - & 0,82910 & - & 0,85050 & $\because$ & - \\
\hline Ubatuba & 0,41535 & 0,54594 & 0.47370 & 0,64227 & 0,13660 & 0,92250 & 0,32290 & 0,80730 & 0,19250 & 0,19668 \\
\hline Ubirajara & 0.14576 & $\ldots-\ldots \ldots$ & 0.22472 & 0.54185 & 0.08310 & 0.91240 & 0.07410 & 0,84000 & 0.44069 & 0.64571 \\
\hline Uchóa & 0,08964 & - & 0,47248 & 0.67797 & 0,03570 & 0,94410 & 0,14080 & 0,83760 & - & - \\
\hline União Paulista & 0,29114 & 0,40580 & 0,58182 & 0,79730 & 0,11110 & 0,92770 & 0,09380 & 0,83580 & 0,60452 & 0,76081 \\
\hline Urảnia & 0,15698 & 0,24649 & 0,63963 & 1.00000 & 0,08760 & 0,92860 & 0,13290 & 0,85840 & 0,50080 & 0,66430 \\
\hline Uru & 0,31646 & 0,74242 & - & - & 0,06810 & 0,94330 & - & - & 0,53736 & 0,73381 \\
\hline Urupès & 0,22830 & 0,57303 & 0,70284 & 0,78120 & 0,09870 & 0,91310 & 0,17470 & 0,82130 & - & - \\
\hline Valentim Gentil & 0,14121 & 0,60907 & 0,25246 & 0,65140 & 0,07480 & 0,92390 & 0,16670 & 0,83700 & 0,70746 & 0,83386 \\
\hline Valinhos & 0,75019 & 0,97431 & 0,62943 & 0,94072 & 0,11060 & 0,92140 & 0,18350 & 0,86170 & $\cdot$ & - \\
\hline Valparaiso & 0,54545 & 0,82694 & 0,51629 & 0,68651 & 0,13900 & 0,95760 & 0,19420 & 0,99870 & 0,03173 & $\therefore$ \\
\hline Vargem & - & - & - & 0,70809 & - & 0,88780 & - & 0,86580 & • & $\cdot$ \\
\hline Vargem Grande do Sul & 0,41269 & 0,44048 & 0,37553 & 0,50317 & 0,08430 & 0,89890 & 0.22430 & 0,86570 & $\cdot$ & - \\
\hline Vargem Grande Paulista & 0,05732 & 0,48227 & 0,53270 & 0,63945 & 0,12510 & 0,92270 & 0,26460 & 0.86540 & 0.17350 & - \\
\hline Várzea Paulista & 0,22211 & 0,41696 & 0.16000 & 0,32442 & 0,08990 & 0.95370 & 0,12020 & 0,85630 & $=$ & - \\
\hline Vera Cruz & 0,55128 & 0,76719 & 0,77279 & 0,84824 & 0,10350 & 0,91220 & 0.19430 & 0,85050 & - & - \\
\hline Vinhedo & 0,54715 & 0,88883 & 0,35613 & 0,67391 & 0,09420 & 0.90930 & 0,17090 & 0,83630 & 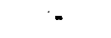 & - \\
\hline Viradouro & 0,07556 & 0,32087 & 0,35574 & 0,51681 & 0.11620 & 0.94200 & 0,25480 & 0,83290 & - & $\cdot$ \\
\hline Vista Alegredo Alto. & 0.32420 & 0,56944 & 0,18824 & 0,42857 & 0,08150 & 0,96860 & 0,15150 & 0,90000 & 0,84833 & $\bullet$ \\
\hline Votorantim & 0,75858 & 0,82955 & 0,23718 & 0,53032 & 0,10450 & 0,93500 & 0,27150 & 0,84150 & 0,80710 & * \\
\hline Votup & 0,39680 & 0,41688 & 0,73208 & 0,84165 & 0,08350 & 0,94620 & 0,15370 & 0,90610 & - & 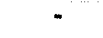 \\
\hline Zacarias & - & 0.79516 & - & 0,88542 & - & 0,94640 & - & 0,82930 & - & - \\
\hline
\end{tabular}

- Dado inexistente 
Tabela 3. Indicadores de Saúde, Segurança e Abastecimento de Água - municipios do Estado de São Paulo - 1991 e 1996.

\begin{tabular}{|c|c|c|c|c|c|c|c|c|c|c|}
\hline \multirow[b]{3}{*}{ Municipio } & \multicolumn{2}{|c|}{ Coef. } & \multicolumn{2}{|c|}{ Coef. } & \multicolumn{2}{|c|}{ Coef. } & \multicolumn{2}{|c|}{ Coef. } & \multicolumn{2}{|c|}{ Coef. } \\
\hline & \multicolumn{2}{|c|}{ INFANTIL } & \multicolumn{2}{|c|}{60 anos + } & \multicolumn{2}{|c|}{ HOMICIDIOS } & \multicolumn{2}{|c|}{ AC. VEIC. MOTOR } & \multicolumn{2}{|c|}{ ABAST. ÁGUA } \\
\hline & 1991 & 1996 & 1991 & 1996 & 1991 & 1996 & 1991 & 1996 & 1991 & 1996 \\
\hline Adamantina & 0,00928 & 0,02222 & 0,02889 & 0.02727 & 0,00006 & 0.00006 & 0,00012 & 0,00027 & 0,84988 & 0,93922 \\
\hline Adolfo & 0,01818 & 0,00000 & 0,02373 & 0,04153 & 0,00000 & 0,00000 & 0,00000 & 0,00000 & 0,75751 & 0,91056 \\
\hline Aguai & 0,02544 & 0,02263 & 0,03379 & 0,03536 & 0,00017 & 0,00008 & 0,00034 & 0,00035 & - & - \\
\hline Áquas da Prala & 0,30435 & 0,01111 & 0,02810 & 0,03608 & 0,00000 & 0,00000 & 0,00015 & 0,00029 & 1,00000 & 1,00000 \\
\hline Águas de Lindóia & 0,01316 & 0,01351 & 0,04313 & 0,02888 & 0,00017 & 0,00014 & 0,00033 & 0,00014 & $\cdot$ & - \\
\hline Aguas de Santa Bárbara & 0,03279 & 0,01235 & 0,03061 & 0,02857 & 0,00000 & 0,00044 & 0,00077 & 0,00022 & 0,73355 & 0,75081 \\
\hline Águas de São Pedro & 0,04000 & 0,00000 & 0,02449 & 0,01825 & 0,00000 & 0,00000 & 0,00000 & 0,00000 & 1,00000 & 1,00000 \\
\hline Agudos & 0,02614 & 0,01780 & 0,03358 & 0,03416 & 0,00017 & 0,00016 & 0,00013 & 0,00019 & 0,91126 & ...... \\
\hline Alambari & - & 0,00000 & - & 0,02589 & - & 0,00000 & - & 0,00029 & - & 1,00000 \\
\hline Alfredo Marcondes & 0,00000 & 0,02439 & 0,03825 & 0,01587 & 0,00000 & 0,00028 & 0,00000 & 0,00000 & 0,71597 & 0,76546 \\
\hline Altair & 0,05172 & 0,02941 & 0,03865 & 0,02905 & 0,00000 & 0,00000 & 0,00031 & 0,00000 & 0,67870 & 0,75558 \\
\hline Altinópolis & 0,01210 & 0,01145 & 0,02496 & 0,02967 & 0,00007 & 0,00007 & 0,00007 & 0,00027 & - & $\cdot$ \\
\hline Alto Alegre & 0,02439 & 0,00000 & 0,02282 & 0,03475 & 0,00000 & 0,00000 & 0,00000 & 0,00000 & 0,54891 & 0,69666 \\
\hline Aluminio & $\cdot$ & 0,01056 & $\cdot$ & 0,03279 & $\cdot$ & 0,000138 & $\cdot$ & 0,00000 & - & $-\cdots$ \\
\hline Álvares Florence & 0,02381 & 0,01724 & 0,01822 & 0,03065 & 0,00000 & 0,00000 & 0,00020 & 0,00000 & 0,51399 & 0,62272 \\
\hline Alvares Machado & 0,04563 & 0,02000 & 0,02776 & 0,03013 & 0,00005 & 0,00019 & 0,00021 & 0,00024 & 0,72901 & 0,88232 \\
\hline Álvaro de Carvalho & 0.01538 & 0,05882 & 0,02920 & 0,02990 & 0,00000 & 0,00000 & 0,00000 & 0,00055 & 0,58051 & 0,84511 \\
\hline Alvinlândia & 0.04348 & 0,01370 & 0.02183 & 0,01984 & 0,00000 & 0.00000 & 0,00000 & 0.00000 & 0.73000 & 0.89450 \\
\hline Americana & 0,01749 & 0,01096 & 0,02803 & 0,03316 & 0,00010 & 0,00012 & 0,00020 & 0,00028 & 1,00000 & - \\
\hline Américo Brasiliense & 0,01699 & 0,01714 & 0,03417 & 0,04518 & 0,00005 & 0,00004 & 0,00020 & 0,00016 & 0,73194 & - \\
\hline Américo de Campos & 0,02041 & 0,02941 & 0,03493 & 0.03130 & 0,00000 & 0,00000 & 0,00036 & 0,00089 & $0,6372 \theta$ & - \\
\hline Amparo & 0,02703 & 0,01873 & 0,03239 & 0,03700 & 0,00004 & 0,00005 & 0,00016 & 0,00023 & - & - \\
\hline Analândia & 0,00000 & 0,02326 & 0,02000 & 0,06985 & 0,00000 & 0,00030 & 0,00000 & 0,00000 & $\cdot$ & $\cdot$ \\
\hline Andradina & 0,02475 & 0,01506 & 0,02959 & 0,02626 & 0,00021 & 0,00018 & 0,00006 & 0,00017 & $\cdot$ & - \\
\hline Angatuba & 0,02401 & 0,01872 & 0,03419 & 0.03304 & 0,00012 & 0,00000 & 0,00035 & 0,00043 & 0,64641 & 0,86169 \\
\hline Anhembi & 0,02667 & 0,01408 & 0.06145 & 0.02421 & 0,00000 & 0,00000 & 0,00000 & 0,00049 & 0,68421 & 0,84833 \\
\hline Anhumas & 0,01639 & 0,03571 & 0,02459 & 0,03717 & 0,00000 & 0,00000 & 0,00000 & 0,00030 & 0,54786 & 0,82067 \\
\hline Aparecida & 0,02703 & 0,01943 & 0,03804 & 0,03994 & 0,00003 & 0,00003 & 0,00024 & 0,00023 & $\cdot$ & - \\
\hline Aparecida toeste & 0,03030 & 0,00000 & 0.03198 & 0,02286 & 0,00000 & 0,00020 & 0,00000 & 0.00040 & 0,69875 & 0.76934 \\
\hline Apiai & 0,07385 & 0,01935 & 0,03920 & 0,05166 & 0,00019 & 0,00004 & 0,00015 & 0,00015 & 0,49635 & 0,98220 \\
\hline Araçariguama & - & 0,02010 & - & 0,04527 & - & 0,000334 & - & 0,00044 & - & 0,38404 \\
\hline Aracatuba & 0,01970 & 0,01418 & 0,02861 & 0,02963 & 0,00008 & 0,00012 & 0,00026 & 0,00023 & 0,92167 & $-\quad \therefore$ \\
\hline Araçoiaba da Serra & 0,03207 & 0,01534 & 0,03289 & 0,03704 & 0,00021 & 0,00012 & 0,00028 & 0,00035 & 0.46350 & 0.62397 \\
\hline Aramina $\quad \ldots . . . . .$. & 0,00000 & 0,01639 & 0,01558 & 0,03101 & 0,00000 & 0,00022 & 0,00025 & 0,00000 & - & - \\
\hline Arandu & 0,01613 & 0,02500 & 0,02244 & 0,02920 & 0,00000 & 0,00000 & 0,00036 & 0,00017 & 0,51444 & 0,64500 \\
\hline Arapel & - & 0,00000 & - & 0,03042 & - & 0,00000 & - & 0,00040 & + & 0,69088 \\
\hline Araraquara & 0,02184 & 0,01393 & 0,03116 & 0,03200 & 0,00009 & 0,00009 & 0,00025 & 0,00031 & 0,93835 & - \\
\hline Araras & 0,02284 & 0,01706 & 0,03091 & 0,03326 & 0,00009 & 0,00012 & 0,00018 & 0,00033 & 0,86198 & - \\
\hline Arealva & 0,01282 & 0,00000 & 0,02527 & 0,02000 & 0,00000 & 0,00014 & 0,00000 & 0,00014 & 0,65115 & 0,78204 \\
\hline Areias & 0,04167 & 0,02128 & 0,02800 & 0,02703 & 0,00000 & 0,00000 & 0,00000 & 0,00000 & 0,59301 & $=$ \\
\hline Areiópolis & 0,02344 & 0,01923 & 0.04000 & 0,03002 & 0,00000 & 0,00020 & 0,00000 & 0,00010 & 0,67414 & 0.75011 \\
\hline Ariranha & 0.01010 & 0,01724 & .0 .02903 & 0,03026 & 0,00000 & 0,00000 & 0,00017 & 0.00000 & 0.85443 & $\ldots$ \\
\hline Artur Nogueira & 0,03386 & 0,01411 & 0,02425 & 0,02563 & 0,00005 & 0,00004 & 0,00061 & 0,00052 & - & $\cdot$ \\
\hline Arujáa & 0,04064 & 0,03709 & 0,03378 & 0,04180 & 0,00019 & 0,00037 & 0,00022 & 0,00035 & 0,73168 & $+\cdots$ \\
\hline Aspásia & - & 0.06667 & - & 0.02513 & - & 0,00000 & - & 0,00000 & - & 0.57273 \\
\hline Assis & 0,02609 & $0,0168 \theta$ & 0.03362 & 0,03089 & 0,00016 & 0,00022 & 0,00032 & 0,00048 & 0,80816 & 0,88398 \\
\hline Atibaia & 0,03239 & 0,02800 & 0,02698 & 0,03130 & 0,00015 & 0,00019 & 0,00036 & 0,00032 & $\cdot$ & - \\
\hline Auriflama & 0,02120 & 0,01581 & 0,01815 & 0,02568 & 0,00000 & 0,00000 & 0,00008 & 0,00060 & 0,82474 & 0,90916 \\
\hline Aval & 0,03191 & 0,01299 & 0.03750 & 0,02511 & 0,00000 & 0,00022 & 0,00000 & 0,00087 & 0.59466 & 0.68977 \\
\hline Avanhandava ... & 0,04217 & 0,02516 & 0,03623 & 0,04035 & 0,00000 & 0,00000 & 0,00013 & 0,00024 & 0.83108 & - \\
\hline Avaré & 0,02903 & 0,02514 & 0,03238 & 0,03906 & 0,00002 & 0,00004 & 0,00023 & 0.00019 & 0,87131 & 0,90494 \\
\hline Bady Bassitt & 0,02083 & 0,01471 & 0.03119 & 0,02360 & 0,00000 & 0,00000 & 0,00035 & 0,00023 & - & $\cdot$ \\
\hline Balbinos & 0,20000 & 0,00000 & 0,03738 & 0,02113 & 0,00000 & 0,00000 & 0,00082 & 0,00000 & 0,65595 & 0,87817 \\
\hline Bálsamo & 0,00870 & 0,00813 & 0,02009 & 0,02119 & 0,00015 & 0,00000 & 0,00015 & 0,00028 & - & - \\
\hline Bananal & 0,00826 & 0,00000 & 0,03140 & 0,03117 & 0,00011 & 0,00000 & 0,00011 & 0,00011 & 0,65049 & 0,80000 \\
\hline Barāo de Antonina & 0,01923 & 0,00000 & 0,03891 & 0,02230 & 0,00033 & 0,00034 & 0,00000 & 0,00000 & 0,67391 & 0,93872 \\
\hline Barbosa & 0,00943 & 0,00000 & 0,05495 & 0,03219 & 0,00000 & 0,00000 & 0,00037 & 0,00018 & 0,75845 & - \\
\hline Bariri & 0,03023 & 0,01603 & 0,03286 & 0,02555 & 0,00004 & 0,00000 & 0,00012 & 0,00026 & 1,00000 & $=$ \\
\hline Barra Bonita & 0,02047 & 0,02015 & 0,02984 & 0,03473 & 0,00007 & 0,00003 & 0,00029 & 0,00012 & 1,00000 & - \\
\hline Barra do Chapéu & $\ldots$ & 0,01550 & .. & 0,04787 & $=$ & 0,00000 & $\cdot$ & 0,00000 & - & 0,37022 \\
\hline Barra do Turvo & 0,03871 & 0,04412 & 0,03678 & 0.02627 & 0,00028 & 0,00065 & 0,00128 & 0,00091 & 0,31075 & 0,34483 \\
\hline Barretos & 0,03212 & 0,04029 & 0,03324 & 0,03718 & 0,00013 & 0,00008 & 0,00021 & 0,00025 & + & $\cdot \cdot \cdot$ \\
\hline Barrinha & 0,02548 & 0,02564 & 0.03632 & 0.04000 & 0,00005 & 0.00028 & 0,00011 & 0,00042 & $\cdot$ & - \\
\hline
\end{tabular}


Tabela 3. Indicadores de Saúde, Segurança e Abastecimento de Água - municipios do Estado de São Paulo - 1991 e 1996.

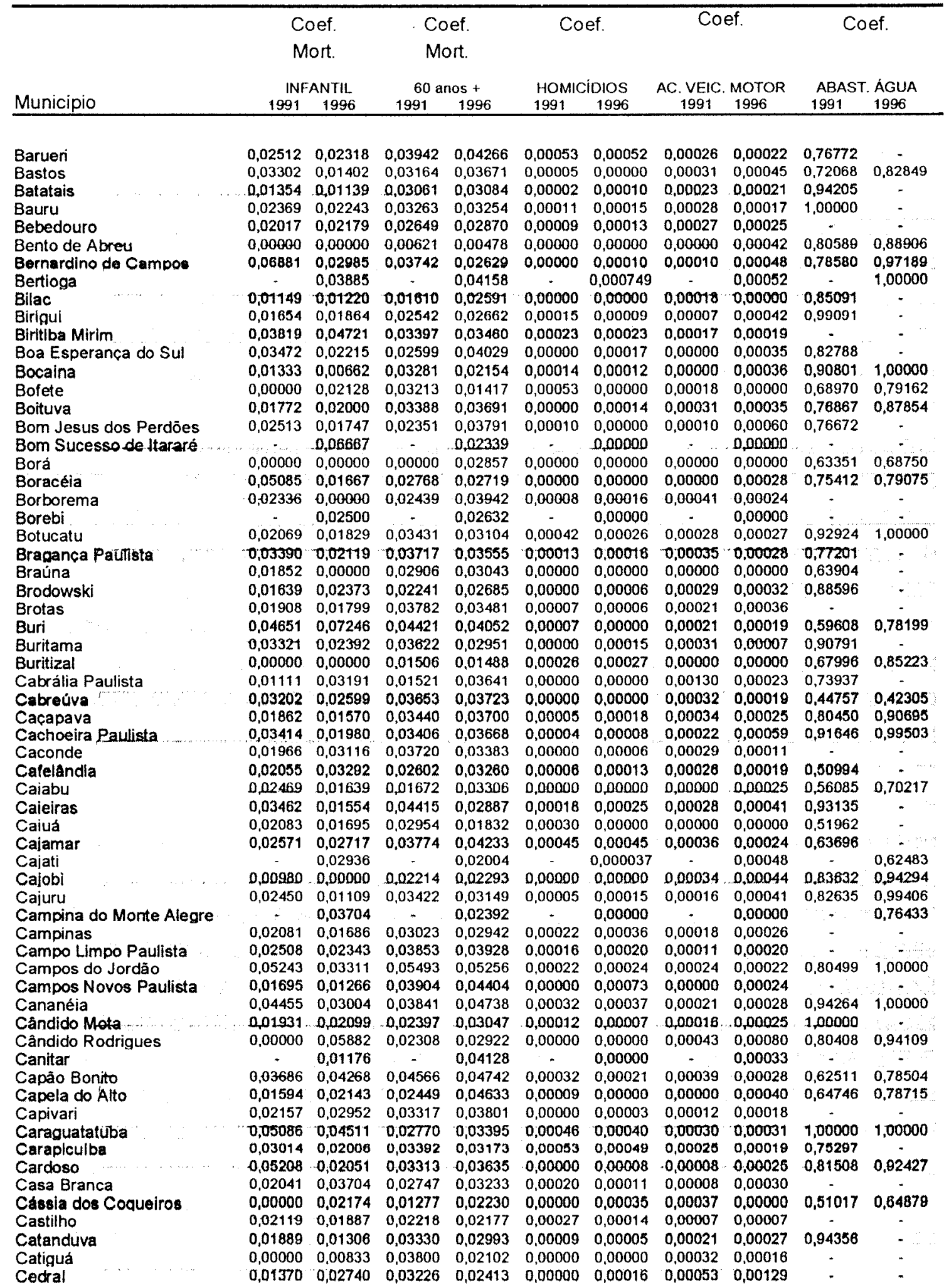


Tabela 3. Indicadores de Saúde, Segurança e Abastecimento de Água - municípios do Estado de São Paulo - 1991 e 1996.

\begin{tabular}{|c|c|c|c|c|c|c|c|c|c|c|}
\hline \multirow{4}{*}{ Municipio } & \multirow{2}{*}{\multicolumn{2}{|c|}{$\begin{array}{l}\text { Coef. } \\
\text { Mort. }\end{array}$}} & \multicolumn{2}{|c|}{ Coef. } & \multirow{2}{*}{\multicolumn{2}{|c|}{ Coef. }} & \multicolumn{2}{|c|}{ Coef. } & \multicolumn{2}{|c|}{ Coef. } \\
\hline & & & & & & & & & & \\
\hline & \multicolumn{2}{|c|}{ INFANTIL } & \multicolumn{2}{|c|}{60 anos +} & \multicolumn{2}{|c|}{ HOMICIDIOS } & \multicolumn{2}{|c|}{ AC. VEIC. MOTOR } & ABAST. & ÁGUA \\
\hline & 1991 & 1996 & 1991 & 1996 & 1991 & 1996 & 1991 & & 1991 & 1996 \\
\hline Cerqueira Cesar & 0,02974 & 0,01606 & 0,03737 & 0,03522 & 0,00000 & 0,00007 & 0,00016 & 0,00021 & 0,80838 & - \\
\hline Cerquilho & 0,01609 & 0,01602 & 0,02765 & 0,02868 & 0,00005 & 0,00004 & 0,00020 & 0,00048 & 0,90067 & - \\
\hline Cesário Lange & 0,01546 & 0,02222 & 0,03281 & 0,05015 & 0,00000 & 0,00008 & 0,00018 & 0,00000 & 0,75773 & 0,64855 \\
\hline Charqueada & 0,03070 & 0,03077 & 0,03535 & 0,04175 & 0,00009 & 0,00000 & 0,00028 & 0,00008 & 0,85609 & 1,00000 \\
\hline Chavantes & 0,03378 & 0,02166 & 0,03262 & 0,02726 & 0,00017 & 0,00008 & 0,00034 & 0,00008 & - & - \\
\hline Clementina & 0,04225 & 0,00000 & 0,02978 & 0,03052 & 0,00021 & 0,00000 & 0,00021 & 0,00019 & 0,83754 & - \\
\hline Colina & 0,02601 & 0,01829 & 0,03092 & 0,03231 & 0,00013 & 0,00000 & 0,00025 & 0,00006 & - & - \\
\hline Colômbia & 0,03571 & 0,02500 & 0,01880 & 0,03448 & 0,00000 & 0,00000 & 0,00000 & 0,00018 & 0,85738 & 0,85331 \\
\hline Conchal & 0,03629 & 0,03166 & 0,03150 & 0,03521 & 0,00016 & 0,00028 & 0,00016 & 0,00033 & 0,65974 & - \\
\hline Conchas & 0,01818 & 0,00990 & 0,02595 & 0,02656 & 0,00000 & 0,00000 & 0,00017 & 0,00015 & - & 0,76749 \\
\hline Cordeirópolis & 0,06767 & 0,02632 & 0,02818 & 0,02802 & 0,00008 & 0,00000 & 0,00008 & 0,00032 & 0,93196 & - \\
\hline Coroados & 0,00000 & 0,01020 & 0,02517 & 0,02804 & 0,00000 & 0,00000 & 0,00026 & 0,00000 & 0,69628 & 0,77595 \\
\hline Coronel Macedo & 0,05376 & 0,00806 & 0,03750 & 0,03820 & 0,00000 & 0,00000 & 0,00000 & 0,00000 & 0,60294 & 0,73606 \\
\hline Corumbatai & 0,02381 & 0,05128 & 0,03268 & 0,02417 & 0,00032 & 0,00029 & 0,00000 & 0,00000 & - & - \\
\hline Cosmópolis & 0,03143 & 0,01902 & 0,02191 & 0,03094 & 0,00009 & 0,00018 & 0,00035 & 0,00013 & - & - \\
\hline Cosmorama & 0,06542 & 0,05155 & 0,01774 & 0,01975 & 0,00000 & 0.00000 & 0,00026 & 0,00000 & 0,59053 & - \\
\hline Cotia & 0,03476 & 0,02514 & 0,03743 & 0,04370 & 0,00037 & 0,00031 & 0,00038 & 0,00031 & 0,71852 & - \\
\hline Cravinhos & 0,01952 & 0,01770 & 0,03433 & 0,04019 & 0,00004 & 0,00019 & 0,00040 & 0,00043 & - & - \\
\hline Cristais Paulista & 0,05376 & 0,02609 & 0,02521 & 0,02119 & 0,00000 & 0.00000 & 0,00000 & 0,00032 & 0,45397 & - \\
\hline Cruzália & 0,01220 & 0,04082 & 0,00912 & 0,00485 & 0,00000 & 0,00000 & 0,00000 & 0,00000 & 0.68818 & 0,91148 \\
\hline Cruzelro & 0,02662 & 0,02381 & 0,04084 & 0,03417 & 0,00010 & 0,00013 & 0,00019 & 0,00024 & ? & - \\
\hline Cubatăo & 0,03210 & 0,02132 & 0,03811 & 0,03440 & 0,00037 & 0,00029 & 0,00035 & 0,00045 & 0,83594 & 0,87250 \\
\hline Cunha & 0,02462 & 0,02715 & 0,04121 & 0,04268 & 0,00026 & 0,00000 & 0,00004 & 0,00004 & - & - \\
\hline Descalvado & 0,01016 & 0,01437 & 0,03823 & 0,03086 & 0,00000 & 0,00004 & 0,00008 & 0,00015 & - & - \\
\hline Diadema & 0,03288 & 0,02127 & 0,03559 & 0,03672 & 0,00086 & 0,00126 & 0,00029 & 0,00032 & 0,68472 & - \\
\hline Dirce Reis & $-\cdots$ & 0,00000 & - & 0,00000 & - & 0,00000 & : & 0,00000 & - & 0.67909 \\
\hline Divinolândia & 0,01533 & 0,01130 & 0,03380 & 0,03237 & 0,00000 & 0,00000 & 0,00025 & 0,00017 & 0,46358 & 0,56696 \\
\hline Dobrada & 0,05385 & 0,00000 & 0.01809 & 0,02906 & 0,00000 & 0,00014 & 0,00029 & 0.00000 & $\cdot$ & - \\
\hline Dois Córregos & 0,02439 & 0,03248 & 0,02778 & 0,02884 & 0,00000 & 0,00005 & 0,00011 & 0,00019 & - & - \\
\hline Dolcinópolis & 0,00000 & 0,00000 & 0,02941 & 0,03093 & 0,00000 & 0,00047 & 0,00000 & 0,00000 & 0,84899 & 0,84339 \\
\hline Dourado & 0,02158 & 0,00862 & 0,02686 & 0,03551 & 0,00013 & 0,00000 & 0,00026 & 0,00061 & 0,89629 & 1,00000 \\
\hline Dracena & 0,02101 & 0,01536 & 0,02961 & 0,02893 & 0,00003 & 0,00015 & 0,00048 & 0,00025 & 0,90280 & - \\
\hline Duartina & 0,04583 & 0,02985 & 0,03138 & 0,02975 & 0,00000 & 0,00000 & 0,00034 & 0,00024 & 0,67436 & - \\
\hline Dumont & 0,00962 & 0.00901 & 0.04154 & 0.01996 & 0,00000 & 0,00000 & 0,00020 & 0,00000 & $\cdot$ & - \\
\hline Echaporã & 0,01408 & 0,01653 & 0,02783 & 0,02716 & 0,00016 & 0,00015 & 0,00032 & 0,00015 & 0,56741 & 0,73774 \\
\hline Eldorado & 0,03621 & 0,02067 & 0,03659 & 0,03976 & 0,00015 & 0,00022 & 0,00015 & 0,00007 & 0.49518 & 0,69760 \\
\hline Elias Fausto & 0,03111 & 0,01439 & 0,02237 & 0,04323 & 0,00000 & 0,00023 & 0,00017 & 0,00008 & - & 0,66346 \\
\hline Elisiário & - & 0,00000 & - & 0,02069 & . & 0,00000 & - & 0,00000 & - & + \\
\hline Embaúba & - & 0,02703 & - & 0,02119 & - & 0,00000 & - & 0,00041 & - & 0,77156 \\
\hline Embu & 0,04495 & 0,02812 & 0,03885 & 0,03867 & 0,00079 & 0,00113 & 0,00028 & 0,00019 & 0,70683 & $\therefore$ \\
\hline Embu-Guaçu & 0,03241 & 0,03575 & 0,03392 & 0,05584 & 0,00045 & 0,00056 & 0,00031 & 0,00024 & 0,60386 & - \\
\hline Emilianópolis & r & 0,00000 & - & 0,01556 & 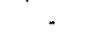 & 0,00000 & - & 0,00138 & - & 0,83163 \\
\hline Engenheiro Coelho & - & 0,02721 & - & 0,03497 & - & 0,00000 & - & 0,00023 & - & - \\
\hline Espirito Santo do Pinhal & 0,03403 & 0,02405 & 0,03632 & 0,03391 & 0,00024 & 0,00003 & 0,00008 & 0.00038 & 0.91073 & 0,96733 \\
\hline Espirito Santo do Turvo & - & 0,00000 & - & 0,04348 & - & 0,00000 & - & 0,00060 & - & 0,99035 \\
\hline Estiva Gerbi & $\cdots$ & 0,02703 & - & 0,03214 & * & 0,00000 & - & 0,00039 & - & - \\
\hline Estrela do Norte & 0,01613 & 0,00000 & 0,14362 & 0,12971 & 0,00000 & 0,00000 & 0,00000 & 0,00000 & 0.61090 & 0,77834 \\
\hline Estrela d'Oeste & 0,03049 & 0,01563 & 0,01355 & 0,00774 & 0,00000 & 0,00000 & 0,00024 & 0,00012 & 0,53976 & 0,66943 \\
\hline Euclides da Cunha Paulista & + & 0,02404 & - & 0,02481 & - & 0,000305 & - & 0,00000 & - & 0,66286 \\
\hline Fartura & 0,02556 & 0,02662 & 0,03777 & 0,02811 & 0,00000 & 0,00007 & 0,00021 & 0,00027 & - & 0,71840 \\
\hline Fernando Prestes & 0,04706 & 0,03448 & 0,02518 & 0,02408 & 0,00000 & 0,00000 & 0,00000 & 0,00019 & 0,82196 & 0,83524 \\
\hline Fernandopolis & 0,02111 & 0,01527 & 0,02740 & 0,02804 & 0,00002 & 0,00003 & 0,00011 & 0,00030 & 0,88787 & 0,99599 \\
\hline Ferraz de Vasconcelos & 0,03864 & 0,02529 & 0,04894 & 0,03820 & 0,00032 & 0,00040 & 0,00019 & 0,00014 & 0,76030 & - \\
\hline Flora Rica & 0,02439 & 0,00000 & 0,03211 & 0,03175 & 0,00000 & 0,00000 & 0,00000 & 0,00044 & 0,67980 & 0,75829 \\
\hline Floreal & 0,00000 & 0,00000 & 0,03611 & 0,03059 & 0,00000 & 0,00000 & 0,00000 & 0,00089 & 0,70385 & 0,81238 \\
\hline Flórida Paulista & 0,01395 & 0,04061 & 0,03220 & 0,02433 & 0,00008 & 0,00000 & 0,00024 & 0,00008 & 0,70926 & 0,85915 \\
\hline Florinia & 0,00000 & 0,07273 & 0,03030 & 0,03042 & 0,00033 & 0,00000 & 0,00000 & 0,00261 & 0.82124 & 0,91676 \\
\hline Franca & 0,01832 & 0,01750 & 0,03161 & 0,03321 & 0.00005 & 0,00002 & 0,00013 & 0,00024 & 0,88990 & 1,00000 \\
\hline Francisco Morato & 0,05100 & 0,03263 & 0,03904 & 0,04329 & 0,00058 & 0,00049 & 0,00007 & 0,00013 & 0,56742 & - \\
\hline Franco da Rocha & 0,03130 & 0,02188 & 0,03926 & 0,03713 & 0,00026 & 0,00065 & 0,00018 & 0,00028 & 0.74712 & $-\ldots$ \\
\hline Gabriel Monteiro & 0,00000 & 0,00000 & 0,02273 & 0,02789 & 0,00000 & 0,00000 & 0,00040 & 0,00038 & 0.52265 & 0,74218 \\
\hline Gália & 0,00565 & 0,04124 & 0.03176 & 0,02860 & 0,00000 & 0,00012 & 0,00000 & 0,00012 & 0,54485 & 0,79496 \\
\hline Garça & 0,03125 & 0,03471 & 0,03366 & 0,03287 & 0,00002 & 0,00012 & 0,00031 & 0,00014 & 0,77956 & - \\
\hline
\end{tabular}


Tabela 3. Indicadores de Saúde, Segurança e Abastecimento de Água - municípios do Estado de São Paulo - 1991 e 1996.

\begin{tabular}{|c|c|c|c|c|c|c|c|c|c|c|}
\hline \multirow[b]{3}{*}{ Municipio } & \multicolumn{2}{|c|}{$\begin{array}{l}\text { Coef. } \\
\text { Mort }\end{array}$} & \multicolumn{2}{|c|}{ Coef. } & \multicolumn{2}{|c|}{ Coef. } & \multicolumn{2}{|c|}{ Coef. } & \multicolumn{2}{|c|}{ Coef. } \\
\hline & \multicolumn{2}{|c|}{ INFANTIL. } & \multicolumn{2}{|c|}{60 anos +} & \multicolumn{2}{|c|}{ HOMICIDIOS } & \multicolumn{2}{|c|}{ AC. VEIC. MOTOR } & \multicolumn{2}{|c|}{ ABAST. ÁGUA } \\
\hline & 1991 & 1996 & 1991 & 1996 & 1991 & 1996 & 1991 & 1996 & 1991 & 1996 \\
\hline Gaståo Vidigal & 0,04082 & 0,00000 & 0,03560 & 0,04573 & 0,00000 & 0,00000 & 0,00052 & 0,00027 & 0,72421 & 0,75049 \\
\hline General Salgado & 0,02715 & 0,03550 & 0,03021 & 0,03448 & 0,00000 & 0,00000 & 0,00000 & 0,00019 & - & - \\
\hline Getulina & 0,01015 & 0,02817 & 0,03406 & 0,02292 & 0,00010 & 0,00019 & 0.00010 & 0,00010 & 0.74453 & - \\
\hline Glicério & 0,05128 & 0,00000 & 0,02874 & 0,02302 & 0,00000 & 0,00000 & 0,00000 & 0,00023 & 0,57047 & - \\
\hline Guaicara & 0,03636 & 0,02286 & 0,03059 & 0,01884 & 0,00000 & 0,00013 & 0,00016 & 0,00013 & , & * \\
\hline Guaimbē & 0,02247 & 0,01563 & 0,05076 & 0,02055 & 0,00019 & 0,00000 & 0,00019 & 0,00000 & - & - \\
\hline Guaíra & 0,01010 & 0,01711 & 0,02811 & 0,03738 & 0,00006 & 0,00018 & 0,00013 & 0,00009 & 0,70204 & - \\
\hline Guapiaçu & 0,02062 & 0,00552 & 0,02618 & 0,03045 & 0,00000 & 0,00000 & 0,00009 & 0,00040 & - & - \\
\hline Guapiara & 0,03992 & 0,05769 & $0,0,3951$ & 0,03467 & 0,00011 & 0,00005 & 0,00022 & 0,00016 & 0,31512 & 0,49385 \\
\hline Guará & 0,00299 & 0,01146 & 0,03833 & 0,04122 & 0,00018 & 0,00006 & 0,00037 & 0,00023 & - & $\cdot$ \\
\hline Guaracal & 0,01471 & 0,00680 & 0,02488 & 0,02628 & 0,00024 & 0,00000 & 0,00012 & 0,00023 & 0,66956 & 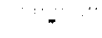 \\
\hline Guaraci & 0,02162 & 0.00526 & 0,03994 & 0,02882 & 0,00000 & 0,00012 & 0,00026 & 0,00012 & - & $\cdot$ \\
\hline Guarani d'Oeste & 0,02273 & $0,0260 \theta$ & 0,03344 & 0,02979 & 0,00000 & 0,00000 & 0,00053 & 0,00206 & 0,82075 & 0,90080 \\
\hline Guarantā & 0,02970 & 0,02857 & 0,02989 & 0,04889 & 0,00036 & 0,00000 & 0,00000 & 0,00000 & - & - \\
\hline Guararapes & 0,03383 & 0,01050 & 0,02954 & 0,02356 & 0,00011 & 0,00007 & 0,00038 & 0,00050 & 0.81616 & $-\cdots$ \\
\hline Guararema & 0,03704 & 0,03795 & 0,02996 & 0,04332 & 0,00011 & 0,00020 & 0,00033 & 0,00050 & 0,48792 & 0,61315 \\
\hline Guaratinguetá & 0,03108 & 0,02076 & 0,03735 & 0,03759 & 0,00015 & 0,00013 & 0,00013 & 0,00028 & - & - \\
\hline Guarei & 0,04167 & 0,02632 & 0,02385 & 0,03085 & 0,00000 & 0,00000 & 0,00024 & 0,00021 & 0,45198 & 0,68676 \\
\hline Guariba & 0,02661 & 0,01901 & 0,03539 & 0,03215 & 0,00010 & 0,00017 & 0,00031 & 0,00013 & 1,00000 & 1,00000 \\
\hline Guarujá & 0,03526 & 0,03106 & 0,03338 & 0,03815 & 0,00026 & 0,00054 & 0.00024 & 0,00026 & 1,00000 & 1,00000 \\
\hline Guarulhos & 0,03360 & $.0,03230$ & 0,03708 & 0,03840 & 0,00044 & 0,00059 & 0,00021 & 0,00026 & 0,64560 & $\therefore$ \\
\hline Guatapará & - & 0,00952 & - & 0,04032 & - & 0,000163 & - & 0,00016 & - & - \\
\hline Guzolândia & 0,00893 & 0,03000 & 0,01146 & 0,03217 & 0,00020 & 0,00021 & 0,00060 & 0,00043 & 0.69447 & 0,88324 \\
\hline Herculândia & 0,00855 & 0,01653 & 0,03175 & 0,03000 & 0,00000 & 0,00000 & 0,00043 & 0,00013 & 0,81997 & - \\
\hline Holambra & - & 0,02174 & - & 0,02010 & - & 0,00000 & + & 0,00047 & + & $\because$ \\
\hline Hortolândia & - & 0,01843 & - & 0,03662 & - & 0,000324 & - & 0,00033 & - & - \\
\hline lacanga & 0,07586 & 0,01835 & 0,03462 & 0,03129 & 0,00013 & 0,00000 & 0,00000 & 0,00025 & $\because-\cdots$ & $\cdots$ \\
\hline lacri & 0,05085 & 0,00000 & 0,03114 & 0,03110 & 0,00000 & 0,00014 & 0,00000 & 0,00014 & 0,62304 & 0,75688 \\
\hline laras & $\therefore$ & 0,01961 & - & 0,01786 & $\cdot$ & 0,00000 & - & 0,00038 & - & 0,76565 \\
\hline Ibaté & 0,02239 & 0.02475 & 0.02521 & 0,03059 & 0,00000 & 0,00026 & 0,00048 & 0,00018 & $\cdot$ & - \\
\hline Ibira & 0,02424 & 0,03497 & 0,02363 & 0,02126 & 0,00000 & 0,00000 & 0,00011 & 0,00033 & 0,82498 & 0,91030 \\
\hline Ibirarema & 0,02521 & 0,02041 & 0,02767 & 0,03683 & 0,00018 & 0,00018 & 0,00018 & 0,00089 & 0,76525 & - \\
\hline $\begin{array}{l}\text { Ibitinga } \\
\text { Ibiúna }\end{array}$ & $\begin{array}{l}0,02832 \\
0,03413\end{array}$ & $\begin{array}{l}0,02802 \\
0,02640\end{array}$ & $\begin{array}{l}0,02944 \\
0,03486\end{array}$ & $\begin{array}{l}0,02955 \\
0,03659\end{array}$ & $\begin{array}{l}0,00008 \\
0,00016\end{array}$ & $\begin{array}{l}0,00012 \\
0,00028\end{array}$ & $\begin{array}{l}0,00013 \\
0,00014\end{array}$ & $\begin{array}{l}0,00026 \\
0,00030\end{array}$ & 0,23419 & 0,31133 \\
\hline lcém & 0,00000 & 0,02586 & 0,02316 & 0,04283 & 0,00000 & 0,00000 & 0,00000 & 0,00000 & 0,82545 & 0,92978 \\
\hline lepê & 0,02260 & 0,00000 & 0,02171 & 0,02808 & 0,00000 & 0,00000 & 0,00014 & 0,00027 & $\cdot$ & - \\
\hline Igaraçu do Tieté & 0,02720 & 0,02193 & 0,03359 & 0,03628 & 0,00024 & 0,00000 & 0,00019 & 0,00014 & - & - \\
\hline Igarapava & 0,01272 & 0,00971 & 0,02684 & 0,03397 & 0,00018 & 0,00008 & 0,00023 & 0,00021 & 0,63720 & 1,00000 \\
\hline Igaratá & 0,01258 & 0,02548 & 0,02200 & 0,02778 & 0,00000 & 0,00014 & 0,00016 & 0,00027 & 0,42603 & 0.61711 \\
\hline lquape & 0,04305 & 0,01908 & 0,04338 & 0,03103 & 0,00016 & 0,00015 & 0,00019 & 0,00026 & 0,94010 & 0,98318 \\
\hline Il ha Comprida & - & 0,02740 & - & 0,02832 & - & 0,000202 & * & 0,00000 & - & 1,00000 \\
\hline Itha Solteira & - & 0,00802 & - & 0,03166 & - & 0.00000 & - & 0.00009 & - & - \\
\hline Ilhabela & 0,02609 & 0,01355 & 0,02991 & 0,03539 & 0,00000 & 0,00029 & 0,00007 & 0,00012 & 0,97524 & 1,00000 \\
\hline Indaiatuba & 0,02703 & 0,01714 & 0,03550 & 0,03188 & 0,00005 & 0,00010 & 0,00020 & 0,00026 & - & - \\
\hline Indiana & 0.03750 & 0.02500 & 0.03133 & 0,03463 & 0.00000 & 0.00000 & 0,00000 & .0 .00063 & - & + \\
\hline Indiaporã & 0,04706 & 0,03125 & 0,05669 & 0,02715 & 0,00021 & 0,00023 & 0,00000 & 0,00045 & 0,82402 & 0,88308 \\
\hline Inúbia Paulista & 0,00000 & 0,02174 & 0,03378 & 0,03785 & 0,00000 & 0,00000 & 0,00000 & 0,00000 & 0,67005 & 0,81680 \\
\hline Ipaussu & 0,04938 & 0,02239 & 0,03350 & 0,03687 & 0,00018 & 0,00008 & 0,00009 & 0,00008 & 0,79876 & - \\
\hline Iperó & 0,01685 & 0,00459 & 0,03540 & 0,03344 & 0,00010 & 0,00013 & 0,00029 & 0,00046 & 0,72590 & 0,78076 \\
\hline Ipeúna & 0,00000 & 0,01563 & 0,01277 & 0,03072 & 0,00000 & 0,00000 & 0,00074 & 0,00056 & 0,70213 & - \\
\hline Iporanga & 0,05128 & 0,02609 & 0,03030 & 0,03409 & 0,00000 & 0,00000 & 0,00000 & 0,00000 & 0,48145 & 0,53663 \\
\hline Ipuã & 0,01587 & 0,02212 & 0,04243 & 0,02964 & 0,00000 & 0,00018 & 0,00029 & 0,00009 & - & - \\
\hline Iracemápolis & 0,01667 & 0,01304 & 0,02974 & 0,03101 & 0,00000 & 0,00000 & 0,00000 & 0,00022 & 0,98465 & - \\
\hline Irapuã & 0,00971 & 0,01905 & 0,02421 & 0,02694 & 0,00000 & 0,00000 & 0,00016 & 0,00000 & 0,72391 & 0,81207 \\
\hline Irapuru & 0,01852 & 0,05556 & 0,02520 & 0,02051 & 0,00000 & 0,00000 & 0,00012 & 0,00013 & $=$ & $\quad-\quad-\cdots$ \\
\hline Itaberá & 0,03722 & 0,03478 & 0,03293 & 0,03495 & 0,00006 & 0,00016 & 0,00011 & 0,00016 & 0,50494 & 0,62043 \\
\hline Itai & 0,04872 & 0,02791 & 0,04146 & 0,03859 & 0,00011 & 0,00010 & 0,00017 & 0,00005 & 0,66503 & 0,82413 \\
\hline Itajobi & 0,04622 & 0,02415 & 0,02362 & 0,02971 & 0,00015 & 0,00000 & 0,00015 & 0,00014 & + & - \\
\hline Itaju & $.0,00000$ & 0,00000 & 0,03042 & 0,01527 & 0,00000 & 0,00000 & 0,00085 & 0,00000 &. & $\therefore$ \\
\hline Itanhaém & 0,03854 & 0,02930 & 0,03691 & 0,02904 & 0,00024 & 0,00027 & 0,00020 & 0,00040 & 1,00000 & 1,00000 \\
\hline Ita $\delta c a$ & . & 0,03093 & - & 0,04416 & • & 0,00000 & - & 0,00000 & $=$ & 0.58860 \\
\hline Itapecerica da Serra & 0,04013 & 0,02524 & 0,03371 & 0,04500 & 0,00057 & 0,00114 & 0,00032 & 0,00032 & 0,63803 & - \\
\hline Itapetininga & 0,02946 & 0,03165 & 0,03575 & 0,04211 & 0,00009 & 0,00011 & 0,00028 & 0,00030 & 0,79821 & 0,94618 \\
\hline
\end{tabular}


Tabela 3. Indicadores de Saúde, Segurança e Abastecimento de Água - municipios do Estado de São Paulo - 1991 e 1996.

\begin{tabular}{|c|c|c|c|c|c|c|c|c|c|c|}
\hline \multirow[b]{3}{*}{ Municipio } & \multicolumn{2}{|c|}{ Coef. } & \multicolumn{2}{|c|}{ Coef. } & \multicolumn{2}{|c|}{ Coef. } & \multicolumn{2}{|c|}{ Coef. } & \multicolumn{2}{|c|}{ Coef. } \\
\hline & \multicolumn{2}{|c|}{ INFANTIL } & \multicolumn{2}{|c|}{60 anos +} & \multicolumn{2}{|c|}{ HOMICIDIOS } & \multicolumn{2}{|c|}{ AC. VEIC. MOTOR } & \multicolumn{2}{|c|}{ ABAST. ÁGUA } \\
\hline & 1991 & 1996 & 1091 & 1996 & 1991 & 1896 & 1991 & 1996 & 1991 & 1996 \\
\hline Itapeva & 0,05553 & 0,04914 & 0,04137 & 0,04109 & 0,00010 & 0,00010 & 0,00025 & 0,00027 & 0,64775 & 0,85878 \\
\hline Itapevi & 0,03917 & 0,03035 & 0,03367 & 0.04085 & 0,00067 & 0,00054 & 0,00019 & 0,00026 & 0.71838 & $\therefore \quad \cdots$ \\
\hline Itapira & 0,03090 & 0,01265 & 0,03744 & 0,03111 & 0,00011 & 0,00025 & 0,00014 & 0,00035 & - & - \\
\hline Itapirapua Paulista & $\cdot$ & 0,02597 & - & 0,03930 & - & 0,000291 & - & 0,00000 & - & 0,46915 \\
\hline Itápolis & 0,01757 & 0,01916 & 0,02722 & 0,02658 & 0,00003 & 0,00003 & 0,00015 & 0,00022 & - & - \\
\hline Itaporanga & 0,04365 & 0,06073 & 0.04220 & 0,05049 & 0,00000 & 0,00014 & 0,00014 & 0,00014 & 0,69493 & 0.75083 \\
\hline Itapui & 0,02381 & 0,01130 & 0,01945 & 0,03150 & 0,00000 & 0,00000 & 0,00011 & 0,00000 & - & - \\
\hline Itapura & 0,04054 & 0,01961 & 0,02787 & 0,02804 & 0,00000 & 0,00026 & 0,00054 & 0,00053 & - & - \\
\hline Itaquaquecetuba & 0,04583 & 0,04391 & 0,03403 & 0,03607 & 0,00063 & 0,00068 & 0,00030 & 0,00028 & 0,61667 & - \\
\hline Itararé & 0,05335 & 0,04485 & 0,03450 & 0,03920 & 0,00019 & 0,00007 & 0,00002 & 0,00011 & - & - \\
\hline Itariri & 0,04887 & 0,02475 & 0,03212 & 0,03791 & 0,00026 & 0,00055 & 0,00035 & 0,00055 & 0,43285 & 0,55326 \\
\hline Itatiba & 0,02275 & 0,01796 & 0,03692 & 0,03522 & 0,00010 & 0,00001 & 0,00023 & 0,00021 & 0,85161 & 0,89406 \\
\hline Itatinga & 0,01529 & 0,01096 & 0,03634 & 0,03818 & 0,00015 & 0,00014 & 0,00007 & 0,00041 & 0,70164 & 0,85298 \\
\hline Itirapina & 0,02604 & 0,02970 & 0,03093 & 0,03193 & 0,00020 & 0,00035 & 0,00051 & 0,00044 & - & + \\
\hline Itirapuã & 0,02000 & 0,01000 & 0,06117 & 0,02928 & 0,00000 & 0,00000 & $0,00020^{\circ}$ & 0,00000 & 0,78858 & 0,85191 \\
\hline Itobi & 0,01695 & 0,04545 & 0,01884 & 0,03156 & 0,00000 & 0,00000 & 0,00015 & 0,00028 & 0,67991 & 0,79402 \\
\hline Itu & 0,02886 & 0,02323 & 0,02958 & 0,03798 & 0.00014 & 0,00018 & 0,00035 & 0,00028 & 0,81806 & - \\
\hline Itupeva & 0,03342 & 0,00716 & 0,03098 & 0,02463 & 0,00006 & 0,00004 & 0,00045 & 0,00000 & 0.49777 & 0,63979 \\
\hline Ituverava & 0,02265 & 0,01380 & 0,03136 & 0,03057 & 0,00006 & 0,00009 & 0,00015 & 0,00020 & - & - \\
\hline Jaborandi & $.0,02885$ & 0,00000 & 0.03205 & 0,02788 & 0,00000 & 0,00000 & 0,00016 & .0,0016 & 0,89337 & 0,87063 \\
\hline Jaboticabal & 0,03120 & 0,02019 & 0,03070 & 0,03472 & 0,00007 & 0,00017 & 0,00025 & 0,00027 & 0,94380 & - \\
\hline Jacarel & 0,01975 & 0,02568 & 0,03738 & 0,03660 & 0,00026 & 0,00039 & 0,00024 & 0,00034 & 0,83988 & + \\
\hline $\mathrm{Jacl}$ & 0,04255 & 0,03704 & 0,03150 & 0,04240 & 0,00000 & 0,00000 & 0,00000 & 0,00027 & - & - \\
\hline Jacupiranga & 0,04597 & 0,01857 & 0,02493 & 0,02183 & 0,00041 & 0,00012 & 0,00095 & 0,00037 & 0,62053 & 0,74333 \\
\hline Jaguariúna & 0,01653 & 0,00575 & 0,02814 & 0,03620 & 0,00000 & 0,00004 & 0,00021 & 0,00026 & 0,88487 & - \\
\hline Jales & 0,02538 & 0,01775 & 0,03377 & $0,02 r 99$ & 0,00007 & 0,00009 & 0,00036 & 0,00027 & 0,88000 & 0,92086 \\
\hline Jambeiro & 0,03636 & 0,01852 & 0,01619 & 0,02676 & 0,00061 & 0,00055 & 0,00000 & 0,00027 & 0,50183 & 0,56231 \\
\hline Jandira & 0,03849 & 0,02861 & 0,04709 & 0,04099 & 0,00053 & 0,00044 & 0,00024 & 0,00028 & 0,69593 & $*$ \\
\hline Jardinópolis & 0,02960 & 0,02330 & 0,03273 & 0,02926 & 0,00000 & 0,00004 & 0,00046 & 0,00029 & - & - \\
\hline Jarinu & 0,03922 & 0,02410 & 0,02835 & 0,03303 & 0,00000 & 0,00041 & 0,00000 & 0,00041 & 0,19828 & 0,25657 \\
\hline Jaú & 0,02217 & 0,02804 & 0,02854 & 0,03060 & 0,00003 & 0,00009 & 0,00020 & 0,00033 & - & $\cdot$ \\
\hline Jeriquara & 0,03279 & 0,01351 & 0,01579 & 0,03587 & 0,00000 & 0,00000 & 0,00000 & 0,00061 & 0,74675 & 0,86715 \\
\hline Joanópolis & 0,02500 & 0,03521 & 0,03258 & 0,03292 & 0,00000 & 0,00011 & 0.00000 & 0,00021 & 0,58051 & . $\quad-$ \\
\hline Joảo Ramalho & 0,00000 & 0,03390 & 0.02347 & 0,01423 & 0,00033 & 0,00000 & 0,00033 & 0,00000 & 0,80514 & - \\
\hline José Bonifácio & 0,01767 & 0,02206 & 0,02936 & 0,03135 & 0,00004 & 0,00008 & 0,00021 & 0,00038 & - & - \\
\hline Júlio Mesquita & 0,04110 & 0,03571 & 0,03274 & 0,02750 & 0,00026 & 0,00000 & 0,00000 & 0,00000 & 0,89266 & . \\
\hline Jundiai & 0,01827 & 0,01684 & 0,03465 & 0,03429 & 0,00010 & 0,00012 & 0,00017 & 0,00028 & - & - \\
\hline Junqueirópolis & 0,01242 & 0,01916 & 0,02516 & 0,02625 & 0,00000 & 0,00006 & 0,00011 & 0,00006 & - & $\therefore$ \\
\hline Juquiá & 0,03440 & 0,02575 & 0,03659 & 0,03744 & 0,00018 & 0,00027 & 0,00035 & 0,00074 & 0,59421 & 0,64927 \\
\hline Juquitiba & 0,03255 & 0,03056 & 0,02855 & 0,04329 & 0,00051 & 0,00030 & 0,00051 & 0,00064 & 0,41419 & 0,39872 \\
\hline Lagoinha & 0,02885 & 0,01031 & 0,03524 & 0,02094 & 0,00000 & 0,00000 & 0,00022 & 0,00021 & 0,54768 & 0,59627 \\
\hline Laranjal Pauilista & 0,00811 & 0,01108 & 0,02690 & 0,02874 & 0,00000 & 0,00019 & 0,00032 & 0,00048 & 0,79673 & - \\
\hline Lavinia & 0,04717 & 0,02804 & 0,04618 & 0,04000 & 0,00000 & 0,00000 & 0,00018 & 0,00000 & 0,63709 & - \\
\hline Lavrinhas & 0,01818 & 0,01942 & 0,04151 & 0,04624 & 0,00021 & 0,00000 & 0,00000 & 0,00075 & 0,56475 & 0,90107 \\
\hline Leme & 0,02763 & 0,02639 & 0,03579 & 0,03941 & 0,00013 & 0,00028 & 0,00016 & 0,00020 & 0,93629 & - \\
\hline Lençois Paylista. & 0,02300 & 0,00862 & 0.03320 & 0,03217 & 0,00016 & 0,00006 & 0,00029 & 0,00030 & 0.99392 & - \\
\hline Limeira & 0,02741 & 0,01998 & 0,03236 & 0,03382 & 0,00010 & 0,00007 & 0,00028 & 0,00024 & 1,00000 & - \\
\hline Lindóla & 0,00000 & 0,01852 & 0,01535 & 0,03614 & 0,00000 & 0,00000 & 0,00049 & 0,00105 & 0,75940 & $\because:$ \\
\hline Lins & 0,02337 & 0.01607 & 0,02959 & 0,03456 & 0,00000 & 0,00008 & 0,00012 & 0,00010 & 0,95038 & 1,00000 \\
\hline Lorena & 0,02766 & 0,02920 & 0,03377 & 0,03786 & 0,00019 & 0,00025 & 0,00019 & 0,00036 & 0,88503 & 0,86015 \\
\hline Lourdes & - & 0,03571 & - & 0,03247 & - & 0,00000 & - & 0,00054 & - & 0,76140 \\
\hline Louveira & 0,01724 & 0,02632 & 0,03484 & 0,03990 & 0,00006 & 0,00015 & 0,00050 & 0,00040 & $\cdots$ & 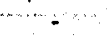 \\
\hline Lucélia & 0,02579 & 0,01661 & 0,02837 & 0,02519 & 0,00000 & 0,00017 & 0,00006 & 0,00017 & 0,80319 & 0,86954 \\
\hline Lucianópolis & 0,00000 & 0,04545 & 0,04000 & 0,04255 & 0,00000 & 0,00000 & 0,00043 & 0,00000 & 0,50336 & 0,82051 \\
\hline Luis Antônio & 0,01942 & 0,03185 & 0,03906 & 0,04167 & 0,00000 & 0,00015 & 0,00017 & 0,00000 & - & - \\
\hline Luiziânia & 0,04839 & 0,01136 & 0,02102 & 0,02500 & 0,00000 & 0,00000 & 0,00024 & 0,00024 & 0,82485 & 0,93575 \\
\hline Lupércio & 0,04000 & 0,01754 & 0,03396 & 0,02932 & 0,00000 & 0,00000 & 0,00000 & 0,00000 & 0,64742 & 0,80952 \\
\hline Lutécia & 0,00000 & 0,00000 & 0.03540 & 0,02151 & 0,00000 & 0.00000 & 0,00000 & 0,00000 & 0,61718 & 0,69032 \\
\hline Macatuba & 0,01724 & 0,01846 & 0,03567 & 0,03298 & 0,00015 & 0,00007 & 0,00022 & 0,00020 & 0,71293 & 0,83869 \\
\hline Macaubal & 0,02679 & 0,00962 & 0,03101 & 0,02964 & 0,00000 & 0,00000 & 0,00014 & 0,00027 & - & $\cdots$ \\
\hline Macedônia & 0,04000 & 0,00000 & 0,03630 & 0,01709 & 0,00000 & 0,00000 & 0,00000 & 0,00000 & 0,55030 & 0,62426 \\
\hline Magda & 0,00000 & 0,00000 & 0,02008 & 0,00949 & 0,00000 & 0,00028 & 0,00054 & 0,00000 & 0,69828 & - \\
\hline Mairinque & 0,03635 & 0,03634 & 0,03543 & 0,04543 & 0,00031 & 0,00023 & 0,00051 & 0,00020 & 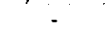 & - \\
\hline
\end{tabular}


Tabela 3. Indicadores de Saúde, Segurança e Abastecimento de Água - municipios do Estado de São Paulo - 1991 e 1996.

\begin{tabular}{|c|c|c|c|c|c|c|c|c|c|c|}
\hline \multirow[b]{4}{*}{ Municipio } & \multirow{2}{*}{\multicolumn{2}{|c|}{$\begin{array}{l}\text { Coef. } \\
\text { Mort. }\end{array}$}} & \multicolumn{2}{|c|}{ Coef. } & \multicolumn{2}{|c|}{ Coef. } & \multicolumn{2}{|c|}{ Coef. } & \multicolumn{2}{|c|}{ Coef. } \\
\hline & & & & & & & & & & \\
\hline & \multicolumn{2}{|c|}{ INFANTIL } & \multicolumn{2}{|c|}{60 anos +} & \multicolumn{2}{|c|}{ HOMICIDIOS } & \multicolumn{2}{|c|}{ AC. VEIC. MOTOR } & \multicolumn{2}{|c|}{ ABAST. ÁGUA } \\
\hline & 1991 & 1996 & 1991 & 1996 & 1991 & 1996 & & & 1991 & 1996 \\
\hline Mairiporã & 0,02543 & 0,02398 & 0,03158 & 0,04372 & 0,00025 & 0,00050 & 0,00038 & 0,00042 & 0,43275 & - \\
\hline Manduri & 0,03623 & 0,03797 & 0,03559 & 0,04361 & 0,00014 & 0,00000 & 0,00014 & 0,00038 & 0,87334 & - \\
\hline Marabá Paulista... & 0,01613 & 0,01351 & 0.02415 & 0,01060 & 0,00000 & 0,00028 & 0,00000 & 0,00000 & 0,60773 & $\therefore$ \\
\hline Maracaí & 0,01550 & 0,01724 & 0,03762 & 0,04021 & 0,00000 & 0,00008 & 0,00040 & 0,00031 & 0,79401 & 0,88303 \\
\hline Marapoama & - & 0,00000 & - & 0,03315 & + & 0,00000 & - & 0,00099 & 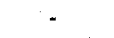 & $\because-$ \\
\hline Mariápolis & 0,00000 & 0,00000 & 0,02835 & 0,01399 & 0,00000 & 0,00000 & 0,00000 & 0,00000 & 0,60512 & 0.75492 \\
\hline Marilia & 0,02651 & 0,02323 & 0,02938 & 0,03032 & 0,00015 & 0,00011 & 0,00032 & 0,00034 & - & $\ldots$ \\
\hline Marinópolis & 0,00000 & 0,02941 & 0.03067 & 0,02591 & 0,00000 & 0,00000 & 0,00000 & 0,00000 & 0,70736 & 0,79766 \\
\hline Martinópolis & 0,02670 & 0,00779 & 0,03129 & 0,02673 & 0,00010 & 0,00005 & 0,00010 & 0,00028 & 0,84075 & - \\
\hline Matāo & 0,01870 & 0,01942 & 0.03035 & 0,02942 & 0,00008 & 0,00010 & 0,00019 & 0,00016 & - & - \\
\hline Maud & $.0,03.197$ & 0,02794 & 0,03447 & $0,03618$. & 0,00058 & 0,00059 & 0,00018 & 0,00020 & 0,72255 & $*$ \\
\hline Mendonça & 0,00000 & 0,00000 & 0,01412 & 0,03085 & 0,00000 & 0,00000 & 0,00000 & 0,00027 & - & - \\
\hline Meridiano & 0,00000 & 0,00000 & 0,01695 & 0,02695 & 0,00000 & 0,00000 & 0,00000 & 0,00051 & 0,60465 & $\cdot$ \\
\hline Mesópolis & - & 0,00000 & - & 0,00948 & - & 0,00000 & - & 0,00101 & - & 0,70588 \\
\hline Miguelópolis & 0,02694 & 0,01685 & 0,02852 & 0,03738 & 0,00006 & 0,00005 & 0,00017 & 0,00016 & $\cdot$ & $*$ \\
\hline Mineiros do Tietê & 0,02538 & 0,02051 & 0,03329 & 0,02293 & 0,00021 & 0,00010 & 0,00000 & 0,00019 & 0,94631 & $\cdot$ \\
\hline Mira Estrela & 0,09756 & 0,00000 & 0,02020 & 0,04049 & 0,00000 & 0,00000 & 0,00000 & 0,00038 & 0,65541 & 0,76923 \\
\hline Miracatu & 0,02490 & 0,03448 & 0,03036 & 0,02910 & 0,00042 & 0,00019 & 0,00121 & 0.00120 & 0,46627 & 0,61458 \\
\hline Mirandópolis & 0,02917 & 0,01583 & 0,03249 & 0,03010 & 0,00016 & 0,00012 & 0,00008 & 0,00024 & - & - \\
\hline Mirante do Paranapanema & 0,02264 & 0,00391 & 0,02549 & 0,02406 & 0,00007 & 0,00000 & 0,00013 & 0,00006 & 0,69719 & - \\
\hline Mirassol & 0,01414 & 0,01381 & 0,02711 & 0,02796 & 0,00000 & 0,00000 & 0,00015 & 0,00016 & - & - \\
\hline Mirassolândia & 0,04167 & 0,00000 & 0,02381 & 0,03934 & 0,00000 & 0,00000 & 0,00000 & 0,00000 & - & - \\
\hline Mococa & 0,02109 & 0.02102 & 0,03308 & 0,03219 & 0,00009 & 0,00006 & 0,00012 & 0,00024 & 0,87187 & 0,90373 \\
\hline Mogi das Cruzes & 0,03283 & 0,03425 & 0,03527 & 0,08714 & 0,00019 & 0,00030 & 0,00024 & 0,00035 & - & - \\
\hline Mogi Guacu & $.0,03008$ & 0,02082 & 0,03344 & 0,01402 & 0,00007 & 0,00010 & 0,00030 & 0,00026 & 1,00000 & - \\
\hline Moii Mirim & 0,01704 & 0,01959 & 0,03558 & 0,02953 & 0,00016 & 0,00011 & 0.00025 & 0,00031 & - & - \\
\hline Mombuca & 0,02326 & 0,00000 & 0,03167 & 0,03196 & 0,00000 & 0,00035 & 0,00038 & 0,00000 & - & 0,71010 \\
\hline Monçōes & 0,03448 & 0,06452 & 0,03297 & 0,01376 & 0,00000 & 0,00000 & 0,00000 & 0,00000 & 0,80205 & 0,88487 \\
\hline Mongaguá & 0,03590 & 0,02041 & 0,03580 & 0,03007 & 0,00027 & 0,00026 & 0,00037 & 0,00044 & 3,52665 & 1,00000 \\
\hline Monte Alegre do Sul & 0,00000 & 0,01389 & 0,03364 & 0,03834 & 0,00000 & 0,00000 & 0,00018 & 0,00084 & - & - \\
\hline Monte Alto & 0,02954 & 0,01153 & 0,02044 & 0,02039 & 0,00003 & 0,00005 & 0,00033 & 0,00024 & 0,94949 & 0,96988 \\
\hline Monte Aprazivel & 0.02041 & 0,01333 & 0,02689 & 0,02469 & 0,00006 & 0,00006 & 0,00017 & 0,00006 & 0,85325 & 0,93277 \\
\hline Monte Azul Paulista & 0,03747 & 0,02073 & 0,02182 & 0,03794 & 0,00000 & 0,00000 & 0,00028 & 0,00043 & 0.77733 & $\therefore$ \\
\hline Monte Castelo & 0,01266 & 0,01471 & 0,01948 & 0,01728 & 0,00000 & 0,00000 & 0,00000 & 0,00045 & 0,65037 & - \\
\hline Monte Mor & 0,02908 & 0,02209 & 0,03431 & 0,03950 & 0,00016 & 0,00035 & 0,00012 & 0,00025 & - & 0,99180 \\
\hline Monteiro Lobato & 0,05085 & 0,01818 & 0,00667 & 0,02462 & 0,00000 & 0,00000 & 0,00000 & 0,00029 & 0,48629 & 0,64252 \\
\hline Morro Acuda & 0,01587 & 0,01590 & 0,03421 & 0,04285 & 0,00019 & 0,00026 & 0,00024 & 0,00043 & - & $\therefore$ \\
\hline Morungaba & 0,01422 & 0,01515 & 0,06250 & 0,02500 & 0,00000 & 0,00011 & 0,00049 & 0,00011 & 0,72132 & 0,71805 \\
\hline Motuca & $\therefore \because$ & 0,00000 & - & 0,01843 & $\cdot$ & 0,00000 & $\cdot$ & 0,00055 & $\cdot$ & - \\
\hline Murutinga do Sul & 0,01961 & 0,00000 & 0,03425 & 0,02331 & 0,00026 & 0,00000 & 0,00000 & 0,00000 & - & $\cdot$ \\
\hline Narandiba & 0,01310 & 0,02740 & 0,04306 & 0,02847 & 0,00000 & 0,00000 & 0,00084 & 0,00115 & 0,57965 & 0,64910 \\
\hline Natividade da Serra & 0,03797 & 0,04902 & 0,02507 & 0,03096 & 0,00000 & 0,00030 & 0,00015 & 0,00015 & 0,53076 & - \\
\hline Nazare Paulista & 0,02703 & 0,01916 & 0,03223 & 0,03611 & 0,00017 & 0,00023 & 0,00052 & 0,00038 & 0,26446 & - \\
\hline Neves Paulista & 001626 & 0,00000 & 0,03509 & 0,02624 & 0,00000 & 0,00000 & 0,00024 & 0,00011 & - & - \\
\hline Nhandeara & 0,00633 & 0,00787 & 0,02743 & 0,03156 & 0.00010 & 0,00000 & 0,00019 & 0,00010 & 0,75096 & 0,84307 \\
\hline Nipoã & 0,00000 & 0,11111 & 0,03125 & 0,02866 & 0,00000 & 0,00000 & 0,00036 & 0,00033 & 0,78637 & 0,89816 \\
\hline Nova Alianca .... & 0,00000 & 0,00000 & 0,01961 & 0,01331 & 0,00000 & 0,00000 & $0 ; 00000$ & 0,00000 & $-0,77679$ & $\cdots-$ \\
\hline Nova Campina & - & 0,07778 & - & 0,02875 & - & 0,00000 & - & 0,00016 & - & 0.42308 \\
\hline Nova Canaã Paulista & $\cdot$ & 0,02941 & - & 0,02827 & - & 0,00000 & - & 0,00000 & - & 0,30465 \\
\hline Nova Europa & 0,01325 & 0,01538 & 0,04471 & 0,02317 & 0,00000 & 0,00000 & 0,00019 & 0,00046 & - & - \\
\hline Nova Granada & 0,03030 & 0,01661 & 0,02739 & 0,03219 & 0,00007 & 0,00012 & 0,00027 & 0,00037 & 0,84329 & 0,92785 \\
\hline Nova Guataporanga & 0,00000 & 0,00000 & 0,02030 & 0,02344 & 0,00047 & 0,00047 & 0,00000 & 0,00000 & 0,76059 & 0,85204 \\
\hline Nova Independència & 0,02857 & 0,04762 & 0,01818 & 0,02620 & 0,00000 & 0,00000 & 0,00000 & 0,00000 & $\cdots$ & $\therefore$ \\
\hline Nova Luzitânia & 0,00000 & 0,04167 & 0,03191 & 0,00826 & 0,00000 & 0,00000 & 0,00000 & 0,00000 & 0,65430 & 0,80854 \\
\hline Nova Odessa... & 0,02086 & 0,03114 & 0,02684 & 0,03423 & 0,00000 & 0,00026 & 0,00030 & 0,00039 & 0,90675 & 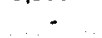 \\
\hline Novais & - & 0,01613 & - & 0,05068 & - & 0,00000 & - & 0,00000 & - & 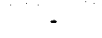 \\
\hline Novo Horizonte & 0,01815 & 0,01126 & 0,03229 & 0,02696 & 0,00000 & 0,00003 & 0,00026 & 0,00022 & 0,79828 & 0,88158 \\
\hline Nuporanga & 0,03604 & 0,02000 & 0,03602 & 0,03147 & 0,00000 & 0,00000 & 0,00000 & 0,00000 & - & - \\
\hline $\begin{array}{l}\text { Ocaucu } \\
\text { Oleo }\end{array}$ & $\begin{array}{l}0,02353 \\
0,00000\end{array}$ & $\begin{array}{l}0,01282 \\
0,02273\end{array}$ & $\begin{array}{l}0,02156 \\
0,02768\end{array}$ & $\begin{array}{l}0,04786 \\
0,04180\end{array}$ & $\begin{array}{l}0,00023 \\
0,00000\end{array}$ & $\begin{array}{l}0,00000 \\
0,00000\end{array}$ & $\begin{array}{l}0,00000 \\
0,00000\end{array}$ & $\begin{array}{l}0,00000 \\
0,00034\end{array}$ & 0,77406 & 0.78456 \\
\hline Olímpia , " & 0,03436 & 0,01395 & 0,03091 & 0,02974 & 0.00005 & 0,00007 & 0,00026 & 0,00027 & - & $\therefore$ \\
\hline Onda Verde & 0,00000 & 0,02439 & 0,01435 & 0,02857 & 0,00000 & 0,00000 & 0,00000 & 0,00000 & 0,66477 & 0,70703 \\
\hline Oriente & 0,03401 & 0,02198 & 0,03521 & 0,02124 & 0,00000 & 0,00000 & 0,00000 & 0,00047 & 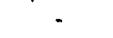 & - \\
\hline
\end{tabular}


Tabela 3. Indicadores de Saúde, Segurança e Abastecimento de Água - municipios do Estado de São Paulo - 1991 e 1996.

\begin{tabular}{|c|c|c|c|c|c|c|c|c|c|c|}
\hline \multirow{3}{*}{ Municipio } & \multicolumn{2}{|c|}{$\begin{array}{l}\text { Coef. } \\
\text { Mort }\end{array}$} & \multicolumn{2}{|c|}{ Coef. } & \multicolumn{2}{|c|}{ Coef. } & \multicolumn{2}{|c|}{ Coef. } & \multicolumn{2}{|c|}{ Coef. } \\
\hline & \multicolumn{2}{|c|}{ INFANTIL } & \multicolumn{2}{|c|}{60 anos +} & \multicolumn{2}{|c|}{ HOMICIDIOS } & \multicolumn{2}{|c|}{ AC. VEIC. MOTOR } & \multicolumn{2}{|c|}{ ABAST. ÁGUA } \\
\hline & 1991 & 1996 & 1991 & 1996 & 1991 & 1996 & 1991 & & & 1996 \\
\hline Orindiúva & 0,01695 & 0,00000 & 0,02674 & 0,02174 & 0,00000 & 0,00000 & 0,00000 & 0,00000 & 0,78994 & 0,84184 \\
\hline Oriandla & 0,01658 & 0,01043 & 0,03221 & 0,04028 & 0,00000 & 0,00000 & 0,00019 & 0,00044 & 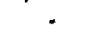 & 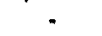 \\
\hline Osasco & 0,03648 & 0,02003 & 0,03706 & 0,03561 & 0,00054 & 0,00060 & 0,00022 & 0,00019 & $\cdot$ & - \\
\hline Oscar Bressane & 0,02128 & 0,00000 & 0,02222 & 0,03876 & 0,00000 & 0,00000 & 0,00000 & 0,00039 & 0,65658 & $0,7 B 700$ \\
\hline Osvaldo Cruz & 0,02612 & 0,01616 & 0,02934 & 0,02270 & 0,00003 & 0,00010 & 0,00003 & 0,00027 & 0,83320 & 0,91594 \\
\hline Ourinhos & 0,02187 & 0,01647 & 0,03246 & 0,03705 & 0,00005 & 0,00027 & 0,00030 & 0,00036 & 0,90967 & + \\
\hline Ouro Verde & 0,01460 & 0,00621 & 0,02018 & 0,02683 & 0,00014 & 0,00028 & 0,00000 & 0,00014 & 0,91027 & - \\
\hline Pacaembú & 0,02010 & 0,01190 & 0,02044 & 0,02515 & 0,00000 & 0,00000 & 0,00016 & 0,00040 & 0,66986 & - \\
\hline Palestina & 0,00617 & 0,01818 & 0,02428 & 0,02164 & 0,00022 & 0,00000 & 0,00022 & 0,00011 & - & - \\
\hline Palmares Pautista & 0,04118 & 0,03153 & 0,02676 & 0,02110 & 0,00014 & 0,00000 & 0,00000 & 0,00000 & 0,78268 & 0,89339 \\
\hline Palmeira d'Oeste & 0,00926 & 0,02439 & 0,02697 & 0,02793 & 0,00000 & 0,00000 & 0,00009 & 0,00009 & 0,61723 & 0,73294 \\
\hline Palmital & 0,03000 & 0,00915 & 0,04336 & 0,03841 & 0,00011 & 0,00010 & 0,00043 & 0,00020 & - & $\therefore$ \\
\hline Panorama & 0,05822 & 0,03618 & 0,01013 & 0,02911 & 0,00024 & 0,00008 & 0,00024 & 0,00023 & 0,74895 & - \\
\hline Paraguaçu Paulista. & 0,02759 & 0,00994 & 0,03693 & 0,03308 & 0,00009 & 0,00016 & 0,00021 & 0,00016 & $=$ & - \\
\hline Paraibuna & 0,05442 & 0,03279 & 0,02287 & 0,03269 & 0,00000 & 0,00019 & 0,00054 & 0,00050 & 0,39558 & - \\
\hline Paralso & 0,01031 & 0,02247 & 0,02934 & 0,02132 & 0,00000 & 0,00000 & 0,00000 & 0,00020 & 0,71404 & $-\therefore$ \\
\hline Paranapanema & 0,02098 & 0,03245 & 0,03893 & 0,03516 & 0,00000 & 0,00000 & 0,00008 & 0,00021 & 0,51820 & 0,68055 \\
\hline Paranapuã & 0,00000 & 0,01493 & 0,02895 & 0,03352 & 0,00000 & 0,00000 & 0,00027 & 0,00000 & 0.73289 & 0,84034 \\
\hline Parapuã̃ & 0,01130 & 0,00680 & 0,01342 & 0,03629 & 0,00009 & 0,00027 & 0,00000 & 0,00098 & 0,70829 & 0,80985 \\
\hline Pardinho & 0,01333 & 0,04494 & 0,03629 & 0,03203 & 0,00029 & 0,00000 & 0,00000 & 0,00024 & 0,61429 & 0,65695 \\
\hline Pariquera-Acu & 0,01857 & 0,02222 & 0,03437 & 0,04075 & 0,00000 & 0,00019 & 0,00030 & 0,00019 & 0,61932 & 0,65908 \\
\hline Parisi & - & 0,00000 & - & 0,05143 & - & 0,00000 & - & 0,00000 & $\cdots$ & - \\
\hline $\begin{array}{l}\text { Patrocinio Paulista } \\
\text { Paulicéla. }\end{array}$ & $\begin{array}{l}0,02778 \\
0,03922\end{array}$ & $\begin{array}{l}0,00521 \\
0,05714\end{array}$ & $\begin{array}{l}0,02137 \\
0,00885\end{array}$ & $\begin{array}{l}0,02427 \\
0,03481\end{array}$ & $\begin{array}{l}0,00000 \\
0,00000\end{array}$ & $\begin{array}{l}0,00009 \\
0,00021\end{array}$ & $\begin{array}{l}0,00000 \\
0,00049\end{array}$ & $\begin{array}{l}0,00000 \\
0,00021\end{array}$ & $\begin{array}{l}0,88696 \\
0,79205\end{array}$ & - \\
\hline Paulinia & 0,01675 & 0,00888 & 0,03027 & 0,03236 & 0,00017 & 0,00014 & 0,00033 & 0,00020 & - & 0,82209 \\
\hline Paulo de Faria & 0,01935 & 0,02158 & 0,02312 & 0,03664 & 0,00000 & 0,00024 & 0,00024 & 0,00024 & 0,84698 & 0,92892 \\
\hline Pederneiras & 0,01843 & 0,02254 & 0,02551 & 0,03708 & 0,00019 & 0,00015 & 0,00044 & 0,00023 & 0.85812 & 0,98203 \\
\hline a Bela & 0,01818 & 0,02913 & 0,03030 & 0,04242 & 0,00000 & 0,00000 & 0,00000 & 0,00000 & 0,18720 & $\ldots$ \\
\hline Pedranópolis & 0,03448 & 0,06250 & 0,03422 & 0,01238 & 0,00000 & 0,00000 & 0,00000 & 0,00000 & 0,58438 & 0,67578 \\
\hline Pedregulho & 0,02966 & 0,01107 & 0,02732 & 0,03122 & 0,00000 & 0,00007 & 0,00036 & 0,00089 & 0,69394 & 0,73853 \\
\hline Pedreira & 0,02060 & 0,01443 & 0,02660 & 0,03002 & 0,00004 & 0,00013 & 0,00007 & 0,00013 & - & - \\
\hline Pedrinhas Paulista & - & 0,02041 & - & 0,02415 & * & 0,00000 & - & 0,00000 & - & 0,92125 \\
\hline Pedro de Toledo & 0,06294 & 0,01887 & 0,01926 & 0,03453 & 0,00026 & 0,00023 & 0,00000 & 0,00035 & 0,54807 & 0,76107 \\
\hline Penápolis & 0,01987 & 0,01902 & 0,03411 & 0,02717 & 0,00006 & 0,00006 & 0,00027 & 0,00031 & 0,97952 & $\therefore$ \\
\hline Pereira Barreto & 0,01484 & 0,02153 & 0,03025 & 0.02937 & 0,00020 & 0,00024 & 0,00031 & 0,00008 & 0,51287 & - \\
\hline Pereiras & 0,05455 & 0,04054 & 0,03670 & 0,03594 & 0,00000 & 0,00000 & 0,00045 & 0,00037 & 0.73924 & - \\
\hline Peruibe & 0,03613 & 0,02979 & 0,02578 & 0,02687 & 0,00046 & 0,00042 & 0,00031 & 0,00017 & 1,00000 & 1,00000 \\
\hline Piacatu & 0,03333 & 0,02597 & 0,04167 & 0,02288 & 0,00000 & 0,00000 & 0,00000 & 0,00044 & 0,68924 & 0,81575 \\
\hline Piedade & 0,04183 & 0,02876 & 0,03952 & 0,03818 & 0,00007 & 0,00009 & 0,00018 & 0,00015 & 0,36214 & 0,50788 \\
\hline Pilar do Sul & 0,03549 & 0,03571 & 0,03118 & 0,04393 & 0,00010 & 0,00009 & 0,00021 & 0,00041 & 0,60673 & 0,61873 \\
\hline Pindamonhangaba & 0,02978 & 0,02120 & 0,03337 & 0,04035 & 0,00018 & 0,00015 & 0,00037 & 0,00022 & 0,86058 & 0,97043 \\
\hline Pindorama & 0,02326 & 0,00000 & 0,03210 & 0,03360 & 0,00008 & 0,00008 & 0,00000 & 0,00023 & $\therefore$ & - \\
\hline Pinhalzinho & 0,02548 & 0,03650 & 0,02619 & 0,03428 & 0,00024 & 0,00010 & 0,00024 & 0,00041 & 0,44592 & - \\
\hline Piquerobi & 0,01786 & 0,02500 & 0,03053 & 0,02970 & 0,00000 & 0,00000 & 0,00000 & 0,00000 & 0,65486 & 0,74256 \\
\hline Piquete & 0,03293 & 0,03831 & 0,04016 & 0,02932 & 0,00000 & 0,00000 & 0,00000 & 0,00026 & 0,70888 & - \\
\hline Piracaia & $.0,04423$ & $.0,03942$ & 0.04306 & $.0,03896$ & 0,00016 & 0,00009 & 0,00026 & 0,00057 & 0.68184 & - \\
\hline Piracicaba & 0,02546 & 0,02085 & 0,03156 & 0,03228 & 0,00016 & 0,00015 & 0,00018 & 0,00023 & 0,88453 & $\cdot$ \\
\hline Piraju & 0,03327 & 0,02794 & 0,03157 & 0,03699 & 0,00008 & 0,00007 & 0,00012 & 0,00041 & 0,74417 & 0,87972 \\
\hline Pirajul & 0,02538 & 0,04502 & 0,04135 & 0,03200 & 0,00011 & 0,00010 & 0,00021 & 0,00020 & - & - \\
\hline Pirangi & 0,02000 & 0,00000 & 0,01719 & 0,02483 & 0,00020 & 0,00000 & 0,00031 & 0,00030 & . & . \\
\hline Pirapora do Bom Jesus & 0,05607 & 0.01195 & 0,01860 & 0,03188 & 0,00025 & 0,00049 & 0,00013 & 0,00020 & - & - \\
\hline Plrapozinho & 0,01471 & 0,01064 & 0.03104 & 0,02667 & 0,00019 & 0,00005 & 0,00005 & 0,00028 & 0,83239 & 0,90558 \\
\hline Pirassununga & 0,01824 & 0,02279 & 0,02777 & 0,03003 & 0,00007 & 0,00016 & 0,00019 & 0,00026 & 1,00000 & - \\
\hline Piratininga $\ldots$ & $.0,03012$ & $.0,0212 B$ & 0,03605 & 0,04478 & 0,00010 & 0,00000 & 0,00042 & 0,00020 & $.0,77011$ & 0,85370 \\
\hline Pitanqueiras & 0,01871 & 0,01757 & 0,03091 & 0,03246 & 0,00011 & 0,00007 & 0,00019 & 0,00038 & 0,71106 & - \\
\hline Planalto & 0,00917 & 0,02222 & 0,02558 & 0,05861 & 0,00029 & 0,00000 & 0,00000 & 0,00028 & 0,74855 & 0,91166 \\
\hline Platina & 0,06383 & 0,00000 & 0,00889 & 0,02510 & 0,00000 & 0,00000 & 0,00213 & 0,00035 & 0,63866 & 0,75743 \\
\hline Poá & 0,02967 & 0,02344 & 0.03634 & 0,04660 & 0,00040 & 0.00029 & 0,00018 & 0,00021 & 0,86130 & - \\
\hline Poloni & 0,02083 & 0,01538 & 0,02584 & 0,02431 & 0,00000 & 0.00000 & 0,00022 & 0,00043 & 0,86253 & 0,91774 \\
\hline Pompéia & 0,02990 & $0 ; 02258$ & 0,03957 & 0,03475 & 0,00006 & 0,00000 & 0,00029 & 0,00040 & - & - \\
\hline Pongai & 0,03030 & 0,01587 & 0,03537 & 0,02506 & 0,00000 & 0,00000 & 0,00000 & 0,00000 & 0,73730 & 0,75911 \\
\hline Pontal & 0,02729 & 0,01587 & 0,03419 & 0,03891 & 0,00004 & 0,00030 & 0,00040 & 0,00019 & 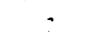 & : - \\
\hline Pontalinda & - & 0,02564 & - & 0,04184 & $\cdot$ & 0,00000 & - & 0,00029 & - & 0,78173 \\
\hline
\end{tabular}


Tabela 3. Indicadores de Saúde, Segurança e Abastecimento de Água - municipios do Estado de São Paulo - 1991 e 1996.

\begin{tabular}{|c|c|c|c|c|c|c|c|c|c|c|}
\hline \multirow[b]{4}{*}{ Municipio } & \multirow{2}{*}{\multicolumn{2}{|c|}{$\begin{array}{l}\text { Coef. } \\
\text { Mort. }\end{array}$}} & \multirow{2}{*}{\multicolumn{2}{|c|}{$\begin{array}{l}\text { Coef. } \\
\text { Mort. }\end{array}$}} & \multicolumn{2}{|c|}{ Coef. } & \multicolumn{2}{|c|}{ Coef. } & \multirow{2}{*}{\multicolumn{2}{|c|}{ Coef. }} \\
\hline & & & & & & & & & & \\
\hline & \multicolumn{2}{|c|}{ INFANTIL } & \multicolumn{2}{|c|}{60 anos +} & \multicolumn{2}{|c|}{ HOMICIDIOS } & \multicolumn{2}{|c|}{ AC. VEIC. MOTOR } & ABAST & ÁGUA \\
\hline & 1991 & 1996 & 1991 & 1996 & 1991 & 1996 & & 1996 & & 1996 \\
\hline Pontes Gestal & 0,00000 & 0,00000 & 0,01843 & 0,03097 & 0,00000 & 0,00000 & 0,00000 & 0,00000 & 0,74457 & 0,91985 \\
\hline Populina & 01266 & 0.01695 & 0,03817 & 0,02889 & 00000 & 0,00000 & 0,00000 & 0,00000 & 66927 & 0.81128 \\
\hline Porangaba & 0.04854 & 0.02222 & 0.03056 & 0,04025 & 00000 & 0.00000 & 0.00071 & 0.00049 & $\ldots=$ & .0 .77467 \\
\hline Porto Feliz & 0,02289 & 0,03064 & 0,04298 & 0,03654 & 0,00011 & 0,00017 & 0,00008 & 0,00015 & 0,80004 & 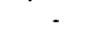 \\
\hline Porto Ferreira & 0,02545 & 0,01966 & 0,02714 & 0,03386 & 0,00010 & 0,00016 & 0,00037 & 0,00023 & 0,87951 & - \\
\hline Potim & - & 0,02874 & - & 0,03268 & - & 0,000169 & - & 0,00008 & - & - \\
\hline Potirendaba & 0,01695 & 0,01493 & 0,02592 & 0,02546 & 0,00000 & 0,00000 & 0,00009 & 0,00016 & 0,61834 & - \\
\hline Pradópolis & 0,03093 & 0,01316 & 0,02286 & 0,03672 & 00000 & 0,00000 & 0,00010 & 0,00035 & - & $\cdots$ \\
\hline Praia Grande & 0,03792 & 0,03091 & 0,02734 & 0,03 & 00045 & 0,00047 & 0,00032 & 0,00034 & 1,00000 & 1,00000 \\
\hline Presidente Alves & 0.04651 & 0,01667 & 0,04177 & 0,03 & 0,00000 & 0,00023 & 0,00044 & 0,00000 & 0.76297 & 0.89324 \\
\hline ente Bernardes & 0,01730 & 0,01485 & 0,02988 & 0,03 & 0,00 & 0,000 & 0,00015 & 0,00 & 0,67502 & 0.82 \\
\hline te Epitácio & 0,04806 & 0,03709 & 0,03559 & 0,03 & 0,00 & 0,000 & 0017 & 0,00 & .78625 & 0,88752 \\
\hline Presidente Prudente & 990 & 0,02046 & 702 & 0,03 & & & 10032 & & 89616 & 1,00000 \\
\hline Presidente Venceslau & 315 & 0,01135 & 187 & 0,0 & & & 0014 & & - & - \\
\hline Promissảo & 460 & 0,03552 & 0,03344 & 0,03203 & 007 & 0,00010 & 0014 & 0.0 & - & - \\
\hline Quatá & 0,02553 & 0,03084 & 0,02033 & 0,03 & 0,00000 & 0,00 & 0,00009 & & 0,75122 & 0,87239 \\
\hline Queiroz & 0,09524 & o,ooono & 0,02646 & 0,04 & 0,00 & 0,00 & 0,00000 & 0,0 & 0,75157 & 0,86146 \\
\hline & 0,01031 & 0,03550 & & 0,0 & & 0,0 & 0,00052 & &, 87662 & 0,94469 \\
\hline & & 0,02740 & 407 & 0,0 & & 0.00 & 0000 & & $\cdot$ & - \\
\hline & & 0,00671 & 305 & 0,03 & & 0,00 & 10000 & & - & - \\
\hline haria & 0,03036 & 0,04545 & 762 & 0,03 & & 0,00 & 0015 & & - & $=$ \\
\hline nçăo da Serra & 905 & 0,01351 & 469 & 0,02 & 50 & 0,00000 & 0025 & & 0,32122 & 0,34630 \\
\hline nte Feldo & 0,03237 & 0,01384 & 3046 & 0,01 & 120 & 0,00 & 0,00013 & 0,0 & 0,84880 & 0,91956 \\
\hline Darir & 0,02532 & 0,04286 & 4193 & 0,03 & 000 & 0,0 & 0000 & & 62695 & 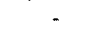 \\
\hline & 0,03745 & 0,02116 & 282 & 0,03 & 16 & & 0035 & &, 63573 & 0,77393 \\
\hline & 0,00000 & 0,04 & & 0,0 & & & 000 & & 66996 & \\
\hline & 04324 & 0,0 & & & & & 0049 & & 20759 & 0,38002 \\
\hline ão Bonito & 24 & 0,01639 & & & & & 0010 & & - & - \\
\hline - Branco & 9259 & 0,06872 & 0,03095 & 0,03 & 05 & 0,00 & 0,00005 & & 0,33185 & 0,47425 \\
\hline rão Corrente & 0,06383 & 0,02941 & 0,01500 & 0,04858 & 000 & 0,00000 & 0,00000 & & 0,71896 & 0,83744 \\
\hline Ribeiráo do sul & 0,01515 & 0.0277 .8 & 0.01010 & 0,03791 & 0,00000 & 0,00000 & 0,00000 & $.0,0$ & 0,62804 & 0,64441 \\
\hline Ribeirão Grande & - & 0,02963 & - & 0,03664 & 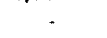 & 0,0001 & + & & + & 0,58094 \\
\hline - Diror & 0,03202 & 0,01872 & 0,03196 & 0,03615 & & & 0,00043 & &, 76623 & - \\
\hline Preto & 070 & 0,01838 & 895 & & & & 0030 & & - & - \\
\hline Rifaina & & & & & & & 0034 & & 91047 & 1,00000 \\
\hline Rincáo & 0.05285 & 0,01485 & 0,02661 & 0,03372 & 0.00000 & 0.0 & 0010 & & 0,82472 & - \\
\hline Rinópolis $\ldots . .$. & 0,04348 & 0,00685 & & 0,03072 & 0,00009 & 0,0 & 0018 & & - & - \\
\hline Rio Claro & & 0,02332 & 0,03158 & 0,03231 & 0,00025 & 0,000 & 0027 & & - & - \\
\hline das Pedras & 0,03057 & 0,01489 & 0,02527 & 0,03241 & 0,00000 & 0,00005 & 0,00011 & 0,00023 & 1,00000 & - \\
\hline Srande da Serra & 0,02658 & 0,02857 & 0,03141 & 0,04698 & 0,00030 & 0,00036 & 0,00010 & & 0,63227 & + \\
\hline Riol & 0.01307 & 0,02817 & 0.05133 & 0,02366 & 0,00000 & & 0,00039 & & 0.91510 & 0.93476 \\
\hline & 0,03524 & 0,03226 & 0,03086 & & 0,00032 & & 0,00000 & & 0,67497 & 0,74887 \\
\hline Rosana & - & 0,01837 & 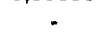 & 0,01847 & . & 0,000044 & . & 0,00013 & . & 0,32720 \\
\hline & 0,02759 & $0,01 \theta 11$ & 0,03333 & 0,02917 & 0,00000 & 0,000 & 0,00033 & & 0,84941 & 0,94746 \\
\hline ácea & 0,06452 & 0,06061 & 0,01081 & 0,02577 & 0,00000 & & 0,00000 & & 0,47626 & 0,77386 \\
\hline néia & 0,00000 & 0,02941 & 0,02869 & 0,02692 & 0,00000 & 0,00000 & 0,00000 & & 0,64107 & 0,79456 \\
\hline & 0,02410 & 0,01389 & 342 & & & & 0,00000 & & 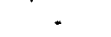 & . \\
\hline Sagres & 0,00000 & 0,02381 & 0,01739 & 0,02110 & 0,00000 & 0,00000 & 0,00000 & 0,00000 & 0,44597 & 0,62891 \\
\hline Sales & 0,03448 & 0,01667 & 0,03988 & 0,03562 & 0,00000 & 0,00000 & 0,00027 & 0,00095 & 0,64963 & . \\
\hline Sales Oliveira & 0,00685 & 0,00000 & 0,02707 & 0,02917 & 0,00013 & 0,00000 & 0,00013 & 0,000 & - & - \\
\hline esópolis & 0,03155 & 0,05031 & 0.03974 & 0,03085 & 0,00009 & 0,00008 & 0,00044 & 0,00031 & 0,60299 & - \\
\hline ouräo & 0,05319 & 0,03571 & 0,03333 & 0,02740 & 0,00000 & 0,00000 & 0,00022 & 0,00023 & 0,64972 & 0,77261 \\
\hline & - & 0,00000 & - & 0,03521 & - & 0,000181 & 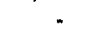 & 0,0 & + & + \\
\hline & 0,02223 & 0.01784 & 0.03209 & 0,03 & 0,00008 & 0,00024 & 0,00024 & & - & - \\
\hline de Pirapóra & & 0,02124 & 0,03479 & 0,03859 & 0,00012 & 0,00023 & 0,00008 & & 0,84617 & 0,95067 \\
\hline Grande & 0,02667 & 0,03676 & 0,02999 & 0,04987 & 0,00000 & 0,00012 & 0,00026 & & 0,74835 & - \\
\hline dovalina & 0,00000 & 0,04688 & 0,03550 & 0,04217 & 0,00042 & 0,00000 & 0,00000 & 0,00036 & 0,56566 & - \\
\hline ta Adélia & 0,01220 & 0,03349 & 0,02623 & 0,03502 & 0,00016 & 0,00000 & 0,00000 & 0,00030 & 0,64053 & - \\
\hline Santa Albertina & 0,03158 & 0,00000 & 0,02610 & 0,02296 & 0,00000 & 0,00000 & 0,00017 & 0,00000 & 0,71901 & 0,80513 \\
\hline Santa Barbara d'Oeste & 0,02242 & 0,01841 & 0,02695 & 0,02898 & 0,00009 & 0,00011 & 0,00014 & 0,00028 & 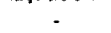 & - \\
\hline & 0,02110 & 0,03347 & 0,04527 & 0,02829 & 0,00029 & 0,00025 & 0,00010 & 0,00042 & - & $=$ \\
\hline re doeste & 0,00000 & 0,02564 & 0,01500 & 0,03636 & 0,00000 & 0,00000 & 0,00040 & 0,00000 & 0,58806 & 0,68820 \\
\hline ruz da Conceiçăo & 0,08333 & 0,00000 & 0,02602 & 0.03552 & 0,00000 & 0,00031 & 0,00000 & 0,00031 & 0,77094 & $\because$ \\
\hline
\end{tabular}


Tabela 3. Indicadores de Saúde, Segurança e Abastecimento de Água - municipios do Estado de São Paulo - 1991 e 1996.

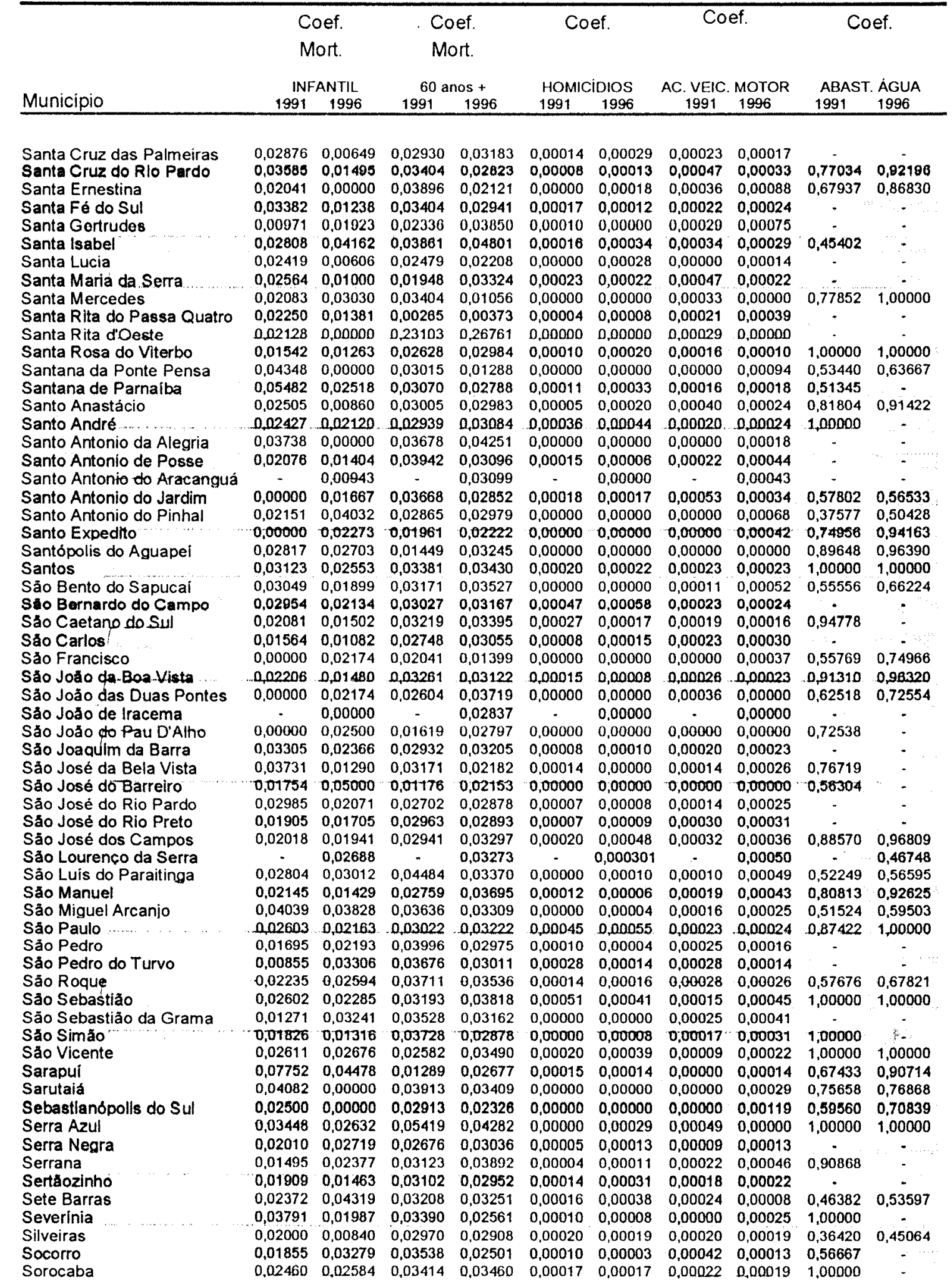


Tabela 3. Indicadores de Saúde, Segurança e Abastecimento de Água - municípios do Estado de São Paulo - 1991 e 1996.

\begin{tabular}{|c|c|c|c|c|c|c|c|c|c|c|}
\hline \multirow[b]{4}{*}{ Municipio } & \multirow{2}{*}{\multicolumn{2}{|c|}{$\begin{array}{l}\text { Coef. } \\
\text { Mort. }\end{array}$}} & \multicolumn{2}{|c|}{ Coef. } & \multicolumn{2}{|c|}{ Coef. } & \multicolumn{2}{|c|}{ Coef. } & \multicolumn{2}{|c|}{ Coef. } \\
\hline & & & $M$ & ort. & & & & & & \\
\hline & \multicolumn{2}{|c|}{ INFANTIL } & \multicolumn{2}{|c|}{60 anos + } & \multicolumn{2}{|c|}{ HOMICÍDIOS } & \multicolumn{2}{|c|}{ AC. VEIC. MOTOR } & \multicolumn{2}{|c|}{ ABAST. AGUA } \\
\hline & 1991 & 1996 & 1991 & 1996 & 1991 & 1996 & 1991 & 1996 & 1991 & 1996 \\
\hline Sud Mennucci & 0,02649 & 0,03200 & 0,01663 & 0,00718 & 0,00000 & 0,00000 & 0,00000 & 0,00082 & 0,84593 & 0,89191 \\
\hline Sumaré & 0,02541 & 0,02179 & 0,02710 & 0,03274 & 0,00037 & 0.00046 & 0,00032 & 0,00023 & 0,87488 & 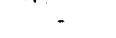 \\
\hline Suzanápolis & - & 0,01852 & - & 0,02807 & . & 0,00000 & - & 0,00000 & - & - \\
\hline Suzano & 0,04821 & 0,03057 & 0,03877 & 0,04008 & 0,00026 & 0,00033 & 0,00016 & 0,00019 & 0,66459 & - \\
\hline Tabapuã & 0,01946 & 0,02326 & 0,03053 & 0,03679 & 0,00010 & 0,00000 & 0,00050 & 0,00048 & 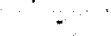 & + \\
\hline Tabatinga & 0,06404 & 0,01880 & 0,02737 & 0,03254 & 0,00009 & 0,00025 & 0,00000 & 0,00033 & - & . \\
\hline Taboão da Serra & $0,03424$. & 0,02068 & 0,04081 & 0,04520 & 0,00066 & 0,00067 & $-0,00031$ & 0,00027 & $-0,78509$ & $\therefore=$ \\
\hline Taciba & 0,05941 & 0,00000 & 0,01146 & 0,03819 & 0,00000 & 0,00000 & 0,00042 & 0,00020 & 0,75400 & 0,80438 \\
\hline Tagual & 0,05882 & 0,02400 & 0,03043 & 0,04228 & 0,00000 & 0,00000 & 0,00016 & 0,00014 & 0,70783 & 0,80446 \\
\hline Taiacu & 0,06780 & 0,01250 & 0,02387 & 0,02111 & 0,00000 & 0,00000 & 0,00000 & 0,00037 & 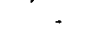 & - \\
\hline Taiưva. & 0,00000 & 0,01250 & 0,03189 & 0,03685 & 0,00000 & 0,00000 & 0,00000 & 0,00000 & $\therefore$ & - \\
\hline Tambaú & 0,03306 & 0,02793 & 0,02889 & 0,02520 & 0,00005 & 0,00019 & 0,00030 & 0,00009 & - & - \\
\hline Tanabi & 0,01449 & 0,01311 & 0,02764 & 0,02645 & 0,00000 & 0,00005 & 0,00037 & 0,00050 & 0,74034 & - \\
\hline Tapiraí & 0,06154 & 0,03704 & 0,05556 & 0,02874 & 0,00000 & 0,00028 & 0,00000 & 0,00042 & 0,53976 & 0,54675 \\
\hline Tapiratiba & 0,02817 & 0,04054 & 0,03653 & 0,02857 & 0,00000 & 0,00000 & 0,00017 & 0,00016 & 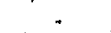 & - \\
\hline Taquaritinga & 0,03372 & 0,02364 & 0,02697 & 0,02759 & 0,00021 & 0,00018 & 0,00006 & 0,00034 & - & $=$ \\
\hline Taquarituba & 0,03066 & 0,03520 & 0,03068 & 0,03359 & 0,00000 & 0,00010 & 0,00038 & 0,00029 & 0,62981 & 0,77947 \\
\hline Taquarivaí & - & 0,03960 & - & 0,02488 & - & 0,00000 & - & 0,00026 & - & 0,41335 \\
\hline Terabal & 0,02174 & 0,01527 & 0,03236 & 0,00917 & 0,00000 & 0,00000 & 0,00000 & 0,00019 & 0,88829 & 0,95805 \\
\hline Taruma & . & 0,02688 & 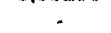 & 0,04569 & 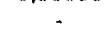 & 0,00000 & . & 0,00039 & 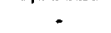 & 0,83618 \\
\hline Tatui & 0,02038 & 0,02806 & 0,03730 & 0,03664 & 0,00012 & 0,00012 & 0,00023 & 0,00021 & 0,84880 & 0,87010 \\
\hline Taubaté & 0,01956 & 0,01931 & 0,03250 & 0,03751 & 0,00018 & 0,00007 & 0,00031 & 0,00043 & 0,82283 & 0.95539 \\
\hline Tejupd & 0.04706 & 0,05155 & 0.03559 & 0,05215 & 0,00000 & $.0,00000$ & 0,00000 & 0,00020 & $\ldots+\ldots$ & $\ldots+\ldots$ \\
\hline Teodoro Sampaio & 0,01824 & 0,01386 & 0,02999 & 0,02030 & 0,00037 & 0,00021 & 0,00059 & 0,00051 & 0,51909 & 0,99730 \\
\hline Terra Roxa & 0,03185 & 0,02484 & 0,02412 & 0,03333 & 0,00030 & 0,00000 & 0,00015 & 0,00000 & 0,93306 & 0,97934 \\
\hline Tietê & 0,02490 & 0,03095 & 0,02505 & 0,02464 & 0,00004 & 0,00004 & 0,00016 & 0,00053 & 0,89526 & - \\
\hline Timburi & 0,10294 & 0,01587 & 0,03409 & 0,03754 & 0,00000 & 0,00000 & 0,00000 & 0,00036 & 0,56929 & 0,73670 \\
\hline Torre de Pedra & - & 0,03571 & - & 0,02913 & - & 0,00000 & - & 0,00000 & - & 0,96154 \\
\hline Torrinha & 0,03247 & 0,00775 & 0,02952 & 0,03395 & 0,00013 & 0,00000 & 0,00013 & 0,00012 & $\cdots \cdot-\cdots$ & + \\
\hline Tremembé & 0,04461 & 0,01965 & 0,03244 & 0,02983 & 0,00004 & 0,00006 & 0,00026 & 0,00035 & 0,87639 & 0,86824 \\
\hline Três Fronteiras & 0,00909 & 0,07353 & 0.02231 & 0,02613 & 0,00000 & 0,00000 & 0,00039 & 0,00039 & 0,61674 & 0,94545 \\
\hline Tuiuti & - & 0,01724 & 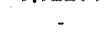 & 0,01362 & 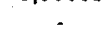 & 0,00000 & - & 0,00000 & - & - \\
\hline Tupà & 0,02102 & 0,02064 & 0,02998 & 0,02750 & 0,00003 & 0,00005 & 0,00020 & 0,00024 & $\therefore$ & 0,95410 \\
\hline Tupi Paulista & 0,02991 & 0,00667 & 0,02684 & 0,02379 & 0,00000 & 0,00000 & 0,00007 & 0,00029 & 0,77860 & - \\
\hline Turiüba & 0,00000 & 0,00000 & 0,03413 & 0.01932 & 0,00048 & 0,00000 & 0,00000 & 0,00050 & 0,67921 & 0,79835 \\
\hline Turmalina & 0,02439 & 0,02500 & 0,01389 & 0,02362 & 0,00036 & 0,00000 & 0,00000 & 0,00000 & 0,56006 & 0,74900 \\
\hline Ubarana & $\because \cdots$ & 0,03125 & $+\cdots$ & 0,04563 & . & 0,00000 & , n & 0,00000 & $\because-$ & 82 \\
\hline Ubatuba & 0,02522 & 0,03622 & 0,03228 & 0,04063 & 0,00021 & 0,00025 & 0,00051 & 0,00019 & 1,00000 & 1,00000 \\
\hline Ubirajara & 0,01299 & 0,00000 & 0.01639 & 0,03171 & 0,00024 & 0,00000 & 0,00000 & 0,00024 & 0,66249 & 0,82286 \\
\hline Uchon & 0,01280 & 0,00714 & 0,02746 & 0,01870 & 0,00000 & 0,00000 & 0,00030 & 0,00011 & 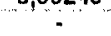 & . \\
\hline Unlao Paulista & 0,00000 & 0,00000 & 0.05263 & 0,02740 & 0,00000 & 0,00000 & 0,00000 & 0,00074 & 0.64972 & 0,78117 \\
\hline Urânia & $0,0,3261$ & 0,01460 & 0,02041 & 0,02065 & 0,00012 & 0.00023 & 0,00047 & 0,00023 & 0,62935 & 0,73677 \\
\hline Uru & 0,07692 & 0,00000 & 0,00645 & 0,02959 & 0,00000 & 0,00000 & 0,00000 & 0,00000 & 0,60345 & 0,77698 \\
\hline Urupess & 0,01163 & 0,01250 & 0,03086 & 0,02733 & 0,00000 & 0,00000 & 0,00000 & 0,00052 & 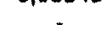 & - \\
\hline Valentim Gentil & 0,01852 & 0,01061 & 0,02952 & 0,02640 & 0,00000 & 0,00014 & 0,00000 & 0,00068 & 0,73805 & 0,84639 \\
\hline Valinhos & 0,01551 & 0,01349 & 0,03056 & 0,03085 & 0,00004 & 0,00007 & 0,00021 & 0,00017 & - & - \\
\hline Valparalso & 0,02096 & 0,01140 & 0,02762 & $0,0223 B$ & 0,00012 & 0,00011 & 0,00012 & 0,00006 & . & - \\
\hline Vargem & + & 0,03488 & - & 0,03704 & + & 0,00000 & . & 0,00017 & . & - \\
\hline Vargem Grande do Sul & 0,02469 & 0,01932 & 0,03126 & 0,03140 & 0,00013 & 0,00009 & 0,00036 & 0,00029 & $\therefore \quad:$ & 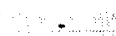 \\
\hline Vargem Grande Paulista & 0,03036 & 0,02640 & 0,04342 & 0,03741 & 0,00006 & 0,00041 & 0,00038 & 0,00028 & 0,60487 & - \\
\hline Várzea Paúlista & 0,02260 & 0,02560 & 0,03139 & 0,04034 & 0,00019 & 0,00030 & 0,00003 & 0,00014 & 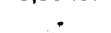 & $\therefore$ \\
\hline Vera Cruz & 0,01508 & 0,01531 & 0,02493 & 0,02946 & 0,00009 & 0,00000 & 0,00027 & 0,00045 & $\because$ & - \\
\hline Vinhedo & 0,00634 & 0,01288 & 0,03576 & 0,03375 & 0,00003 & 0,00012 & 0,00012 & 0,00034 & . & - \\
\hline Viradouro & 0,01394 & 0,01394 & 0,03620 & 0,02627 & 0,00008 & 0,00007 & 0,00008 & 0,00020 & 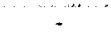 & - \\
\hline Vista Alegre do Alto & 0,00000 & 0,00000 & 0,03859 & 0,02973 & 0,00000 & 0,00000 & 0,00028 & 0,00166 & 0,84833 & - \\
\hline Votorantim & 0,03036 & 0,01981 & 0,03390 & 0,03862 & 0,00007 & 0,00014 & 0,00016 & 0,00015 & 0,82738 & . \\
\hline Votuporanga & 0,01399 & 0,01004 & 0,03111 & 0,03104 & 0,00006 & 0,00007 & 0,00020 & 0,00034 & ? & $\approx$ \\
\hline Zacarias & - & 0,00000 & - & 0,01124 & . & 0,00000 & - & 0,00051 & - & 0,73069 \\
\hline
\end{tabular}

\section{( - ) Dados Inexistentes}

